Cochrane Database of Systematic Reviews

\title{
Vaccines for preventing influenza in the elderly (Review)
}

Demicheli V, Jefferson T, Di Pietrantonj C, Ferroni E, Thorning S, Thomas RE, Rivetti A

Demicheli V, Jefferson T, Di Pietrantonj C, Ferroni E, Thorning S, Thomas RE, Rivetti A.

Vaccines for preventing influenza in the elderly.

Cochrane Database of Systematic Reviews 2018, Issue 2. Art. No.: CD004876.

DOI: 10.1002/14651858.CD004876.pub4.

www.cochranelibrary.com 
TABLE OF CONTENTS

ABSTRAC

PLAIN LANGUAGE SUMMARY

SUMMARY OF FINDINGS

BACKGROUND

OBJECTIVES

METHODS

RESULTS

Figure 1.

Figure 2.

DISCUSSION

AUTHORS' CONCLUSIONS

ACKNOWLEDGEMENTS

REFERENCES

\section{CHARACTERISTICS OF STUDIES}

DATA AND ANALYSES

Analysis 1.1. Comparison 1: Influenza vaccines versus placebo: randomised controlled trials - parenteral vaccine, Outcome 1: Influenza

Analysis 1.2. Comparison 1: Influenza vaccines versus placebo: randomised controlled trials - parenteral vaccine, Outcome 2: Influenza-like illness

Analysis 1.3. Comparison 1: Influenza vaccines versus placebo: randomised controlled trials - parenteral vaccine, Outcome 3: Pneumonia

Analysis 1.4. Comparison 1: Influenza vaccines versus placebo: randomised controlled trials - parenteral vaccine, Outcome 4: All deaths

Analysis 2.1. Comparison 2: Influenza vaccines versus placebo: randomised controlled trials - parenteral vaccine - adverse events, Outcome 1: General malaise

Analysis 2.2. Comparison 2: Influenza vaccines versus placebo: randomised controlled trials - parenteral vaccine - adverse events, Outcome 2: Nausea

Analysis 2.3. Comparison 2: Influenza vaccines versus placebo: randomised controlled trials - parenteral vaccine - adverse events, Outcome 3: Upper respiratory tract symptoms

Analysis 2.4. Comparison 2: Influenza vaccines versus placebo: randomised controlled trials - parenteral vaccine - adverse events, Outcome 4: Headache

Analysis 2.5. Comparison 2: Influenza vaccines versus placebo: randomised controlled trials - parenteral vaccine - adverse events, Outcome 5: Fever

Analysis 2.6. Comparison 2: Influenza vaccines versus placebo: randomised controlled trials - parenteral vaccine - adverse events, Outcome 6: Local tenderness/sore arm

Analysis 2.7. Comparison 2: Influenza vaccines versus placebo: randomised controlled trials - parenteral vaccine - adverse events, Outcome 7: Swelling - erythema - induration

Analysis 3.1. Comparison 3: Influenza vaccines versus placebo: randomised controlled trials - inactivated aerosol vaccine, Outcome 1: Influenza

Analysis 3.2. Comparison 3: Influenza vaccines versus placebo: randomised controlled trials - inactivated aerosol vaccine, Outcome 2: Influenza-like illness

Analysis 4.1. Comparison 4: Influenza vaccines versus placebo: randomised controlled trials - live aerosol vaccine, Outcome 1: Influenza

Analysis 5.1. Comparison 5: Influenza vaccines versus placebo: randomised controlled trials - live aerosol vaccine - adverse events, Outcome 1: General malaise

Analysis 5.2. Comparison 5: Influenza vaccines versus placebo: randomised controlled trials - live aerosol vaccine - adverse events, Outcome 2: Fever

Analysis 5.3. Comparison 5: Influenza vaccines versus placebo: randomised controlled trials - live aerosol vaccine - adverse events, Outcome 3: Upper respiratory tract symptoms

Analysis 5.4. Comparison 5: Influenza vaccines versus placebo: randomised controlled trials - live aerosol vaccine - adverse events, Outcome 4: Lower respiratory tract symptoms

Analysis 6.1. Comparison 6: Influenza vaccines versus no vaccination: cohort studies in nursing homes, Outcome 1: Influenza . Analysis 6.2. Comparison 6: Influenza vaccines versus no vaccination: cohort studies in nursing homes, Outcome 2: Influenzalike illness 
Analysis 6.3. Comparison 6: Influenza vaccines versus no vaccination: cohort studies in nursing homes, Outcome 3: Pneumonia

Analysis 6.4. Comparison 6: Influenza vaccines versus no vaccination: cohort studies in nursing homes, Outcome 4: Hospitalisation for influenza-like illness or pneumonia

Analysis 6.5. Comparison 6: Influenza vaccines versus no vaccination: cohort studies in nursing homes, Outcome 5: Deaths from flu or pneumonia

Analysis 6.6. Comparison 6: Influenza vaccines versus no vaccination: cohort studies in nursing homes, Outcome 6: All deaths . Analysis 6.7. Comparison 6: Influenza vaccines versus no vaccination: cohort studies in nursing homes, Outcome 7: Influenza cases (clinically defined without clear definition)

Analysis 7.1. Comparison 7: Influenza and pneumococcal vaccines versus no vaccination: case-control studies in nursing homes, Outcome 1: Influenza-like illness

Analysis 8.1. Comparison 8: Influenza vaccines versus no vaccination: cohort studies in community-dwellers, Outcome 1: Influenza

Analysis 8.2. Comparison 8: Influenza vaccines versus no vaccination: cohort studies in community-dwellers, Outcome 2: Influenza-like illness

Analysis 8.3. Comparison 8: Influenza vaccines versus no vaccination: cohort studies in community-dwellers, Outcome 3: Pneumonia

Analysis 8.4. Comparison 8: Influenza vaccines versus no vaccination: cohort studies in community-dwellers, Outcome 4: Hospitalisation for flu or pneumonia

Analysis 8.5. Comparison 8: Influenza vaccines versus no vaccination: cohort studies in community-dwellers, Outcome 5: Hospitalisation for any respiratory disease

Analysis 8.6. Comparison 8: Influenza vaccines versus no vaccination: cohort studies in community-dwellers, Outcome 6: Deaths from flu or pneumonia

Analysis 8.7. Comparison 8: Influenza vaccines versus no vaccination: cohort studies in community-dwellers, Outcome 7: Deaths from respiratory disease

Analysis 8.8. Comparison 8: Influenza vaccines versus no vaccination: cohort studies in community-dwellers, Outcome 8: All deaths

Analysis 8.9. Comparison 8: Influenza vaccines versus no vaccination: cohort studies in community-dwellers, Outcome 9: Hospitalisation for heart disease

Analysis 8.10. Comparison 8: Influenza vaccines versus no vaccination: cohort studies in community-dwellers, Outcome 10: Combined outcome: all deaths or severe respiratory illness

Analysis 9.1. Comparison 9: Influenza vaccines versus no vaccination: cohort studies in community - adjusted rates, Outcome 1: Hospitalisation for influenza or pneumonia

Analysis 9.2. Comparison 9: Influenza vaccines versus no vaccination: cohort studies in community - adjusted rates, Outcome 2: Hospitalisation for any respiratory disease

Analysis 9.3. Comparison 9: Influenza vaccines versus no vaccination: cohort studies in community - adjusted rates, Outcome 3: Hospitalisation for heart disease

Analysis 9.4. Comparison 9: Influenza vaccines versus no vaccination: cohort studies in community - adjusted rates, Outcome 4: All deaths

Analysis 9.5. Comparison 9: Influenza vaccines versus no vaccination: cohort studies in community - adjusted rates, Outcome 5: Combined outcome: all deaths or severe respiratory illness

Analysis 10.1. Comparison 10: Influenza vaccines versus no vaccination: cohort studies in community-dwellers - risk groups, Outcome 1: Influenza

Analysis 10.2. Comparison 10: Influenza vaccines versus no vaccination: cohort studies in community-dwellers - risk groups, Outcome 2: Pneumonia

Analysis 10.3. Comparison 10: Influenza vaccines versus no vaccination: cohort studies in community-dwellers - risk groups, Outcome 3: Hospitalisation for influenza or pneumonia

Analysis 10.4. Comparison 10: Influenza vaccines versus no vaccination: cohort studies in community-dwellers - risk groups, Outcome 4: Hospitalisation for any respiratory disease

Analysis 10.5. Comparison 10: Influenza vaccines versus no vaccination: cohort studies in community-dwellers - risk groups, Outcome 5: Deaths from respiratory disease

Analysis 10.6. Comparison 10: Influenza vaccines versus no vaccination: cohort studies in community-dwellers - risk groups, Outcome 6: All deaths

Analysis 10.7. Comparison 10: Influenza vaccines versus no vaccination: cohort studies in community-dwellers - risk groups, Outcome 7: Hospitalisation for heart disease 
Analysis 10.8. Comparison 10: Influenza vaccines versus no vaccination: cohort studies in community-dwellers - risk groups, Outcome 8: Combined outcome: all deaths or severe respiratory illness

Analysis 11.1. Comparison 11: Influenza vaccines versus no vaccination: cohort studies in community-dwellers - no risk groups, Outcome 1: Influenza

Analysis 11.2. Comparison 11: Influenza vaccines versus no vaccination: cohort studies in community-dwellers - no risk groups, Outcome 2: Pneumonia

Analysis 11.3. Comparison 11: Influenza vaccines versus no vaccination: cohort studies in community-dwellers - no risk groups, Outcome 3: Hospitalisation for influenza or pneumonia

Analysis 11.4. Comparison 11: Influenza vaccines versus no vaccination: cohort studies in community-dwellers - no risk groups, Outcome 4: Hospitalisation for any respiratory disease

Analysis 11.5. Comparison 11: Influenza vaccines versus no vaccination: cohort studies in community-dwellers - no risk groups, Outcome 5: Deaths from respiratory disease

Analysis 11.6. Comparison 11: Influenza vaccines versus no vaccination: cohort studies in community-dwellers - no risk groups, Outcome 6: All deaths

Analysis 11.7. Comparison 11: Influenza vaccines versus no vaccination: cohort studies in community-dwellers - no risk groups, Outcome 7: Hospitalisation for heart disease

Analysis 11.8. Comparison 11: Influenza vaccines versus no vaccination: cohort studies in community-dwellers - no risk groups, Outcome 8: Combined outcome: all deaths or severe respiratory illness

Analysis 12.1. Comparison 12: Influenza and pneumococcal vaccines versus no vaccination: cohort studies in communitydwellers, Outcome 1: Influenza-like illness

Analysis 12.2. Comparison 12: Influenza and pneumococcal vaccines versus no vaccination: cohort studies in communitydwellers, Outcome 2: Hospitalisation for influenza or pneumonia or respiratory disease

Analysis 12.3. Comparison 12: Influenza and pneumococcal vaccines versus no vaccination: cohort studies in communitydwellers, Outcome 3: Deaths from influenza or pneumonia

Analysis 12.4. Comparison 12: Influenza and pneumococcal vaccines versus no vaccination: cohort studies in communitydwellers, Outcome 4: All deaths

Analysis 13.1. Comparison 13: Influenza vaccines with adjuvant versus no vaccination: cohort studies in community-dwellers, Outcome 1: Influenza-like illness

Analysis 13.2. Comparison 13: Influenza vaccines with adjuvant versus no vaccination: cohort studies in community-dwellers, Outcome 2: Hospitalisation for influenza or pneumonia or respiratory disease

Analysis 13.3. Comparison 13: Influenza vaccines with adjuvant versus no vaccination: cohort studies in community-dwellers, Outcome 3: All deaths

Analysis 14.1. Comparison 14: Influenza vaccines versus no vaccination: case-control studies in community, Outcome 1: Hospitalisations for influenza or pneumonia

Analysis 14.2. Comparison 14: Influenza vaccines versus no vaccination: case-control studies in community, Outcome 2: Hospitalisations for any respiratory disease

Analysis 14.3. Comparison 14: Influenza vaccines versus no vaccination: case-control studies in community, Outcome 3: Deaths from influenza or pneumonia

Analysis 14.4. Comparison 14: Influenza vaccines versus no vaccination: case-control studies in community, Outcome 4: Pneumonia (no better defined)

Analysis 15.1. Comparison 15: Influenza vaccines versus no vaccination: case-control studies in community - adjusted rates, Outcome 1: Hospitalisations for influenza or pneumonia

Analysis 15.2. Comparison 15: Influenza vaccines versus no vaccination: case-control studies in community - adjusted rates, Outcome 2: Hospitalisations for any respiratory disease

Analysis 15.3. Comparison 15: Influenza vaccines versus no vaccination: case-control studies in community - adjusted rates, Outcome 3: Deaths from pneumonia or influenza

Analysis 16.1. Comparison 16: Influenza and pneumococcal vaccines versus no vaccination: case-control studies in community, Outcome 1: Hospitalisations for influenza or pneumonia

Analysis 17.1. Comparison 17: Influenza and pneumococcal vaccines versus no vaccination: case-control studies in community - adjusted rates, Outcome 1: Hospitalisations for influenza or pneumonia

Analysis 18.1. Comparison 18: Sensitivity analysis: comparison 01: subgroup analysis by study quality, Outcome 1: Influenzalike illness

ADDITIONAL TABLES 
[Intervention Review]

\section{Vaccines for preventing influenza in the elderly}

Vittorio Demicheli ${ }^{1}$, Tom Jefferson ${ }^{2}$, Carlo Di Pietrantonj ${ }^{3}$, Eliana Ferroni ${ }^{4}$, Sarah Thorning 5 , Roger E Thomas ${ }^{6}$, Alessandro Rivetti ${ }^{7}$

1Italy. 2Department of Continuing Education, University of Oxford, Oxford, Italy. ${ }^{3}$ Regional Epidemiology Unit SeREMI, Local Health Unit Alessandria- ASL AL, Alessandria, Italy. ${ }^{4}$ Epidemiological System of the Veneto Region, Regional Center for Epidemiology, Veneto Region, Padova, Italy. ${ }^{5}$ GCUH Library, Gold Coast Hospital and Health Service, Southport, Australia. ${ }^{6}$ Department of Family Medicine, Faculty of Medicine, University of Calgary, Calgary, Canada. ${ }^{7}$ S.S.D. Epidemiologia - Dipartimento di Prevenzione, ASL CN2 Alba Bra, Alba, Italy

Contact: Vittorio Demicheli, vittorio.demicheli@libero.it.

Editorial group: Cochrane Acute Respiratory Infections Group.

Publication status and date: Edited (no change to conclusions), published in Issue 10, 2021.

Citation: Demicheli V, Jefferson T, Di Pietrantonj C, Ferroni E, Thorning S, Thomas RE, Rivetti A. Vaccines for preventing influenza in the elderly. Cochrane Database of Systematic Reviews 2018, Issue 2. Art. No.: CD004876. DOI: 10.1002/14651858.CD004876.pub4.

Copyright (c) 2018 The Cochrane Collaboration. Published by John Wiley \& Sons, Ltd.

\section{A B S T R A C T}

\section{Background}

The consequences of influenza in the elderly (those age 65 years or older) are complications, hospitalisations, and death. The primary goal of influenza vaccination in the elderly is to reduce the risk of death among people who are most vulnerable. This is an update of a review published in 2010. Future updates of this review will be made only when new trials or vaccines become available. Observational data included in previous versions of the review have been retained for historical reasons but have not been updated because of their lack of influence on the review conclusions.

\section{Objectives}

To assess the effects (efficacy, effectiveness, and harm) of vaccines against influenza in the elderly.

\section{Search methods}

We searched the Cochrane Central Register of Controlled Trials (CENTRAL) (the Cochrane Library 2016, Issue 11), which includes the Cochrane Acute Respiratory Infections Group's Specialised Register; MEDLINE (1966 to 31 December 2016); Embase (1974 to 31 December 2016); Web of Science (1974 to 31 December 2016); CINAHL (1981 to 31 December 2016); LILACS (1982 to 31 December 2016); WHO International Clinical Trials Registry Platform (ICTRP; 1 July 2017); and ClinicalTrials.gov (1 July 2017).

\section{Selection criteria}

Randomised controlled trials (RCTs) and quasi-RCTs assessing efficacy against influenza (laboratory-confirmed cases) or effectiveness against influenza-like illness (ILI) or safety. We considered any influenza vaccine given independently, in any dose, preparation, or time schedule, compared with placebo or with no intervention. Previous versions of this review included 67 cohort and case-control studies. The searches for these trial designs are no longer updated.

\section{Data collection and analysis}

Review authors independently assessed risk of bias and extracted data. We rated the certainty of evidence with GRADE for the key outcomes of influenza, ILI, complications (hospitalisation, pneumonia), and adverse events. We have presented aggregate control group risks to illustrate the effect in absolute terms. We used them as the basis for calculating the number needed to vaccinate to prevent one case of each event for influenza and ILI outcomes. 


\section{Main results}

We identified eight RCTs (over 5000 participants), of which four assessed harms. The studies were conducted in community and residential care settings in Europe and the USA between 1965 and 2000. Risk of bias reduced our certainty in the findings for influenza and ILI, but not for other outcomes.

Older adults receiving the influenza vaccine may experience less influenza over a single season compared with placebo, from $6 \%$ to $2.4 \%$ (risk ratio (RR) $0.42,95 \%$ confidence interval ( $\mathrm{Cl}$ ) 0.27 to 0.66 ; low-certainty evidence). We rated the evidence as low certainty due to uncertainty over how influenza was diagnosed. Older adults probably experience less ILI compared with those who do not receive a vaccination over the course of a single influenza season (3.5\% versus $6 \%$; RR $0.59,95 \% \mathrm{Cl} 0.47$ to 0.73 ; moderate-certainty evidence). These results indicate that 30 people would need to be vaccinated to prevent one person experiencing influenza, and 42 would need to be vaccinated to prevent one person having an ILI.

The study providing data for mortality and pneumonia was underpowered to detect differences in these outcomes. There were 3 deaths from 522 participants in the vaccination arm and 1 death from 177 participants in the placebo arm, providing very low-certainty evidence for the effect on mortality (RR $1.02,95 \% \mathrm{Cl} 0.11$ to 9.72). No cases of pneumonia occurred in one study that reported this outcome (very low-certainty evidence). No data on hospitalisations were reported. Confidence intervals around the effect of vaccines on fever and nausea were wide, and we do not have enough information about these harms in older people (fever: $1.6 \%$ with placebo compared with $2.5 \%$ after vaccination (RR 1.57, 0.92 to 2.71 ; moderate-certainty evidence)); nausea ( $2.4 \%$ with placebo compared with $4.2 \%$ after vaccination (RR $1.75,95 \% \mathrm{Cl} 0.74$ to 4.12 ; low-certainty evidence)).

\section{Authors' conclusions}

Older adults receiving the influenza vaccine may have a lower risk of influenza (from $6 \%$ to $2.4 \%$ ), and probably have a lower risk of ILI compared with those who do not receive a vaccination over the course of a single influenza season (from $6 \%$ to $3.5 \%$ ). We are uncertain how big a difference these vaccines will make across different seasons. Very few deaths occurred, and no data on hospitalisation were reported. No cases of pneumonia occurred in one study that reported this outcome. We do not have enough information to assess harms relating to fever and nausea in this population.

The evidence for a lower risk of influenza and ILI with vaccination is limited by biases in the design or conduct of the studies. Lack of detail regarding the methods used to confirm the diagnosis of influenza limits the applicability of this result. The available evidence relating to complications is of poor quality, insufficient, or old and provides no clear guidance for public health regarding the safety, efficacy, or effectiveness of influenza vaccines for people aged 65 years or older. Society should invest in research on a new generation of influenza vaccines for the elderly.

\section{PLAIN LANGUAGE SUMMARY}

\section{Vaccines for preventing seasonal influenza and its complications in people aged 65 or older}

\section{Review aim}

The aim of this Cochrane Review, first published in 2006, was to summarise research that looks at the effects of immunising the elderly (those aged 65 years or older) with influenza vaccine during influenza seasons. We used information from randomised trials comparing influenza vaccine with dummy vaccine or with nothing. The influenza vaccines were prepared by treating influenza viruses with a chemical that kills the virus (inactivated virus), and the vaccination was given by injection through the skin. We were interested in showing the effects of vaccines on reducing the number of elderly with confirmed influenza, the number who had influenza-like symptoms such as headache, high temperature, cough, and muscle pain (influenza-like illness, of ILI), and harms from vaccination. We looked for evidence of the impact of influenza or ILI such as hospital admission, complications, and death. We will update this review in the future only when new trials or vaccines become available.

Observational data from 67 studies included in previous versions of the review have been retained for historical reasons but have not been updated because of their lack of influence on the review conclusions.

\section{What was studied in this review?}

Over 200 viruses cause ILI, producing the same symptoms (fever, headache, aches, pains, cough, and runny nose). Without laboratory tests, doctors cannot distinguish between viruses, as they last for days and rarely lead to serious illness. At best, vaccines are only effective against influenza $A$ and $B$, which represent about $5 \%$ of all circulating viruses. Inactivated vaccine is prepared by treating influenza viruses with a specific chemical agent that 'kills' the virus. Final preparations may contain either the complete viruses (whole-virion vaccine) or the active part of them (split or subunit vaccines). These vaccines are typically administered by injection through the skin. The virus strains contained in the vaccine are usually those that are expected to circulate in the following epidemic seasons (two type A and one or two B strains), which are recommended by the World Health Organization (seasonal vaccine). Pandemic vaccine contains only the virus strain that is responsible for the pandemic (e.g. the type A H1N1 for the 2009 to 2010 pandemic).

\section{Key messages}


Inactivated vaccines can reduce the proportion of elderly who have influenza and ILI. Data on deaths were sparse, and we found no data on hospitalisations due to complications. However, variation in the results of studies means we cannot be certain about how big a difference these vaccines will make across different seasons.

\section{Main results}

We found eight randomised controlled trials (over 5000 people), of which four assessed harms. The studies were conducted in community and residential care settings in Europe and the USA between 1965 and 2000.

Older adults receiving the influenza vaccine may experience less influenza over a single season, from $6 \%$ to $2.4 \%$, meaning that 30 people would need to be vaccinated with inactivated influenza vaccines to avoid one case of influenza. Older adults also probably experience less ILI, from $6 \%$ to $3.5 \%$, meaning that 42 people would need to be vaccinated to prevent one case of ILI. The amount of information on pneumonia and mortality was limited. Data were insufficient to be certain about the effect of vaccines on mortality. No cases of pneumonia occurred in one study that reported this outcome, and no data on hospitalisations were reported. We do not have enough information to assess harms relating to fever and nausea in this population.

The impact of influenza vaccines in older people is modest, irrespective of setting, outcome, population, and study design. How up to date is this review?

The evidence is current to 31 December 2016. 


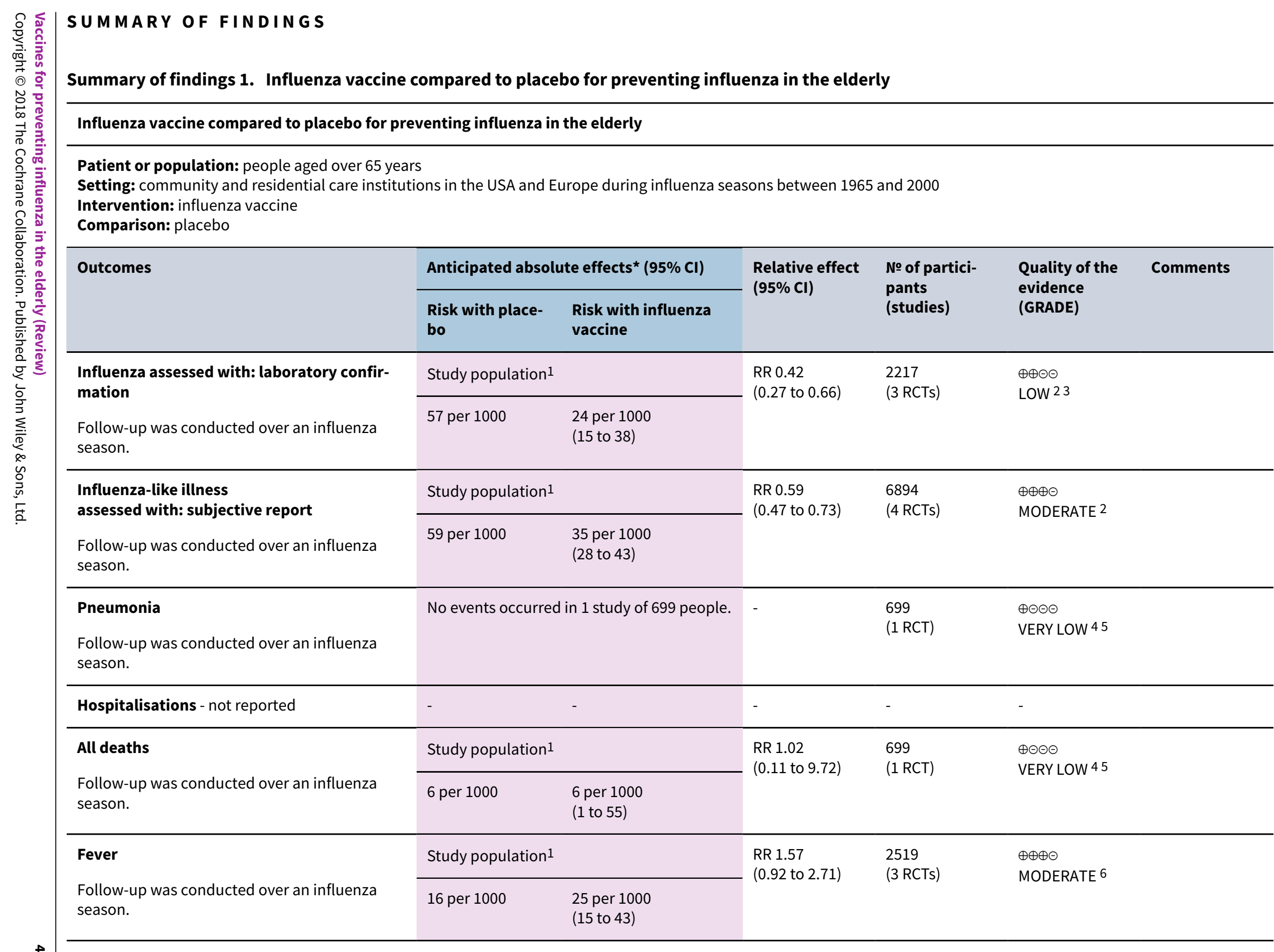




\begin{tabular}{|c|c|c|c|c|c|}
\hline \multirow{2}{*}{\multicolumn{2}{|c|}{ 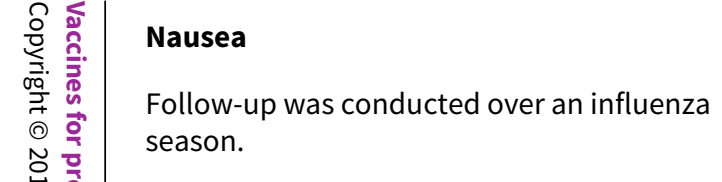 }} & \multicolumn{2}{|c|}{ Study population 1} & \multirow{2}{*}{$\begin{array}{l}\text { RR } 1.75 \\
(0.74 \text { to } 4.12)\end{array}$} & \multirow{2}{*}{$\begin{array}{l}672 \\
(1 \mathrm{RCT})\end{array}$} \\
\hline & & 24 per 1000 & $\begin{array}{l}42 \text { per } 1000 \\
\text { (18 to } 98)\end{array}$ & & \\
\hline 芧. & \multicolumn{5}{|c|}{$\begin{array}{l}\text { *The risk in the intervention group (and its } 95 \% \text { confidence interval) is based on the assumed risk in the comparison group and the relative effect of the intervention (and } \\
\text { its } 95 \% \mathrm{CI} \text { ). } \\
\text { Cl: confidence interval; RCT: randomised controlled trial; RR: risk ratio }\end{array}$} \\
\hline 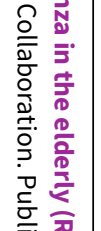 & \multicolumn{5}{|c|}{$\begin{array}{l}\text { GRADE Working Group grades of evidence } \\
\text { High quality: We are very confident that the true effect lies close to that of the estimate of the effect. } \\
\text { Moderate quality: We are moderately confident in the effect estimate: the true effect is likely to be close to the estimate of the effect, but there is a possibility that it is sub- } \\
\text { stantially different. } \\
\text { Low quality: Our confidence in the effect estimate is limited: the true effect may be substantially different from the estimate of the effect. } \\
\text { Very low quality: We have very little confidence in the effect estimate: the true effect is likely to be substantially different from the estimate of effect. }\end{array}$} \\
\hline
\end{tabular}

${ }^{1}$ Control group risk taken as aggregate of the study control group risks.

2Downgraded one level due to serious risk of bias. Most of the evidence summarised in the meta-analysis comes from studies with high or unclear risk of bias for more than one 'Risk of bias' domain.

${ }^{3}$ Downgraded due to indirectness. Uncertainty over the definition, testing, and surveillance of influenza in older trials.

${ }^{4}$ Downgraded two levels due to very serious imprecision. No events occurred in one study of nearly 700 people. The study was likely underpowered to detect effects on either pneumonia or mortality.

${ }^{5}$ Downgraded one level due to serious risk of bias. One study contributing data to this outcome had high risk of selection bias.

${ }^{6}$ Downgraded one level due to serious imprecision. Confidence intervals for nausea and fever were wide and include reduction and increase in risk of adverse events.

${ }^{7}$ Downgraded one level due to serious risk of bias. One study contributing data to this outcome had unclear risk of selection bias. 


\section{B A C K G R O U N D}

\section{Description of the condition}

Viral respiratory disease imposes a heavy burden on society. The majority of viral respiratory disease (influenza-like illness (ILI)) is caused by many different agents that are not clinically distinguishable from one another. A variable proportion of ILI (7\% to $15 \%$ on average) is caused by influenza viruses and is known as influenza (Jefferson 2009a).

Influenza is an acute respiratory infection caused by a virus of the Orthomyxoviridae family. Three serotypes are known (A, B, and $C$ ). Influenza causes an acute febrile illness with muscle ache, headache, and cough. Although the median duration of the acute illness is three days, cough and malaise can persist for weeks. Complications of influenza include otitis media, pneumonia, secondary bacterial pneumonia, exacerbations of chronic respiratory disease, and bronchiolitis in children. Additionally, influenza can cause a range of non-respiratory complications including febrile convulsions, Reye's syndrome, and myocarditis (Treanor 2016; Wiselka 1994). Efforts to prevent or minimise the impact of seasonal influenza in the second part of the 20th century centred on the use of vaccines. Due to the yearly changes in viral antigenic configuration and the lack of carry-over protection from year to year, a new vaccination campaign needs to be organised annually, with a huge scientific and logistic effort to ensure production and delivery of the vaccines.

\section{Description of the intervention}

Currently there are three types of influenza vaccines:

1. whole-virion vaccines, which consist of complete viruses that have been 'killed' or inactivated, so that they are not infectious but retain their strain-specific antigenic properties;

2. subunit virion vaccines, which are made of surface antigens $(H$ and N) only; and

3. split-virion vaccines, in which the viral structure is broken up by a disrupting agent.

These vaccines contain both surface and internal antigens. In addition, a variety of non-European manufacturers produce live attenuated vaccines. Traditionally, whole-virion vaccines are thought to be less well tolerated due to the presence of a lipid stratum on the surface of the viral particles (a remnant of the host cell membrane coating the virion, when budding from the host cell).

Influenza vaccines are produced worldwide. Periodic antigenic drifts and shifts pose problems for vaccine production and procurement, as a new vaccine closely matching the circulating antigenic configuration must be produced and procured for the beginning of each new influenza 'season'. To achieve this, the World Health Organization (WHO) has established a worldwide surveillance system, allowing for the identification and isolation of viral strains circulating the different parts of the globe. Sentinel practices (designated primary care points) recover viral particles from the nasopharynx of people with influenza-like symptoms, and the samples are swiftly sent to the laboratories of the national influenza centres (110 laboratories in 79 countries). When new strains are detected, the samples are sent to one of the four WHO reference centres (London, Atlanta, Tokyo, and Melbourne) for antigenic analysis. Information on the circulating strain is then sent to the WHO, which in February of each year recommends, through a committee, the strains to be included in the vaccine for the forthcoming 'season'. Individual governments may or may not follow the WHO recommendations. Surveillance and early identification thus play a central part in the composition of the vaccine.

The global influenza spread and burden can be assessed by consulting the WHO Global Influenza Surveillance and Response System (GISRS) web page, which provides an overview and country comparison options (www.who.int/influenza/resources/ charts/en/).

\section{How the intervention might work}

Vaccines work by simulating an infection and stimulating the body to produce antibodies against the threat and activate other defence mechanisms.

Vaccines have been the main global weapon to minimise the impact of influenza in the elderly for the last four decades, as people aged 65 and older are at higher risk of complications, hospitalisations, and death from influenza. According to the Centers for Disease Control and Prevention, the primary goal of influenza vaccination in the elderly is to reduce the risk of complications among people who are most vulnerable (ACIP 2005; CDC 2004). Vaccines containing yearly WHO recommended influenza strains are used worldwide (Grohskopf 2016; Treanor 2016; WHO 2016).

The European Medicines Agency (EMA) recently made changes to the registration of seasonal, pre-pandemic, and pandemic influenza vaccines (EMA 2014; Wijnans 2016). Changes were introduced in 2014, triggered by the realisation that antibody responses are not sufficient predictors of field protection, as our reviews have consistently shown over the years. Most of the data for influenza vaccines included in our reviews are from registered vaccines, and yet the field protection afforded is modest or negligible. In addition, the methods of standardisation of antibody titres were lacking. The new rules for adults and elderly require demonstration of non-inferiority of antibody response (immunogenicity) by a candidate seasonal influenza vaccine compared to an established one. In addition, whenever a demonstration of clinical efficacy is necessary, EMA encourages minimal use of placebo and encourages the use of active controls (such as non-influenza vaccines) with ILI (and relevant polymerase chain reaction (PCR) results) as a primary endpoint. Clinical effectiveness should be tested by carrying out (preferably prospective) cohort studies or nested so-called test negative case-control studies following the European Centre for Disease Prevention and Control protocol (ECDC 2009a; ECDC 2009b).

Harms surveillance is now required with a follow-up of at least 6 months' duration and in the general elderly population a database of at least 3000 people exposed to the vaccine. Enhanced vaccine vigilance data should be collected as soon as possible at the beginning of the vaccination campaign each year.

\section{Why it is important to do this review}

Due to the unique production cycle of influenza vaccines (they are tested using surrogate outcomes - antibody stimulation - ahead of each influenza 'season'), past performance is probably the only reliable way to predict future performance. 
An accurate assessment of the effects (efficacy, effectiveness, and safety profile) of influenza vaccines is essential to allow for rational choice between alternative strategies. This review, with its two companion reviews (Demicheli 2014; Jefferson 2012), are longrunning reviews. They are among the most consistently accessed in the whole Cochrane Database of Systematic Reviews, confirming the importance of the topic and interest in it. Periodic updates, some stretching back almost two decades, have allowed us to include an increasing number of studies on the effects of influenza vaccines and monitor their impact on our reviews (Table 1 ).

The reviews are not methodologically homogeneous, as their methods reflect the history and development of Cochrane Reviews. In particular, the inclusion of observational studies, which was initially favoured for the assessment of harms, has been a source of discussion. In the elderly, randomised evidence represents $11 \%$ of included studies because no eligible trials have been completed in the past three decades, while numerous observational studies are completed each year.

Historically, observational studies have been of poor methodological quality, often reporting conflicting or paradoxical results, preventing the drawing of firm conclusions. However, inclusion of particular study types and increasing size of the data sets has not led to a change in the conclusion of the reviews, while leading to a greatly increased workload. This is the main reason why the authors, the review group, and the Cochrane editors have decided to stabilise all three reviews, that is to not carry out routine updates of the observational data set and to update the randomised data set if certain conditions are fulfilled in the future.

For the same reason, the observational content of this review and its companions have been retained as historical evidence of the life cycle of the reviews.

We plan to update the randomised evidence in this review if any or all of the following conditions are fulfilled in the future:

- a trial assessing the clinical effects of the evolution of current technologies becomes available;

- a new type of vaccine is developed; or

- a new credible causal paradigm for influenza is put forward.

For an overview of the three reviews, see the covering editorial at https://community.cochrane.org/news/why-have-three-longrunning-cochrane-reviews-influenza-vaccines-been-stabilised.

\section{O B J E C T IVES}

To assess the effects (efficacy, effectiveness, and harm) of vaccines against influenza in the elderly.

\section{ME T HOD S}

\section{Criteria for considering studies for this review}

\section{Types of studies}

We considered randomised controlled trials (RCTs) or quasi-RCTs. We have not sought new cohort and case-control studies for the update of this review, but we have retained the data from previous versions for historical reasons. For study design definitions, see Appendix 1.

\section{Types of participants}

Elderly participants aged 65 years or older, irrespective of setting. We excluded studies assessing efficacy in selected groups affected by a specific chronic pathology (i.e. diabetes or cardiac disease), as we were interested in the whole population. The question of whether these vaccines are effective in specific at-risk populations is the topic of other reviews.

\section{Types of interventions}

1. Vaccination with any influenza vaccine given independently, in any dose, preparation, or time schedule, compared with placebo or with no intervention.

2. We also considered new, as yet unlicensed vaccine types (e.g. live attenuated and DNA vaccines).

3. Vaccination of staff in order to protect patients and residents admitted into hospitals, nursing homes, and long-term care facilities has been assessed by a separate review (Thomas 2010).

4. We excluded studies in which a vaccine was administered after the beginning of the epidemic period.

5. We excluded old oil adjuvant vaccine or vaccines with a content greater than $15 \mu \mathrm{g}$ of haemagglutinin/strain/dose from the safety assessment.

\section{Types of outcome measures}

\section{Primary outcomes}

\section{For treatment efficacy and effectiveness}

We included outcomes occurring within the epidemic period (the six-month winter period, if not better specified). When trial authors presented data according to different levels of viral circulation, we only included data restricted to higher viral circulation.

1. Cases of influenza, laboratory-confirmed (by means of viral isolation, serological supporting evidence), or both.

2. Cases of influenza, clinically defined from a list of likely respiratory and systemic signs and symptoms. We accepted the trial authors' definition of clinical illness because some countries have their own official definition.

3. Cases of influenza (as defined above) admitted to hospital.

4. Deaths (total).

5. Deaths due to influenza (as defined above) or to its complications.

6. Other direct or indirect indicator of disease impact: pneumonia; hospitalisation due to any respiratory disease, and hospitalisation due to heart disease.

We excluded studies with generic outcomes (e.g. deaths from all causes) and long-term (one-year) follow-up, as most illnesses were most likely due to causes other than influenza. We excluded studies reporting only serological outcomes.

\section{Secondary outcomes}

\section{For adverse events}

1. Local events for aerosol vaccines (upper respiratory tract infection symptoms such as cough, coryza, sore throat, and hoarseness) within seven days of vaccination. 
2. Local events for parenteral vaccines (tenderness/soreness, erythema, induration, and arm stiffness) within seven days from vaccination.

3. Systemic events (myalgia, fever, headache, fatigue, indisposition, rash, angioedema, and asthma) within seven days from vaccination.

4. Rare events (thrombocytopenia, neurological disorders, and Guillain-Barré syndrome.

\section{Search methods for identification of studies}

\section{Electronic searches}

For this 2016 update we searched the Cochrane Central Register of Controlled Trials (CENTRAL; 2016, Issue 11, searched 31 December 2016 via the Cochrane Library), which contains the Cochrane Acute Respiratory Infections Group's Specialised Register; MEDLINE (Ovid) (1966 to 31 December 2016); Embase (Elsevier) (1974 to 31 December 2016); Web of Science (Thomson Reuters) (1974 to 31 December 2016); Cumulative Index to Nursing and Allied Health Literature (CINAHL) (EBSCO) (1981 to 31 December 2016); Latin American and Caribbean Health Sciences Information Database (LILACS) (Bireme) (1982 to 31 December 2016); World Health Organization International Clinical Trials Registry Platform (WHO ICTRP; www.who.int/ictrp/en, 1 July 2017); and ClinicalTrials.gov (www.clinicaltrials.gov, 1 July 2017).

The MEDLINE search (Appendix 2) was combined with the Cochrane Highly Sensitive Search Strategy for identifying randomised trials in MEDLINE: sensitivity- and precision-maximising version (2008) revision; Ovid format (Lefebvre 2011), and these search terms were adapted to search Embase (Appendix 3), Web of Science (Appendix 4), CINAHL (Appendix 5), LILACS (Appendix 6), WHO ICTRP (Appendix 7), and ClinicalTrials.gov (Appendix 7).

There were no language or publication restrictions.

\section{Searching other resources}

The 2016 update included searches of the databases just listed to identify trials only. For details of other resources searched for previous versions of the review, see Appendix 8.

\section{Data collection and analysis}

\section{Selection of studies}

Two review authors (TOJ, EF) independently applied inclusion criteria to all identified and retrieved articles.

\section{Data extraction and management}

Two review authors (EF and LAA) independently performed data extraction using a data extraction form (Appendix 9). Two review authors (TOJ, CDP) checked data and entered the data into Review Manager 5 (RevMan 2014).

We extracted data on the following.

1. Methodological quality of studies

2. Study design (Appendix 1)

3. Description of setting

4. Characteristics of participants

5. Description of vaccines (content and antigenic match)

6. Description of viral circulation degree
7. Description of outcomes
8. Length of follow-up
9. Publication status
10.Date of study
11.Location of study

\section{Assessment of risk of bias in included studies}

\section{Experimental studies}

All review authors independently assessed the methodological quality of the included studies using criteria from the Cochrane Handbook for Systematic Reviews of Interventions (Higgins 2011), and results were introduced into the sensitivity analysis.

We classified studies according to the following criteria.

\section{Randomisation}

$A=$ individual participants allocated to vaccine or control group. $B=$ groups of participants allocated to vaccine or control group.

\section{Generation of the allocation sequence}

$A=$ adequate, e.g. table of random numbers or computer-generated random numbers.

$B$ = inadequate, e.g. alternation, date of birth, day of the week, or case record number.

$\mathrm{C}=$ not described.

\section{Allocation concealment}

$A=$ adequate, e.g. numbered or coded identical containers administered sequentially, on-site computer system that can only be accessed after entering the characteristics of an enrolled participant, or serially numbered, opaque, sealed envelopes.

$\mathrm{B}=$ possibly adequate, e.g. sealed envelopes that are not sequentially numbered or opaque.

$C=$ inadequate, e.g. open table of random numbers.

$\mathrm{D}=$ not described.

\section{Blinding}

$A=$ adequate double-blinding, e.g. placebo vaccine.

$B=$ single-blind, e.g. blinded outcome assessment.

$\mathrm{C}=$ no blinding.

\section{Follow-up}

Average duration of follow-up and number of losses to follow-up.

\section{Non-experimental studies}

In previous versions of this review we carried out quality assessment of non-RCTs in relation to the presence of potential confounders that could make interpretation of the results difficult. We evaluated the quality of case-control and cohort studies (prospective and retrospective) using the appropriate NewcastleOttawa Scales (NOS) (Appendix 10). Due to the lack of empirical evidence on the impact that the methodological quality has on the results of non-RCTs, this evaluation was only used at the analysis stage as a mean of interpretation of the results, and a set of sensitivity analyses was performed for this scope. We classified studies as at low risk of bias (up to one inadequate item in the NOS), medium risk of bias (up to three inadequate items), high risk of bias (more than three inadequate items), and very high risk of bias (when there was no description of methods). 
In case of disagreement between the review authors, TOJ arbitrated.

\section{Measures of treatment effect}

We summarised efficacy (against influenza) and effectiveness (against influenza-like illness) estimates as risk ratio (RR) (using a $95 \%$ confidence interval $(\mathrm{Cl})$ ) or odds ratio (OR) (using a $95 \% \mathrm{Cl}$ ). Absolute vaccine efficacy (VE) is expressed as a proportion, using the formula VE = 1 - RR or VE = 1 - OR whenever significant. When not significant, we reported the relevant RR or OR.

We have calculated the number needed to vaccinate (NNV) as the reciprocal of the risk difference. Rather than use the pooled risk difference, we have multiplied an illustrative control group risk by the RR to generate a difference in risk.

\section{Unit of analysis issues}

We identified no studies with a cluster design, and no studies contributed more than one treatment comparison to the analyses.

\section{Dealing with missing data}

In earlier versions of the review, we considered contacting the first or corresponding author of the study to request missing data whenever we identified non-reporting or partial reporting of data. This proved to be a major task with few returns. It was not carried out for this update as we are stabilising this review, that is we will update the randomised data set if certain conditions are fulfilled in the future.

\section{Assessment of heterogeneity}

We calculated the 12 statistic for every pooled estimate to assess the effect on statistical heterogeneity. The $\mathrm{I}^{2}$ statistic can be interpreted as the proportion of total variation among effect estimates that is due to heterogeneity rather than sampling error, and it is intrinsically independent of the number of studies. When the 12 statistic is less than $30 \%$, there is little concern about statistical heterogeneity (Higgins 2002; Higgins 2003).

\section{Assessment of reporting biases}

Prior to the 2010 update, we carried out a complete re-extraction of all studies and reassessed their methodological quality. We also assessed concordance between data presented and conclusions and direction of conclusions (in favour or not of the performance of influenza vaccines). We also looked at the relationship between these variables and study funding and journal of publication (see 'Potential biases in the review process' in the Discussion and Jefferson 2009b).

\section{Data synthesis}

Aggregation of data was dependent on the sensitivity and homogeneity of definitions of exposure, populations, and outcomes used. Where we found studies to be homogenous, we carried out a meta-analysis of these studies within each design category. We pooled whole, split, and subunit vaccines, as in community studies this information was not reported. When a study reported data for more than one influenza season or for more than one setting, we considered these separately, creating separate data sets. Within the data sets, we used the term 'observation' to describe an occurrence (i.e. a particular outcome such as fever) and not number of participants, as multiple outcomes were sometimes recorded for the same participant. We used random-effects models throughout to take account of the between-study variance in our findings (DerSimonian 1986).

We analysed non-RCT separately from RCT evidence.

We grouped reports first according to the setting of the study (community or long-term care facilities) and then by level of viral circulation and vaccine matching (when trial authors presented data according to different levels of viral circulation, we included only data relating to higher viral circulation). We considered a period 'epidemic' when the weekly incidence rate exceeded the seasonal threshold. A vaccine was defined as 'matching' when the vaccine strains were antigenically similar to the wild circulating strains. We further stratified by co-administration of pneumococcal polysaccharide vaccine (PPV) and by different types of influenza vaccines (live, inactivated, with adjuvant).

Wherever possible, we performed a quantitative analysis adjusted for confounders if the cohort or case-control studies used the same methods of adjustment (logistic regression) for the same confounders (sex, age, smoking, and comorbidities). We constructed a comparison with effect sizes adjusted for the effects of possible known confounders and their standard error, which we derived from the reported confidence intervals (Greenland 1987), and performed quantitative analysis with the inverse of the variance (Higgins 2011).

We included the findings of one case-control study reporting data stratified by risk factors for influenza by use of the inverse variance combining stratum-specific effect size and overall effect size (Mullooly 1994).

\section{Subgroup analysis and investigation of heterogeneity}

We did a further analysis to investigate the causes of heterogeneity. To assess the effect of viral circulation and vaccine matching on overall heterogeneity, we calculated heterogeneity within each grouping and compared its sum with the overall heterogeneity (Greenland 1987).

\section{Sensitivity analysis}

We performed a subanalysis of studies describing a better defined epidemic period for most significant comparisons. We then tested effect size from cohort studies conducted in long-term care facilities (where data are more plentiful), stratified by methodological quality of the studies.

\section{Summary of findings and assessment of the certainty of the evidence}

We created a Summary of findings 1 using the following outcomes: influenza, ILI, pneumonia, hospitalisation, all deaths, fever, and nausea. We used the five GRADE considerations (study limitations, consistency of effect, imprecision, indirectness, and publication bias) to assess the quality of a body of evidence as it relates to the studies that contributed data to the meta-analyses for the prespecified outcomes (Atkins 2004). We used methods and recommendations described in Section 8.5 and Chapter 12 of the Cochrane Handbook for Systematic Reviews of Interventions (Higgins 2011), employing GRADEpro GDT software (GRADEpro GDT 2014). We justified all decisions to down- or upgrade the quality of studies using footnotes, and made comments to aid readers' understanding of the review where necessary. We have restricted 
our focus in the 'Summary of findings' table to evidence from randomised studies comparing influenza vaccine with placebo, which was the most commonly adopted strategy.

\section{RESULTS}

\section{Description of studies}

\section{Results of the search}

In the first publication of this review (Rivetti 2006), we identified 4400 titles of reports of potentially relevant studies and screened these for retrieval. We excluded 4088 reports by screening titles and abstracts and retrieved 312 reports for detailed assessment; 241 reports did not fulfil our inclusion criteria.
In the 2010 review update (Rivetti 2010), we identified 1435 reports of potentially relevant studies. We retrieved 18 studies for further evaluation; we included four and excluded 14 for various reasons. We identified two case-control studies, Jordan 2007 and PuigBarbera 2007, and two cohort studies, Hara 2006 and Leung 2007, fulfilling the inclusion criteria.

For this 2016 update we did not identify new randomised evidence.

\section{Included studies}

We included 75 studies in previous versions of the review: 68 studies were used to assess efficacy/effectiveness, and 8 were included in the safety assessment (one RCT was included in both assessments). See Figure 1 for study flow. 
Figure 1. Study flow. We identified no new randomised controlled trials for the 2016 update and stabilisation.

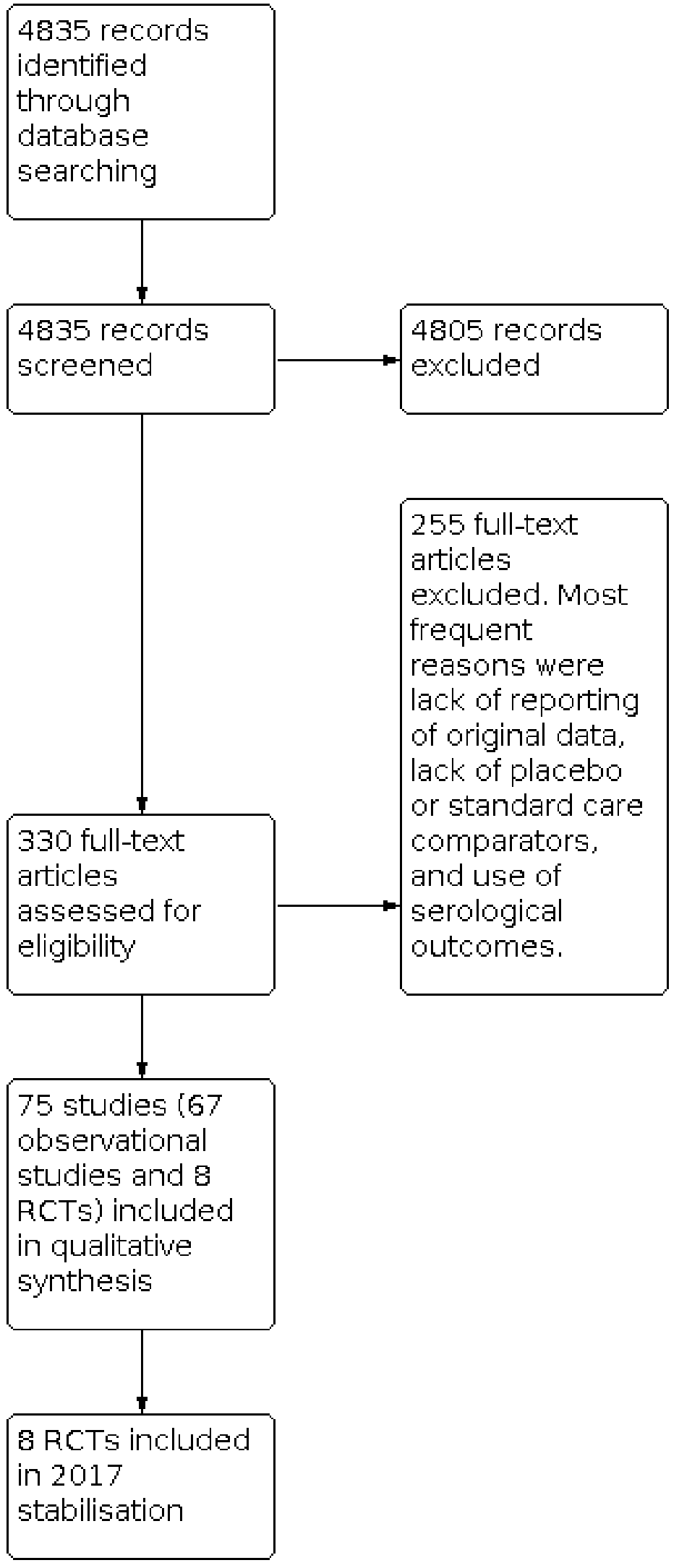


The 65 studies included in the efficacy/effectiveness assessment were split into subsets by influenza season or setting or vaccine type, resulting in 100 data sets.

We identified eight published RCTs published over four decades involving just over 5000 participants (Allsup 2004; Edmondson 1971; Govaert 1993; Govaert 1994a; Keitel 1996; Margolis 1990a; Rudenko 2001; Stuart 1969; Treanor 1994). Four of these RCTs only reported safety outcomes (Govaert 1993; Keitel 1996; Margolis 1990a; Treanor 1994).

Fifty-one cohort studies resulted in 80 data sets (Arden 1988; Arroyo 1984; Aymard 1979a; Aymard 1979b; Caminiti 1994; Cartter 1990a; Cartter 1990b; Cartter 1990c; Christenson 2001a; Christenson 2001b; Christenson 2004a; Christenson 2004b; Coles 1992; Comeri 1995; Consonni 2004a; Consonni 2004b; Cuneo Crovari 1980; Currier 1988; D'Alessio 1969; Davis 2001a; Davis 2001b; Deguchi 2001; Feery 1976; Fleming 1995; Fyson 1983a; Fyson 1983b; Gavira Iglesias 1987; Gené Badia 1991; Goodman 1982; Gross 1988; Hak 2002a; Hak 2002b; Hara 2006; Horman 1986; Howarth 1987a; Howarth 1987b; Howells 1975a; Howells 1975b; Howells 1975c; Isaacs 1997; Kawai 2003; Leung 2007; Lopez Hernandez 1994; Mangtani 2004b; Mangtani 2004c; Mangtani 2004d; Mangtani 2004e; Mangtani 2004f; Mangtani 2004g; Mangtani 2004h; Mangtani 2004i; Mangtani 2004j; Meiklejohn 1987; Monto 2001; Morens 1995; Mukerjee 1994; Murayama 1999; Nichol 1994a; Nichol 1994b; Nichol 1994c; Nichol 1998a; Nichol 1998b; Nichol 2003a; Nichol 2003b; Nicholson 1999; Nordin 2001a; Nordin 2001b; Patriarca 1985a; Patriarca 1985b; Pregliasco 2002; Ruben 1974; Saah 1986a; Saah 1986b; Saah 1986c; Saito 2002a; Saito 2002b; Shapiro 2003; Strassburg 1986; Taylor 1992; Voordouw 2003).

Twelve case-control studies resulted in 14 data sets (Ahmed 1995; Ahmed 1997; Crocetti 2001; Fedson 1993a; Fedson 1993b; Foster 1992; Jordan 2007; Mullooly 1994; Ohmit 1995a; Ohmit 1995b; Ohmit 1999; Puig-Barberà 1997; Puig-Barberà 2004; Puig-Barbera 2007).

Roughly half $(n=52)$ the data sets reported $A / H 3 N 2$ virus circulating; $4 \%(n=4)$ B viruses, $1 \%(n=1) A / H 1 N 1,1 \%(n=1) A /$ $\mathrm{H} 2 \mathrm{~N} 2$, and $7 \%(\mathrm{n}=7)$ reported $\mathrm{A} / \mathrm{H} 3 \mathrm{~N} 2$ and $\mathrm{A} / \mathrm{H} 1 \mathrm{~N} 1$ circulating at the same time. The remaining $37 \%(n=35)$ of the data sets provided insufficient information on circulating subtypes.

Twenty-four studies resulting in 39 data sets collected information about the health conditions of vaccinated and unvaccinated people and reported stratified results or adjusted rates. Participants suffering from lung disease, heart disease, renal disease, diabetes and other endocrine disorders, immunodeficiency or immunosuppressive diseases, cancer, dementia or stroke, vasculitis, and rheumatic disease were considered as belonging to risk groups.

The included studies used the recommended and licenced vaccine formulation, even if some authors did not declare vaccine composition.

In the RCTs, the comparison was placebo. All cohort studies compared the effects of vaccination against no vaccination.

In our safety assessment, we included four RCTs (Govaert 1993; Keitel 1996; Margolis 1990a; Treanor 1994), and we commented on three surveillance studies with a non-comparative design assessing rare events (Guillain-Barré syndrome) in the text but did not include them in our meta-analysis (Kaplan 1982; Lasky 1998; Schonberger 1979). One RCT assessed a vaccine that has not been in production for decades (Stuart 1969); its harms data were not extracted.

\section{Excluded studies}

The most frequent reasons for study exclusion were lack of presentation of original data, lack of placebo or standard care comparator, and presence of antibody titres as outcomes. A complete list with reasons for exclusion is provided in the Characteristics of excluded studies table.

\section{Risk of bias in included studies}

The results of our 'Risk of bias' assessment were as follows.

\section{Cohort/case-control studies (from previous versions of the review)}

- Low risk of bias: 18

- Medium risk of bias: 31

- High risk of bias: 11

- Very high risk of bias: 3

\section{Surveillance studies (from previous versions of the review)}

For three surveillance studies assessing rare harms, we did not perform quality evaluation. All studies were population based with good case findings and case definitions.

\section{Allocation}

\section{Experimental studies}

- Allocation concealment: adequate 3

- Allocation concealment: unclear 1

- Allocation concealment: inadequate 0

- Allocation concealment: not described 5

\section{Blinding}

See 'Potential biases in the review process' in the Discussion.

\section{Incomplete outcome data}

The vast majority of evidence for our review stems from non-RCTs. In most of the trials, the quality of the text was such that we could not assess the impact of any incomplete outcome data (Jefferson 2009b).

\section{Selective reporting}

Selective reporting including major inconsistencies between different parts of the text was a common feature. See 'Potential biases in the review process' in the Discussion.

\section{Other potential sources of bias}

See 'Potential biases in the review process' in the Discussion.

\section{Effects of interventions}

See: Summary of findings 1 Influenza vaccine compared to placebo for preventing influenza in the elderly 


\section{Randomised controlled trials}

Given the heterogeneous nature of the vaccines tested (monovalent, trivalent, live, or inactivated aerosol vaccines), setting, follow-up, and outcome definition, we could draw no firm conclusions from this body of evidence. Only three trials specified follow-up (Govaert 1994a; Rudenko 2001; Stuart 1969), which ranged from 42 to 180 days.

We have presented the findings of the most important outcomes in Summary of findings 1.

Influenza vaccines may reduce the risk of influenza from $6 \%$ in unvaccinated people to $2.4 \%$ following vaccination (vaccine efficacy (VE) 58\%, risk ratio (RR) $0.42,95 \%$ confidence interval (CI) 0.27 to 0.66 ; low-certainty evidence) (Summary of findings 1 ). These results gave a number needed to vaccinate (NNV) of 30 (Analysis 1.1).

Based on a meta-analysis of four trials of inactivated vaccines (Allsup 2004; Edmondson 1971; Govaert 1994a; Stuart 1969), vaccines probably reduce the risk of ILI from $6 \%$ in unvaccinated people to 3.5\% following vaccination (VE 41\%, RR 0.59 95\% Cl 0.47 to 0.73 ; moderate-certainty evidence). These results gave a NNV of 42 (Analysis 1.2).

There was very limited information available regarding the effects of vaccines on risk of hospitalisation, pneumonia, and death. No study reported hospitalisations. One study of 699 participants reported no cases of pneumonia (very low-certainty evidence), and that 4 deaths occurred at comparable rates between the groups (RR $1.02,95 \% \mathrm{Cl} 0.11$ to 9.72 ; very low-certainty evidence).

Although small increases in fever (from 1.6\% to 2.5\%; RR 1.57, 95\% $\mathrm{Cl} 0.92$ to 2.71; moderate-certainty evidence) and nausea (from $2.4 \%$ to $4.2 \%$; RR $1.75,95 \% \mathrm{Cl} 0.74$ to 4.12 ; low-certainty evidence) occurred following influenza vaccination, $\mathrm{Cls}$ for these results are wide, and we downgraded the certainty of evidence in both cases for imprecision (Summary of findings 1 ).

Increased risks of general malaise, upper respiratory tract symptoms, and headache following vaccination ranged between 1.1 and 1.57, although the $\mathrm{Cls}$ are wide for all of these outcomes (see Analysis 2.1; Analysis 2.3; Analysis 2.4). Following vaccination there were increased risks of sore arm (RR $3.56,95 \% \mathrm{Cl} 2.61$ to 4.87) (Analysis 2.6) and swelling (RR $8.23,95 \% \mathrm{Cl} 3.98$ to 17.05 ) (Analysis 2.7) compared with placebo.

Three studies assessed the effects of inactivated aerosol vaccine (Edmondson 1971; Rudenko 2001; Treanor 1994). There was no evidence of lower risk of influenza or ILI following vaccination compared with placebo with vaccine matching in the presence of an outbreak (Analysis 3.1; Analysis 3.2), or with vaccine matching outside of an outbreak (influenza: Analysis 4.1). Effect sizes for harms (namely malaise, fever, upper and lower respiratory tract symptoms) were all higher with vaccines, but the size of the study contributing data to these outcomes was small, and the confidence interval includes there being no increase in these events with the vaccines (see Analysis 5.1; Analysis 5.2; Analysis 5.3; Analysis 5.4).

\section{Cohort studies in long-term care facilities (from previous versions of the review)}

Thirty cohort studies in long-term care facilities contributed data to 41 data sets and over 34,000 observations (Arden 1988; Arroyo 1984; Aymard 1979a; Aymard 1979b; Cartter 1990a; Cartter 1990b; Cartter 1990c; Coles 1992; Cuneo Crovari 1980; Currier 1988; Deguchi 2001; Feery 1976; Fyson 1983a; Fyson 1983b; Goodman 1982; Gross 1988; Horman 1986; Howarth 1987a; Howarth 1987b; Howells 1975a; Howells 1975b; Howells 1975c; Isaacs 1997; Leung 2007; Meiklejohn 1987; Monto 2001; Morens 1995; Mukerjee 1994; Murayama 1999; Patriarca 1985a; Patriarca 1985b; Ruben 1974; Saah 1986a; Saah 1986b; Saah 1986c; Saito 2002a; Saito 2002b; Strassburg 1986; Taylor 1992). These studies were very focused and were fairly well resourced: 35 data sets reported virologic surveillance that confirmed influenza virus circulation, and 22 data sets had short follow-up (less than three months). The studies assessed the effects of vaccines in residential communities. The resident population is described in about half of the included data sets as predominantly aged older than 75 years, with multiple chronic pathologies and a high dependency level. However, breakdown of potential confounding factors (such as age, sex, smoking status, and underlying chronic disease) is rarely reported by vaccine exposure, making correction of confounders impossible.

\section{Studies recorded during outbreaks or periods of high viral circulation (from previous versions of the review)}

Of the 41 data sets, 30 data sets with a total of 9879 observations were recorded during outbreaks or periods of high viral circulation (Arden 1988; Arroyo 1984; Aymard 1979a; Aymard 1979b; Cartter 1990a; Cartter 1990b; Cartter 1990c; Coles 1992; Cuneo Crovari 1980; Currier 1988; Feery 1976; Fyson 1983a; Fyson 1983b; Goodman 1982; Gross 1988; Horman 1986; Isaacs 1997; Leung 2007; Meiklejohn 1987; Monto 2001; Morens 1995; Mukerjee 1994; Murayama 1999; Patriarca 1985a; Ruben 1974; Saah 1986a; Saah 1986b; Strassburg 1986; Taylor 1992). The influenza virus subtype is positively identified in 28 data sets (A/H3N2 in 25 data sets). The focus of 22 data sets from 19 studies was on assessment of the effect of vaccination on single epidemic sources (Arden 1988; Arroyo 1984; Cartter 1990a; Cartter 1990b; Cartter 1990c; Coles 1992; Cuneo Crovari 1980; Currier 1988; Feery 1976; Fyson 1983a; Fyson 1983b; Goodman 1982; Horman 1986; Isaacs 1997; Meiklejohn 1987; Morens 1995; Murayama 1999; Ruben 1974; Saah 1986a; Saah 1986b; Strassburg 1986; Taylor 1992). Viral circulation was confirmed by isolates, increases in antibody titres, or observation of an epidemic of ILI in an institution at the same time as influenza A or B circulation in the surrounding community. A high proportion of cases classified as ILI were probably influenza cases. Twentytwo data sets from 18 studies provided information about vaccine content match with circulating influenza viruses (Arden 1988; Aymard 1979a; Cartter 1990a; Cartter 1990b; Cartter 1990c; Feery 1976; Fyson 1983a; Fyson 1983b; Goodman 1982; Gross 1988; Hara 2006; Horman 1986; Isaacs 1997; Meiklejohn 1987; Monto 2001; Morens 1995; Mukerjee 1994; Murayama 1999; Patriarca 1985a; Saah 1986b; Strassburg 1986; Taylor 1992). We thus grouped our analyses by viral circulation and vaccine match.

Efficacy of the vaccines against influenza was tested in only six data sets (1250 observations) (Cuneo Crovari 1980; Feery 1976; Gross 1988; Morens 1995; Ruben 1974; Taylor 1992), and was not significant both for vaccine matching (RR $1.04,95 \% \mathrm{Cl} 0.43$ to 2.51 ; 
Analysis 6.1.1) and when matching was absent or unknown (RR $0.47,95 \% \mathrm{Cl} 0.22$ to 1.04 ; Analysis 6.1.2).

Twenty-two data sets assessed the effectiveness of influenza vaccines in preventing ILI (Analysis 6.1; Analysis 6.2). In these data sets, follow-up was restricted to an outbreak period, and the authors reported a virologic surveillance that confirmed influenza virus circulation.
The overall effectiveness of vaccines (VE) against ILI was $23 \%$ ( $6 \%$ to $36 \%$; RR $0.77,95 \% \mathrm{Cl} 0.64$ to 0.94 ; Analysis 6.2 .1 ) when vaccine matching was good and not significantly different from no vaccination (RR $0.80,95 \% \mathrm{Cl} 0.60$ to 1.05 ; Analysis 6.2 .2 ) when matching was poor or unknown. Heterogeneity was high, even within the same influenza season and within the same institution when data from different accommodation blocks were analysed. We noted no association (correlation coefficient 0.09) between vaccine coverage and attack rate of ILI (Figure 2).

Figure 2. Relationship between vaccination rate and attack rate

\section{Relationship between vaccination rate and attack rate}

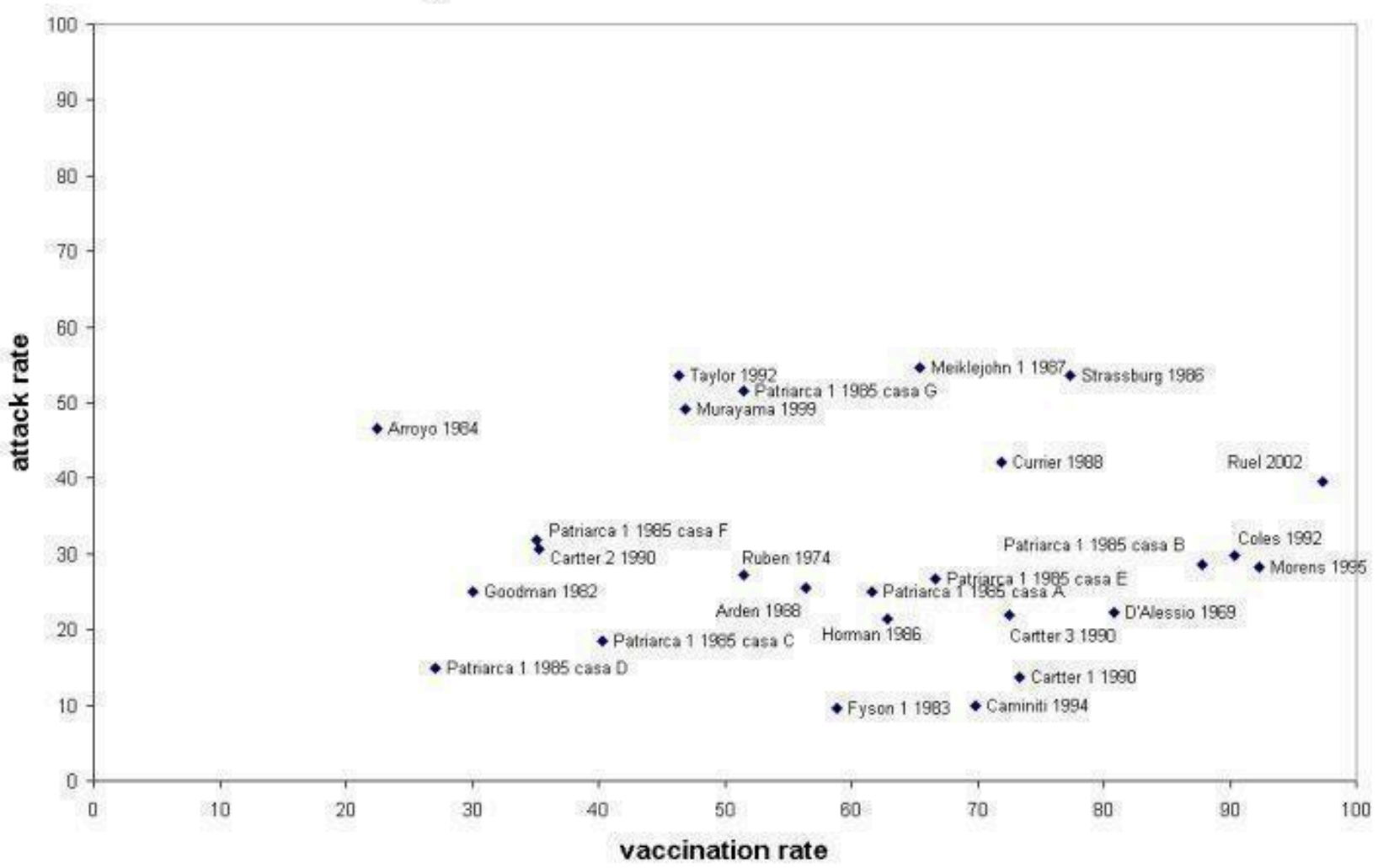

The effectiveness of the vaccines in preventing pneumonia was assessed in 13 data sets (Analysis 6.3.1 and Analysis 6.3.2; 8446 observations). All of them reported virologic surveillance, and eight had follow-ups shorter than three months (Arroyo 1984; Coles 1992; Currier 1988; Horman 1986; Meiklejohn 1987; Morens 1995; Patriarca 1985a; Taylor 1992). Well-matched vaccines were $46 \%$ (30\% to $58 \%$; Analysis 6.3.1) effective in preventing pneumonia (Gross 1988; Horman 1986; Meiklejohn 1987; Monto 2001; Morens 1995; Patriarca 1985a; Saah 1986b; Taylor 1992). When matching was poor or unknown (Arroyo 1984; Coles 1992; Currier 1988; Leung 2007; Saah 1986a), vaccines had no effect (RR $0.68,95 \% \mathrm{Cl} 0.39$ to 1.21; Analysis 6.3.2). Excluding studies with the longest follow-up, that is six months, did not affect our conclusions (Gross 1988; Saah 1986a; Saah 1986b).

Eight data sets assessed the effectiveness of well-matched vaccines in preventing hospitalisation for influenza or pneumonia (Arden 1988; Cartter 1990a; Cartter 1990b; Cartter 1990c; Meiklejohn 1987;
Murayama 1999; Patriarca 1985a; Taylor 1992). All of them had a brief and well-defined follow-up; effectiveness was $45 \%$ (16\% to $64 \%$; Analysis 6.4.1). Two studies reported a non-significant effect when the vaccine did not match the circulating strain or was not reported (Analysis 6.4.2) (Coles 1992; Leung 2007).

Vaccination had a significant effect on the prevention of deaths due to influenza or pneumonia, though this was in the presence of considerable heterogeneity between the 20 data sets (Analysis 6.5.1 and Analysis 6.5.2) (Arroyo 1984; Cartter 1990a; Cartter 1990b; Cartter 1990c; Coles 1992; Feery 1976; Fyson 1983a; Fyson 1983b; Goodman 1982; Horman 1986; Meiklejohn 1987; Monto 2001; Morens 1995; Murayama 1999; Patriarca 1985a; Ruben 1974; Saah 1986a; Saah 1986b; Strassburg 1986; Taylor 1992). Eighteen studies reported virologic surveillance to confirm influenza virus circulation; of these, 16 had a follow-up shorter than three months, and two had a four-month follow-up (Feery 1976; Monto 2001). 
Two studies lacked virologic surveillance and had a follow-up of six months (Saah 1986a; Saah 1986b).

The vaccine was effective if it was a good match (VE 42\%; $17 \%$ to $59 \%$; Analysis 6.5.1), otherwise it was not effective (RR $0.34,95 \% \mathrm{Cl}$ 0.11 to 1.02 ; Analysis 6.5.2).

Excluding two studies with a six-month follow-up and absence of viral surveillance affects the summary estimate more than the efficacy in the 'epidemic-matching' group, which drops from $42 \%$ to $39 \%$ ( $95 \% \mathrm{Cl} 12$ to 58 ) (Saah 1986a; Saah 1986b).

Only one small study with a six-month follow-up assessed the effectiveness in reducing all-cause mortality (Gross 1988), which was found to be significant (60\%; $23 \%$ to $79 \%$; Analysis 6.6 .1 ).

\section{Studies carried out during low viral circulation (from previous versions of the review)}

Eleven data sets (27,283 observations) assessed the effects of influenza vaccines in 350 institutional facilities during low viral circulation (Caminiti 1994; Deguchi 2001; Howarth 1987a; Howarth 1987b; Howells 1975a; Howells 1975b; Howells 1975c; Patriarca 1985b; Saah 1986c; Saito 2002a; Saito 2002b). Apart from Patriarca 1985 , in this subgroup we found studies with the longest (five to six months) and most poorly defined follow-up. Two of these studies did not report virologic surveillance (Deguchi 2001; Saah 1986c).

The vaccines were $33 \%$ effective (2\% to $54 \%$; Analysis 6.2 .3 ) in preventing ILI (Caminiti 1994; Patriarca 1985b; Saito 2002a; Saito 2002b), but had no significant effects in preventing influenza (RR $0.23,95 \% \mathrm{Cl} 0.05$ to 1.03; Analysis 6.1 .3 ). This observations is based on two data sets from a single, relatively small study (691 observations) (Howarth 1987a; Howarth 1987b). Both comparisons are from well-matched vaccines.

We identified a few data sets that assessed the effectiveness of vaccines in preventing complications. Four briefly reported data sets from two studies carried out in situations of low viral circulation and poor vaccine matching reported a combined effectiveness of $65 \%$ (32\% to $82 \%$; Analysis 6.3 .4 ) in preventing pneumonia (Howells 1975a; Howells 1975b; Howells 1975c; Saah 1986c).

During periods of low viral circulation, vaccines did prevent hospital admission for pneumonia or influenza (VE 68\%; 24\% to $86 \%$; Analysis 6.4.3). However, one of the included studies was at high risk of bias, meaning that this outcome may not be accurate (Deguchi 2001). The study was set in 301 nursing homes comprising 22,462 elderly participants during the non-epidemic 1998 to 1999 season in Japan. The same study has a large weight in the analysis of effectiveness against deaths by influenza and pneumonia (VE $71 \%$; $43 \%$ to $85 \%$; Analysis 6.5 .3 and Analysis 6.5.4) (Caminiti 1994; Deguchi 2001; Howells 1975a; Howells 1975b; Howells 1975c; Patriarca 1985b; Saah 1986c)

\section{Cohort studies in community-dwelling elderly (from previous versions of the review)}

We included 21 studies with 40 data sets in elderly participants living in open communities (Christenson 2001a; Christenson 2001b; Christenson 2004a; Christenson 2004b; Comeri 1995; Consonni 2004a; Consonni 2004b; Davis 2001a; Davis 2001b; Davis 2001c; Fleming 1995; Gavira Iglesias 1987; Gené Badia 1991; Hak 2002a;
Hak 2002b; Hara 2006; Kawai 2003; Lopez Hernandez 1994; Mangtani 2004b; Mangtani 2004c; Mangtani 2004d; Mangtani 2004e; Mangtani 2004f; Mangtani 2004g; Mangtani 2004h; Mangtani 2004i; Mangtani 2004j; Nichol 1994a; Nichol 1994b; Nichol 1994c; Nichol 1998a; Nichol 1998b; Nichol 2003a; Nichol 2003b; Nicholson 1999; Nordin 2001a; Nordin 2001b; Pregliasco 2002; Shapiro 2003; Voordouw 2003). The studies contained over 3 million observations, mainly collected using data-linkage from insurance reimbursement, hospital, or primary care databases; 13 of these studies reported data stratified or adjusted by risk factors and other potential confounders. These studies had long follow-ups: 12 data sets had a follow-up $=<3$ months; 13 data sets had a follow-up ranging from 4 to 5 months; 8 data sets had a follow-up ranging from 6 to 7 months; 4 data sets had a follow-up ranging from 8 to 12 months; and 2 data sets were without a well-defined followup. In nine data sets, follow-up was defined by relying on virologic surveillance, and three data sets had laboratory confirmation of cases. On the basis of this large body of evidence, we divided our analysis into six separate comparisons.

\section{Inactivated influenza vaccines in all community-dwelling elderly (from previous versions of the review)}

Our second comparison relied on 1 million observations in 20 data sets from 16 studies (Christenson 2001a; Christenson 2004a; Comeri 1995; Davis 2001c; Fleming 1995; Gavira Iglesias 1987; Gené Badia 1991; Hara 2006; Kawai 2003; Lopez Hernandez 1994; Mangtani 2004a; Nichol 1994a; Nichol 1994b; Nichol 1994c; Nichol 1998b; Nichol 2003a; Nichol 2003b; Nicholson 1999; Shapiro 2003; Voordouw 2003).

In elderly individuals living in the community, inactivated influenza vaccines were not effective against ILI, influenza, or pneumonia. No comparison provided enough data for stratification by viral circulation and vaccine matching.

Eight data sets (784,643 observations) with medium to long followup (135 to 365 days) addressed vaccine effectiveness against hospitalisations for influenza or pneumonia (Christenson 2001a; Christenson 2004a; Nichol 1994a; Nichol 1994b; Nichol 1994c; Nichol 1998b; Nichol 2003a; Nichol 2003b). Well-matched vaccines prevented hospital admissions for these illnesses (VE 26\%; 12\% to $38 \%$; Analysis 8.4.1) but not for cardiac disease (RR $0.87,95 \% \mathrm{Cl}$ 0.67 to 1.12 ; Analysis 8.9). Excluding the only study with a one-year follow-up (Christenson 2004a), effectiveness in preventing hospital admissions was increased to $29 \%(95 \% \mathrm{Cl} 14$ to 42$)$.

\section{Inactivated influenza vaccines in all community-dwelling elderly (adjusted for confounders) (from previous versions of the review)}

This is another data set with seven studies contributing 19 data sets with over a million observations from several consecutive influenza seasons (Davis 2001a; Davis 2001b; Davis 2001c; Fleming 1995; Mangtani 2004b; Mangtani 2004c; Mangtani 2004d; Mangtani 2004e; Mangtani 2004f; Mangtani 2004g; Mangtani 2004h; Mangtani 2004i; Mangtani 2004j; Nichol 1998a; Nichol 2003a; Nichol 2003b; Nordin 2001a; Nordin 2001b; Voordouw 2003). Most of the studies included in this analysis used data linkage and adjusted their odds ratio (OR) calculations to allow for the effect of confounding of several variables (sex, age, smoking, comorbidities). The effects of the vaccines were all significant. 
Hospitalisations for influenza or pneumonia: eight data sets (based on 949,215 observations), all but one with a follow-up lasting 135 days (OR 0.73, 95\% Cl 0.67 to 0.79; Analysis 9.1) (Davis 2001a; Davis 2001b; Davis 2001c; Nichol 1998a; Nichol 2003a; Nichol 2003b; Nordin 2001b). Excluding the data set with the longest follow-up (eight months), Nordin 2001a, did not change the result.

Hospitalisations for respiratory diseases: OR $0.78,95 \% \mathrm{Cl} 0.72$ to 0.85 (Analysis 9.2). Data sets have a follow-up of 135 days or less, so a sensitivity analysis appears to be superfluous.

Hospitalisation for cardiac disease: OR $0.76,95 \% \mathrm{Cl} 0.70$ to 0.82 (Analysis 9.3). Data sets have a follow-up of 135 days or less, so a sensitivity analysis appears to be superfluous.

Mortality due to all causes: seven data sets with follow-up ranging from 75 to 240 days: OR $0.53,95 \% \mathrm{Cl} 0.46$ to 0.61 (Analysis 9.4) (Fleming 1995; Nichol 1998a; Nichol 2003a; Nichol 2003b; Nordin 2001a; Nordin 2001b; Voordouw 2003). Excluding data sets with a follow-up period equal to or longer than six months, Nordin 2001a and Voordouw 2003, did not change the final result.

Death from respiratory disease was not significantly affected. Seven data sets with a follow-up ranging from 75 to 210 days assessed the effect on mortality due to all causes (VE 42\%; 24\% to 55\%; Analysis 8.8) (Fleming 1995; Gené Badia 1991; Lopez Hernandez 1994; Nichol 2003a; Nichol 2003b; Shapiro 2003; Voordouw 2003). Excluding four data sets with a follow-up equal to or longer than six months, Gené Badia 1991, Lopez Hernandez 1994, Voordouw 2003, or a non-defined follow-up (Shapiro 2003), the efficacy falls from $42 \%$ to $39 \%(95 \% \mathrm{Cl} 28$ to 49$)$.

\section{Inactivated influenza vaccines in community-dwelling elderly at risk of influenza complications (from previous versions of the review)}

In the third comparison, we assessed the effectiveness of inactivated influenza vaccines in elderly individuals living in the community and at risk of complications associated with influenza. People with any of the following underlying conditions were considered at risk of complications: lung disease, heart disease, renal disease, diabetes and other endocrine disorders, immunodeficiency or immunosuppressive diseases, cancer, dementia or stroke, vasculitis, or rheumatic disease. Seven data sets from six studies were relevant. The only significant effect was that for deaths from all causes (VE $61 \%$; $3 \%$ to $84 \%$; Analysis 10.6) from 68,032 observations with high heterogeneity $\left(I^{2}=94.1 \%\right)$ (Fleming 1995; Shapiro 2003; Voordouw 2003).

\section{Inactivated influenza vaccines in community-dwelling elderly without risk of influenza complications (from previous versions of the review)}

In this stratum, six studies with seven data sets contributed several hundred thousand observations (Fleming 1995; Hak 2002a; Hak 2002b; Mangtani 2004a; Nichol 1998a; Shapiro 2003; Voordouw 2003). However, most outcomes were only assessed by one study. The only notable results were the vaccines' effectiveness in preventing hospital admission for influenza or pneumonia (VE 50\%; $37 \%$ to $60 \%$; Analysis 11.3 ), although this observation was based on only one data set with 101,619 observations (Nichol 1998a), and there was a lack of effect on all-cause mortality (RR 0.65, 95\% Cl 0.33 to $1.29 ; 43,821$ observations; Analysis 11.6) (Fleming 1995; Shapiro 2003; Voordouw 2003).
Inactivated influenza and polysaccharide vaccine (PPV) on community-dwelling elderly (from previous versions of the review)

Three studies assessed the impact of inactivated influenza and concomitant PPV on hospitalisations for influenza or pneumonia or respiratory diseases (VE 33\%; 30\% to $36 \%$, based on 518,748 observations; Analysis 12.2) (Christenson 2001b; Christenson 2004b; Consonni 2004b), and two data sets assessed the effect on all-cause mortality (VE 56\%; 54\% to 59\%; Analysis 12.4) (Christenson 2001b; Consonni 2004b).

The addition of PPV did not appear to improve the performance of influenza vaccines significantly.

\section{Adjuvant influenza vaccines in all community-dwelling elderly (from previous versions of the review)}

Two small studies with a combined denominator of 498 assessed the impact of vaccines containing a virosomal adjuvant in preventing ILI (VE 70\%; 44\% to 84\%; Analysis 13.1) and hospitalisations (RR $0.17,95 \% \mathrm{Cl} 0.02$ to 1.28 ; Analysis 13.2.3) during a year of low viral circulation but with a vaccine with a good match (Consonni 2004a; Pregliasco 2002). The study by Consonni 2004a also assessed the impact on all-cause mortality and found no effect (RR 2.10, 95\% Cl 0.10 to 43.10; Analysis 13.3.3). This is not surprising given its population size of 129 people (too small for any significant effect to be evident).

\section{Case-control studies (from previous versions of the review)}

We included 12 studies contributing 14 data sets (Ahmed 1995; Ahmed 1997; Crocetti 2001; Fedson 1993a; Fedson 1993b; Foster 1992; Jordan 2007; Mullooly 1994; Ohmit 1995a; Ohmit 1995b; Ohmit 1999; Puig-Barberà 1997; Puig-Barberà 2004; Puig-Barbera 2007). Eight data sets from seven studies assessed the effects of inactivated influenza vaccines on community-dwelling elderly (Ahmed 1995; Ahmed 1997; Crocetti 2001; Fedson 1993a; Fedson 1993b; Jordan 2007; Puig-Barberà 1997; Puig-Barbera 2007); five looked at the co-administration of inactivated influenza with PPV on institutionalised elderly (Foster 1992; Mullooly 1994; Ohmit 1995a; Ohmit 1995b; Ohmit 1999); one study was of adjuvant influenza with PPV on community-dwelling elderly (Puig-Barberà 2004); and one was of adjuvanted influenza vaccines (MF59) alone (Puig-Barbera 2007). Only three of these studies, all of which assessed influenza and pneumococcal vaccines, had a long followup (six months). Since all data sets adjusted their ORs for likely confounding factors, we structured our analysis on five strata, further subdividing each analysis by viral circulation and vaccine matching whenever possible.

\section{Inactivated influenza vaccines on community-dwelling elderly (from previous versions of the review)}

Before adjustment, inactivated influenza vaccines were associated with an increased risk of admission for any respiratory disease (OR $1.08,95 \% \mathrm{Cl} 0.92$ to 1.26 ; 20,582 observations; Analysis 14.2.1) (Ahmed 1997; Fedson 1993a; Fedson 1993b), and did not prevent hospital admission for influenza and pneumonia in elderly individuals living in the community (OR $0.89,95 \% \mathrm{Cl} 0.69$ to 1.15; 1074 observations; Analysis 14.1) (Crocetti 2001; Puig-Barberà 1997), or affect hospitalisation for ILI (Analysis 14.2.2), Jordan 2007 , or affect mortality from influenza and pneumonia, though this conclusion was based on a relatively small data set of 1092 
observations (Analysis 14.3.1) (Ahmed 1995). The single study on adjuvanted vaccines showed no effect on pneumonia no better defined (Analysis 14.4.1) (Puig-Barbera 2007).

\section{Inactivated influenza vaccines on community-dwelling elderly - adjusted analysis (from previous versions of the review)}

After adjustment, however, the vaccines did reduce the risk of death from influenza and pneumonia (OR $0.74,95 \% \mathrm{Cl} 0.60$ to 0.92 ; Analysis 15.3) (Ahmed 1995; Mullooly 1994), and prevent admission for influenza and pneumonia (OR 0.59, $95 \% \mathrm{Cl} 0.47$ to 0.74 ; Analysis 15.1), Crocetti 2001, Foster 1992, Mullooly 1994, Puig-Barberà 1997, Puig-Barberà 2004, and for all respiratory diseases (OR 0.71, 95\% $\mathrm{Cl} 0.56$ to 0.90; Analysis 15.2) (Ahmed 1997; Fedson 1993a; Fedson 1993b).

\section{Possible causes of observed heterogeneity - post hoc analysis}

Of the 15 main comparisons with 61 outcome combinations, we noted in a subsequent analysis that seven comparisons with 20 outcome combinations had an 12 statistic greater than $30 \%$ and that the heterogeneity of these studies could be explained by grouping by viral circulation and vaccine matching.

\section{Safety}

We included data on local and systemic harms. For local harms, we included tenderness, sore arm, swelling, erythema, and induration. Similar local symptoms were pooled in the analysis due to small data sets. Systemic symptoms were general malaise, fever, headache, nausea, and respiratory tract symptoms.

The only studies evaluating rare adverse events were three surveillance studies assessing Guillain-Barré syndrome with neither cohort nor case-control design (Table 2) (Kaplan 1982; Lasky 1998; Schonberger 1979). Case finding was carried out by interviewing neurologists or by searching discharge diagnoses databases. Vaccination rates in the relevant populations were estimated from specific survey or from national immunisation survey. All studies were conducted in the USA and assessed the entire population irrespective of age. Lasky 1998 and Schonberger 1979 reported outcome stratified by age, allowing data extraction for elderly people. We reported the results of these studies in Table 2. The strong and significant association between $A / N e w$ Jersey/76 swine vaccine and Guillain-Barré syndrome during the 1976 to 1977 influenza season was not confirmed in subsequent seasons, when other vaccines not containing A/New Jersey/76 were used.

\section{DISCUSSION}

\section{Summary of main results}

Our findings show that according to randomised evidence, the effectiveness of trivalent inactivated influenza vaccines in elderly individuals, when considered in absolute terms, is modest irrespective of setting, outcome, population, and study design. The certainty of the evidence was low for influenza and moderate for ILI. Our estimates were consistently below those usually quoted for economic modelling or decision making. In view of the known variability of incidence and effect of influenza, we constructed a large number of comparisons and strata to minimise possible heterogeneity between studies and to aid comparability. We also performed subanalysis of studies describing better defined epidemic periods. Despite our attempts, we noted significant residual heterogeneity among studies that could be explained only in part by different study designs, methodological quality, settings, viral circulation, vaccine types and matching, age, population types, and risk factors. We think the residual heterogeneity could be the result of the unpredictable nature of the spread of influenza and ILI and the bias caused by the non-randomised nature of our evidence base. Our sensitivity analysis did not affect the final result.

\section{Overall completeness and applicability of evidence}

Whatever the causes of observed variability, we believe that the decision to vaccinate against influenza cannot be made based on the results of single studies, or reporting observations from a few seasons; rather, it should be taken on the basis of all available evidence. The conclusions drawn from studies done in individuals living in long-term care facilities differ from those drawn from studies in individuals living in the community. Studies done in residents of care homes often indicate the inevitably improvised nature of efforts to study the effect of vaccination during an epidemic. The resident population is usually more homogeneous than that in the community: older, with similar viral exposure and risk levels. Despite remaining heterogeneity and an overestimation of the effects as a result of study design, it is possible to detect a gradient of effectiveness, in which vaccines have little effect on cases of ILI. This finding suggests that control of influenza through vaccination is a possibility. However, the effectiveness of vaccines in the community is modest, irrespective of adjustment for systematic differences between vaccine recipients and nonrecipients. The difficulties of achieving good coverage in those who need it most or the diluting effect on vaccines for influenza of other agents circulating in the community (causing ILI, clinically indistinguishable from influenza) might be to blame. We noted empirical proof of both these possibilities, with differential vaccine uptake among the same population (linked to age, sex, and health status) and a low effect on ILI throughout our data sets, even in periods of supposedly high influenza viral circulation, when the proportion of cases of ILI caused by influenza are highest and the possible benefits of vaccination should be greatest.

The impact of vaccines on pneumonia, mortality, and hospitalisations from the randomised evidence available is insufficient to draw conclusions. Very few studies have captured data on these outcomes, and where we have obtained data, the rate of events was too low to be able to determine the size of effect (Summary of findings 1 ).

Safety does not appear to be a particular problem: the public health safety profile of the vaccines is acceptable. However, relatively few studies assessed safety outcomes.

\section{Quality of the evidence}

We rated the quality of evidence to be moderate for ILI and fever, low for influenza and nausea, and very low for hospitalisations and death (Summary of findings 1). Most of the available evidence for these outcomes is from studies with unclear risk of bias across multiple domains. Fever was the only outcome where we did not consider bias to be influential due to consistency in direction and size of effect with the low risk of bias study (Govaert 1994a). The lack of detail regarding the diagnosis of influenza limits the applicability of our findings to laboratory-confirmed influenza and is a source of indirectness. 
For other outcomes (e.g. nausea and fever), the method of ascertainment is less uncertain due to the expected mechanism of action of vaccines.

Imprecision arising from wide Cls or low event rates, or both, affects the evidence for adverse events, death, and pneumonia to varying degrees. The $\mathrm{Cls}$ for fever and nausea were wide (serious imprecision), but death and pneumonia were rare events in the studies, prompting us to downgrade two levels for very serious imprecision. The rating of very low quality for the latter two outcomes reflects the sparse nature of the data available for analysis.

The main problem with interpreting our substantial data set is caused by the relative scarcity of randomised controlled trials (RCTs). Only one trial assessed currently available vaccines and reached satisfactory completion (Govaert 1994a). The remainder of the data set consists of evidence from non-RCTs.

Our main concern was the quality of the non-RCTs, which likely affected the estimates of effect reported in our review. The findings of the included cohort studies are likely to have been affected to varying degrees by selection bias. Differential uptake of influenza vaccines is linked to several factors (anxiety over unwanted effects, disease threat perception, societal and economic conditions, education, health status) and hence to outcome. Confounding by indication (people with chronic illness or people who are perceived to be frailer than others are more likely to be vaccinated) might reduce the estimated vaccine efficacy. People with terminal illness or with socio-economic disadvantages are less likely to be vaccinated, and this fact might enhance vaccine efficacy. Both these interpretations are based on empirical evidence. For example, one cohort study had difficulty achieving high coverage in those most at need (Gené Badia 1991). Differential vaccine uptake and the resulting selection bias is the most likely explanation for the high effectiveness of influenza vaccines in preventing deaths from all causes. A good example of the potential effect of such confounders is the apparently counterintuitive effectiveness of the vaccines in elderly individuals living in the community. In this population, vaccine effectiveness shows an implausible sequence: the vaccines are apparently ineffective in the prevention of influenza, ILI, pneumonia, hospital admissions, or deaths from any respiratory disease, but are effective in the prevention of hospital admission for influenza and pneumonia and in the prevention of deaths from all causes.

Non-RCT evidence in this review is open to any alternative interpretation and consistently fails to give satisfactory answers. Since the publication of our 2006 review (Rivetti 2006), several empirical studies looking at the effect of selection bias in retrospective cohorts (variously called selection bias, confounding by indication, or healthy user effect) have been published. Some confirmed the presence and effect of confounders (Eurich 2008; Fukushima 2008; Glezen 2006; Hirota 2008; Jackson 2006a; Jackson 2006b; Jackson 2006c; Jackson 2006d; Jackson 2006e). Other studies, mainly carried out by the authors of cohort studies in question, failed to find any effect of confounding on mortality once adjustment had been carried out (Groenwold 2008; Groenwold 2009; Hak 2006; Nichol 2007). For example, proof of bias was provided by a study evaluating the risk of hospitalisation and death in vaccinated compared with unvaccinated seniors during influenza and non-influenza periods (Jackson 2006a). Consistent with other published studies, during influenza season, vaccination was associated with a $44 \%$ reduction in risk of all-cause mortality. However, in the period before the influenza season, vaccination was associated with a $61 \%$ reduction in risk of this outcome. The reduction in risk before the influenza season indicates the presence of bias due to preferential selection of vaccination by relatively healthy seniors, and the strength of that bias is sufficient to account entirely for the association found during the influenza season. In a second, nested case-control study, seniors with functional markers of frailty (such as dependence on washing) were found to be at a greatly increased risk of death and were less likely to have received influenza vaccine, indicating that these factors are important sources of bias in assessment of influenza vaccine effectiveness (Jackson 2006b).

Regardless of the results of empirical studies, the sheer implausibility of the effectiveness sequence which ends with high estimates of effect against mortality from all causes points to considerable confounding and calls into question the reliability of using such non-specific outcomes. Systematic differences between the intervention and control arms of cohort studies are likely to be the result of a baseline imbalance in health status and other known and unknown systematic differences in the two groups of participants. The rationale of the work starts from the observation that the $47 \%$ reduction in risk of all-cause mortality in elderly community dwellers observed in our review exceeds by far the estimated possible impact of influenza on winterseasonal mortality of $5 \%$ in an average season (Glezen 2006). Until improvement of cohort study design is available, the use in nonRCTs of highly non-specific outcome indicators, such as all-cause mortality, is likely to lead to unrealistic estimates of the effects of the vaccines.

Evidence from RCTs, in which bias is reduced to a minimum, is scant and badly reported. Unfortunately, because of the global recommendations on influenza vaccination, placebo-controlled trials, which could clarify the effects of influenza vaccines in individuals, are no longer considered possible on ethical grounds.

Since publication of the first version of this review, we have noted increased reliance of the case test-negative study design to assess influenza vaccine effectiveness post hoc, that is after the influenza 'season'. The case test-negative design is described in detail elsewhere (Foppa 2013; Valenciano 2012).

The data included in a case test-negative design are sometimes harvested from an ongoing networked surveillance cohort. In this case, the case test-negative design is described as 'nested' within the cohort. The source cohort can include community and hospitalised cases and controls, allowing flexibility. In Europe, the surveillance programme has a formal structure and is known as Influenza - Monitoring Vaccine Effectiveness (I-MOVE). I-MOVE is partly funded and co-ordinated by the European Centre for Disease Prevention and Control (sites.google.com/site/epiflu/ Home) (Kissling 2017).

Briefly, the study design, which is similar to a case-control design, consists of selecting influenza cases (e.g. cases of ILI who have tested positive for influenza) and controls (cases of ILI who have tested negative) and calculating the relevant odds ratio (OR). Cases and controls are subsequently stratified by vaccination status. An estimate of vaccines effectiveness (VE) is derived from the OR of influenza in vaccinated/unvaccinated participants using the standard formula VE = $1-\mathrm{OR} \%$. The practice of using the OR 
estimate as an approximation of the risk ratio was first used in a 1980 study on pneumococcal vaccine (Broome 1980).

Despite their popularity, test-negative designs have limited public health significance.

The design does not test field effectiveness, but the capacity of the vaccines to generate a negative polymerase chain reaction result (what we would call laboratory efficacy). Both cases and controls are symptomatic, so any prevention is solely focused on the negativity of laboratory tests. In addition, no useful public health absolute measures of effect can be derived (such as absolute risk reduction and its reciprocal number needed to vaccinate) by such designs, as the background rates of infection and viral circulation are not part of the calculation of the estimates of effect. The mathematical method first used by Broome and colleagues is correct if three key assumptions are met:

1. the risk of non-influenza ILI is the same in vaccinated and non-vaccinated individuals (a factor called "k" by Broome and colleagues) (Broome 1980);

2. the attack rate in the vaccinated population is low; and

3. the circulating serotypes are similar to those in the selected population within the case-control studies based on testnegative design.

All assumptions are unlikely to be fulfilled at the same time, especially in multicentre/multi country surveillance cohorts with a non-random sampling frame. For example, Cowling and colleagues reported an increased risk of non-influenza respiratory virus infections associated with receipt of inactivated influenza vaccine. In addition, the OR will give falsely high VE if the attack rate in the vaccinated population is high (Cowling 2012; Orenstein 1985). Apart from these fundamental design problems, case test-negative studies are also affected by poor reporting. (See also Perencevich 2013a; Perencevich 2013b).

\section{Potential biases in the review process}

The publication of our 2006 review sparked a discussion that continues to this day (Rivetti 2006). Because we are conscious that (despite the inconclusive evidence) we could have introduced our own biases into the reviewing process, we re-extracted and reassessed all studies included in this and all other reviews of influenza vaccine studies (259 primary studies, reporting 274 data sets). We worked independently in two teams of two, extracting directly into pre-set forms with rigid criteria but using the same quality assessment scales used in the original version of the review. As well as assessing quality of study design, we assessed concordance between data presented and conclusions and direction of conclusions (in favour or not of the performance of influenza vaccines). We also looked at the relationship between these variables and study funding and journal of publication. We found that higher-quality studies were significantly more likely to show concordance between data presented and conclusions (OR $16.35,95 \% \mathrm{Cl} 4.24$ to 63.04$)$ and less likely to favour effectiveness of vaccines $(0.04,0.02$ to 0.09$)$. Government-funded studies were less likely to have conclusions favouring the vaccines $(0.45,0.26$ to 0.90$)$. A higher mean journal impact factor was associated with complete or partial industry funding compared with government or private funding and no funding (differences between means 5.04). Study size was not associated with concordance, content of take-home message, funding, or study quality. Higher citation index factor was associated with partial or complete industry funding (Jefferson 2009b).

We concluded that the general quality of influenza vaccines studies is very low and that publication in prestigious journals is associated with partial or total industry funding. We could not explain this association with study quality, size or study status (registration trials using surrogate outcomes such as antibody titres were not included in the review).

\section{Agreements and disagreements with other studies or reviews}

Nichol provides a useful overview of reviews of influenza vaccines in all age groups (Nichol 2008). For the elderly, she identified our review and a review by $V u$ 2002. Although the point estimates appear approximately similar across the reviews, both $\mathrm{Vu}$ and Nichol fail to assess study quality and interpret results accordingly. We have summarised other main reviews identified below.

The review Belongia 2016 includes 56 case test-negative studies. The authors briefly list five methodological quality criteria which do not appear to have been validated. The authors do not list blinding of assessors to vaccination status, a very well-known source of bias in case-control studies. The authors report substantial variation in vaccine effectiveness, but mention none of the limitations of testnegative designs.

The review by Darvishian 2017 includes data from 4975 elderly who had been included in previous test-negative studies. The text refers to "individual participant data meta-analysis", but the basic problems with test-negative designs are not addressed, and previous study authors were asked to extract their own study data on provided forms with no methodological quality assessment. The authors conclude that "Influenza vaccination is moderately effective against laboratory-confirmed influenza in elderly people during epidemic seasons".

The review by Osterholm 2012 included comparative studies with data from the USA and influenza diagnosed by polymerase chain reaction. The authors found variable effectiveness but a lack of evidence in the elderly.

\section{AUTHORS' CONCLUSIONS}

\section{Implications for practice}

Healthy older adults receiving the influenza vaccine may be at lower risk of influenza (from $6 \%$ to $2.4 \%$, low-certainty evidence) and are probably at lower risk of influenza-like illness (ILI) (from $6 \%$ to $3.5 \%$, moderate-certainty evidence) compared with those who do not receive a vaccination over the course of a single influenza season. Our uncertainty in the effect on influenza reflects a lack of information about how the diagnosis was confirmed in the studies and judgements of high or unclear risk of bias.

The findings of our review indicate that implementing vaccination programmes for elderly people may lead to reductions in influenza and ILI, but randomised studies to date have provided insufficient data on complications. Very few deaths occurred in the trials, and no data on hospitalisation were reported. No cases of pneumonia occurred in one study that reported this outcome. The sparse nature of the data overall may reflect the low risk of developing complications in the healthy population of interest and low rates 
of ILI and influenza in the trials. Vaccination probably increases fever from $1.6 \%$ to $2.5 \%$ (moderate-certainty evidence) and may increase nausea from $2.4 \%$ to $4.2 \%$, but for both of these harms the confidence interval is wide. Similar effects were observed for headache, general malaise, and upper respiratory tract symptoms. Sore arm and swelling occurred more frequently with vaccination.

Policymakers considering funding vaccine programmes and individuals contemplating vaccination should take into account the likely benefits in terms of the reductions in the risk of influenza and ILI (3.5\% and $2.5 \%$, respectively), uncertainty over complications, and possible increases in harms.

\section{Implications for research}

Investment in the development of better vaccines than are currently available should be linked to better knowledge of the causes and patterns of ILI in different communities. The additional effects of vaccinating carers in reducing transmission in nursing homes should be assessed. The effect of vaccination of high-risk groups should also be further assessed.

Until such time as the role of vaccines for preventing complications of influenza in the elderly is clarified, more comprehensive and effective strategies for the control of acute respiratory infections should be investigated. These should include several preventive interventions that take into account the multi-agent nature of ILI and its context (such as personal hygiene and adequate food, water, and sanitation).

When a new vaccination or preventive technology becomes available, an adequately powered, publicly funded, high-quality placebo-controlled trial run over several seasons should be undertaken. New insights on the role of viruses and other agents in the genesis of influenza and ILI are also needed.

\section{ACKNOWLEDGEMENTS}

The 2016 update was funded by the Cochrane Review Support Programme.

The review authors wish to acknowledge Daniela Rivetti, Melanie Rudin and Lubna Al-Ansary as previous authors.

The authors gratefully acknowledge the following people for commenting on previous drafts: Amy Zelmer, Laila Tata, Lohne Simonsen, Sree Nair Maryann Napoli, Anne Lyddiat, Wendy Keitel, Ludovic Reveiz, Mark Jones, Chris Del Mar and Geoff Spurling.

For this 2016 update, we acknowledge help and comments received from Liz Dooley, Toby Lasserson, David Honeyman, Janet Wale, Soumyadeep Bhaumik, Mark Jones, and Jenny Doust. We thank Lisa Winer for copy-editing this update. 


\section{RE F E R E N C E S}

\section{References to studies included in this review}

Ahmed 1995 \{published data only\}

Ahmed AE, Nicholson KG, Nguyen-Van-Tam JS. Reduction in mortality associated with influenza vaccine during 1989-90 epidemic. Lancet 1995;346(8975):591-5.

\section{Ahmed 1997 \{published data only\}}

Ahmed AH, Nicholson KG, Nguyen-van Tam JS, Pearson JC. Effectiveness of influenza vaccine in reducing hospital admissions during the 1989-90 epidemic. Epidemiology and Infection 1997;118(1):27-33.

\section{Allsup 2004 \{published data only\}}

Allsup S, Haycox A, Regan M, Gosney M. Is influenza vaccination cost effective for healthy people between ages 65 and 74 years? A randomised controlled trial. Vaccine 2004;23(5):639-45.

\section{Arden 1988 \{published data only\}}

Arden NH, Patriarca PA, Fasano MB, Lui KJ, Harmon MW, Kendal AP, et al. The roles of vaccination and amantadine prophylaxis in controlling an outbreak of influenza $A(H 3 N 2)$ in a nursing home. Archives of Internal Medicine 1988;148(4):865-8.

\section{Arroyo 1984 \{published data only\}}

Arroyo JC, Postic B, Brown A, Harrison K, Birgenheier R, Dowda H. Influenza A/Philippines/2/82 outbreak in a nursing home: limitations of influenza vaccination in the aged. American Journal of Infection Control 1984;12(6):329-34.

\section{Aymard 1979a \{published data only\}}

Aymard M, Bentejac MC, Larbaigt G, Michaut D, Triau R. Efficacy of the antiinfluenza $A$ vaccination during epidemics due to $A /$ $\mathrm{VIC} / 3 / 75$ and $A /$ Texas/ $1 / 77$ viruses. Developments in Biological Standardization 1979;43:231-9.

\section{Aymard 1979b \{published data only\}}

Aymard M, Bentejac MC, Larbaigt G, Michaut D, Triau R. Efficacy of the antiinfluenza $A$ vaccination during epidemics due to $A$ / $\mathrm{VIC} / 3 / 75$ and $\mathrm{A} / \mathrm{Texas} / 1 / 77$ viruses. Developments in Biological Standardization 1979;43:231-9.

\section{Caminiti 1994 \{published data only\}}

Caminiti C, Ricco D, Tanzi ML, Borrini B, Corsello A, Biasio LR, et al. Field evaluation of influenza vaccine efficacy in a population of institutionalized elderly. L'igiene Moderna 1994;101(2):163-75.

\section{Cartter 1990a \{published data only\}}

Cartter ML, Renzullo PO, Helgerson SD, Martin SM, Jekel JF. Influenza outbreaks in nursing homes: how effective is influenza vaccine in the institutionalized elderly? Infection Control and Hospital Epidemiology 1990;11(9):473-8.

\section{Cartter 1990b \{published data only\}}

Cartter ML, Renzullo PO, Helgerson SD, Martin SM, Jekel JF. Influenza outbreaks in nursing homes: how effective is influenza vaccine in the institutionalized elderly? Infection Control and Hospital Epidemiology 1990;11(9):473-8.
Cartter 1990c \{published data only\}

Cartter ML, Renzullo PO, Helgerson SD, Martin SM, Jekel JF. Influenza outbreaks in nursing homes: how effective is influenza vaccine in the institutionalized elderly? Infection Control and Hospital Epidemiology 1990;11(9):473-8.

\section{Christenson 2001a \{published data only\}}

Christenson B, Lundbergh P, Hedlund J, Ortqvist A. Effects of a large-scale intervention with influenza and 23-valent pneumococcal vaccines in adults aged 65 years or older: a prospective study. Lancet 2001;357(9261):1008-11.

\section{Christenson 2001b \{published data only\}}

Christenson B, Lundbergh P, Hedlund J, Ortqvist A. Effects of a large-scale intervention with influenza and 23-valent pneumococcal vaccines in adults aged 65 years or older: a prospective study. Lancet 2001;357(9261):1008-11.

\section{Christenson 2004a \{published data only\}}

Christenson B, Hedlund J, Lundbergh P, Ortqvist A. Additive preventive effect of influenza and pneumococcal vaccines in elderly persons. European Respiratory Journal 2004;23(3):363-8.

\section{Christenson 2004b \{published data only\}}

Christenson B, Hedlund J, Lundbergh P, Ortqvist A. Additive preventive effect of influenza and pneumococcal vaccines in elderly persons. European Respiratory Journal 2004;23(3):363-8.

\section{Coles 1992 \{published data only\}}

Coles FB, Balzano GJ, Morse DL. An outbreak of influenza A $(\mathrm{H} 3 \mathrm{~N} 2)$ in a well immunized nursing home population. Journal of the American Geriatrics Society 1992;40(6):589-92.

\section{Comeri 1995 \{published data only\}}

Comeri L, Tinella M, Croce E, Arzese M. Protective efficacy of antiinfluenza vaccination in the elderly. L'igiene Moderna 1995;103(6):651-6.

\section{Consonni 2004a \{published data only\}}

Consonni S, Sandrini C, Segato E, Perruchini E, Bergamaschini L, Vergani $C$. Tolerability and efficacy of anti-influenza vaccination alone and associated with antipneumococcal vaccination in an elderly ambulatory population and adherence to the vaccination campaign. Journal of Preventive Medicine and Hygiene 2004;45:45-50.

\section{Consonni 2004b \{published data only\}}

Consonni S, Sandrini C, Segato E, Perruchini E, Bergamaschini L, Vergani C. Tolerability and efficacy of anti-influenza vaccination alone and associated with antipneumococcal vaccination in an elderly ambulatory population and adherence to the vaccination campaign. Journal of Preventive Medicine and Hygiene 2004;45:45-50.

\section{Crocetti 2001 \{published data only\}}

Crocetti E, Arniani S, Bordoni F, Maciocco G, Zappa M, Buiatti E. Effectiveness of influenza vaccination in the elderly in a community in Italy. European Journal of Epidemiology 2001;17(2):163-8 


\section{Cuneo Crovari 1980 \{published data only\}}

Cuneo Crovari P, Gasparini R, Crovari P. Efficacy of influenza vaccination: results in a community controlled for 2 years. Bollettino dell'Istituto Sieroterapico Milanese 1980;59(4):306-13.

\section{Currier 1988 \{published data only\}}

Currier M, Coffman T, Boyd P, Fremd B, Israel E. Influenza vaccine efficacy in a Maryland nursing home. Maryland Medical Journal 1988;37(10):781-3.

\section{D'Alessio 1969 \{published data only\}}

D'Alessio DJ, Cox PM Jr, Dick EC. Failure of inactivated influenza vaccine to protect an aged population. JAMA 1969;210(3):485-9.

\section{Davis 2001a \{published data only\}}

Davis JW, Lee E, Taira DA, Chung RS. Influenza vaccination, hospitalizations, and costs among members of a Medicare managed care plan. Medical Care 2001;39(12):1273-80.

\section{Davis 2001b \{published data only\}}

Davis JW, Lee E, Taira DA, Chung RS. Influenza vaccination, hospitalizations, and costs among members of a Medicare managed care plan. Medical Care 2001;39(12):1273-80.

\section{Davis 2001c \{published data only\}}

Davis JW, Lee E, Taira DA, Chung RS. Influenza vaccination, hospitalizations, and costs among members of a Medicare managed care plan. Medical Care 2001;39(12):1273-80.

\section{Deguchi 2001 \{published data only\}}

Deguchi Y, Nishimura K. Efficacy of influenza vaccine in elderly persons in welfare nursing homes: reduction in risks of mortality and morbidity during an influenza A (H3N2) epidemic. Journals of Gerontology. Series A, Biological Sciences and Medical Sciences 2001;56(6):M391-4.

\section{Edmondson 1971 \{published data only\}}

Edmondson WP Jr, Rothenberg R, White PW, Gwaltney JM Jr. A comparison of subcutaneous, nasal, and combined influenza vaccination. II. Protection against natural challenge. American Journal of Epidemiology 1971;93(6):480-6.

\section{Fedson 1993a \{published data only\}}

Fedson DS, Wajda A, Nicol JP, Hammond GW, Kaiser DL, Roos LL. Clinical effectiveness of influenza vaccination in Manitoba. JAMA 1993;270(16):1956-61.

\section{Fedson 1993b \{published data only\}}

Fedson DS, Wajda A, Nicol JP, Hammond GW, Kaiser DL, Roos LL. Clinical effectiveness of influenza vaccination in Manitoba. JAMA 1993;270(16):1956-61.

\section{Feery 1976 \{published data only\}}

Feery BJ, Evered MG, Morrison El. Different protection rates in various groups of volunteers given subunit influenza virus vaccine in 1976. Journal of Infectious Diseases 1979;139(2):237-41.

\section{Fleming 1995 \{published data only\}}

Fleming DM, Watson JM, Nicholas S, Smith GE, Swan AV. Study of the effectiveness of influenza vaccination in the elderly in the epidemic of 1989-90 using a general practice database. Epidemiology and Infection 1995;115(3):581-9.

Foster 1992 \{published data only\}

Foster DA, Talsma A, Furumoto-Dawson A, Ohmit SE, Margulies JR, Arden NH, et al. Influenza vaccine effectiveness in preventing hospitalization for pneumonia in the elderly. American Journal of Epidemiology 1992;136(3):296-307.

Fyson 1983a \{published data only\}

Fyson RE. Influenza outbreaks in two institutions for the elderly - Ontario. Canadian Diseases Weekly Report 1983;9:37.

Fyson 1983b \{published data only\}

Fyson RE. Influenza outbreaks in two institutions for the elderly - Ontario. Canadian Diseases Weekly Report 1983;9:37.

Gavira Iglesias 1987 \{published data only\}

Gavira Iglesias FJ, Rodriguez Lopez FC, Berni Maestre RM. Analysis of an influenza vaccination campaign in rural environment. Revista de Sanidad e Higiene Publica 1987;61(7-8):759-81.

\section{Gené Badia 1991 \{published data only\}}

Gene Badia J, Calero Munoz S, Castanera Ribe C, Gran Rovireta A. Effectiveness of an anti-influenza vaccination program in 4 primary care centers. Gaceta Sanitaria 1991;5(26):203-8.

\section{Goodman 1982 \{published data only\}}

Goodman RA, Orenstein WA, Munro TF, Smith SC, Sikes RK. Impact of influenza $\mathrm{A}$ in a nursing home. JAMA 1982;247(10):1451-3.

\section{Govaert 1993 \{published data only\}}

Govaert TM, Dinant GJ, Aretz K, Masurel N, Sprenger MJ, Knottnerus JA. Adverse reactions to influenza vaccine in elderly people: randomised double blind placebo controlled trial. $B M J$ 1993;307(6910):988-90.

\section{Govaert 1994a \{published data only\}}

Govaert TM, Thijs CT, Masurel N, Sprenger MJ, Dinant GJ, Knottnerus JA. The efficacy of influenza vaccination in elderly individuals. A randomized double-blind placebo-controlled trial. JAMA 1994;272(21):1661-5.

\section{Gross 1988 \{published data only\}}

Gross PA, Quinnan GV, Rodstein M, LaMontagne JR, Kaslow RA, Saah AJ, et al. Association of influenza immunization with reduction in mortality in an elderly population. A prospective study. Archives of Internal Medicine 1988;148(3):562-5.

\section{Hak 2002a \{published data only\}}

Hak E, Nordin J, Wei F, Mullooly J, Poblete S, Strikas R, et al. Influence of high-risk medical conditions on the effectiveness of influenza vaccination among elderly members of 3 large managed-care organizations. Clinical Infectious Diseases 2002:35(4):370-7. 
Hak 2002b \{published data only\}

Hak E, Nordin J, Wei F, Mullooly J, Poblete S, Strikas R, et al. Influence of high-risk medical conditions on the effectiveness of influenza vaccination among elderly members of 3 large managed-care organizations. Clinical Infectious Diseases 2002;35(4):370-7.

\section{Hara 2006 \{published data only\}}

Hara M, Sakamoto T, Tanaka K. Effectiveness of influenza vaccination in preventing influenza-like illness among community-dwelling elderly: population-based cohort study in Japan. Vaccine 2006;24(27-8):5546-51.

\section{Horman 1986 \{published data only\}}

Horman JT, Stetler HC, Israel E, Sorley D, Schipper MT, Joseph JM. An outbreak of influenza A in a nursing home. American Journal of Public Health 1986;76(5):501-4.

\section{Howarth 1987a \{published data only\}}

Howarth DM, Chaston TM, Lickiss K, Weekes JR, O'Doherty C, Foster RE, et al. Age-related responses to influenza vaccination in the Newcastle region during 1983 and 1984. Medical Journal of Australia 1987;146(10):514-7.

\section{Howarth 1987b \{published data only\}}

Howarth DM, Chaston TM, Lickiss K, Weekes JR, O'Doherty C, Foster RE, et al. Age-related responses to influenza vaccination in the Newcastle region during 1983 and 1984. Medical Journal of Australia 1987;146(10):514-7.

\section{Howells 1975a \{published data only\}}

Howells CH, Vesselinova-Jenkins CK, Evans AD, James J. Influenza vaccination and mortality from bronchopneumonia in the elderly. Lancet 1975;1(7903):381-3.

\section{Howells 1975b \{published data only\}}

Howells CH, Vesselinova-Jenkins CK, Evans AD, James J. Influenza vaccination and mortality from bronchopneumonia in the elderly. Lancet 1975;1(7903):381-3.

\section{Howells 1975c \{published data only\}}

Howells CH, Vesselinova-Jenkins CK, Evans AD, James J. Influenza vaccination and mortality from bronchopneumonia in the elderly. Lancet 1975;1(7903):381-3.

\section{Isaacs 1997 \{published data only\}}

Isaacs S, Dickinson C, Brimmer G. Outbreak of influenza A in an Ontario nursing home - January 1997. Canada Communicable Disease Report 1997;23(14):105-8.

\section{Jordan 2007 \{published data only\}}

Jordan RE, Hawker JI, Ayres JG, Tunnicliffe W, Adab P, Olowokure B, et al. A case-control study of elderly patients with acute respiratory illness: effect of influenza vaccination on admission to hospital in winter 2003-2004. Vaccine 2007;25(46):7909-13.

\section{Kaplan 1982 \{published data only\}}

Kaplan JE, Katona P, Hurwitz ES, Schonberger LB. GuillainBarre syndrome in the United States, 1979-1980 and 1980-1981.
Lack of an association with influenza vaccination. JAMA 1982;248(6):698-700.

Kawai 2003 \{published data only\}

Kawai N, Ikematsu H, Iwaki N, Satoh I, Kawashima T, Tsuchimoto T, et al. A prospective, internet-based study of the effectiveness and safety of influenza vaccination in the 2001-2002 influenza season. Vaccine 2003;21(31):4507-13.

Keitel 1996 \{published data only\}

Keitel WA, Cate TR, Atmar RL, Turner CS, Nino D, Dukes CM, et al. Increasing doses of purified influenza virus hemagglutinin and subvirion vaccines enhance antibody responses in the elderly. Clinical and Diagnostic Laboratory Immunology 1996;3(5):507-10.

\section{Lasky 1998 \{published data only\}}

Lasky T, Terracciano GJ, Magder L, Koski CL, Ballesteros M, Nash D, et al. The Guillain-Barre syndrome and the 1992-1993 and 1993-1994 influenza vaccines. New England Journal of Medicine 1998;339(25):1797-802.

\section{Leung 2007 \{published data only\}}

Leung JCK. Effectiveness of influenza vaccination among elderly home residents in Hong Kong: a retrospective cohort study. Hong Kong Practitioner 2007;29(4):123-33.

\section{Lopez Hernandez 1994 \{published data only\}}

Lopez Hernandez B, Vazquez J, Fernandez E, Martinez B, Romero J, Arribas L. Effectiveness of anti-flu vaccine in the elderly. Atencion Primaria 1994;14(1):532-6.

\section{Mangtani 2004a \{published data only\}}

Mangtani P, Cumberland P, Hodgson CR, Roberts JA, Cutts FT, Hall AJ. A cohort study of the effectiveness of influenza vaccine in older people, performed using the United Kingdom general practice research database. Journal of Infectious Diseases 2004;190(1):1-10.

\section{Mangtani 2004b \{published data only\}}

Mangtani P, Cumberland P, Hodgson CR, Roberts JA, Cutts FT, Hall AJ. A cohort study of the effectiveness of influenza vaccine in older people, performed using the United Kingdom general practice research database. Journal of Infectious Diseases 2004;190(1):1-10.

\section{Mangtani 2004c \{published data only\}}

Mangtani P, Cumberland P, Hodgson CR, Roberts JA, Cutts FT, Hall AJ. A cohort study of the effectiveness of influenza vaccine in older people, performed using the United Kingdom general practice research database. Journal of Infectious Diseases 2004;190(1):1-10.

\section{Mangtani 2004d \{published data only\}}

Mangtani P, Cumberland P, Hodgson CR, Roberts JA, Cutts FT, Hall AJ. A cohort study of the effectiveness of influenza vaccine in older people, performed using the United Kingdom general practice research database. Journal of Infectious Diseases 2004;190(1):1-10. 
Mangtani 2004e \{published data only\}

Mangtani P, Cumberland P, Hodgson CR, Roberts JA, Cutts FT, Hall AJ. A cohort study of the effectiveness of influenza vaccine in older people, performed using the United Kingdom general practice research database. Journal of Infectious Diseases 2004;190(1):1-10.

\section{Mangtani 2004f $\{$ published data only\}}

Mangtani P, Cumberland P, Hodgson CR, Roberts JA, Cutts FT, Hall AJ. A cohort study of the effectiveness of influenza vaccine in older people, performed using the United Kingdom general practice research database. Journal of Infectious Diseases 2004;190(1):1-10.

\section{Mangtani 2004g \{published data only\}}

Mangtani P, Cumberland P, Hodgson CR, Roberts JA, Cutts FT, Hall AJ. A cohort study of the effectiveness of influenza vaccine in older people, performed using the United Kingdom general practice research database. Journal of Infectious Diseases 2004;190(1):1-10.

\section{Mangtani 2004h \{published data only\}}

Mangtani P, Cumberland P, Hodgson CR, Roberts JA, Cutts FT, Hall AJ. A cohort study of the effectiveness of influenza vaccine in older people, performed using the United Kingdom general practice research database. Journal of Infectious Diseases 2004;190(1):1-10.

\section{Mangtani 2004i \{published data only\}}

Mangtani P, Cumberland P, Hodgson CR, Roberts JA, Cutts FT, Hall AJ. A cohort study of the effectiveness of influenza vaccine in older people, performed using the United Kingdom general practice research database. Journal of Infectious Diseases 2004;190(1):1-10.

\section{Mangtani 2004j \{published data only\}}

Mangtani P, Cumberland P, Hodgson CR, Roberts JA, Cutts FT, Hall AJ. A cohort study of the effectiveness of influenza vaccine in older people, performed using the United Kingdom general practice research database. Journal of Infectious Diseases 2004;190(1):1-10.

\section{Margolis 1990a \{published data only\}}

Margolis KL, Nichol KL, Poland GA, Pluhar RE. Frequency of adverse reactions to influenza vaccine in the elderly. A randomized, placebo-controlled trial. JAMA 1990;264(9):1139-41.

\section{Meiklejohn 1987 \{published data only\}}

Meiklejohn G, Hall H. Unusual outbreak of influenza A in a Wyoming nursing home. Journal of the American Geriatric Society $1987 ; 35(8): 742-6$.

\section{Monto 2001 \{published data only\}}

Monto AS, Hornbuckle K, Ohmit SE. Influenza vaccine effectiveness among elderly nursing home residents: a cohort study. American Journal of Epidemiology 2001;154(2):155-60.

\section{Morens 1995 \{published data only\}}

Morens DM, Rash VM. Lessons from a nursing home outbreak of influenza A. Infection Control and Hospital Epidemiology 1995;16(5):275-80.

\section{Mukerjee 1994 \{published data only\}}

Mukerjee A. Spread of influenza: a study of risk factors in homes for the elderly in Wales. Journal of Epidemiology and Community Health 1994;48(6):602-3.

\section{Mullooly 1994 \{published data only\}}

Mullooly JP, Bennett MD, Hornbrook MC, Barker WH, Williams WW, Patriarca PA, et al. Influenza vaccination programs for elderly persons: cost-effectiveness in a health maintenance organization. Annals of Internal Medicine 1994;121(12):947-52.

\section{Murayama 1999 \{published data only\}}

Murayama N, Suzuki H, Arakawa M, Nerome K, Mizuta K, Kameyama K. Two outbreaks of influenza A (H3N2) in a Japanese nursing home in the winter of 1996-1997, with differing vaccine efficacy. Tohoku Journal of Experimental Medicine 1999;188(4):289-98.

\section{Nichol 1994a \{published data only\}}

Nichol KL, Margolis KL, Wuorenma J, Von Sternberg T. The efficacy and cost effectiveness of vaccination against influenza among elderly persons living in the community. New England Journal of Medicine 1994;331(12):778-84.

\section{Nichol 1994b \{published data only\}}

Nichol KL, Margolis KL, Wuorenma J, Von Sternberg T. The efficacy and cost effectiveness of vaccination against influenza among elderly persons living in the community. New England Journal of Medicine 1994;331(12):778-84.

\section{Nichol 1994c \{published data only\}}

Nichol KL, Margolis KL, Wuorenma J, Von Sternberg T. The efficacy and cost effectiveness of vaccination against influenza among elderly persons living in the community. New England Journal of Medicine 1994;331(12):778-84.

\section{Nichol 1998a \{published data only\}}

Nichol KL, Wuorenma J, von Sternberg T. Benefits of influenza vaccination for low-, intermediate-, and high-risk senior citizens. Archives of Internal Medicine 1998;158(16):1769-76.

\section{Nichol 1998b \{published data only\}}

Nichol KL, Wuorenma J, von Sternberg T. Benefits of influenza vaccination for low-, intermediate-, and high-risk senior citizens. Archives of Internal Medicine 1998;158(16):1769-76.

\section{Nichol 2003a \{published data only\}}

Nichol KL, Nordin J, Mullooly J, Lask R, Fillbrandt K, Iwane M. Influenza vaccination and reduction in hospitalizations for cardiac disease and stroke among the elderly. New England Journal of Medicine 2003;348(14):1322-32.

\section{Nichol 2003b \{published data only\}}

Nichol KL, Nordin J, Mullooly J, Lask R, Fillbrandt K, Iwane M. Influenza vaccination and reduction in hospitalizations for 
cardiac disease and stroke among the elderly. New England Journal of Medicine 2003;348(14):1322-32.

Nicholson 1999 \{published data only\}

Nicholson KG, Kent J, Hammersley V. Influenza A among community-dwelling elderly persons in Leicestershire during winter 1993-4; cigarette smoking as a risk factor and the efficacy of influenza vaccination. Epidemiology and Infection 1999;123(1):103-8.

\section{Nordin 2001a \{published data only\}}

Nordin J, Mullooly J, Poblete S, Strikas R, Petrucci R, Wei F, et al. Influenza vaccine effectiveness in preventing hospitalizations and deaths in persons 65 years or older in Minnesota, New York, and Oregon: data from 3 health plans. Journal of Infectious Diseases 2001;184(6):665-70.

\section{Nordin 2001b \{published data only\}}

Nordin J, Mullooly J, Poblete S, Strikas R, Petrucci R, Wei F, et al. Influenza vaccine effectiveness in preventing hospitalizations and deaths in persons 65 years or older in Minnesota, New York, and Oregon: data from 3 health plans. Journal of Infectious Diseases 2001;184(6):665-70.

\section{Ohmit 1995a \{published data only\}}

Ohmit SE, Monto AS. Influenza vaccine effectiveness in preventing hospitalization among the elderly during influenza type A and type B seasons. International Journal of Epidemiology 1995;24(6):1240-8.

\section{Ohmit 1995b \{published data only\}}

Ohmit SE, Monto AS. Influenza vaccine effectiveness in preventing hospitalization among the elderly during influenza type A and type B seasons. International Journal of Epidemiology 1995;24(6):1240-8.

\section{Ohmit 1999 \{published data only\}}

Ohmit SE, Arden NH, Monto AS. Effectiveness of inactivated influenza vaccine among nursing home residents during an influenza type A (H3N2) epidemic. Journal of the American Geriatric Society 1999;47(2):165-71.

\section{Patriarca 1985a \{published data only\}}

Patriarca PA, Weber JA, Parker RA, Hall WN, Kendal AP, Bregman DJ, et al. Efficacy of influenza vaccine in nursing homes. Reduction in illness and complications during an influenza A (H3N2) epidemic. JAMA 1985;253(8):1136-9.

\section{Patriarca 1985b \{published data only\}}

Patriarca PA, Weber JA, Parker RA, Hall WN, Kendal AP, Bregman DJ, et al. Efficacy of influenza vaccine in nursing homes. Reduction in illness and complications during an influenza A (H3N2) epidemic. JAMA 1985;253(8):1136-9.

\section{Pregliasco 2002 \{published data only\}}

Pregliasco F, Giardini G, Sandrini MC, Perucchini E, Vergani C. Protective efficacy of Inflexal $V$ in the elderly pazinte [Efficacia protettiva di Inflexal V nel pazinte anziano]. Vaccine at a Glance 2002;1(1):2-5.

\section{Puig-Barberà 1997 \{published data only\}}

Puig-Barbera J, Marquez-Calderon S, Masoliver-Fores A, LloriaPaes F, Ortega-Dicha A, Gil-Martin M, et al. Reduction in hospital admissions for pneumonia in non-institutionalised elderly people as a result of influenza vaccination: a case-control study in Spain. Journal of Epidemiology and Community Health 1997;51(5):526-30.

\section{Puig-Barberà 2004 \{published data only\}}

Puig-Barbera J, Diez-Domingo J, Perez Hoyos S, Belenguer Varea A, Gonzalez Vidal D. Effectiveness of the MF59-adjuvanted influenza vaccine in preventing emergency admissions for pneumonia in the elderly over 64 years of age. Vaccine 2004;23(3):283-9.

\section{Puig-Barbera 2007 \{published data only\}}

Puig-Barberà J, Díez-Domingo J, Varea AB, Chavarri GS, Rodrigo JA, Hoyos SP et al. Effectiveness of MF59-adjuvanted subunit influenza vaccine in preventing hospitalisations for cardiovascular disease, cerebrovascular disease and pneumonia in the elderly. Vaccine 2007;25(42):7313-21.

\section{Ruben 1974 \{published data only\}}

Ruben FL, Johnston F, Streiff EJ. Influenza in a partially immunized aged population. Effectiveness of killed Hong Kong vaccine against infection with the England strain. JAMA 1974;230(6):863-6.

\section{Rudenko 2001 \{published data only\}}

Rudenko LG, Arden NH, Grigorieva E, Naychin A, Rekstin A, Klimov Al, et al. Immunogenicity and efficacy of Russian live attenuated and US inactivated influenza vaccines used alone and in combination in nursing home residents. Vaccine 2000;19(2-3):308-18

\section{Saah 1986a $\{$ published data only\}}

Saah AJ, Neufeld R, Rodstein M, La Montagne JR, Blackwelder WC, Gross P, et al. Influenza vaccine and pneumonia mortality in a nursing home population. Archives of Internal Medicine 1986;146(12):2353-7.

\section{Saah 1986b \{published data only\}}

Saah AJ, Neufeld R, Rodstein M, La Montagne JR, Blackwelder WC, Gross P, et al. Influenza vaccine and pneumonia mortality in a nursing home population. Archives of Internal Medicine 1986;146(12):2353-7.

\section{Saah 1986c \{published data only\}}

Saah AJ, Neufeld R, Rodstein M, La Montagne JR, Blackwelder WC, Gross P, et al. Influenza vaccine and pneumonia mortality in a nursing home population. Archives of Internal Medicine 1986;146(12):2353-7.

\section{Saito 2002a \{published data only\}}

Saito R, Suzuki H, Oshitani H, Sakai T, Seki N, Tanabe N. The effectiveness of influenza vaccine against influenza A (H3N2) virus infections in nursing homes in Niigata, Japan, during the 1998-1999 and 1999-2000 seasons. Infection Control and Hospital Epidemiology 2002;23(2):82-6. 
Saito 2002b \{published data only\}

Saito R, Suzuki H, Oshitani H, Sakai T, Seki N, Tanabe N. The effectiveness of influenza vaccine against influenza A (H3N2) virus infections in nursing homes in Niigata, Japan, during the 1998-1999 and 1999-2000 seasons. Infection Control and Hospital Epidemiology 2002;23(2):82-6.

\section{Schonberger 1979 \{published data only\}}

Schonberger LB, Bregman DJ, Sullivan-Bolyai JZ, Keenlyside RA, Ziegler DW, Retailliau HF, et al. Guillain-Barre syndrome following vaccination in the National Influenza Immunization Program, United States, 1976-1977. American Journal of Epidemiology 1979;110(2):105-23.

\section{Shapiro 2003 \{published data only\}}

Shapiro Y, Shemer J, Heymann A, Shalev V, Maharshak N, Chodik $\mathrm{G}$, et al. Influenza vaccination: reduction in hospitalizations and death rates among members of "Maccabi Healthcare Services" during the 2000-2001 influenza season. Israel Medical Association Journal 2003;5(10):706-8.

\section{Strassburg 1986 \{published data only\}}

Strassburg MA, Greenland S, Sorvillo FJ, Lieb LE, Habel LA. Influenza in the elderly: report of an outbreak and a review of vaccine effectiveness reports. Vaccine 1986;4(1):38-44.

\section{Stuart 1969 \{published data only\}}

Stuart WH, Dull HB, Newton LH, McQueen JL, Schiff ER. Evaluation of monovalent influenza vaccine in a retirement community during the epidemic of 1965-66. JAMA 1969;209(2):232-8.

\section{Taylor 1992 \{published data only\}}

Taylor JL, Dwyer DM, Coffman T, Groves C, Patel J, Israel E. Nursing home outbreak of influenza A (H3N2): evaluation of vaccine efficacy and influenza case definitions. Infection Control and Hospital Epidemiology 1992;13(2):93-7.

\section{Treanor 1994 \{published data only\}}

Treanor J, Dumyati G, O'Brien D, Riley MA, Riley G, Erb S, et al. Evaluation of cold-adapted, reassortant influenza $B$ virus vaccines in elderly and chronically ill adults. Journal of Infectious Diseases 1994;169(2):402-7.

\section{Voordouw 2003 \{published data only\}}

Voordouw BC, van der Linden PD, Simonian S, van der Lei J, Sturkenboom MC, Stricker BH. Influenza vaccination in community-dwelling elderly: impact on mortality and influenza-associated morbidity. Archives of Internal Medicine 2003;163(9):1089-94.

\section{References to studies excluded from this review}

\section{Allsup 2001 \{published data only\}}

Allsup SJ, Gosney M, Regan M, Haycox A, Fear S, Johnstone FC. Side effects of influenza vaccination in healthy older people: a randomised single-blind placebo-controlled trial. Gerontology 2001;47(6):311-4.
Allsup 2003 \{published data only\}

Allsup S, Gosney M, Haycox A, Regan M. Cost-benefit evaluation of routine influenza immunisation in people 65-74 years of age. Health Technology Assessment 2003;7(24):iii-x, 1-65.

Anonymous 1995 \{published data only\}

Influenza vaccination in the elderly: a bona fide clinical trial. Hospital Practice 1995;30(2):100.

Anonymous 2004b \{published data only\}

Vaccination protects against influenza deaths in elderly. Pharmaceutical Journal 2004;273(7318):410.

\section{Ansaldi 2002 \{published data only\}}

Ansaldi F, Tominz R, D'Agaro P, Michieletto F, Quadranti M, Cornelio $\mathrm{G}$, et al. Influenza vaccination among the elderly in Trieste: comparison of a cross-sectional study and routine public health surveillance [Vaccinazione anti-influenzale negli anziani a Trieste: confronto fra uno studio trasversale ed il sistema di sorveglianza passivo]. Annali di Igiene: Medicina Preventiva e di Comunità 2002;14(4):305-11.

\section{Arden 1986 \{published data only\}}

Arden NH, Patriarca PA, Kendal P. Experiences in the use and efficacy of inactivated influenza vaccine in nursing homes. In: Kendal AP, Patriarca PA, editors(s). Options for the Control of Influenza. New York: Alan R. Liss, 1986:155-68.

\section{Armstrong 2004 \{published data only\}}

Armstrong BG, Mangtani P, Fletcher A, Kovats S, McMichael A, Pattenden $S$, et al. Effect of influenza vaccination on excess deaths occurring during periods of high circulation of influenza: cohort study in elderly people. BMJ 2004;329(7467):660.

Arroyo 1988 \{published data only\}

Arroyo JC, Jordan W, Milligan L. Upper respiratory tract infection and serum antibody responses in nursing home patients. American Journal of Infection Control 1988;16(4):152-8.

\section{Arya 2003 \{published data only\}}

Arya SC. Influenza and other vaccine uptake in the elderly in England. Vaccine 2003;21(25-6):3527.

\section{Ayala-Montiel 2004 \{published data only\}}

Ayala-Montiel O, Mascarenas de los Santos C, GarciaHernandez D, Rendon-Muniz J, Garcia-Olvera L. Reactogenicity of the simultaneous administration of influenza and pneumococcal vaccines in adults over 55 years of age. Revista de Investigacion Clinica 2004;56(1):27-31.

\section{Baldo 1999 \{published data only\}}

Baldo V, Menegon T, Buoro S, Scalici C, Vesco A, Perale S, et al. Vaccination against influenza in the elderly. Experience with adjuvant vaccines. Annali di Igiene: Medicina Preventiva e di Comunità 1999;11(5):369-74.

\section{Barker 1980 \{published data only\}}

Barker WH, Mullooly JP. Influenza vaccination of elderly persons. Reduction in pneumonia and influenza hospitalizations and deaths. JAMA 1980;244(22):2547-9. 
Bektimirov 1993 \{published data only\}

Bektimirov TA. The immunization of elderly people against influenza. Voprosy Virusologii 1993;38(6):242-5.

Belshe 2004 \{published data only\}

Belshe RB, Nichol KL, Black SB, Shinefield H, Cordova J, Walker R, et al. Safety, efficacy, and effectiveness of live, attenuated, cold-adapted influenza vaccine in an indicated population aged 5-49 years. Clinical Infectious Diseases 2004;39(7):920-7.

\section{Ben-Yehuda 2003 \{published data only\}}

Ben-Yehuda A, Joseph A, Barenholz Y, Zeira E, Even-Chen S, Louria-Hayon I, et al. Immunogenicity and safety of a novel IL-2supplemented liposomal influenza vaccine (INFLUSOME-VAC) in nursing-home residents. Vaccine 2003;21(23):3169-78.

\section{Berg 2004 \{published data only\}}

Berg GD, Thomas E, Silverstein S, Neel CL, Mireles M. Reducing medical service utilization by encouraging vaccines: randomized controlled trial. American Journal of Preventive Medicine 2004;27(4):284-8.

\section{Buxton 2001 \{published data only\}}

Buxton JA, Skowronski DM, Ng H, Marion SA, Li Y, King A, et al. Influenza revaccination of elderly travelers: antibody response to single influenza vaccination and revaccination at 12 weeks. Journal of Infectious Diseases 2001;184(2):188-91.

\section{Carman 2000 \{published data only\}}

Carman WF, Elder AG, Wallace LA, McAulay K, Walker A, Murray GD, et al. Effects of influenza vaccination of health-care workers on mortality of elderly people in long-term care: a randomised controlled trial. Lancet 2000;355(9198):93-7.

\section{Castilla 2006 \{published data only\}}

Castilla J, Arregui L, Baleztena J, Barricarte A, Brugos A, Carpintero $\mathrm{M}$, et al. Incidence of influenza and influenza vaccine effectiveness in the 2004-2005 season. Anales del Sistema Sanitario de Navarra 2006;29(1):97-106.

\section{Chen 2004 \{published data only\}}

Chen YH, Liou SH, Chou CC, Su WL, Loh CH, Lin SH. Influenza and pneumococcal vaccination of the elderly in Taiwan. Vaccine 2004;22(21-2):2806-11.

\section{Chlibek 2002 \{published data only\}}

Chlibek R, Beran J, Splino M. Effectiveness of influenza vaccination in healthy adults - a fourfold decrease in influenza morbidity during one influenza season. Epidemiologie, Mikrobiologie, Imunologie 2002;51(2):47-51.

\section{Christenson 2002 \{published data only\}}

Christenson B, Lundbergh P. Comparison between cohorts vaccinated and unvaccinated against influenza and pneumococcal infection. Epidemiology and Infection 2002;129(3):515-24

\section{Chumakov 1992 \{published data only\}}

Chumakov MP, Beregovskii NA, Linev MB, Reizin FN, Malyshkina LP, Matrosovich MN, et al. Use of highly purified subvirion trivalent flu vaccine ("Grippovak") in groups with a high risk of complications. Zhurnal Mikrobiologii, Epidemiologii, $i$ Immunobiologii 1992;3:55-7.

Cohen 2004 \{published data only\}

Cohen J. Vaccine policy. Immunizing kids against flu may prevent deaths among the elderly. Science 2004;306(5699):1123.

\section{Conne 1997 \{published data only\}}

Conne P, Gauthey L, Vernet P, Althaus B, Que JU, Finkel B, et al. Immunogenicity of trivalent subunit versus virosomeformulated influenza vaccines in geriatric patients. Vaccine 1997;15(15):1675-9.

\section{Cruijff 1999 \{published data only\}}

Cruijff M, Thijs C, Govaert T, Aretz K, Dinant GJ, Knottnerus A. The effect of smoking on influenza, influenza vaccination efficacy and on the antibody response to influenza vaccination. Vaccine 1999;17(5):426-32.

D'Alessandro 2004 \{published data only\}

D'Alessandro D, Ciriminna S, Rossini A, Bossa MC, Fara GM. Requests of medical examinations after pneumococcal \& influenza vaccination in the elderly. Indian Journal of Medical Research 2004;119(Suppl):108-14.

\section{de Bernardi 2002 \{published data only\}}

de Bernardi di Valserra M, Zanasi A, Ragusa S, Gluck R, Herzog C. An open-label comparison of the immunogenicity and tolerability of intranasal and intramuscular formulations of virosomal influenza vaccine in healthy adults. Clinical Therapeutics 2002;24(1):100-11.

\section{de Bruijn 2004 \{published data only\}}

de Bruijn IA, Nauta J, Gerez L, Palache AM. Virosomal influenza vaccine: a safe and effective influenza vaccine with high efficacy in elderly and subjects with low pre-vaccination antibody titers. Virus Research 2004;103(1-2):139-45.

\section{Deguchi 2000a \{published data only\}}

Deguchi Y, Takasugi Y. Efficacy of influenza vaccine in the elderly: reduction in risks of mortality and morbidity during an influenza A (H3N2) epidemic for the elderly in nursing homes. International Journal of Clinical \& Laboratory Research 2000;30(1):1-4.

\section{Deguchi 2000b \{published data only\}}

Deguchi Y, Takasugi Y, Tatara K. Efficacy of influenza vaccine in the elderly in welfare nursing homes: reduction in risks of mortality and morbidity during an influenza A (H3N2) epidemic. Journal of Medical Microbiology 2000;49(6):553-6.

\section{Deguchi 2000c \{published data only\}}

Deguchi Y, Takasugi Y, Nishimura K. Vaccine effectiveness for influenza in the elderly in welfare nursing homes during an influenza A ( $\mathrm{H} 3 \mathrm{~N} 2)$ epidemic. Epidemiology and Infection 2000;125(2):393-7. 
Deibel 1970 \{published data only\}

Deibel R, Decher W, Jacobs J. Observations during Hong Kong influenza epidemic. New York State Journal of Medicine 1970;70(22):2799-805.

\section{De Serres 2004 \{published data only\}}

De Serres G, Skowronski DM, Guay M, Rochette L, Jacobsen K, Fuller T, et al. Recurrence risk of oculorespiratory syndrome after influenza vaccination: randomized controlled trial of previously affected persons. Archives of Internal Medicine 2004;164(20):2266-72.

\section{Elder 1996 \{published data only\}}

Elder AG, O'Donnell B, McCruden EA, Symington IS, Carman WF. Incidence and recall of influenza in a cohort of Glasgow healthcare workers during the 1993-4 epidemic: results of serum testing and questionnaire. BMJ 1996;313(7067):1241-2.

\section{Ender 2001 \{published data only\}}

Ender PT, DeRussy PK, Caldwell MM, Taylor SE, Trevino SC, Ybarra D. The effect of a multivitamin on the immunologic response to the influenza vaccine in the elderly. In: Infectious Diseases in Clinical Practice. Vol. 10. Lippincott Williams \& Wilkins, Inc., 2001:81-5.

\section{Erofeeva 2001 \{published data only\}}

Erofeeva MK, Paramonova MS, Maksakova VL, Kolyvanova IL, Nikolaeva EV, Shadrin AS. Vaccine prophylaxis in elderly patients. Zhurnal Mikrobiologii, Epidemiologii, i Immunobiologi 2001;3:91-3.

\section{Fedson 1992 \{published data only\}}

Fedson DS, Wajda A, Nicol JP, Roos LL. Disparity between influenza vaccination rates and risks for influenza-associated hospital discharge and death in Manitoba in 1982-1983. Annals of Internal Medicine 1992;116(7):550-5.

\section{Fedson 1993 \{published data only\}}

Fedson DS, Waida A, Nicol JP, Roos LL. "The old man's friend". Lancet 1993;342(8870):561.

\section{Fitzner 2001 \{published data only\}}

Fitzner KA, Shortridge KF, McGhee SM, Hedley AJ. Costeffectiveness study on influenza prevention in Hong Kong. Health Policy 2001;56(3):215-34.

\section{Fukumi 1969 \{published data only\}}

Fukumi H. Interpretation of influenza antibody patterns in man. Existence and significance of Hong Kong antibody in old people prior to the Hong Kong influenza epidemic. Bulletin of the World Health Organization 1969;41(3):469-73.

\section{Fukushima 1999 \{published data only\}}

Fukushima T, Nakayama K, Monma M, Sekizawa K, Sasaki H. Influenza vaccination in bedridden patients. Archives of Internal Medicine 1999;159(3):316-7.

\section{Galanti 1976 \{published data only\}}

Galanti B, Picciotto L, Ruggiero G, Romano E, Vaccaro L. Homologous and heterologous antibody response induced in man by anti-influenza vaccine containing $\mathrm{A} /$ England/42/72 and B/Massachusetts/71. Bollettino dell'Istituto Sieroterapico Milanese 1976;55(71):13-7.

Galasso 1977 \{published data only\}

Galasso GJ, Tyeryar FJ Jr, La Montagne JR. Overview of clinical trials of influenza vaccines, 1976. Journal of Infectious Diseases 1977;136(Suppl):425-8.

\section{Garcia-Doval 2001 \{published data only\}}

Garcia-Doval I, Roson E, Feal C, De la Torre C, Rodriguez T, Cruces MJ. Generalized bullous fixed drug eruption after influenza vaccination, simulating bullous pemphigoid. Acta Dermato-Venereologica 2001;81(6):450-1.

\section{Garcia-Garcia 2009 \{published data only\}}

Garcia-Garcia L, Valdespino-Gómez JL, Lazcano-Ponce E, Jiminez-Corona A, Higuera-Iglesias A, Cruz-Hervert P, et al. Partial protection of seasonal trivalent inactivated vaccine against novel pandemic influenza A/H1N1 2009: case-control study in Mexico City. BMJ 2009;339:3928. [DOI: 10.1136/ bmj.b3928

\section{Gasparini 2002 \{published data only\}}

Gasparini R, Lucioni C, Lai P, Maggioni P, Sticchi L, Durando P. Cost-benefit evaluation of influenza vaccination in the elderly in the Italian region of Liguria. Vaccine 2002;20(Suppl 5):B50-4.

\section{Gavira 1990 \{published data only\}}

Gavira FJ, Lardinois R. Cost-effectiveness analysis of antigrippal vaccination in a rural population (La Victoria, Cordoba). Medicina Clinica 1990;94(20):777-81.

\section{Gendon 1988 \{published data only\}}

Gendon I. Prevention of influenza in the aged. Zhurnal Mikrobiologii, Epidemiologii, i Immunobiologii 1988;9(9):93-6.

\section{Giglio 1994 \{published data only\}}

Giglio E, Roggi L, Bonanni P, Giacchi M, Gasparini R. Influenza vaccination in subjects of the local health unit of Arezzo (Tuscany - Italy) during the winter 1990/91. Journal of Preventive Medicine and Hygiene 1994;35(3-4):125-30.

\section{Glass 1978 \{published data only\}}

Glass RI, Brann EA, Slade JD, Jones WE, Scally MJ, Craven RB, et al. Community-wide surveillance of influenza after outbreaks due to H3N2 (A/Victoria/75 and A/Texas/77) and H1N1 (A/ USSR/77) influenza viruses, Mercer County, New Jersey, 1978. Journal of Infectious Diseases 1978;138(5):703-6.

\section{Glezen 1987 \{published data only\}}

Glezen WP, Decker M, Joseph SW, Mercready RG Jr. Acute respiratory disease associated with influenza epidemics in Houston, 1981-1983. Journal of Infectious Diseases 1987;155(6):1119-26.

\section{Gomez de Caso 1996 \{published data only\}}

Gomez de Caso JA, Franco Yague JA, Castillo Izquierdo JM, Ruiz Cosin C. Study of a disease outbreak in a home for the aged. Atencion Primaria 1996;17(3):211-4. 


\section{Govaert 1994b \{published data only\}}

Govaert TM, Sprenger MJ, Dinant GJ, Aretz K, Masurel N, Knottnerus JA. Immune response to influenza vaccination of elderly people. A randomized double-blind placebo-controlled trial. Vaccine 1994;12(13):1185-9.

Gowda 1979 \{published data only\}

Gowda HT. Influenza in a geriatric unit. Postgraduate Medical Journal 1979;55(641):188-91.

\section{Grigor'eva 1994 \{published data only\}}

Grigor'eva EP, Rekstin AR, Rudenko LG, Ramirez A, Barro M, Lisovskaia KV et al. The immunogenic properties and prophylactic efficacy of a live polyvalent influenza vaccine in children 5 to 14 years old. Voprosy Virusologii 1994;39(1):26-9.

\section{Grigor'eva 2002 \{published data only\}}

Grigor'eva EP, Desheva luA, Donina SA, Naikhin AN, Rekstin AR, Barantseva IB, et al. The comparative characteristics of the safety, immunogenic activity and prophylactic potency of the adult and children types of live influenza vaccine in schoolchildren aged 7-14 years. Voprosy Virusologii 2002;47(4):24-7.

\section{Gross 1977 \{published data only\}}

Gross PA. Reactogenicity and immunogenicity of bivalent influenza vaccine in one- and two-dose trials in children: a summary. Journal of Infectious Diseases 1977;136(Suppl):616-25.

\section{Gross 1995 \{published data only\}}

Gross PA, Hermogenes AW, Sacks HS, Lau J, Levandowski RA. The efficacy of influenza vaccine in elderly persons. A metaanalysis and review of the literature. Annals of Internal Medicine 1995;123(7):518-27.

\section{Guarino 1977 \{published data only\}}

Guarino F, Di Peppe C, D'Antonio D, Melena E, Lattanzio FM. Immunity to the HSW1N1 virus in the older population of Chieti. Bollettino della Societa Italiana di Biologia Sperimentale 1977;53(21):1942-4.

\section{Guillevin 1983 \{published data only\}}

Guillevin L, Levy Y. Hypersensitivity reaction following vaccination against influenza. Presse Medicale 1983;12(26):1668-9.

\section{Gutierrez 2001 \{published data only\}}

Gutierrez EB, Li HY, Santos AC, Lopes MH. Effectiveness of influenza vaccination in elderly outpatients in Sao Paulo city, Brazil. Revista do Instituto de Medicina Tropical de Sao Paulo 2001;43(6):317-20.

\section{Hak 1998 \{published data only\}}

Hak E, van Essen GA, Buskens E, Stalman W, de Melker RA. Is immunising all patients with chronic lung disease in the community against influenza cost effective? Evidence from a general practice based clinical prospective cohort study in Utrecht, the Netherlands. Journal of Epidemiology and Community Health 1998;52(2):120-5.
Hall 1981 \{published data only\}

Hall WN, Goodman RA, Noble GR, Kendal AP, Steece RS. An outbreak of influenza $B$ in an elderly population. Journal of Infectious Diseases 1981;144(4):297-302.

\section{Hampson 1997 \{published data only\}}

Hampson AW, Irving LB. Influenza vaccination: cost-effective health care for the older adult? Journal of Quality in Clinical Practice 1997;17(1):3-11.

\section{Hara 2008 \{published data only\}}

Hara M, Sakamoto T, Tanaka K. Influenza vaccine effectiveness among elderly persons living in the community during the 2003-2004 season. Vaccine 2008;26(50):6477-80.

\section{Harling 2004 \{published data only\}}

Harling R, Hayward A, Watson JM. Implications of the incidence of influenza-like illness in nursing homes for influenza chemoprophylaxis: descriptive study. $B M J$ 2004;329(7467):663-4.

\section{Harper 1985 \{published data only\}}

Harper C, Gibson J. Re: Efficacy of influenza vaccine. JAMA 1985;254(11):1451-2.

\section{Hedlund 2003 \{published data only\}}

Hedlund J, Christenson B, Lundbergh P, Ortqvist A. Effects of a large-scale intervention with influenza and 23-valent pneumococcal vaccines in elderly people: a 1-year follow-up. Vaccine 2003;21(25-6):3906-11.

Helliwell 1988 \{published data only\}

Helliwell BE, Drummond MF. The costs and benefits of preventing influenza in Ontario's elderly. Canadian Journal of Public Health 1988;79(3):175-80.

\section{Hennessen 1978 \{published data only\}}

Hennessen W, Jacob H, Quast U. Neurologic affections after influenza inoculation (author's transl). Der Nervenarzt 1978;49(2):90-6.

\section{Herzog 2003 \{published data only\}}

Herzog NS, Bratzler DW, Houck PM, Jiang H, Nsa W, Shook C, et al. Effects of previous influenza vaccination on subsequent readmission and mortality in elderly patients hospitalized with pneumonia. American Journal of Medicine 2003;115(6):454-61.

\section{Heymann 2004 \{published data only\}}

Heymann AD, Shapiro Y, Chodick G, Shalev V, Kokia E, Kramer E, et al. Reduced hospitalizations and death associated with influenza vaccination among patients with and without diabetes. Diabetes Care 2004;27(11):2581-4.

\section{Hirota 1997 \{published data only\}}

Hirota Y, Kaji M, Ide S, Kajiwara J, Kataoka K, Goto S et al. Antibody efficacy as a keen index to evaluate influenza vaccine effectiveness. Vaccine 1997;15(9):962-7.

Hoberman 2003 \{published data only\}

Hoberman A, Greenberg DP, Paradise JL, Rockette HE, Lave JR, Kearney DH et al. Effectiveness of inactivated influenza 
vaccine in preventing acute otitis media in young children: a randomized controlled trial. JAMA 2003;290(12):1608-16.

Hope-Simpson 1970 \{published data only\}

Hope-Simpson RE. First outbreak of Hong Kong influenza in a general practice population in Great Britain. A field and laboratory study. British Medical Journal 1970;3(714):74-7.

\section{Howell 1967 \{published data only\}}

Howell RW. Long-term efficacy of oil-adjuvant influenza vaccine in an industrial population. British Journal of Industrial Medicine 1967;24(1):66-70.

\section{Hurwitz 1983 \{published data only\}}

Hurwitz ES, Holman RC, Nelson DB, Schonberger LB. National surveillance for Guillain-Barre syndrome: January 1978-March 1979. Neurology 1983;33(2):150-7.

\section{Icardi 2002 \{published data only\}}

Icardi G, Durando P, Marasso P, Lai P. Vaccinations for adults at risk and the elderly. Annali di Igiene: Medicina Preventiva e di Comunita 2002;14(Suppl 3):51-8.

\section{Ikematsu 1998 \{published data only\}}

Ikematsu H, Nabeshima A, Kakuda K, Yamaji K, Hayashi J, Goto S, et al. Impact of influenza epidemics and efficacy of vaccination among geriatric inpatients. Kansenshogaku Zasshi 1998;72(1):60-6

\section{Ikematsu $\mathbf{2 0 0 0}$ \{published data only\}}

Ikematsu H, Nabeshima A, Yong C, Hayashi J, Goto S, Oka T, et al. The efficacy of influenza vaccine among geriatric inpatients. Kansenshogaku Zasshi 2000;74(1):17-23.

\section{Isahak 2007 \{published data only\}}

Isahak I, Mahayiddin AA, Ismail R. Effectiveness of influenza vaccination in prevention of influenza-like illness among inhabitants of old folk homes. Southeast Asian Journal of Tropical Medicine \& Public Health 2007;38(5):841-8.

\section{Jackson 1999 \{published data only\}}

Jackson LA, Holmes SJ, Mendelman PM, Huggins L, Cho I, Rhorer J. Safety of a trivalent live attenuated intranasal influenza vaccine, FluMist, administered in addition to parenteral trivalent inactivated influenza vaccine to seniors with chronic medical conditions. Vaccine 1999;17(15-6):1905-9.

\section{Jackson 2002 \{published data only\}}

Jackson LA, Yu O, Heckbert SR, Psaty BM, Malais D, Barlow WE, et al. Influenza vaccination is not associated with a reduction in the risk of recurrent coronary events. American Journal of Epidemiology 2002;156(7):634-40.

\section{Jahnz-Rozyk 2003 \{published data only\}}

Jahnz-Rozyk K. Pharmaco-economics of anti-influenza vaccinations. Polski Merkuriusz Lekarski 2003;14(84):679-81.

\section{Jani 1994 \{published data only\}}

Jani FM, Gray JP, Lanham J. Influenza vaccine and dermatomyositis. Vaccine 1994;12(15):1484.

\section{Jarstrand 1974 \{published data only\}}

Jarstrand C, Tunevall G. The significance of bacterial superinfection in influenza. Scandinavian Journal of Infectious Diseases 1974;6(2):137-44.

\section{Jovanovic 1977 \{published data only\}}

Jovanovic D, Delvaux AM. Clinical acceptability of live influenza vaccine in high risk subjects and children. Experience with three consecutive recombinant strains. Developments in Biological Standardization 1977;39:105-12.

\section{Kaplan 1983 \{published data only\}}

Kaplan JE, Schonberger LB, Hurwitz ES, Katona P. GuillainBarre syndrome in the United States, 1978-1981: additional observations from the national surveillance system. Neurology 1983;33(5):633-7.

\section{Keavey 1999 \{published data only\}}

Keavey S. Preparing for the next influenza outbreak - or (inevitably) pandemic. JAAPA 1999;12(11):28-30, 33-4, 37-40.

\section{King 1997 \{published data only\}}

King D, Morgan R. Giving influenza vaccination to all elderly people would raise ethical issues. BMJ 1997;314(7077):373.

\section{Knight 1984 \{published data only\}}

Knight RS, Duncan JS, Davis CJ, Warlow CP. Influenza vaccination and Guillain-Barre syndrome. Lancet 1984;1(8373):394.

\section{Knottnerus 1996 \{published data only\}}

Knottnerus JA. Influenza in the Netherlands. Pharmacoeconomics 1996;9(Suppl 3):46-9; discussion 50-3.

Kurland 1984 \{published data only\}

Kurland LT, Molgaard CA, Kurland EM, Erdtmann FJ, Stebbing GE. Lack of association of swine flu vaccine and rheumatoid arthritis. Mayo Clinic Proceedings 1984;59(12):816-21.

\section{Landi 2003 \{published data only\}}

Landi F, Onder G, Cesari M, Gravina EM, Lattanzio F, Russo A, et al. Effects of influenza vaccination on mortality among frail, community-living elderly patients: an observational study. Aging Clinical and Experimental Research 2003;15(3):254-8.

\section{Landi 2006 \{published data only\}}

Landi F, Onder G, Cesari M, Russo A, Barillaro C, Bernabei R, et al. In a prospective observational study, influenza vaccination prevented hospitalization among older home care patients. Journal of Clinical Epidemiology 2006;59(10):1072-7.

\section{Lavergne 1980 \{published data only\}}

Lavergne B, Frappier-Davignon L, Chagnon A, Burr-Paxton M, Quevillon M, Pavilanis V et al. Reactogenicity and serologic response to trivalent inactivated $\mathrm{A} /$ Texas, $\mathrm{A} / \mathrm{USSR}$ and $\mathrm{B} / \mathrm{Hong}$ Kong whole-virus influenza vaccine in human volunteers. Canadian Journal of Public Health 1980;71(1):25-31. 
Lawson 2000 \{published data only\}

Lawson F, Baker V, Au D, McElhaney JE. Standing orders for influenza vaccination increased vaccination rates in inpatient settings compared with community rates. Journals of Gerontology. Series A, Biological Sciences and Medical Sciences 2000;55(9):M522-6.

\section{Lindahl 1999 \{published data only\}}

Lindahl G, Perman E. Influenza vaccine caused problems in joints. Compensation from the drug insurance authority. Lakartidningen 1999;96(37):3912-4.

\section{Lohse 1999 \{published data only\}}

Lohse A, Michel F, Auge B, Toussirot E, Wendling D. Vascular purpura and cryoglobulinemia after influenza vaccination. Case-report and literature review. Revue du Rhumatisme (English ed.) 1999;66(6):359-60.

\section{Luce 2001 \{published data only\}}

Luce BR, Zangwill KM, Palmer CS, Mendelman PM, Yan L, Wolff MC, et al. Cost-effectiveness analysis of an intranasal influenza vaccine for the prevention of influenza in healthy children. Pediatrics 2001;108(2):E24.

Mair 1974 \{published data only\}

Mair HJ, Sansome DA, Tillett HE. A controlled trial of inactivated monovalent influenza $A$ vaccines in general practice. Journal of Hygiene 1974;73(2):317-27.

\section{Mandal 1973 \{published data only\}}

Mandal SK. Influenza outbreak. British Medical Journal 1973;1(5851):481.

\section{Manzano 2000 \{published data only\}}

Manzano E, Grau A, Sequeira E, Valles JA. Possible toxicoderma secondary to influenza vaccination. Atencion Primaria 2000;26(6):429.

\section{Manzoli 2007 \{published data only\}}

Manzoli L, Villari P, Granchelli C, Savino A, Carunchio C, Pacifico D, et al. Cohort analysis on influenza vaccine effectiveness for the elderly as a study case to evaluate an alternative approach involving general practitioners for routine assessment of vaccination impact. European Journal of Public Health 2007;17:28-9.

\section{Margolis 1990b \{published data only\}}

Margolis KL, Nichol KL, Poland GA, Pluhar RE. Frequency of adverse reactions to influenza vaccine in the elderly. A randomized, placebo-controlled trial. JAMA 1990;264(9):1139-41.

\section{Marine 1973 \{published data only\}}

Marine WM, Thomas JE. Age-related response to 1000 CCA unit zonally purified, inactivated influenza vaccines in volunteers in the USA. Postgraduate Medical Journal 1973;49(569):164-8.

\section{Marinich 1997 \{published data only\}}

Marinich IG, Paramonova MS, Erofeeva MK, Maksakova VL, Nikolaeva VM, Naikhin AN, et al. The immunoprophylaxis of influenza among elderly persons. Zhurnal Mikrobiologii, Epidemiologii, i Immunobiologii 1997;3:60-4.

Martin 1997 \{published data only\}

Martin JT. Development of an adjuvant to enhance the immune response to influenza vaccine in the elderly. Biologicals 1997;25(2):209-13.

Marwick 1995 \{published data only\}

Marwick C. Influenza vaccine first to reach immunization goal. JAMA 1995;273(10):765.

\section{Masurel 1979 \{published data only\}}

Masurel N. Immunization of elderly subjects with subunit and total virus vaccine containing $\mathrm{H} 1 \mathrm{~N} 1$ influenza virus. Nederlands Tijdschrift Voor Geneeskunde 1979;123(6):196-9.

Maxim 1998 \{published data only\}

Maxim R. Adult immunization. Medicine and Health, Rhode Island 1998;81(8):272-3.

Mayon-White 1994 \{published data only\}

Mayon-White RT. Vaccination for the elderly. British Journal of Hospital Medicine 1994;51(6):265, 267.

McCall 1996 \{published data only\}

McCall TB. Vaccination against influenza in healthy adults. New England Journal of Medicine 1996;334(6):403-4.

McCarthy 1978 \{published data only\} McCarthy NJ. Influenza 1978. Medical Journal of Australia 1978;1(6):314.

McElhaney 2002 \{published data only\}

McElhaney JE. Influenza: a preventable lethal disease. Journals of Gerontology. Series A, Biological Sciences and Medical Sciences 2002;57(10):M627-8.

McGuffey 1993 \{published data only\} McGuffey EC. Flu vaccinations. American Pharmacy 1993;NS33(11):24.

Meiklejohn 1989 \{published data only\}

Meiklejohn G, Hoffman R, Graves P. Effectiveness of influenza vaccine when given during an outbreak of influenza $\mathrm{A} / \mathrm{H} 3 \mathrm{~N} 2$ in a nursing home. Journal of the American Geriatrics Society 1989;37(5):407-10.

Mendelman 2001 \{published data only\}

Mendelman PM, Cordova J, Cho I. Safety, efficacy and effectiveness of the influenza virus vaccine, trivalent, types $A$ and $B$, live, cold-adapted (CAIV-T) in healthy children and healthy adults. Vaccine 2001;19(17-9):2221-6.

Meynaar 1991 \{published data only\}

Meynaar IA, van't Wout JW, Vandenbroucke JP, van Furth R. Use of influenza vaccine in the Netherlands. $B M J$ 1991;303(6801):508. 
Mignogna 2000 \{published data only\}

Mignogna MD, Lo Muzio L, Ruocco E. Pemphigus induction by influenza vaccination. International Journal of Dermatology 2000;39(10):800

\section{Miller 1975 \{published data only\}}

Miller LW, Hume EB, O'Brien FR, Togo Y, Hornick RB. Alice strain live attenuated influenza (H3N2) vaccine in an elderly population. American Journal of Epidemiology 1975;101(4):340-6.

\section{Modlin 1977 \{published data only\}}

Modlin JF, Smith DH, Harding L. Clinical trials of bivalent A/New Jersey/76-A/Victoria/75 influenza vaccines in high-risk children. Journal of Infectious Diseases 1977;136(Suppl):626-31.

\section{Monto 1994 \{published data only\}}

Monto AS. Influenza vaccines for the elderly. New England Journal of Medicine 1994;331(12):807-8

\section{Moreno 2009 \{published data only\}}

Moreno J, De la Hoz F, Rico A, Cotes K, Porras A. Flu vaccine effectiveness: a metaanalysis. Biomedica 2009;29(1):87-97.

\section{Mostow 1969 \{published data only\}}

Mostow SR, Schoenbaum SC, Dowdle WR, Coleman MT, Kaye HS. Studies with inactivated influenza vaccines purified by zonal centrifugation. 1. Adverse reactions and serological responses. Bulletin of the World Health Organization 1969;41(3):525-30

\section{Mostow 1988 \{published data only\}}

Mostow SR. Influenza - a controllable disease? Journal of the American Geriatrics Society 1988;36(3):281-3.

\section{Nguyen-van-Tam 1992 \{published data only\}}

Nguyen-van-Tam JS, Nicholson KG. Influenza deaths in Leicestershire during the 1989-90 epidemic: implications for prevention. Epidemiology and Infection 1992;108(3):537-45.

\section{Nichol 1996 \{published data only\}}

Nichol KL, Margolis KL, Wouremna J, von Sternberg T. Effectiveness of influenza vaccine in the elderly. Gerontology 1996;42(5):274-9.

\section{Nichol 1999a \{published data only\}}

Nichol KL, Goodman M. The health and economic benefits of influenza vaccination for healthy and at-risk persons aged 65 to 74 years. Pharmacoeconomics 1999;16(Suppl 1):63-71.

\section{Nichol 1999b \{published data only\}}

Nichol KL. Complications of influenza and benefits of vaccination. Vaccine 1999;17(Suppl 1):47-52.

\section{Nichol 1999c \{published data only\}}

Nichol KL, Baken L, Nelson A. Relation between influenza vaccination and outpatient visits, hospitalization, and mortality in elderly persons with chronic lung disease. Annals of Internal Medicine 1999;130(5):397-403.

\section{Nichol 1999d \{published data only\}}

Nichol KL, Mendelman PM, Mallon KP, Jackson LA, Gorse GJ, Belshe RB, et al. Effectiveness of live, attenuated intranasal influenza virus vaccine in healthy, working adults: a randomized controlled trial. JAMA 1999;282(2):137-44.

Nichol 2002 \{published data only\}

Nichol KL, Goodman M. Cost effectiveness of influenza vaccination for healthy persons between ages 65 and 74 years. Vaccine 2002;20(Suppl 2):21-4.

Nichol 2007 \{published data only\}

Nichol KL, Nordin JD, Nelson DB, Mullooly JP, Hak E. Effectiveness of influenza vaccine in the community-dwelling elderly [see comment]. New England Journal of Medicine 2007;357(14):1373-81.

Nicholson 1979 \{published data only\}

Nicholson KG, Tyrrell DA, Harrison P, Potter CW, Jennings R, Clark $A$, et al. Clinical studies of monovalent inactivated whole virus and subunit A/USSR/77 (H1N1) vaccine: serological responses and clinical reactions. Journal of Biological Standardization 1979;7(2):123-36.

Nicholson 1983 \{published data only\}

Nicholson KG, Tyrrell DA, Howells CH, Schild GC, Oxford J. Live influenza vaccines. Lancet 1983;2(8349):564-5.

Nicholson 1990a \{published data only\}

Nicholson KG, Baker DJ, Farquhar A, Hurd D, Kent J, Smith SH. Acute upper respiratory tract viral illness and influenza immunization in homes for the elderly. Epidemiology and Infection 1990;105(3):609-18.

Nicholson 1990b \{published data only\}

Nicholson KG. Influenza vaccination and the elderly. BMJ 1990;301(6753):617-8.

Nicholson 1992 \{published data only\}

Nicholson KG, Baker DJ, Chakraverty P, Farquhar A, Hurd D, Kent J, et al. Immunogenicity of inactivated influenza vaccine in residential homes for elderly people. Age and Ageing 1992;21(3):182-8

Nielsen 1996 \{published data only\} Nielsen PV. Vaccination against influenza of the elderly population of Copenhagen. Ugeskrift for Laeger 1996;158(48):6928.

Nygaard 1999 \{published data only\}

Nygaard HA. Prevention of influenza in nursing homes. Tidsskrift for den Norske Laegeforening 1999;119(14):2079.

Odelin 1993 \{published data only\}

Odelin MF, Pozzetto B, Aymard M, Defayolle M, Jolly-Million J. Role of influenza vaccination in the elderly during an epidemic of A/H1N1 virus in 1988-1989: clinical and serological data. Gerontology 1993;39(2):109-16. 
Odelin 2003 \{published data only\}

Odelin MF, Momplot C, Bourlet T, Gonthier R, Aymard M, Pozzetto B. Temporal surveillance of the humoral immunity against influenza vaccine in the elderly over 9 consecutive years. Gerontology 2003;49(4):233-9.

Ohmit 1995 \{published data only\}

Ohmit SE, Furumoto-Dawson A, Monto AS, Fasano N. Influenza vaccine use among an elderly population in a community intervention. American Journal of Preventive Medicine 1995;11(4):271-6.

\section{Ortqvist 2007 \{published data only\}}

Ortqvist A, Granath F, Askling J, Hedlund J. Influenza vaccination and mortality: prospective cohort study of the elderly in a large geographical area [see comment]. European Respiratory Journal 2007;30(3):414-22.

\section{Oshitani 2000 \{published data only\}}

Oshitani H, Saito R, Seki N, Tanabe N, Yamazaki O, Hayashi S, et al. Influenza vaccination levels and influenza-like illness in longterm-care facilities for elderly people in Niigata, Japan, during an influenza A (H3N2) epidemic. Infection Control and Hospital Epidemiology 2000;21(11):728-30.

\section{Parkin 1978 \{published data only\}}

Parkin WE, Beecham HJ, Streiff E, Sharrar RG, Harris JC. Relationship studied in Pennsylvania. Guillain-Barre syndrome and influenza immunization. Pennsylvania Medicine 1978;81(4):47-8, 50-2.

\section{Parsons 1997 \{published data only\}}

Parsons JE, Wilson DH, Luke KF, Carrangis J. Influenza vaccination among the elderly in South Australia. Medical Journal of Australia 1997;167(8):456.

Patel 1988 \{published data only\}

Patel U, Bradley JR, Hamilton DV. Henoch-Schonlein purpura after influenza vaccination. BMJ 1988;296(6639):1800.

\section{Patriarca 1985 \{published data only\}}

Patriarca PA, Weber JA, Meissner MK, Stricof RL, Dateno B, Braun JE. Use of influenza vaccine in nursing homes. Journal of the American Geriatrics Society 1985;33(7):463-6.

\section{Patriarca 1994 \{published data only\}}

Patriarca PA. A randomized controlled trial of influenza vaccine in the elderly. Scientific scrutiny and ethical responsibility. JAMA 1994;272(21):1700-1.

\section{Pena-Rey 2003 \{published data only\}}

Pena-Rey I, Perez-Farinos N, Sarria-Santamera A. Determinants of flu vaccination in Galician women over 65 years old. Atencion Primaria 2003;31(7):462-3.

\section{Perez 2000 \{published data only\}}

Perez C, Loza E, Tinture T. Giant cell arteritis after influenza vaccination. Archives of Internal Medicine 2000;160(17):2677.

\section{Perez-Tirse 1992 \{published data only\}}

Perez-Tirse J, Gross PA. Review of cost-benefit analyses of influenza vaccine. Pharmacoeconomics 1992;2(3):198-206.

Perucchini 2004 \{published data only\}

Perucchini E, Consonni S, Sandrini MC, Bergamaschini L, Vergani C. Adverse reactions to influenza vaccine alone or with pneumococcal vaccine in the elderly. Journal of the American Geriatrics Society 2004;52(7):1219-20.

Peters 1988 \{published data only\}

Peters NL, Meiklejohn G, Jahnigen DW. Antibody response of an elderly population to a supplemental dose of influenza $B$ vaccine. Journal of the American Geriatrics Society 1988;36(7):593-9.

Philip 1969 \{published data only\}

Philip RN, Bell JA, Davis DJ, Beem MO, Beigelman PM, Engler JI, et al. Epidemiologic studies on influenza in familial and general population groups, 1951-1956. V. Effectiveness of adjuvant vaccines. American Journal of Epidemiology 1969;90(6):471-83.

Phillips 1970 \{published data only\}

Phillips CA, Forsyth BR, Christmas WA, Gump DW, Whorton EB, Rogers I, et al. Purified influenza vaccine: clinical and serologic responses to varying doses and different routes of immunization. Journal of Infectious Diseases 1970;122(1):26-32.

Phillips 1971 \{published data only\}

Phillips WP, Hughes JN. Immunization against influenza. Community Health (Bristol) 1971;2(5):245-9.

Piedra 2002 \{published data only\} Piedra PA, Yan L, Kotloff K, Zangwill K, Bernstein DI, King J, et al. Safety of the trivalent, cold-adapted influenza vaccine in preschool-aged children. Pediatrics 2002;110(4):662-72.

Poe 1977 \{published data only\}

Poe GS, Massey JT. Estimating influenza cases and vaccinations by means of weekly rapid reporting system; methodological considerations and results obtained in the U.S. health interview survey. Public Health Reports 1977;92(4):299-306.

Poland 2002 \{published data only\}

Poland GA. If you could halve the mortality rate, would you do it? Clinical Infectious Diseases 2002;35(4):378-80.

\section{Potter 1997 \{published data only\}}

Potter J, Stott DJ, Roberts MA, Elder AG, O'Donnell B, Knight PV, et al. Influenza vaccination of health care workers in long-termcare hospitals reduces the mortality of elderly patients. Journal of Infectious Diseases 1997;175(1):1-6.

Powers 1991 \{published data only\}

Powers DC, Fries LF, Murphy BR, Thumar B, Clements ML. In elderly persons live attenuated influenza $A$ virus vaccines do not offer an advantage over inactivated virus vaccine in inducing serum or secretory antibodies or local immunologic memory. Journal of Clinical Microbiology 1991;29(3):498-505. 
Pregliasco 1997 \{published data only\}

Pregliasco F, Sodano L, Mensi C, Borghetti MC, Camorali L, D'Argenio P. Anti-influenza vaccination: knowledge, attitude and practice of the elderly residing in the city of Milan. Annali di Igiene: Medicina Preventiva e di Comunita 1997;9(2):127-31.

Pregliasco 1999 \{published data only\}

Pregliasco F, Sodano L, Mensi C, Selvaggi MT, Adamo B, D'Argenio $P$, et al. Influenza vaccination among the elderly in Italy. Bulletin of the World Health Organization 1999;77(2):127-31.

Profeta 1987 \{published data only\}

Profeta ML, Guidi G, Meroni PL, Palmieri R, Palladino G, Cantone V, et al. Influenza vaccination with adjuvant RU41740 in the elderly. Lancet 1987;1 (8539):973.

Provinciali 1994 \{published data only\}

Provinciali M, Di Stefano G, Muzzioli M, Scarpazza P, Colombo D, Migliorino $M$, et al. Impaired antibody response to influenza vaccine in institutionalized elderly. Annals of the New York Academy of Sciences 1994;717:307-14.

Puig Barberà 1995 \{published data only\}

Puig Barbera J, Marquez Calderon S. Effectiveness of influenza vaccine in the elderly. A critical review of the bibliography. Medicina Clinica 1995;105(17):645-8.

\section{Puretz 1979 \{published data only\}}

Puretz DH. Some thoughts on the 1976 swine flu immunization program: what went wrong? Journal of School Health 1979;49(7):410-2.

Pyhala 1997 \{published data only\}

Pyhala R, Hovi T. Influenza vaccinations - use with care. Duodecim 1997;113(21):2129, 2131.

Quinlisk 1990 \{published data only\}

Quinlisk P, Smithee L. Shanghai in Oklahoma? Journal of the Oklahoma State Medical Association 1990;83(11):562-4.

Quinnan 1983 \{published data only\}

Quinnan GV, Schooley R, Dolin R, Ennis FA, Gross P, Gwaltney JM. Serologic responses and systemic reactions in adults after vaccination with monovalent $A / U S S R / 77$ and trivalent A/USSR/77, A/Texas/77, B/Hong Kong/72 influenza vaccines. Reviews of Infectious Diseases 1983;5(4):748-57.

\section{Rao 1982 \{published data only\}}

Rao BL, Kadam SS, Pavri KM, Kothavale VS. Epidemiological, clinical, and virological features of influenza outbreaks in Pune, India, 1980. Bulletin of the World Health Organization 1982;60(4):639-42.

\section{Read 2000 \{published data only\}}

Read CA, Mohsen A, Nguyen-Van-Tam JS, McKendrick M, Kudesia G. Outbreaks of influenza A in nursing homes in Sheffield during the 1997-1998 season: implications for diagnosis and control. Journal of Public Health Medicine 2000;22(1):116-20.
Reedy 2000 \{published data only\}

Reedy JL, Paul SM, Zanna MT. Influenza: prevention and treatment. New Jersey Medicine 2000;97(11):41-50.

Ruben 1973 \{published data only\}

Ruben FL. Effectiveness of current killed influenza vaccines against influenza A-England-42-72. Journal of Infectious Diseases 1973;127(5):576-7.

Rubin 1973 \{published data only\}

Rubin RJ, Gregg MB. "English flu" - a primer. New England Journal of Medicine 1973;288(9):467-8.

Rudenko 1981 \{published data only\}

Rudenko LG, Zykov MP. Protection of the elderly against influenza (a review of the literature). Vrachebnoe Delo 1981;12:8-11.

Rudenko 1993 \{published data only\}

Rudenko LG, Slepushkin AN, Monto AS, Kendal AP, Grigorieva EP, Burtseva EP et al. Efficacy of live attenuated and inactivated influenza vaccines in schoolchildren and their unvaccinated contacts in Novgorod, Russia. Journal of Infectious Diseases 1993;168(4):881-7.

Ruel 2002 \{published data only\}

Ruel N, Odelin MF, Jolly J, Momplot C, Diana MC, Bourlet T, et al. Outbreaks due to respiratory syncytial virus and influenza virus $\mathrm{A} / \mathrm{H} 3 \mathrm{~N}$ in institutionalized aged. Role of immunological status to influenza vaccine and possible implication of caregivers in the transmission. Presse Medicale 2002;31(8):349-55.

Ruf 2004 \{published data only\}

Ruf BR, Colberg K, Frick M, Preusche A. Open, randomized study to compare the immunogenicity and reactogenicity of an influenza split vaccine with an MF59-adjuvanted subunit vaccine and a virosome-based subunit vaccine in elderly. Infection 2004;32(4):191-8.

\section{Runehagen 2002 \{published data only\}}

Runehagen A, Petersson C. Free vaccine and increased information suggested to increase the vaccination coverage. A questionnaire study concerning influenza vaccination of elderly persons and other risk groups. Lakartidningen 2002;99(6):496-7.

Russell 2001 \{published data only\}

Russell ML, Ferguson CA. Improving population influenza vaccine coverage through provider feedback and best practice identification. Canadian Journal of Public Health 2001;92(5):345-6.

Ryan 1984 \{published data only\}

Ryan MP, MacLeod AF. A comparison of adverse effects of two influenza vaccines, and the influence on subsequent uptake. Journal of the Royal College of General Practitioners 1984;34(265):442-4.

Sadler 2000 \{published data only\}

Sadler C. Needle work. Nursing Standard 2000;15(7):18-9. 
Sandrini 1997 \{published data only\}

Sandrini MC, Pregliasco F, Mensi C, Giardini G, Lucchi T, Santambrogio D, et al. Immunogenicity and efficacy field evaluation (1994-1995 season) of influenza vaccine in a noninstitutionalized elderly population. Annali di Igiene: Medicina Preventiva e di Comunita 1997;9(5):373-9.

\section{Saslaw 1966 \{published data only\}}

Saslaw S, Carlisle HN, Perkins RL. Effect of dosage and influenza vaccine content on antibody response in an aged population. American Journal of the Medical Sciences 1966;251(2):195-206.

\section{Satsuta 1985 \{published data only\}}

Satsuta K, Ogawa M, Makabe A, Ichinose T. On death due to influenza. Nippon Ika Daigaku Zasshi 1985;52(3):347-51.

\section{Schoenbaum 1969 \{published data only\}}

Schoenbaum SC, Mostow SR, Dowdle WR, Coleman MT, Kaye HS. Studies with inactivated influenza vaccines purified by zonal centrifugation. 2. Efficacy. Bulletin of the World Health Organization 1969;41(3):531-5.

\section{Schwartz 1995 \{published data only\}}

Schwartz K. Efficacy of influenza vaccine in the elderly. Journal of Family Practice 1995;40(3):298-9.

\section{Selvaraj 1998 \{published data only\}}

Selvaraj N, Moonis M, Ravin P. Hemiparesis following influenza vaccination. Postgraduate Medical Journal 1998;74(876):633-5.

\section{Serie 1977 \{published data only\}}

Serie C, Barme M, Hannoun C, Thibon M, Beck H, Aquino JP. Effects of vaccination on an influenza epidemic in a geriatric hospital. Developments in Biological Standardization 1977:39:317-21.

\section{Sethi 2002 \{published data only\}}

Sethi S. Bacterial pneumonia. Managing a deadly complication of influenza in older adults with comorbid disease. Geriatrics 2002;57(3):56-61.

\section{Sharbaugh 1997 \{published data only\}}

Sharbaugh RJ. Influenza - it's that time again. Home Care Provider 1997;2(5):227-8.

\section{Shinkawa 2002 \{published data only\}}

Shinkawa M, Nakayama K, Hirai H, Monma M, Sasaki H. Depression and immunoreactivity in disabled older patients. Journal of the American Geriatrics Society 2002;50(1):198-9.

\section{Shoji 2003 \{published data only\}}

Shoji $\mathrm{H}$, Kaji M. The influenza vaccination and neurological complications. Internal Medicine 2003;42(2):139.

\section{Siewert 1988 \{published data only\}}

Siewert M, Drinka P, Langer E. High rates of immunization in a nursing home. American Journal of Infection Control 1988;16(5):228-30.
Simonsen 2005 \{published data only\}

Simonsen L, Reichert TA, Viboud C, Blackwelder WC, Taylor RJ, Miller MA. Impact of influenza vaccination on seasonal mortality in the US elderly population. Archives of Internal Medicine 2005;165(3):265-72.

\section{Skowronski 2003 \{published data only\}}

Skowronski DM, De Serres G, Scheifele D, Russell ML, Warrington R, Davies HD, et al. Randomized, double-blind, placebo-controlled trial to assess the rate of recurrence of oculorespiratory syndrome following influenza vaccination among persons previously affected. Clinical Infectious Diseases 2003;37(8):1059-66.

\section{Skull 2009 \{published data only\}}

Skull SA, Andrews RM, Byrnes GB, Campbell DA, Kelly HA, Brown GV, et al. Hospitalized community-acquired pneumonia in the elderly: an Australian case-cohort study. Epidemiology \& Infection 2009;137(2):194-202.

\section{Slepuskin 1967 \{published data only\}}

Slepuskin AN, Bobyleva TK, Russina AE, Vitkina BS, Ellengorn NS, Zdanov VM. Evaluation of the effectiveness of large-scale vaccination against influenza in the USSR. Bulletin of the World Health Organization 1967;36(3):385-95.

Sloan 1993 \{published data only\}

Sloan DS. Influenza immunization in elderly people. BMJ 1993;307(6913):1213-4.

\section{Socan 2004 \{published data only\}}

Socan M, Frelih T, Janet E, Petras T, Peternelj B. Reactions after pneumococcal vaccine alone or in combination with influenza vaccine. Vaccine 2004;22(23-4):3087-91.

Solomon 1984 \{published data only\}

Solomon R, Morlino J, Martucci M, Ney D. Adverse drug reaction after administration of influenza vaccine. Journal of the Medical Society of New Jersey 1984;81(7):573-4.

Solomon 1996 \{published data only\} Solomon A, Frucht-Pery J. Bilateral simultaneous corneal graft rejection after influenza vaccination. American Journal of Ophthalmology 1996;121(6):708-9.

Solomon 1999 \{published data only\} Solomon A, Siganos CS, Frucht-Pery J. Adverse ocular effects following influenza vaccination. Eye 1999;13(Pt 3a):381-2.

\section{Spencer 1979 \{published data only\}}

Spencer MJ, Cherry JD, Powell KR, Sumaya CV. A clinical trial with Alice/R-75 strain, live attenuated serum inhibitor-resistant intranasal bivalent influenza A/B vaccine. Medical Microbiology and Immunology 1979;167(1):1-9.

\section{Sprenger 1990 \{published data only\}}

Sprenger MJ, Diepersloot RJ, Beyer WE, Masurel N. Influenzarelated excess mortality in the Netherlands 1989/90. Lancet 1990;336(8711):382. 
Squarcione 2003 \{published data only\}

Squarcione S, Sgricia S, Biasio LR, Perinetti E. Comparison of the reactogenicity and immunogenicity of a split and a subunitadjuvanted influenza vaccine in elderly subjects. Vaccine 2003;21(11-2):1268-74.

\section{Stamboulian 1999 \{published data only\}}

Stamboulian D, Bonvehi PE, Nacinovich FM, Ruttimann RW. Immunization against influenza in the elderly: the Argentinian experience, 1993-1997. Vaccine 1999;17(Suppl 1):53-6.

\section{Stott 2001 \{published data only\}}

Stott DJ, Carman WF, Elder AG. Influenza in old age. Age and Ageing 2001;30(5):361-3.

Tamblyn 1997 \{published data only\}

Tamblyn SE. Preventing influenza outbreaks in longterm care facilities. Canadian Medical Association Journal 1997; 157(7):927-8.

\section{Thompson 1988 \{published data only\}}

Thompson MP. Is routine influenza immunization indicated for people over 65 years of age? An affirmative view. Journal of Family Practice 1988;26(2):211-4.

\section{Treanor 1992 \{published data only\}}

Treanor JJ, Mattison HR, Dumyati G, Yinnon A, Erb S, O'Brien $D$ et al. Protective efficacy of combined live intranasal and inactivated influenza A virus vaccines in the elderly. Annals of Internal Medicine 1992;117(8):625-33.

\section{Treanor 1998 \{published data only\}}

Treanor JJ, Betts RF. Evaluation of live, cold-adapted influenza $A$ and $B$ virus vaccines in elderly and high-risk subjects. Vaccine 1998;16(18):1756-60.

\section{Tsai 2007 \{published data only\}}

Tsai Y-W, Huang W-F, Wen Y-W, Chen P-F. The relationship between influenza vaccination and outpatient visits for upper respiratory infection by the elderly in Taiwan. Value in Health 2007;10(2):117-27.

\section{Upshur 2000 \{published data only\}}

Upshur RE, Goel V. Measuring the impact of influenza on the hospital admission rates of the elderly in Ontario: a five-year admission rate analysis, 1988-1993. Canadian Journal of Public Health 2000;91(2):144-7.

\section{Urquhart 1974 \{published data only\}}

Urquhart GE. Serum IgM and IgA responses in influenza A infections. Journal of Clinical Pathology 1974;27(3):198-201.

\section{Uyeki 2003 \{published data only\}}

Uyeki TM, Zane SB, Bodnar UR, Fielding KL, Buxton JA, Miller JM, et al. Large summertime influenza $A$ outbreak among tourists in Alaska and the Yukon Territory. Clinical Infectious Diseases 2003;36(9):1095-102.

Vallee 2000 \{published data only\} Vallee JP. Flu and antiviral agents..... Presse Medicale 2000;29(2):84-5.

\section{Van Horren 1976 \{published data only\}}

Van Horren J. Letter: Influenza vaccine and P.P.D. skin-test reactivity. Lancet 1976;1(7949):44.

van Vuuren 2009 \{published data only\}

van Vuuren A, Rheeder P, Hak E. Effectiveness of influenza vaccination in the elderly in South Africa. Epidemiology \& Infection 2009;137(7):994-1002.

Verde 1973 \{published data only\}

Verde F, Frezza G, Russo V, Visconti M. Antibody response to anti-influenza vaccination with vaccine purified by differential ultracentrifugation and with vaccine purified by zonal ultracentrifugation. Bollettino della Societa Italiana di Biologia Sperimentale 1973;49(4):178-81.

Verweij 2002 \{published data only\}

Verweij M, van Den Hoven M. Influenza vaccination rates and informed consent in Dutch nursing homes: survey of nursing home physicians. BMJ 2002;324(7333):328.

Vila-Corcoles 2005 \{published data only\}

Vila-Corcoles A, Ochoa-Gondar O, Ansa-Echeverria X Gomez-Sorribes A, Espelt-Aluja P, Pascual-Moron I. Influenza vaccination and mortality in the elderly [see comment]. Medicina Clinica 2005;125(18):689-91.

\section{Visconti 1973 \{published data only\}}

Visconti M, Verde F, Frezza G, Russo V. Persistence of antibodies inhibiting hemagglutination by influenza viruses in aged vaccinated women. Changes in antibody titer after revaccination. Bollettino della Societa Italiana di Biologia Sperimentale 1973;49(4):173-7.

Voordouw 2004 \{published data only\}

Voordouw AC, Sturkenboom MC, Dieleman JP, Stijnen T, Smith DJ, van der Lei J et al. Annual revaccination against influenza and mortality risk in community-dwelling elderly persons. JAMA 2004;292(17):2089-95.

\section{Voordouw 2006 \{published data only\}}

Voordouw BC, Sturkenboom MC, Dieleman JP, Stijnen T, van der Lei J, Stricker BH. Annual influenza vaccination in community-dwelling elderly individuals and the risk of lower respiratory tract infections or pneumonia. Archives of Internal Medicine 2006;166(18):1980-5.

\section{Vu 2002 \{published data only\}}

Vu T, Farish S, Jenkins M, Kelly H. A meta-analysis of effectiveness of influenza vaccine in persons aged 65 years and over living in the community. Vaccine 2002;20(13-4):1831-6.

\section{Wagner 1993 \{published data only\}}

Wagner TA, Skiba R. Tolerance of preventive influenza vaccination with a subunit vaccine. Bevolkerung und Kultur. Reihe 7: Gesundheitswesen 1993;55(11):587-8.

Wagner 1994 \{published data only\}

Wagner TA. Placebo-controlled study on effectiveness of influenza vaccination? Deutsche Medizinische Wochenschrift 1994;119(30):1057-8. 
Wakefield 1990 \{published data only\}

Wakefield IR. Influenza vaccination and the elderly. BMJ 1990;301(6762):1216.

\section{Wang 1986 \{published data only\}}

Wang A, Hannoun C, Cadiot P. Theoretical and practical prospects of influenza vaccination in aged persons [Perspectives theoriques et pratiques de la vaccination antigrippale chez la personne agee]. Medecine et Hygiene 1986;44(1656):1373-6.

\section{Wang 2002 \{published data only\}}

Wang CS, Wang ST, Chou P. Efficacy and cost-effectiveness of influenza vaccination of the elderly in a densely populated and unvaccinated community. Vaccine 2002;20(19-20):2494-9.

\section{Warburton 1972 \{published data only\}}

Warburton MF, Jacobs DS, Langsford WA, White GE. Herd immunity following subunit influenza vaccine administration. Medical Journal of Australia 1972;2(2):67-70.

Wareing 2001 \{published data only\} Wareing MD, Tannock GA. Live attenuated vaccines against influenza; an historical review. Vaccine 2001;19(25-6):3320-30.

Watson 1997 \{published data only\}

Watson JM, Cordier JF, Nicholson KG. Does influenza immunisation cause exacerbations of chronic airflow obstruction or asthma? Thorax 1997;52(2):190-4.

\section{Weaver 2001 \{published data only\}}

Weaver M, Krieger J, Castorina J, Walls M, Ciske S. Costeffectiveness of combined outreach for the pneumococcal and influenza vaccines. Archives of Internal Medicine 2001;161(1):111-20.

Wiehl 2001 \{published data only\}

Wiehl M. Influenza vaccination. Even colleagues try and avoid it. MMW Fortschritte der Medizin 2001;143(43):14.

\section{Williams 1980 \{published data only\}}

Williams GO. Vaccines in older patients: combating the risk of mortality. Geriatrics 1980;35(11):55-7, 63-4.

Wilson 1994 \{published data only\}

Wilson R. Influenza vaccination. Thorax 1994;49(11):1079-80.

\section{Winer 1984 \{published data only\}}

Winer JB, Hughes RA, Bradley GW, Scadding JW. Guillain-Barre syndrome and influenza vaccine. Lancet 1984;1(8387):1182.

\section{Wise 1977 \{published data only\}}

Wise TG, Dolin R, Mazur MH, Top FH Jr, Edelman R, Ennis FA. Serologic responses and systemic reactions in adults after vaccination with bivalent $A /$ Victoria/75-A/New Jersey/76 and monovalent B/Hong Kong/72 influenza vaccines. Journal of Infectious Diseases 1977;136(Suppl):507-17.

\section{Wood 2000 \{published data only\}}

Wood SC, Nguyen VH, Schmidt C. Economic evaluations of influenza vaccination in the elderly: impact on public health policy (for bibl. only). Disease Management and Health Outcomes 2000;8(5):273-85.

Woratz 1984 \{published data only\}

Woratz C, Sinnecker H, Woratz G, Giard W, Muller D, Hajduk F et al. Use of excess mortality as a criterion of effectiveness in vaccination for the prevention of influenza. Zeitschrift fur die Gesamte Hygiene und ihre Grenzgebiete 1984;30(9):488-90.

\section{Yassi 1993 \{published data only\}}

Yassi A, Mcgill M, Holton C, Nicolle L. Morbidity, cost and role of health care worker transmission in an outbreak in a tertiary care hospital. Canadian Journal of Infectious Diseases 1993;4(1):52-6.

Zambon 2001 \{published data only\}

Zambon M, Hays J, Webster A, Newman R, Keene O. Diagnosis of influenza in the community: relationship of clinical diagnosis to confirmed virological, serologic, or molecular detection of influenza. Archives of Internal Medicine 2001;161(17):2116-22.

\section{Zimmerman 2004 \{published data only\}}

Zimmerman RK, Nowalk MP, Bardella IJ, Fine MJ, Janosky JE, Santibanez TA et al. Physician and practice factors related to influenza vaccination among the elderly. American Journal of Preventive Medicine 2004;26(1):1-10.

\section{Zoffmann 1977 \{published data only\}}

Zoffmann $\mathrm{H}$, Von Magnus $\mathrm{H}$. Swine influenza. Ugeskrift for Laeger 1977;139(5):259-61.

\section{Zourbas 1973 \{published data only\}}

Zourbas J, Barme M, Paillard R, Reynaud R, Morvan A, Megret $P$. New advance in influenza vaccination. 2. Clinical and immunologic study, in Rennes, of a Pasteur 30-c strain. Nouvelle Presse Medicale 1973;2(29):1939-43.

\section{Zuckerman 1990 \{published data only\}}

Zuckerman M, Oxford J, Wood J, Taylor J. Influenza A (H3N2) component of recommended vaccine induces antibody to current virus. Lancet 1990;335(8682):179-80.

\section{Zuckerman 1992 \{published data only\}}

Zuckerman M, Cox R, Oxford J, Taylor J, Wood J, Haaheim L. Activity of influenza vaccine against virus strains now circulating. Lancet 1992;339(8785):118.

\section{Zuckerman 1993 \{published data only\}}

Zuckerman M, Cox R, Taylor J, Wood J, Haaheim L, Oxford J. Rapid immune response to influenza vaccination. Lancet 1993;342(8879):1113.

\section{Additional references \\ ACIP 2005}

Advisory Committee on Immunization Practices. Prevention and control of influenza. Recommendations of the Advisory Committee on Immunization Practices (ACIP). Morbidity and Mortality Weekly Report 2005;54(RR-8):1-40. 


\section{Atkins 2004}

Atkins D, Best D, Briss PA, Eccles M, Falck-Ytter Y, Flottorp S, et al, GRADE Working Group. Grading quality of evidence and strength of recommendations. BMJ 2004;328(7454):1490.

\section{Belongia 2016}

Belongia EA, Simpson MD, King JP, Sundaram ME, Kelley NS, Osterholm MT, et al. Variable influenza vaccine effectiveness by subtype: a systematic review and meta-analysis of test-negative design studies. Lancet Infectious Diseases 2016;16(8):942-51.

\section{Broome 1980}

Broome C, Facklam R, Fraser D. Pneumococcal disease after pneumococcal vaccination - an alternative method to estimate the efficacy of pneumococcal vaccine. New England Journal of Medicine 1980;303(10):549-52.

\section{CDC 2004}

Centers for Disease Control and Prevention. Updated interim influenza vaccination recommendations: 2004-2005 influenza season. www.cdc.gov/flu (accessed 31 December 2004).

\section{Cowling 2012}

Cowling B, Fang V, Nishiura H, Chan K-H, Ng S, Ip DKM, et al. Increased risk of noninfluenza respiratory virus infections associated with receipt of inactivated influenza vaccine. Clinical Infectious Diseases 2012;54(12):1778-83.

\section{Darvishian 2017}

Darvishian M, van den Heuvel ER, Bissielo A, Castilla J, Cohen C, Englund $\mathrm{H}$, et al. Effectiveness of seasonal influenza vaccination in community-dwelling elderly people: an individual participant data meta-analysis of test-negative design case-control studies. Lancet Respiratory Medicine 2017;5(3):200-11. [DOI: 10.1016/ S2213-2600(17)30043-7]

\section{Demicheli 2014}

Demicheli V, Jefferson T, Al-Ansary LA, Ferroni E, Rivetti A, Di Pietrantonj $C$. Vaccines for preventing influenza in healthy adults. Cochrane Database of Systematic Reviews 2014, Issue 3. Art. No: CD001269. [DOI: 10.1002/14651858.CD001269.pub5]

\section{DerSimonian 1986}

DerSimonian R, Laird N. Meta-analysis in clinical trials. Controlled Clinical Trials 1986;7(3):177-88.

\section{Dickersin 1994}

Dickersin K, Scherer R, Lefebvre C. Identifying relevant studies for systematic reviews. BMJ 1994;309:1286-91.

\section{ECDC 2009a}

Kissling E, Moren A, Valenciano M. Protocol for case-control studies to measure pandemic and seasonal influenza vaccine effectiveness in the European Union and European Economic Area Member States. ECDC Technical Document (accessed on 18 May 2017) 2009. [WEB: ecdc.europa.eu/en/publications/ Publications/0907_TED_Influenza_AH1N1_Measuring Influenza_Vaccine_Effectiveness_Protocol_Case_Control_ Studies.pdf]

\section{ECDC 2009b}

Kissling E, Moren A, Valenciano M. Protocol for cohort database studies to measure pandemic and seasonal influenza vaccine effectiveness in the European Union and European Economic Area Member States. ECDC Technical Document (accessed on 18 May 2017) 2009. [WEB: ecdc.europa.eu/en/publications/ Publications/0907_TER_Influenza_AH1N1_Measuring_ Influenza_Vaccine_Effectiveness_Protocol_Cohort_Database_ Studies.pdf]

\section{EMA 2014}

European Medicine Agency. Guideline on influenza vaccines. Non-clinical and clinical module. European Medicines Agency (www.ema.europa.eu/docs/en_GB/document_library/ Scientific_guideline/2014/07/WC500170300.pdf) 2014 (last accessed on May 18, 2017);(EMA/CHMP/VWP/457259/2014).

\section{Eurich 2008}

Eurich DT, Marrie TJ, Johnstone J, Majumdar SR. Mortality reduction with influenza vaccine in patients with pneumonia outside "flu" season: pleiotropic benefits or residual confounding? [see comment]. American Journal of Respiratory \& Critical Care Medicine 2008;178(5):527-33.

\section{Foppa 2013}

Foppa I, Haberc M, Ferdinandsa J, Shaya D. The case testnegative design for studies of the effectiveness of influenza vaccine. Vaccine 2013;31(30):3104-9.

\section{Fukushima 2008}

Fukushima W, Hayashi Y, Mizuno Y, Suzuki K, Kase T, Ohfuji S, et al. Selection bias in evaluating of influenza vaccine effectiveness: a lesson from an observational study of elderly nursing home residents. Vaccine 2008;26(50):6466-9.

\section{Glezen 2006}

Glezen WP, Simonsen L. Commentary: benefits of influenza vaccine in US elderly - new studies raise questions. International Journal of Epidemiology 2006;35(2):352-3. [DOI: 10.1093/ije/ dyi293]

\section{GRADEpro GDT 2014 [Computer program]}

GRADE Working Group, McMaster University GRADEpro GDT. Hamilton (ON): GRADE Working Group, McMaster University, 2014.

\section{Greenland 1987}

Greenland S. Quantitative methods in the review of epidemiologic literature. Epidemiologic Reviews 1987;9:1-30.

\section{Groenwold 2008}

Groenwold RHH, Hoes AW, Nichol KL, Hak E. Quantifying the potential role of unmeasured confounders: the example of influenza vaccination. International Journal of Epidemiology 2008;37(6):1422-9.

\section{Groenwold 2009}

Groenwold RHH, Hak E, Hoes AW. Pooling of confounders did not induce residual confounding in influenza vaccination studies. Annals of Epidemiology 2009;19(6):432-6. 


\section{Grohskopf 2016}

Grohskopf LA, Sokolow LZ, Broder KR, Olsen SJ, Karron RA, Jernigan DB, et al. Prevention and control of seasonal influenza with vaccines. Morbidity and Mortality Weekly Report 2016;65(5):1-54. [DOI: 10.15585/mmwr.rr6505a1]

\section{Hak 2006}

Hak E, Hoes AW, Nordin J, Nichol KL. Benefits of influenza vaccine in US elderly - appreciating issues of confounding bias and precision. International Journal of Epidemiology 2006;35(3):800-2.

\section{Higgins 2002}

Higgins JP, Thompson SG. Quantifying heterogeneity in a metaanalysis. Statistics in Medicine 2002;21(11):1539-58.

\section{Higgins 2003}

Higgins JP, Thompson SG, Deeks JJ, Altman DG. Measuring inconsistency in meta-analyses. BMJ 2003;327(7414):557-60.

\section{Higgins 2011}

Higgins JP, Green S (editors). Cochrane Handbook for Systematic Reviews of Interventions Version 5.1.0 (updated March 2011). The Cochrane Collaboration, 2011. Available from handbook.cochrane.org.

\section{Hirota 2008}

Hirota Y. Ecological fallacy and scepticism about influenza vaccine efficacy in Japan: the Maebashi study. Vaccine 2008;26(50):6473-6.

\section{Jackson 2006a}

Jackson LA, Jackson ML, Nelson JC, Neuzil KM, Weiss NS. Evidence of bias in estimates of influenza vaccine effectiveness in seniors. International Journal of Epidemiology 2006;35(2):337-44. [DOI: 10.1093/ije/dyi274]

\section{Jackson 2006b}

Jackson LA, Nelson JC, Benson P, Neuzil KM, Reid RJ, Psaty BM, et al. Functional status is a confounder of the association of influenza vaccine and risk of all cause mortality in seniors. International Journal of Epidemiology 2005;35(2):345-52. [DOI: 10.1093/ije/dyi275]

\section{Jackson 2006c}

Jackson LA, Jackson ML, Weiss NS. Bias in studies of influenza vaccine effectiveness: the authors reply to Hak et al. International Journal of Epidemiology 2006;35(3):799-800.

\section{Jackson 2006d}

Jackson LA, Nelson JC, Benson P, Neuzil KM, Reid RJ, Psaty BM, et al. Functional status is a confounder of the association of influenza vaccine and risk of all cause mortality in seniors [see comment]. International Journal of Epidemiology 2006;35(2):345-52.

\section{Jackson 2006e}

Jackson LA, Jackson ML, Nelson JC, Neuzil KM, Weiss NS. Evidence of bias in estimates of influenza vaccine effectiveness in seniors [see comment]. International Journal of Epidemiology 2006;35(2):337-44

\section{Jefferson 2009a}

Jefferson TO. Mistaken identity: seasonal influenza versus influenza-like illness. Clinical Evidence 2009;329:1-4.

\section{Jefferson 2009b}

Jefferson T, Di Pietrantonj C, Debalini MG, Rivetti A, Demicheli V. Study quality, concordance, take home message, funding and impact: their relationship in influenza vaccines studies. BMJ 2009;338:b354. [DOI: 10.1136/bmj.b354 ]

\section{Jefferson 2012}

Jefferson T, Rivetti A, Di Pietrantonj C, Demicheli V, Ferroni E. Vaccines for preventing influenza in healthy children. Cochrane Database of Systematic Reviews 2012, Issue 8. Art. No: CD004879. [DOI: 10.1002/14651858.CD004879.pub4]

\section{Kissling 2017}

Kissling E, Rondy M, I-MOVE/I-MOVE+ study team. Early 2016/17 vaccine effectiveness estimates against influenza $A(H 3 N 2)$ : IMOVE multicentre case control studies at primary care and hospital levels in Europe. Euro Surveillance 2017;22(7):30464. [DOI: 10.2807/1560-7917.ES.2017.22.7.30464]

\section{Lefebvre 2011}

Lefebvre C, Manheimer E, Glanville J. Chapter 6: Searching for studies. In: Higgins JP, Green S, editors(s). Cochrane Handbook for Systematic Reviews of Interventions Version 5.1.0 (updated March 2011). The Cochrane Collaboration, 2011. Available from handbook.cochrane.org.

\section{Nichol 2008}

Nichol KL. Efficacy and effectiveness of influenza vaccination. Vaccine 2008;26:D17-22.

\section{Orenstein 1985}

Orenstein W, Bernier R, Dondero T, Hinman AR, Marks JS, Bart KL, et al. Field evaluation of vaccine efficacy. Bulletin of the World Health Organization 1985;63(6):1055-68.

\section{Osterholm 2012}

Osterholm MT, Kelley NS, Sommer A, Belongia EA. Efficacy and effectiveness of influenza vaccines: a systematic review and meta-analysis. Lancet Infectious Diseases 2012;12(1):36-44.

\section{Perencevich 2013a}

Perencevich E. Pondering vexing issues in infection prevention and control. haicontroversies.blogspot.com.au/2015/09/thereis-no-such-thing-as-patient-safety.html\#!/ (accessed 22 May 2017).

\section{Perencevich 2013b}

Perencevich EN. How should we calculate influenza vaccine effectiveness? blog.acpinternist.org/2013/02/how-should-wecalculate-influenza_7.html (accessed 22 May 2017).

\section{RevMan 2014 [Computer program]}

Nordic Cochrane Centre, The Cochrane Collaboration Review Manager 5 (RevMan 5). Version 5.3. Copenhagen: Nordic Cochrane Centre, The Cochrane Collaboration, 2014. 


\section{SIGN 2009}

Scottish Intercollegiate Guideline Network. Search filters, methodology. www.sign.ac.uk/methodology/filters.html (accessed 2 October 2009).

\section{Thomas 2010}

Thomas RE, Jefferson T, Lasserson TJ. Influenza vaccination for healthcare workers who work with the elderly. Cochrane Database of Systematic Reviews 2010, Issue 2. Art. No: CD005187. [DOI: 10.1002/14651858.CD005187.pub2]

\section{Treanor 2016}

Treanor J. Influenza vaccination. New England Journal of Medicine 2016;375(13):1261-8. [DOI: 10.1056/NEJMcp1512870]

\section{Valenciano 2012}

Valenciano M, Ciancio BC, the I-MOVE study team. I-MOVE: a European network to measure the effectiveness of influenza vaccines. Euro Surveillance 2012;17(39):20281.

\section{WHO 2016}

World Health Organization. Recommended composition of influenza virus vaccines for use in the 2016-2017 Northern Hemisphere influenza season. Weekly Epidemiological Record 2016;91(10):121-32.

\section{CHARACTERISTICS OF STUDIES}

Characteristics of included studies [ordered by study ID]

\section{Wijnans 2016}

Wijnans L, Voordouw B. A review of the changes to the licensing of influenza vaccines in Europe. Influenza and Other Respiratory Viruses 2016;10(1):2-8

\section{Wiselka 1994}

Wiselka M. Influenza: diagnosis, management and prophylaxis. BMJ 1994;308(6940):1341-5.

\section{References to other published versions of this review} Jefferson 2005

Jefferson T, Rivetti D, Rivetti A, Rudin M, Di Pietrantonj C, Demicheli V. Efficacy and effectiveness of influenza vaccines in elderly people: a systematic review. Lancet 2005;366(9492):1165-74.

\section{Rivetti 2006}

Rivetti D, Jefferson T, Thomas R, Rudin M, Rivetti A, Di Pietrantonj $C$, et al. Vaccines for preventing influenza in the elderly. Cochrane Database of Systematic Reviews 2006, Issue 3. Art. No: CD004876. [DOI: 10.1002/14651858.CD004876.pub2]

\section{Rivetti 2010}

Jefferson T, Di Pietrantonj C, Al-Ansary LA, Ferroni, Thorning S, Thomas RE. Vaccines for preventing influenza in the elderly. Cochrane Database of Systematic Reviews 2010, Issue 2. Art. No: CD004876. [DOI: 10.1002/14651858.CD004876.pub2]

\section{Ahmed 1995}

\section{Study characteristics}

\begin{tabular}{ll} 
Methods & $\begin{array}{l}\text { Case-control study conducted in England, during the } 1989 \text { to } 1990 \text { influenza season, in the communi- } \\
\text { ty. Data sources were: death certificates, general practitioner records. Follow-up period was } 4 \text { Novem- } \\
\text { ber } 1989 \text { to } 23 \text { February 1990. Cases died from influenza during the } 1989 \text { epidemic; controls died in the } \\
\text { same period a year later and were matched for age, sex, and residence }\end{array}$ \\
\hline Participants & $\begin{array}{l}1092 \text { people } 16 \text { years or older; } 412 \text { cases and } 1256 \text { controls were identified; } 315 \text { and } 777 \text { were included } \\
\text { in the analysis, respectively }\end{array}$ \\
\hline Interventions & Parenteral influenza vaccine. Vaccine strains matched the circulating strain \\
\hline Outcomes & Certified influenza death \\
\hline Notes & $\begin{array}{l}\text { 2 exposure definitions were used: current vaccinees and previous vaccinees (vaccinated between } 1985 \\
\text { and 1989) the first was used; pneumococcal vaccination was very unlikely; circulating strain was A/Eng- } \\
\text { land/308/89. The season was an epidemic one. The study controls for confounders in analysis: health } \\
\text { status, previous vaccination. Quantitative analysis was also performed. }\end{array}$
\end{tabular}

\section{Risk of bias}


Ahmed 1995 (Continued)

Allocation concealment Unclear risk $\quad$ B - Unclear
(selection bias)

Ahmed 1997

\section{Study characteristics}

\begin{tabular}{|c|c|c|}
\hline Methods & \multicolumn{2}{|c|}{$\begin{array}{l}\text { Case-control study conducted in England, during the } 1989 \text { to } 1990 \text { influenza season, in the community. } \\
\text { Data sources were: hospital and general practitioner records. Follow-up period was } 1 \text { December } 1989 \\
\text { to } 31 \text { January 1990. Cases were hospitalised and their discharge diagnosis or cause of death was pneu- } \\
\text { monia, influenza, emphysema, or bronchitis; community controls were matched for age and sex. Spe- } \\
\text { cific controls were matched for cases who died; controls died } 6 \text { to } 12 \text { months later. }\end{array}$} \\
\hline Participants & \multicolumn{2}{|c|}{$\begin{array}{l}445 \text { patients admitted to hospital ( } 303 \text { cases were identified; } 156 \text { cases and } 289 \text { controls were included } \\
\text { in the analysis, respectively), } 16 \text { years of age or older }\end{array}$} \\
\hline Interventions & \multicolumn{2}{|c|}{ Parenteral influenza vaccine. Vaccine strains matched the circulating strain. } \\
\hline Outcomes & \multicolumn{2}{|c|}{$\begin{array}{l}\text { Hospitalisation from pneumonia, influenza, emphysema, or bronchitis (ICD } 466,480.9 \text { to } 482.9,485 \text { to } \\
492.8 \text { ) }\end{array}$} \\
\hline Notes & \multicolumn{2}{|c|}{$\begin{array}{l}2 \text { exposure definitions were used: current vaccinees and previous vaccinees (vaccinated between } 1985 \\
\text { and 1989): the first was used; pneumococcal vaccination was very unlikely; circulating strain was A/ } \\
\text { England/308/89. The season was an epidemic one. The study controls for confounders in analysis: } \\
\text { health status, previous vaccination. Quantitative analysis was also performed. }\end{array}$} \\
\hline \multicolumn{3}{|l|}{ Risk of bias } \\
\hline Bias & Authors' judgement & Support for judgement \\
\hline $\begin{array}{l}\text { Allocation concealment } \\
\text { (selection bias) }\end{array}$ & Unclear risk & B - Unclear \\
\hline
\end{tabular}

Allsup 2004

\section{Study characteristics}

\begin{tabular}{ll} 
Methods & $\begin{array}{l}\text { Experimental study conducted in Liverpool, UK during the } 1999 \text { to } 2000 \text { influenza season, randomised, } \\
\text { single-blind, placebo controlled. Data sources were self administered questionnaire and medical } \\
\text { records. Follow-up period was the entire winter season. }\end{array}$ \\
\hline Participants & $\begin{array}{l}729 \text { community-dwelling elderly without risk factors (552 treated and } 177 \text { controls, all included in the } \\
\text { analysis), } 65 \text { to } 74 \text { years old }\end{array}$ \\
\hline Interventions & $\begin{array}{l}\text { Parenteral influenza vaccine: A/Beijing/262/95, A/Sydney/5/97, B/Beijing/184/93. All participants also } \\
\text { received pneumococcal vaccine. Vaccine strains matched the circulating strains. }\end{array}$ \\
\hline Outcomes & $\begin{array}{l}\text { Clinically defined ILI (all of the following symptoms: sudden onset, fever, cough, prostration, weak- } \\
\text { ness, myalgia, widespread aches), pneumonia, hospitalisation for any respiratory illness, death from all } \\
\text { causes }\end{array}$ \\
\hline
\end{tabular}


Allsup 2004 (Continued)

Notes
Vaccine contained the WHO recommended strains. The study was supposed to run for 2 influenza seasons: $99-00$ and 00-01. After the first season, the UK's Department of Health changed the coverage policy for influenza vaccine, and recruitment to the placebo arm dwindled, affecting the validity of the trial.

\section{Risk of bias}

\begin{tabular}{lll}
\hline Bias & Authors' judgement & Support for judgement \\
\hline $\begin{array}{l}\text { Random sequence genera- } \\
\text { tion (selection bias) }\end{array}$ & Low risk & Computer random number generation \\
\hline $\begin{array}{l}\text { Allocation concealment } \\
\text { (selection bias) }\end{array}$ & Low risk & $\begin{array}{l}\text { Opaque envelopes were sealed and serially numbered to assign participants to } \\
\text { intervention. }\end{array}$ \\
\hline $\begin{array}{l}\text { Blinding (performance } \\
\text { bias and detection bias) } \\
\text { All outcomes }\end{array}$ & Unclear risk & Described as placebo controlled, but no further details provided. \\
\hline $\begin{array}{l}\text { Incomplete outcome data } \\
\text { (attrition bias) } \\
\begin{array}{l}\text { All outcomes } \\
\hline\end{array}\end{array}$ & Unclear risk & Insufficient information available to reliably assess. \\
\hline
\end{tabular}

Arden 1988

\section{Study characteristics}

\begin{tabular}{|c|c|c|}
\hline Methods & \multicolumn{2}{|c|}{$\begin{array}{l}\text { Authors investigated an outbreak in a nursing home, in Atlanta, USA, during the } 1984 \text { to } 1985 \text { influenza } \\
\text { season; active surveillance; medical records were reviewed. Follow-up period was } 26 \text { January } 1985 \text { to } 1 \\
\text { February 1985. Pharyngeal swab and paired sera were collected to confirm diagnosis. }\end{array}$} \\
\hline Participants & \multicolumn{2}{|c|}{55 nursing home residents ( 31 treated and 24 controls, all included in the analysis), mean age 85 years } \\
\hline Interventions & \multicolumn{2}{|c|}{$\begin{array}{l}\text { Parenteral influenza vaccine: A/Philippines/2/82, A/Chile/83, B/USSR/84. Vaccine strains probably } \\
\text { matched circulating strains. }\end{array}$} \\
\hline Outcomes & \multicolumn{2}{|c|}{$\begin{array}{l}\text { Clinically defined ILI (fever } 38.7^{\circ} \mathrm{C} \text { or greater, cough, coryza, sore throat); hospitalisation from ILI; ILI } \\
\text { severity (not extracted) }\end{array}$} \\
\hline Notes & \multicolumn{2}{|c|}{$\begin{array}{l}7 \text { days after the outbreak started, all residents were given amantadine. Successive outcomes were not } \\
\text { accounted for. The circulating strain was related to A/Philippines/2/82. }\end{array}$} \\
\hline \multicolumn{3}{|l|}{ Risk of bias } \\
\hline Bias & Authors' judgement & Support for judgement \\
\hline $\begin{array}{l}\text { Allocation concealment } \\
\text { (selection bias) }\end{array}$ & Unclear risk & B - Unclear \\
\hline
\end{tabular}

\section{Study characteristics}


Arroyo 1984 (Continued)

Methods
Authors investigated an outbreak in a nursing home, in Columbia, UK, during the 1982 to 1983 influenza season; active surveillance by home staff. Follow-up period was 31 January 1983 to 25 February 1983. Pharyngeal swab and paired sera were collected to confirm diagnosis from 13 and 32 participants, respectively.

\begin{tabular}{ll}
\hline Participants & $\begin{array}{l}116 \text { nursing home residents (26 treated and } 90 \text { controls, all included in the analysis) with underlying ill- } \\
\text { nesses, } 30 \text { to } 108 \text { years old (mean age } 71 \text { years) }\end{array}$ \\
\hline $\begin{array}{l}\text { Parenteral influenza vaccine: A/Brazil/11/78; A/Bangkok/1/79; B/Singapore/79. Vaccine strains did not } \\
\text { match circulating strains. }\end{array}$ \\
\hline $\begin{array}{l}\text { ILI (any acute respiratory tract infection occurring during outbreak, with or without fever), pneumonia, } \\
\text { death from respiratory disease }\end{array}$ \\
\hline $\begin{array}{l}10 \text { participants were given amantadine, not indicated if vaccinees or unvaccinated. The circulating } \\
\text { strain was related to A/Philippines/2/82. }\end{array}$ \\
\hline Risk of bias & Authors' judgement Support for judgement \\
\hline Bias & Unclear risk $\quad$ B - Unclear \\
\hline $\begin{array}{l}\text { Allocation concealment } \\
\text { (selection bias) }\end{array}$ &
\end{tabular}

Aymard 1979a

\section{Study characteristics}

\begin{tabular}{ll}
\hline Methods & $\begin{array}{l}\text { Authors investigated an outbreak in a geriatric hospital in France during the } 1976 \text { to } 1977 \text { influenza sea- } \\
\text { son. }\end{array}$ \\
\hline Participants & 100 nursing home residents ( 50 treated and 50 controls, all included in the analysis) \\
\hline Interventions & Bivalent parenteral vaccine: A/Vic/3/75; B/HK/1/72. Vaccine strains matched circulating strains. \\
\hline Outcomes & Disease and deaths without further specifications \\
\hline Notes & $\begin{array}{l}\text { Part of a surveillance study conducted in several communities; poor description of methods; circulat- } \\
\text { ing strains were mostly A/Vic/3/75 like }\end{array}$ \\
\hline Risk of bias & Authors' judgement Support for judgement \\
\hline Bias & Unclear risk $\quad$ D - Not used \\
\hline $\begin{array}{l}\text { Allocation concealment } \\
\text { (selection bias) }\end{array}$ &
\end{tabular}

\section{Study characteristics}


Aymard 1979b (Continued)

Methods Authors investigated an outbreak in a geriatric hospital in France during the 1977 to 1978 influenza season.

\begin{tabular}{ll}
\hline Participants & 155 nursing home residents ( 85 treated and 70 controls, all included in the analysis) \\
\hline Interventions & Bivalent parenteral vaccine: $\mathrm{A} / \mathrm{Vic} / 3 / 75 ; \mathrm{B} / \mathrm{HK} / 1 / 73$. Vaccine strains did not match circulating strains. \\
\hline Outcomes & Disease and deaths without further specifications. \\
\hline Notes & $\begin{array}{l}\text { Part of a surveillance study conducted in several communities; poor description of methods; circulat- } \\
\text { ing strains were mostly A/Tex/1/77 like }\end{array}$ \\
\hline
\end{tabular}

\section{Risk of bias}

\begin{tabular}{lll}
\hline Bias & Authors' judgement & Support for judgement \\
\hline $\begin{array}{l}\text { Allocation concealment } \\
\text { (selection bias) }\end{array}$ & Unclear risk & D - Not used \\
\hline
\end{tabular}

Caminiti 1994

\begin{tabular}{ll}
\hline Study characteristics & \\
\hline Methods & $\begin{array}{l}\text { Prospective cohort study conducted in Italy during the } 1990 \text { to } 1991 \text { influenza season; medical charts, } \\
\text { hospital records, and death certificate archives were reviewed. Follow-up period was } 1 \text { December } 1990 \\
\text { to } 30 \text { April } 1991.110 \text { participants were tested for serological follow-up. Throat swabs were obtained } \\
\text { from ill residents. }\end{array}$ \\
\hline Participants & $\begin{array}{l}242 \text { nursing home residents (169 treated and } 73 \text { controls, all included in the analysis; } 77 \text { and } 33 \text { were } \\
\text { tested for serological follow-up, respectively), } 55 \text { to } 99 \text { years old }\end{array}$ \\
\hline Interventions & $\begin{array}{l}\text { Parenteral influenza vaccine: A/Guizhou/54/89; A/Singapore/6/86; B/Yagamata/16/88. Vaccine strains } \\
\text { matched the circulating strains. }\end{array}$ \\
\hline Outcomes & $\begin{array}{l}\text { Clinically defined ILI (fever + at least } 2 \text { of the following: cough, coryza, sore throat, myalgia, headache, } \\
\text { shivering), hospitalisation for ILI, hospitalisation for all respiratory illness, deaths from respiratory ill- } \\
\text { ness }\end{array}$ \\
\hline Notes & $\begin{array}{l}\text { Circulating strain: B/Yagamata-like. Vaccinated and control groups were roughly comparable as under- } \\
\text { lying disease: vaccinated participants had more chronic respiratory diseases. The influenza season was } \\
\text { relatively mild. Data were reported by health status. }\end{array}$
\end{tabular}

\section{Risk of bias}

\begin{tabular}{lll}
\hline Bias & Authors' judgement & Support for judgement \\
\hline $\begin{array}{l}\text { Allocation concealment } \\
\text { (selection bias) }\end{array}$ & Low risk & A - Adequate \\
\hline
\end{tabular}

\section{Study characteristics}


Cartter 1990a (Continued)

Methods

Authors investigated an outbreak in a skilled care nursing home, in Connecticut, USA, during the 1984 to 1985 influenza season; medical records were reviewed. Follow-up period was 1 December 1984 to 15 January 1985. Paired sera specimens were obtained from some ill residents.

$\begin{array}{ll}\text { Participants } & \begin{array}{l}131 \text { residents (96 treated and } 48 \text { controls, } 96 \text { and } 35 \text { included in the analysis respectively), } 65 \text { to } 95 \\ \text { years old }\end{array}\end{array}$ Interventions Parenteral influenza vaccine: A/Philippines/2/82; A/Chile/83; B/USSR/100/82. Vaccine strains probably matched circulating strains.

$\begin{array}{ll}\text { Outcomes } & \begin{array}{l}\text { Clinically defined ILI (fever } 37.8^{\circ} \mathrm{C} \text { or greater, cough, coryza, sore throat); hospitalisation from ILI; } \\ \text { deaths occurring within } 2 \text { weeks of ILI with no other explanation }\end{array}\end{array}$
deaths occurring within 2 weeks of ILI with no other explanation

Notes Amantadine was not used. There was serological evidence of $A(H 3 N 2)$ influenza infections.

\section{Risk of bias}

\begin{tabular}{lll}
\hline Bias & Authors' judgement & Support for judgement \\
\hline $\begin{array}{l}\text { Allocation concealment } \\
\text { (selection bias) }\end{array}$ & Unclear risk & B - Unclear \\
\hline
\end{tabular}

\section{Cartter 1990b}

\section{Study characteristics}

\begin{tabular}{ll}
\hline Methods & $\begin{array}{l}\text { Authors investigated an outbreak in a skilled nursing home, in Connecticut, USA, during the 1984 to } \\
1985 \text { influenza season; medical records were reviewed. Follow-up period was } 15 \text { January } 1985 \text { to } 15 \\
\text { February 1985. Throat swab and paired sera specimens were obtained from some ill residents. }\end{array}$ \\
\hline Participants & 85 residents (30 treated and 55 controls, all included in the analysis), 33 to 95 years old \\
\hline Interventions & $\begin{array}{l}\text { Parenteral influenza vaccine: A/Philippines/2/82; A/Chile/83; B/USSR/100/83. Vaccine strains probably } \\
\text { matched circulating strains. }\end{array}$ \\
\hline Outcomes & $\begin{array}{l}\text { Clinically defined ILI (fever } 37.8^{\circ} \mathrm{C} \text { or greater, cough, coryza, sore throat); hospitalisation from ILI; } \\
\text { deaths occurring within } 2 \text { weeks of ILI with no other explanation }\end{array}$ \\
\hline Notes & $\begin{array}{l}9 \text { days after the outbreak started amantadine prophylaxis was given to most of the remaining well res- } \\
\text { idents. Successive outcomes were not accounted for. The circulating strain was related to A/Philip- } \\
\text { pines/2/82. }\end{array}$ \\
\hline Risk of bias & Authors' judgement Support for judgement \\
\hline Bias & Unclear risk \\
\hline $\begin{array}{l}\text { Allocation concealment } \\
\text { selection bias) }\end{array}$
\end{tabular}

\section{Cartter 1990c}

\section{Study characteristics}


Cartter 1990c (Continued)

Methods

Authors investigated an outbreak in a multiple-level care facility in Connecticut, USA, during the 1984 to 1985 influenza season; medical records were reviewed. Follow-up period was 1 February 1985 to 10 April 1985. Throat swab and paired sera specimens were obtained from some ill residents.

$\begin{array}{ll}\text { Participants } & 458 \text { residents (332 treated and } 151 \text { controls, } 332 \text { and } 126 \text { included in the analysis respectively), } 64 \text { to } \\ 104 \text { years old }\end{array}$

Interventions $\quad$ Parenteral influenza vaccine: A/Philippines/2/82; A/Chile/83; B/USSR/100/84. Vaccine strains probably matched circulating strains.

\begin{tabular}{ll}
\hline Outcomes & $\begin{array}{l}\text { Clinically defined ILI (fever } 37.8^{\circ} \mathrm{C} \text { or greater, cough, coryza, sore throat); hospitalisation from ILI; } \\
\text { deaths occurring within } 2 \text { weeks of ILI with no other explanation }\end{array}$ \\
\hline Notes & $\begin{array}{l}42 \text { days after the outbreak started amantadine prophylaxis was given to most of the remaining well } \\
\text { residents. Successive outcomes were not accounted for. The circulating strain was related to A/Philip- } \\
\text { pines/2/82. }\end{array}$
\end{tabular}

\section{Risk of bias}

\begin{tabular}{lll}
\hline Bias & Authors' judgement & Support for judgement \\
\hline $\begin{array}{l}\text { Allocation concealment } \\
\text { (selection bias) }\end{array}$ & Unclear risk & B - Unclear \\
\hline
\end{tabular}

\section{Christenson 2001a}

\section{Study characteristics}

\begin{tabular}{ll}
\hline Methods & $\begin{array}{l}\text { Prospective cohort study conducted in Stockholm, Sweden during the 1998 to 1999 influenza season, } \\
\text { in the community. Data sources were vaccination database and discharge diagnoses database. Fol- } \\
\text { low-up period was 1 December } 1998 \text { to } 31 \text { May } 1999.23 \% \text { of vaccinees received flu vaccine alone; } 76 \% \\
\text { of vaccinated received flu and pneumococcal vaccine. } 841 \text { participants had only pneumococcal vac- } \\
\text { cine. Only flu vaccinated were included in analysis. }\end{array}$ \\
\hline Participants & $\begin{array}{l}182,609 \text { community-dwelling elderly (23,224 treated and 159,385 controls included in the analysis), } 65 \\
\text { years or older }\end{array}$ \\
\hline Interventions & $\begin{array}{l}\text { Parenteral influenza vaccine: A/Beijing/262/95; A/Sydney/5/97; B/Harbin/7/94. Vaccine strains matched } \\
\text { the circulating strain. }\end{array}$ \\
\hline Outcomes & $\begin{array}{l}\text { Hospitalisation from influenza (ICD-X: J10.0, J10.1, J10.8, J11.0, J11.1, J11.8), hospitalisation from } \\
\text { pneumonia (ICD-X: J12- J18, J69.0, A48.1); deaths from influenza and deaths from pneumonia were not } \\
\text { available for this comparison }\end{array}$ \\
\hline Notes & $\begin{array}{l}\text { Vaccinated people had higher education, more underlying diseases, and smoked less. Circulating strain } \\
\text { was A/Sydney (H3N2). The season was probably an epidemic one. 6\% of the population lived in a nurs- } \\
\text { ing home. The study controls for age in analysis. }\end{array}$ \\
\hline
\end{tabular}

\section{Risk of bias}

\begin{tabular}{lll}
\hline Bias & Authors' judgement & Support for judgement \\
\hline $\begin{array}{l}\text { Allocation concealment } \\
\text { (selection bias) }\end{array}$ & Unclear risk & B - Unclear \\
\hline
\end{tabular}


Christenson 2001b

\section{Study characteristics}

Methods

Prospective cohort study conducted in Stockholm, Sweden during the 1998 to 1999 influenza season in the community. Data sources were vaccination database and discharge diagnoses database. Follow-up period was 1 December 1998 to 31 May 1999. 23\% of vaccinees received flu vaccine alone; 76\% of vaccinated received flu and pneumococcal vaccine. 841 participants had only pneumococcal vaccine. All data were included in a separate analysis.

\begin{tabular}{ll}
\hline Participants & $\begin{array}{l}259,627 \text { community-dwelling elderly }(100,242 \text { treated and 159,385 controls included in the analysis), } 65 \\
\text { years or older }\end{array}$ \\
\hline Interventions & $\begin{array}{l}\text { Parenteral influenza vaccine: A/Beijing/262/95; A/Sydney/5/97; B/Harbin/7/94; pneumococcal vaccine. } \\
\text { Vaccine strains matched the circulating strain. }\end{array}$ \\
\hline Outcomes & $\begin{array}{l}\text { Hospitalisation from influenza (ICD-X: J10.0, J10.1, J10.8, J11.0, J11.1, J11.8), deaths from influenza, } \\
\text { hospitalisation from pneumonia (ICD-X: J12- J18, J69.0, A48.1), deaths from pneumonia; all deaths }\end{array}$ \\
\hline Notes & $\begin{array}{l}\text { Vaccinated people had higher education, more underlying diseases, and smoked less. Circulating strain } \\
\text { was A/Sydney (H3N2). The season was probably an epidemic one. } 6 \% \text { of the population lived in a nurs- } \\
\text { ing home. The study controls for age in analysis. }\end{array}$
\end{tabular}

\section{Risk of bias}

\begin{tabular}{lll}
\hline Bias & Authors' judgement & Support for judgement \\
\hline $\begin{array}{l}\text { Allocation concealment } \\
\text { (selection bias) }\end{array}$ & Unclear risk & B - Unclear \\
\hline
\end{tabular}

Christenson 2004a

\section{Study characteristics}

Methods

Prospective cohort study conducted in Stockholm, Sweden during the 1999 to 2000 influenza season, in the community. Data sources were vaccination database and discharge diagnoses database. Follow-up period was December 1999 to November 2000. 23\% of vaccinated received flu vaccine alone; $58 \%$ of vaccinated received flu and pneumococcal vaccine. $19 \%$ of vaccinated participants received pneumococcal vaccine alone. Only flu vaccinated were included in analysis.

\begin{tabular}{ll}
\hline Participants & $\begin{array}{l}\text { 163,391 community-dwelling elderly }(29,346 \text { treated and 134,045 controls were included in the analy- } \\
\text { sis), } 65 \text { years or older }\end{array}$ \\
\hline Interventions & $\begin{array}{l}\text { Parenteral influenza vaccine: A/Beijing/262/95; A/Sydney/5/97; B/Harbin/7/94. Vaccine strains matched } \\
\text { the circulating strain. }\end{array}$ \\
\hline Outcomes & $\begin{array}{l}\text { Hospitalisation from influenza (ICD-X: J10.0, J10.1, J10.8, J11.0, J11.1, J11.8), in-hospital deaths from } \\
\text { influenza, hospitalisation from pneumonia (ICD-X: J12- J18, J69.0, A48.1), in-hospital deaths from } \\
\text { pneumonia }\end{array}$ \\
\hline Notes & $\begin{array}{l}\text { Vaccinated people had higher education, more underlying diseases, and smoked less. Circulating strain } \\
\text { was A/Sydney (H3N2). The season was probably an epidemic one. } 6 \% \text { of the population lived in a nurs- } \\
\text { ing home. }\end{array}$
\end{tabular}

\section{Risk of bias}


Christenson 2004a (Continued)

\begin{tabular}{lll} 
Bias & Authors' judgement & Support for judgement \\
\hline $\begin{array}{l}\text { Allocation concealment } \\
\text { (selection bias) }\end{array}$ & Unclear risk & B - Unclear \\
\hline
\end{tabular}

\section{Christenson 2004b}

\section{Study characteristics}

\begin{tabular}{ll}
\hline Methods & $\begin{array}{l}\text { Prospective cohort study conducted in Stockholm, Sweden during the } 1999 \text { to } 2000 \text { influenza season, } \\
\text { in the community. Data sources were vaccination database and discharge diagnoses database. Fol- } \\
\text { low-up period was December } 1999 \text { to May } 2000.23 \% \text { of vaccinees received flu vaccine alone; } 58 \% \text { of } \\
\text { vaccinated received flu and pneumococcal vaccine. } 19 \% \text { of vaccinated received pneumococcal vaccine } \\
\text { alone. All data were included in a separate analysis. }\end{array}$ \\
\hline Participants & $\begin{array}{l}258,747 \text { community-dwelling elderly (124,702 treated and 134,045 controls were included in the analy- } \\
\text { sis), } 65 \text { years or older }\end{array}$ \\
\hline Interventions & $\begin{array}{l}\text { Parenteral influenza vaccine: A/Beijing/262/95; A/Sydney/5/97; B/Harbin/7/94; pneumococcal vaccine. } \\
\text { Outcomes }\end{array}$ \\
\hline $\begin{array}{l}\text { Hospitalisation from influenza (ICD-X: J10.0, J10.1, J10.8, J11.0, J11.1, J11.8), hospitalisation from } \\
\text { pneumonia (ICD-X: J12- J18, J69.0, A48.1); in-hospital deaths from influenza and in-hospital deaths } \\
\text { from pneumonia were not available for the 6-month period. }\end{array}$ \\
$\begin{array}{l}\text { Vaccinated people had higher education, more underlying diseases, and smoked less. Circulating strain } \\
\text { was A/Sydney (H3N2). The season was probably an epidemic one. 6\% of the population lived in a nurs- } \\
\text { ing home. }\end{array}$
\end{tabular}

\section{Risk of bias}

\begin{tabular}{lll}
\hline Bias & Authors' judgement & Support for judgement \\
\hline $\begin{array}{l}\text { Allocation concealment } \\
\text { (selection bias) }\end{array}$ & Unclear risk & B - Unclear \\
\hline
\end{tabular}

Coles 1992

\section{Study characteristics}

Methods

Authors investigated an outbreak in a skilled nursing home, in New York, USA during the 1987 to 1988 influenza season; individual charts were reviewed. Follow-up period was 26 December 1987 to 25 January 1988. Throat swab and paired sera specimens were obtained from some ill residents.

\begin{tabular}{ll}
\hline Participants & $\begin{array}{l}124 \text { nursing home residents (112 treated and } 12 \text { controls, all included in the analysis), } 20 \text { to } 100 \text { years } \\
\text { old (mean age } 85 \text { years). } 105 \text { participants had } 1 \text { or more underlying medical conditions. }\end{array}$ \\
\hline Interventions & $\begin{array}{l}\text { Parenteral influenza vaccine: A/Taiwan/1/86; A/Leningrad/360/86; B/Ann Arbor/1/86. Vaccine strains } \\
\text { did not match the circulating strain. }\end{array}$ \\
\hline Outcomes & $\begin{array}{l}\text { Clinically defined ILI (fever } 100^{\circ} \mathrm{F} \text { or greater, cough, coryza, sore throat, pneumonia); pneumonia; hos- } \\
\text { pitalisation from ILI; flu-related deaths }\end{array}$
\end{tabular}


Coles 1992 (Continued)

Notes

Vaccinated and not vaccinated participants were similar as underlying conditions. The circulating strain was Shanghai/11/87. Only 1 participant received amantadine prophylaxis.

\section{Risk of bias}

\begin{tabular}{lll}
\hline Bias & Authors' judgement & Support for judgement \\
\hline $\begin{array}{l}\text { Allocation concealment } \\
\text { (selection bias) }\end{array}$ & Low risk & A - Adequate \\
\hline
\end{tabular}

Comeri 1995

\section{Study characteristics}

Methods

Retrospective cohort study conducted in Italy during the 1991 to 1992 influenza season, in the community. Data sources were self administered questionnaire and vaccination registry. Follow-up period was 1 December 1991 to 29 February 1992. Random samples of vaccinated and control participants were extracted from vaccination and population registries.

\begin{tabular}{|c|c|c|}
\hline Participants & \multicolumn{2}{|c|}{$\begin{array}{l}213 \text { community-dwelling elderly ( } 150 \text { treated and } 63 \text { controls; number of participants included in the } \\
\text { analysis unknown), } 65 \text { years or older }\end{array}$} \\
\hline Interventions & \multicolumn{2}{|c|}{ Parenteral influenza vaccine. Matching unknown, probably yes according to literature data. } \\
\hline Outcomes & \multicolumn{2}{|c|}{ Clinically defined ILI (fever, cough, sore throat, myalgia, headache, weakness) } \\
\hline Notes & \multicolumn{2}{|c|}{ Very poor description of methods, poor definitions, data extracted from percentages } \\
\hline \multicolumn{3}{|l|}{ Risk of bias } \\
\hline Bias & Authors' judgement & Support for judgement \\
\hline $\begin{array}{l}\text { Allocation concealment } \\
\text { (selection bias) }\end{array}$ & High risk & C - Inadequate \\
\hline
\end{tabular}

Consonni 2004a

\section{Study characteristics}

\begin{tabular}{ll}
\hline Methods & $\begin{array}{l}\text { Prospective cohort study conducted in Italy during the } 2002 \text { to } 2003 \text { influenza season, in the commu- } \\
\text { nity. Data sources were self administered questionnaire and phone interviews. Follow-up period went } \\
\text { from enrolment to April } 2003 . \text { Ambulatory patients were enrolled at random to undergo either adjuvant } \\
\text { or subunit influenza vaccine plus antipneumococcal vaccine. A control group of unvaccinated patients } \\
\text { was also enrolled. Only flu vaccinated were included in analysis. }\end{array}$ \\
\hline Participants & $\begin{array}{l}235 \text { ambulatory patients (166 vaccinated with adjuvant vaccine, } 69 \text { controls; all included in analysis), } \\
65 \text { years or older }\end{array}$ \\
\hline Interventions & Adjuvant virosomal vaccine. Vaccine strains probably matched the circulating strain. \\
\hline Cutcomes & gia, chills or sweating, weakness + at least 1 respiratory symptom: cough, sore throat, nasal conges-
\end{tabular}


Consonni 2004a (Continued)

tion), hospitalisation for all respiratory diseases, all deaths. Acute respiratory infection was also defined.

\begin{tabular}{ll}
\hline Notes & $\begin{array}{l}\text { Vaccinated people had higher impairment. No information about flu activity; probably not epidemic } \\
\text { year. }\end{array}$
\end{tabular}

\title{
Risk of bias
}

\begin{tabular}{lll}
\hline Bias & Authors' judgement & Support for judgement \\
\hline $\begin{array}{l}\text { Allocation concealment } \\
\text { (selection bias) }\end{array}$ & Unclear risk & B - Unclear \\
\hline
\end{tabular}

Consonni $2004 b$

\section{Study characteristics}

Prospective cohort study conducted in Italy during the 2002 to 2003 influenza season, in the commu-
nity. Data sources were self administered questionnaire and phone interviews. Follow-up period went
from enrolment to April 2004. Ambulatory patients were enrolled at random to undergo either adjuvant
or subunit influenza vaccine plus antipneumococcal vaccine. A control group of unvaccinated patients
was also enrolled. All data were included in a separate analysis.

\begin{tabular}{|c|c|c|}
\hline Participants & \multicolumn{2}{|c|}{$\begin{array}{l}374 \text { ambulatory patients ( } 166 \text { vaccinated with adjuvant vaccine, } 139 \text { vaccinated with flu + pneumo vac- } \\
\text { cine; } 69 \text { controls; all included in analysis), } 66 \text { years or older }\end{array}$} \\
\hline Interventions & \multicolumn{2}{|c|}{$\begin{array}{l}\text { Adjuvant virosomal vaccine; subunit influenza vaccine; antipneumococcal vaccine. Vaccine strains } \\
\text { probably matched the circulating strain. }\end{array}$} \\
\hline Outcomes & \multicolumn{2}{|c|}{$\begin{array}{l}\text { Clinically defined ILI (fever } 38^{\circ} \mathrm{C} \text { or more + at least } 1 \text { systemic symptom: headache, discomfort, myal- } \\
\text { gia, chills or sweating, weakness + at least } 1 \text { respiratory symptom: cough, sore throat, nasal conges- } \\
\text { tion), hospitalisation for all respiratory diseases, all deaths. Acute respiratory infection was also de- } \\
\text { fined. }\end{array}$} \\
\hline Notes & \multicolumn{2}{|c|}{$\begin{array}{l}\text { Vaccinated people had higher impairment. No information about flu activity; probably not epidemic } \\
\text { year. }\end{array}$} \\
\hline \multicolumn{3}{|l|}{ Risk of bias } \\
\hline Bias & Authors' judgement & Support for judgement \\
\hline $\begin{array}{l}\text { Allocation concealment } \\
\text { (selection bias) }\end{array}$ & Unclear risk & D - Not used \\
\hline
\end{tabular}

Crocetti 2001

\section{Study characteristics}

Methods

\begin{abstract}
Case-control study conducted in Italy during the 1994 to 1995 influenza season, in the community. Data sources were database discharge diagnoses and mailed questionnaire. Follow-up period was 1 December 1994 to 31 March 1995. Cases were people discharged from hospital with pneumonia and influenza; community controls were matched for age, sex, and residence.
\end{abstract}


Crocetti 2001 (Continued)

Participants

825 residents of the province of Florence ( 275 cases and 550 controls were included in analysis; non-response rate was $15 \%$ in each group), 65 years or older

\begin{tabular}{ll}
\hline Interventions & Parenteral influenza vaccine. Vaccine strains did not match the circulating strain. \\
\hline Outcomes & Hospitalisation from pneumonia and influenza (ICD 480-487) \\
\hline Notes & $\begin{array}{l}\text { Pneumococcal vaccination was very unlikely. The season was an epidemic one. The study controls for } \\
\text { confounders in analysis: disability, socio-economic factors, and smoking habits. Quantitative analysis } \\
\text { was also performed. }\end{array}$
\end{tabular}

\section{Risk of bias}

\begin{tabular}{lll}
\hline Bias & Authors' judgement & Support for judgement \\
\hline $\begin{array}{l}\text { Allocation concealment } \\
\text { (selection bias) }\end{array}$ & Unclear risk & B - Unclear \\
\hline
\end{tabular}

\section{Cuneo Crovari 1980}

\section{Study characteristics}

\begin{tabular}{ll} 
Methods & $\begin{array}{l}\text { Prospective cohort study conducted in Italy during the } 1978 \text { to } 1979 \text { influenza season. Authors investi- } \\
\text { gated an outbreak in a nursing home; individual cards were reviewed. Follow-up period was } 1 \text { Novem- } \\
\text { ber } 1978 \text { to } 31 \text { May } 1979 . \text { Throat swab and paired sera specimens were obtained from residents. }\end{array}$ \\
\hline Participants & 196 nursing home residents ( 86 treated and 110 controls, all included in the analysis), 60 years or older \\
\hline Interventions & $\begin{array}{l}\text { Parenteral influenza vaccine: A/Texas/1/77; A/USSR/90/77; B/Hong Kong/8/73. Matching between vac- } \\
\text { cine and circulating strains is unknown. }\end{array}$
\end{tabular}

Outcomes Positive culture or 4-fold antibody titre increase with or without symptoms. Only symptomatic cases were included in the analysis.

\begin{tabular}{ll}
\hline Notes & Poor reporting of methods; no confounders control. The circulating strain was related to $B /$ Hong \\
Kong $/ 5 / 72$.
\end{tabular}
Kong/5/72.

\section{Risk of bias}

\begin{tabular}{lll}
\hline Bias & Authors' judgement & Support for judgement \\
\hline $\begin{array}{l}\text { Allocation concealment } \\
\text { (selection bias) }\end{array}$ & High risk & C - Inadequate \\
\hline
\end{tabular}

Currier 1988

\section{Study characteristics}

Methods

Authors investigated an outbreak in an intermediate and domiciliary care nursing home, in Maryland, USA during the 1987 to 1988 influenza season; medical records were reviewed. Follow-up period was 8 January 1988 to 26 January 1988. Throat swabs and acute sera specimens were obtained from some ill residents. 
Currier 1988 (Continued) Participants 126 nursing home residents ( 87 treated and 34 controls were included in the analysis; data on immuni-
sation status for 5 residents were not available), mean age 87 years

Interventions

Parenteral influenza vaccine: A/Taiwan/1/86; A/Leningrad/360/86; B/Ann Arbor/1/86. Vaccine strains did not match the circulating strain.

\begin{tabular}{ll}
\hline Outcomes & $\begin{array}{l}\text { Clinically defined ILI (fever } 99.8^{\circ} \mathrm{F} \text { or greater }+1 \text { of the following: cough, congestion, sore throat) or pos- } \\
\text { itive throat culture; pneumonia; deaths were also reported but not by immunisation status }\end{array}$ \\
\hline Notes & $\begin{array}{l}\text { Vaccinated and not vaccinated participants were similar as underlying conditions, only senile dementia } \\
\text { was more frequent in vaccinees. The circulating strain was A/Leningrad-like. }\end{array}$
\end{tabular}

\section{Risk of bias}

\begin{tabular}{lll}
\hline Bias & Authors' judgement & Support for judgement \\
\hline $\begin{array}{l}\text { Allocation concealment } \\
\text { (selection bias) }\end{array}$ & Unclear risk & B - Unclear \\
\hline
\end{tabular}

\section{D'Alessio 1969}

\section{Study characteristics}

\begin{tabular}{|c|c|c|}
\hline Methods & \multicolumn{2}{|c|}{$\begin{array}{l}\text { Prospective outbreak investigation study conducted in the USA during the } 1967 \text { to } 1968 \text { influenza sea- } \\
\text { son. Authors investigated an outbreak in a nursing home. Follow-up period was December } 1967 \text { and } \\
\text { January 1968. Throat swab and sera specimens were obtained from all ill residents and from an addi- } \\
\text { tional group of } 27 \text { residents with no illness. }\end{array}$} \\
\hline Participants & \multicolumn{2}{|c|}{$\begin{array}{l}176 \text { nursing home residents ( } 131 \text { treated and } 31 \text { controls were included in the analysis, data on immu- } \\
\text { nisation status for } 14 \text { residents were not available) }\end{array}$} \\
\hline Interventions & \multicolumn{2}{|c|}{$\begin{array}{l}\text { Parenteral influenza vaccine: A2/Japan/170/62; A2/Taiwan/1/64; B/Massachusetts/3/66. Matching be- } \\
\text { tween vaccine and circulating strains is unknown. }\end{array}$} \\
\hline Outcomes & \multicolumn{2}{|c|}{ Clinically defined ILI (fever $37.8^{\circ} \mathrm{C}$ or greater, headache, cough, sore throat, myalgia, and prostration) } \\
\hline Notes & \multicolumn{2}{|c|}{ Poor reporting; no confounders control. The circulating strain was A2/Wis/1/68. } \\
\hline \multicolumn{3}{|l|}{ Risk of bias } \\
\hline Bias & Authors' judgement & Support for judgement \\
\hline $\begin{array}{l}\text { Allocation concealment } \\
\text { (selection bias) }\end{array}$ & High risk & C - Inadequate \\
\hline
\end{tabular}

Davis 2001a

\section{Study characteristics}

$\begin{array}{ll}\text { Methods } & \text { Prospective cohort study conducted in Hawaii during the } 1994 \text { to } 1995 \text { influenza season, in the com- } \\ \text { munity. Data source was insurance claim records. Follow-up period was } 15 \text { November } 1994 \text { to } 31 \text { March } \\ \text { 1995. Only 10\% of vaccinated participants and 3\% of unvaccinated participants received pneumococ- } \\ \text { cal vaccination. }\end{array}$


Davis 2001a (Continued)

Participants $\quad 77,951$ person periods members of a medical care program $(44,271$ treated and 33,680 controls, all included in the analysis), 65 years or older

Interventions

Parenteral influenza vaccine. Vaccine strains probably did not match the circulating strain (literature data).

\begin{tabular}{ll}
\hline Outcomes & Hospitalisation from pneumonia and influenza (ICD 480-487), hospitalisation from all respiratory condi- \\
tions (ICD 460-462, 465-466, 480-487, 500-518), hospitalisation from congestive heart failure (ICD 428)
\end{tabular}
tions (ICD 460-462, 465-466, 480-487, 500-518), hospitalisation from congestive heart failure (ICD 428)

Notes Odds ratios were adjusted by age and health status. Frequencies data were not available. To perform quantitative analysis, adjusted data were used. The season had low epidemic levels.

\section{Risk of bias}

\begin{tabular}{lll}
\hline Bias & Authors' judgement & Support for judgement \\
\hline $\begin{array}{l}\text { Allocation concealment } \\
\text { (selection bias) }\end{array}$ & Low risk & A - Adequate \\
\hline
\end{tabular}

Davis 2001b

\section{Study characteristics}

\begin{tabular}{ll}
\hline Methods & $\begin{array}{l}\text { Prospective cohort study conducted in Hawaii during the } 1995 \text { to } 1996 \text { influenza season, in the com- } \\
\text { munity. Data source was insurance claim records. Follow-up period was } 15 \text { November } 1995 \text { to } 31 \text { March } \\
\text { 1996. Only 10\% of vaccinated participants and 3\% of unvaccinated participants received pneumococ- } \\
\text { cal vaccination. }\end{array}$ \\
\hline Participants & $\begin{array}{l}77,951 \text { person periods members of a medical care programme (44,271 treated and 33,680 controls, all } \\
\text { included in the analysis), } 65 \text { years or older }\end{array}$ \\
\hline Interventions & Parenteral influenza vaccine. Vaccine strains probably matched the circulating strain (literature data). \\
\hline Outcomes & $\begin{array}{l}\text { Hospitalisation from pneumonia and influenza (ICD 480-487), hospitalisation from all respiratory condi- } \\
\text { tions (ICD 460-462, 465-466, 480-487, 500-518), hospitalisation from congestive heart failure (ICD 428) }\end{array}$ \\
\hline Notes & Odds ratios were adjusted by age and health status. Frequencies data were not available. To perform \\
quantitative analysis, adjusted data were used. The season was probably an epidemic one.
\end{tabular}

\section{Risk of bias}

\begin{tabular}{lll}
\hline Bias & Authors' judgement & Support for judgement \\
\hline $\begin{array}{l}\text { Allocation concealment } \\
\text { (selection bias) }\end{array}$ & Low risk & A - Adequate \\
\hline
\end{tabular}

Davis 2001c

\section{Study characteristics}

Methods

Prospective cohort study conducted in Hawaii during the 1996 to 1997 influenza season, in the community. Data source was insurance claim records. Follow-up period was 15 November 1996 to 31 March 
Davis 2001c (Continued)

1997. Only $10 \%$ of vaccinated participants and $3 \%$ of unvaccinated participants received pneumococcal vaccination.

\begin{tabular}{ll}
\hline Participants & $\begin{array}{l}\text { 77,951 person periods members of a medical care programme (44,271 treated and 33,680 controls, all } \\
\text { included in the analysis), } 65 \text { years or older }\end{array}$ \\
\hline Interventions & Parenteral influenza vaccine. Vaccine strains probably matched the circulating strain (literature data). \\
\hline Outcomes & $\begin{array}{l}\text { Hospitalisation from pneumonia and influenza (ICD 480-487), hospitalisation from all respiratory condi- } \\
\text { tions (ICD 460-462, 465-466, 480-487, 500-518), hospitalisation from congestive heart failure (ICD 428) }\end{array}$ \\
\hline Notes & $\begin{array}{l}\text { Odds ratios were adjusted by age and health status. Frequencies data were not available. To perform } \\
\text { quantitative analysis, adjusted data were used. The season was probably an epidemic one. }\end{array}$ \\
\hline Risk of bias & Authors' judgement Support for judgement \\
\hline Bias & Low risk
\end{tabular}

Deguchi 2001

\section{Study characteristics}

Methods

Prospective cohort study conducted in Japan during the 1998 to 1999 influenza season. Follow-up period was 1 November 1998 to 31 March 1999. 301 nursing homes were surveyed during an epidemic season; only a few residences had an outbreak of respiratory infections. Reports of illness were provided by study site staff.

\begin{tabular}{ll} 
Participants & $\begin{array}{l}\text { 22,462 residents in } 301 \text { nursing homes (10,739 treated and 11,723 controls, all included in the analysis), } \\
65 \text { years or older }\end{array}$ \\
\hline Interventions & $\begin{array}{l}\text { Parenteral influenza vaccine: A/Beijing/262/95; A/Sydney/5/97; B/Mie/1/93. Vaccine strains probably } \\
\text { matched circulating strains. }\end{array}$ \\
\hline Outcomes & $\begin{array}{l}\text { Clinical ILI (any of the following symptoms: fever, runny nose, sore throat, cough, headache, muscle } \\
\text { aches, chills, vomiting, decreased activity, irritability, wheezing, pulmonary congestion), hospitalisa- } \\
\text { tion due to severe illness, deaths due to influenza }\end{array}$ \\
\hline Notes & $\begin{array}{l}\text { Poor description of methods, poor definitions; some cases were laboratory confirmed, but number of } \\
\text { such cases was not indicated. Groups were comparable as age and gender. Health status was not inves- } \\
\text { tigated. }\end{array}$
\end{tabular}

\section{Risk of bias}

\begin{tabular}{lll} 
Bias & Authors' judgement & Support for judgement \\
\hline $\begin{array}{l}\text { Allocation concealment } \\
\text { (selection bias) }\end{array}$ & High risk & C - Inadequate \\
\hline
\end{tabular}


Edmondson 1971

\section{Study characteristics}

\begin{tabular}{|c|c|c|}
\hline Methods & \multicolumn{2}{|c|}{$\begin{array}{l}\text { Experimental study conducted in Virginia, USA during the } 1968 \text { to } 1969 \text { influenza season. } 4 \text { arms: par- } \\
\text { enteral vaccine, aerosol vaccine, both, placebo. Methods are described in another article. }\end{array}$} \\
\hline Participants & \multicolumn{2}{|c|}{$\begin{array}{l}266 \text { elderly psychiatric patients ( } 90 \text { in the parenteral arm, } 89 \text { in the aerosol arm, } 88 \text { in the arm with both } \\
\text { administrations, } 87 \text { in the placebo arm) }\end{array}$} \\
\hline Interventions & \multicolumn{2}{|c|}{$\begin{array}{l}\text { Monovalent inactivated A2 Hong Kong influenza vaccine. Vaccine strains probably matched the circu- } \\
\text { lating strains. }\end{array}$} \\
\hline Outcomes & \multicolumn{2}{|c|}{$\begin{array}{l}\text { Clinically defined ILI (fever }+1 \text { or } 2 \text { respiratory symptoms or at least } 2 \text { systemic symptoms, lasting } \\
\text { longer than } 1 \text { day; } 3 \text { respiratory symptoms or } 2 \text { respiratory symptoms + } 2 \text { systemic symptoms, lasting } \\
\text { longer than } 2 \text { days); laboratory-confirmed influenza }\end{array}$} \\
\hline Notes & \multicolumn{2}{|c|}{ The study year was an epidemic one; circulating strain was A2 HK. } \\
\hline \multicolumn{3}{|l|}{ Risk of bias } \\
\hline Bias & Authors' judgement & Support for judgement \\
\hline $\begin{array}{l}\text { Random sequence genera- } \\
\text { tion (selection bias) }\end{array}$ & Unclear risk & Insufficient details provided. \\
\hline $\begin{array}{l}\text { Allocation concealment } \\
\text { (selection bias) }\end{array}$ & Unclear risk & Insufficient details provided. \\
\hline $\begin{array}{l}\text { Blinding (performance } \\
\text { bias and detection bias) } \\
\text { All outcomes }\end{array}$ & Unclear risk & Insufficient details provided. \\
\hline $\begin{array}{l}\text { Incomplete outcome data } \\
\text { (attrition bias) } \\
\text { All outcomes }\end{array}$ & Unclear risk & Insufficient details provided. \\
\hline
\end{tabular}

\section{Fedson 1993a}

\section{Study characteristics}

\begin{tabular}{ll}
\hline Methods & $\begin{array}{l}\text { Case-control study conducted in Manitoba, Canada during the } 1982 \text { to } 1983 \text { influenza season, in the } \\
\text { community. Data source was insurance claim records. Follow-up period was } 1 \text { December } 1982 \text { to } 28 \\
\text { February 1983. Cases were admitted to the hospital with a lower respiratory tract condition as first di- } \\
\text { agnosis; community controls were matched for age, sex, and residence. }\end{array}$ \\
\hline Participants & $\begin{array}{l}10,471 \text { non-institutionalised people, } 70 \% \text { were older than } 65 \text { years (2619 cases and } 7828 \text { controls, all in- } \\
\text { cluded in analysis) }\end{array}$ \\
\hline Interventions & Parenteral influenza vaccine. Vaccine strains matched the circulating strain. \\
\hline Outcomes & $\begin{array}{l}\text { Hospitalisation from a lower respiratory tract condition (ICD 466, 480-487, 490-496, 500-519), deaths } \\
\text { from any respiratory condition, deaths from all causes. Data about deaths were not reported. }\end{array}$ \\
\hline Notes & $\begin{array}{l}\text { Circulating strain: A/Bangkok/1/79-like. The season was an epidemic one. The study controls for con- } \\
\text { founders in analysis: health status. Quantitative analysis was also performed. }\end{array}$
\end{tabular}


Fedson 1993a (Continued)

Risk of bias

\begin{tabular}{lll}
\hline Bias & Authors' judgement & Support for judgement \\
\hline $\begin{array}{l}\text { Allocation concealment } \\
\text { (selection bias) }\end{array}$ & Low risk & A-Adequate \\
\hline
\end{tabular}

Fedson 1993b

\section{Study characteristics}

\begin{tabular}{ll}
\hline Methods & $\begin{array}{l}\text { Case-control study conducted in Manitoba, Canada during the } 1985 \text { to } 1986 \text { influenza season, in the } \\
\text { community. Data source was insurance claim records. Follow-up period was 1 December 1985 to 15 } \\
\text { February 1986. Cases were admitted to the hospital with a lower respiratory tract condition as first di- } \\
\text { agnosis; community controls were matched for age, sex, and residence. }\end{array}$ \\
\hline Participants & $\begin{array}{l}9666 \text { non-institutionalised people, 70\% were older than } 65 \text { years (2417 cases and 7249 controls, all in- } \\
\text { cluded in analysis) }\end{array}$ \\
\hline Interventions & Parenteral influenza vaccine. Vaccine strains matched the circulating strain. \\
\hline Outcomes & $\begin{array}{l}\text { Hospitalisation from a lower respiratory tract condition (ICD 466, 480-487, 490-496, 500-519), deaths } \\
\text { from any respiratory condition, deaths from all causes. Data about deaths were not reported. }\end{array}$ \\
\hline $\begin{array}{l}\text { Notes } \\
\text { Risk of bias }\end{array}$ & $\begin{array}{l}\text { Circulating strain: A/Philippines/2/82-like. The season was an epidemic one. The study controls for con- } \\
\text { founders in analysis: health status. Quantitative analysis was also performed. }\end{array}$ \\
\hline Bias & Authors' judgement Support for judgement \\
\hline $\begin{array}{l}\text { Allocation concealment } \\
\text { (selection bias) }\end{array}$ & Low risk Adequate \\
\hline
\end{tabular}

Feery 1976

\section{Study characteristics}

$\begin{array}{ll}\text { Methods } & \text { Prospective cohort study conducted in Melbourne, Australia during the } 1976 \text { influenza season. Au- } \\ \text { thors investigated an outbreak in a nursing home. Follow-up period was from mid-April to mid-August. } \\ \text { Throat swabs and paired sera specimens were obtained from residents. }\end{array}$

\begin{tabular}{ll}
\hline Participants & 222 nursing home residents (154 treated and 68 controls, all included in the analysis); elderly \\
\hline Interventions & $\begin{array}{l}\text { Parenteral influenza vaccine: A/Victoria/3/75; A/Scotland/840/74; B/Hong Kong/8/73. Vaccine strains } \\
\text { matched circulating strains. }\end{array}$ \\
\hline Outcomes & Laboratory-confirmed influenza, deaths from influenza \\
\hline Notes & Poor reporting; no confounders control. The circulating strain was A/Victoria/3/75.
\end{tabular}

\section{Risk of bias}


Feery 1976 (Continued)

\begin{tabular}{lll} 
Bias & Authors' judgement & Support for judgement \\
\hline $\begin{array}{l}\text { Allocation concealment } \\
\text { (selection bias) }\end{array}$ & High risk & C-Inadequate \\
\hline
\end{tabular}

Fleming 1995

\section{Study characteristics}

\begin{tabular}{ll}
\hline Methods & $\begin{array}{l}\text { Retrospective cohort study conducted in UK during the } 1989 \text { to } 1990 \text { influenza season, in the commu- } \\
\text { nity. Data source was the general practitioner database. Follow-up period was } 1 \text { November } 1989 \text { to } 15 \\
\text { January 1990. As vaccines used in } 1988 \text { and } 1989 \text { were antigenically closely related, } 2 \text { exposure defini- } \\
\text { tions were used: recently vaccinated and previously vaccinated. }\end{array}$ \\
\hline Participants & $\begin{array}{l}9391 \text { people who had at least a general practitioner's consultation in previous months (599 treated and } \\
8792 \text { controls, all included in the analysis), 55 years or older }\end{array}$ \\
\hline Interventions & Parenteral influenza vaccine: A/Shanghai/1197-like. Vaccine strains matched the circulating strain. \\
\hline Outcomes & Death, death or severe respiratory illness, death or any respiratory illness without further specification \\
\hline Notes & $\begin{array}{l}\text { Important epidemic year. The study controls for confounders in analysis: age, gender, health status. Da- } \\
\text { ta were stratified by health status: people with minor underlying conditions are considered as healthy. } \\
\text { People vaccinated during the previous year are considered as "non vaccinated". Quantitative analysis } \\
\text { was also performed. }\end{array}$ \\
\hline Risk of bias & $\begin{array}{l}\text { Authors' judgement Support for judgement } \\
\text { Bias }\end{array}$ \\
\hline $\begin{array}{l}\text { Allocation concealment } \\
\text { Unclear risk }\end{array}$ \\
\hline
\end{tabular}

Foster 1992

\section{Study characteristics}

Methods

Case-control study conducted in Michigan, USA during the 1989 to 1990 influenza season, in the community. Data sources were: discharge diagnoses, mailed questionnaire. Follow-up period was 1 November 1989 to 30 April 1990. Cases were admitted to the hospital with pneumonia or influenza; community controls were randomly selected.

\begin{tabular}{ll}
\hline Participants & 1907 non-institutionalised people (1354 cases and 2389 controls were identified; 721 and 1786 were in- \\
cluded in analysis, respectively), 65 years or older
\end{tabular}

\begin{tabular}{ll}
\hline Interventions & Parenteral influenza vaccine; $35 \%$ of cases and $28 \%$ of controls received pneumococcal vaccination. \\
Vaccine strains matched the circulating strain.
\end{tabular}

\begin{tabular}{ll}
\hline Outcomes & Hospitalisation from pneumonia and influenza (ICD 480.8-483, 484.7-487.1) \\
\hline Notes & $\begin{array}{l}\text { Circulating strain: A/Shanghai/11/87. The season was an epidemic one. The study controls for con- } \\
\text { founders in analysis: health status, flu activity, pneumococcal vaccination, smoke. Peak data were } \\
\text { used. Quantitative analysis was also performed. }\end{array}$ \\
\hline \hline
\end{tabular}


Foster 1992 (Continued)

\section{Risk of bias}

\begin{tabular}{lll}
\hline Bias & Authors' judgement & Support for judgement \\
\hline $\begin{array}{l}\text { Allocation concealment } \\
\text { (selection bias) }\end{array}$ & Unclear risk & B - Unclear \\
\hline
\end{tabular}

Fyson 1983a

\section{Study characteristics}

\begin{tabular}{ll}
\hline Methods & $\begin{array}{l}\text { Authors investigated an outbreak in a nursing home in Canada during the 1982 to } 1983 \text { influenza sea- } \\
\text { son; active surveillance. Follow-up period was } 3 \text { November } 1982 \text { to } 17 \text { January } 1983 . \text { Throat swab and } \\
\text { paired sera specimens were obtained from some residents. }\end{array}$ \\
\hline Participants & $\begin{array}{l}545 \text { chronically ill nursing home residents (321 treated and 224 controls, all included in the analysis); } 18 \\
\text { to } 103 \text { years old, mean age } 80 \text { years }\end{array}$ \\
\hline Interventions & $\begin{array}{l}\text { Parenteral influenza vaccine, whole and subvirion: A/Brazil/11/78; A/Bangkok/1/79; B/Singa- } \\
\text { pore/222/79. Vaccine strains probably matched circulating strains. }\end{array}$ \\
\hline Outcomes & $\begin{array}{l}\text { Acute respiratory symptoms: fever, congestion, cough, sore throat, general malaise, without a clear de- } \\
\text { finition; death from pneumonia }\end{array}$ \\
\hline Notes & $\begin{array}{l}\text { Poor reporting; no confounders control. Circulating strain: A/Bangkok/1/79-like; no other viruses were } \\
\text { identified }\end{array}$ \\
\hline Risk of bias & Authors' judgement Support for judgement \\
\hline $\begin{array}{l}\text { Bias } \\
\text { (selection bias) }\end{array}$ & Unclear risk Unclear \\
\hline
\end{tabular}

Fyson 1983b

\section{Study characteristics}

\begin{tabular}{ll}
\hline Methods & $\begin{array}{l}\text { Authors investigated an outbreak in a nursing home in Canada during the 1982 to } 1983 \text { influenza sea- } \\
\text { son; partial surveillance for delayed notification of outbreak. Follow-up period was } 30 \text { November } 1982 \\
\text { to } 9 \text { January 1983. Throat swab and paired sera specimens were obtained from some residents. }\end{array}$ \\
\hline Participants & $\begin{array}{l}171 \text { female, chronically ill nursing home residents (53 treated and } 118 \text { controls, all included in the } \\
\text { analysis); } 19 \text { to } 105 \text { years old }\end{array}$ \\
\hline Interventions & $\begin{array}{l}\text { Parenteral whole influenza vaccine: A/Brazil/11/78; A/Bangkok/1/79; B/Singapore/222/80. Vaccine } \\
\text { strains probably matched circulating strains. }\end{array}$ \\
\hline Outcomes & Clinically defined ILI without further specification; death from pneumonia \\
\hline Notes & Poor reporting; no confounders control. Circulating strain: A/Bangkok/1/79-like \\
\hline
\end{tabular}


Fyson 1983b (Continued)

Risk of bias

\begin{tabular}{lll}
\hline Bias & Authors' judgement & Support for judgement \\
\hline $\begin{array}{l}\text { Allocation concealment } \\
\text { (selection bias) }\end{array}$ & Unclear risk & B - Unclear \\
\hline
\end{tabular}

Gavira Iglesias 1987

\section{Study characteristics}

Methods Prospective cohort study conducted in Spain during the 1984 to 1985 influenza season, in the community. Data source was a questionnaire retrospectively applied by investigators in June to July 1985 (door-to-door survey). The whole population of a rural village was investigated.

\begin{tabular}{|c|c|c|}
\hline Participants & \multicolumn{2}{|c|}{268 community-dwelling (188 treated and 80 controls, all included in the analysis), 65 years or older } \\
\hline Interventions & \multicolumn{2}{|c|}{ Parenteral influenza vaccine: A/Philippines/2/82; A/Chile/1/83; B/USSR/100/83. Matching unknown. } \\
\hline Outcomes & \multicolumn{2}{|c|}{$\begin{array}{l}\text { Clinically defined ILI (fever } 39^{\circ} \mathrm{C} \text { or more, chills, general malaise, myalgia, headache, arthralgia, con- } \\
\text { junctivitis, lasting } 3 \text { days or more) }\end{array}$} \\
\hline Notes & \multicolumn{2}{|c|}{$\begin{array}{l}\text { None of the observed deaths was due to flu-related illness. The season had low epidemic levels. Sub- } \\
\text { group analysis was performed but only for the whole population. }\end{array}$} \\
\hline \multicolumn{3}{|l|}{ Risk of bias } \\
\hline Bias & Authors' judgement & Support for judgement \\
\hline $\begin{array}{l}\text { Allocation concealment } \\
\text { (selection bias) }\end{array}$ & High risk & C - Inadequate \\
\hline
\end{tabular}

Gené Badia 1991

\section{Study characteristics}

Prospective cohort study conducted in Spain during the 1988 to 1989 influenza season, in the com-
munity. Data sources were the health centre register, death certificate archives, hospital records. Fol-
low-up period was 1 November 1988 to 30 May 1989 . In the first of the 4 health centres, all elderly peo-
ple were enrolled; in the others only people approaching the centre for health reasons were enrolled.

Participants 4558 people enrolled at 4 health centres (1998 treated and 2560 controls, all included in the analysis), 65 years or older, mean age 74 years

\begin{tabular}{ll}
\hline Interventions & Parenteral influenza vaccine. Vaccine strains matched the circulating strain. \\
\hline Outcomes & $\begin{array}{l}\text { All hospitalisations and hospitalisation from cardio-respiratory causes (ICD 401-414 and 460-519); } \\
\text { deaths from all causes. Only deaths from all causes are included in analysis. }\end{array}$ \\
\hline Notes & The season was an epidemic one.
\end{tabular}

\section{Risk of bias}


Gené Badia 1991 (Continued)

\begin{tabular}{lll} 
Bias & Authors' judgement & Support for judgement \\
\hline $\begin{array}{l}\text { Allocation concealment } \\
\text { (selection bias) }\end{array}$ & Unclear risk & B - Unclear \\
\hline
\end{tabular}

Goodman 1982

\section{Study characteristics}

\begin{tabular}{|c|c|c|}
\hline Methods & \multicolumn{2}{|c|}{$\begin{array}{l}\text { Authors investigated an outbreak in a nursing home, in Atlanta, USA during the } 1980 \text { to } 1981 \text { influenza } \\
\text { season; medical charts and hospital charts were reviewed. Follow-up period was } 12 \text { December } 1980 \text { to } \\
21 \text { January } 1981 \text {. Throat swab and paired sera specimens were obtained from some residents. }\end{array}$} \\
\hline Participants & \multicolumn{2}{|c|}{$\begin{array}{l}120 \text { nursing home residents ( } 36 \text { treated and } 84 \text { controls, all included in the analysis), } 47 \text { to } 95 \text { years old } \\
\text { (median age } 80 \text { years). Participants required intermediate and skilled nursing care. }\end{array}$} \\
\hline Interventions & \multicolumn{2}{|c|}{$\begin{array}{l}\text { Parenteral influenza vaccine: A/Bangkok/1/79; A/Brazil/11/78; B/Singapore/222/78. Vaccine strains } \\
\text { probably matched circulating strains. }\end{array}$} \\
\hline Outcomes & \multicolumn{2}{|c|}{$\begin{array}{l}\text { Clinically defined ILI (fever } 37.7^{\circ} \mathrm{C} \text { or greater or cough in the outbreak period ( } 12 \text { December } 1980 \text { to } 21 \\
\text { January 1981)), death from ILI. Hospitalisation and pneumonia were also accounted for, but results } \\
\text { were not presented by immunisation status. }\end{array}$} \\
\hline Notes & \multicolumn{2}{|c|}{$\begin{array}{l}\text { No confounders control. The circulating strain was A/Bangkok/1/79-like. Serological tests were nega- } \\
\text { tive for other pathogens. }\end{array}$} \\
\hline \multicolumn{3}{|l|}{ Risk of bias } \\
\hline Bias & Authors' judgement & Support for judgement \\
\hline $\begin{array}{l}\text { Allocation concealment } \\
\text { (selection bias) }\end{array}$ & Unclear risk & B - Unclear \\
\hline
\end{tabular}

Govaert 1993

\section{Study characteristics}

Methods Experimental study conducted in the Netherlands during the 1991 to 1992 influenza season, randomised, double-blind, placebo controlled; randomisation scheme was stratified according to health status. Follow-up period was 48 hours after vaccination. Adverse reactions were self reported on postal questionnaire completed 4 weeks after vaccination

\begin{tabular}{ll}
\hline Participants & $\begin{array}{l}1838 \text { not known as belonging to a high-risk group (927 treated and } 911 \text { controls; } 23 \text { and } 9 \text { dropped out, } \\
\text { respectively), } 60 \text { years or older }\end{array}$ \\
\hline Interventions & $\begin{array}{l}\text { Parenteral influenza recommended vaccine: A/Singapore/6/86; A/Beijing/357/89; B/Beijing/1/97; B/ } \\
\text { Panama/45/90 }\end{array}$ \\
\hline Outcomes & $\begin{array}{l}\text { Local: swelling, itching, warm feeling, pain when touched, constant pain, discomfort. Systemic: fever, } \\
\text { headache, malaise, other complaints }\end{array}$ \\
\hline Notes & $\begin{array}{l}\text { Harms were reported for all participants and by risk condition. Data regarding all participants were in- } \\
\text { cluded }\end{array}$
\end{tabular}


Govaert 1993 (Continued)

Risk of bias

\begin{tabular}{|c|c|c|}
\hline Bias & Authors' judgement & Support for judgement \\
\hline $\begin{array}{l}\text { Random sequence genera- } \\
\text { tion (selection bias) }\end{array}$ & Low risk & Adequate description \\
\hline $\begin{array}{l}\text { Allocation concealment } \\
\text { (selection bias) }\end{array}$ & Low risk & Adequate description \\
\hline $\begin{array}{l}\text { Blinding (performance } \\
\text { bias and detection bias) } \\
\text { All outcomes }\end{array}$ & Low risk & Described as placebo controlled, but no additional information was available \\
\hline $\begin{array}{l}\text { Incomplete outcome data } \\
\text { (attrition bias) } \\
\text { All outcomes }\end{array}$ & Low risk & Adequate description of follow up and attrition \\
\hline
\end{tabular}

Govaert 1994a

\section{Study characteristics}

\begin{tabular}{ll}
\hline Methods & Experimental study conducted in the Netherlands during the 1991 to 1992 influenza season, in the \\
community. Follow-up period was 1 November 1991 to 30 April 1992. Randomised, double-blind, place- \\
bo controlled; randomisation scheme was stratified according to health status.
\end{tabular}

\begin{tabular}{ll}
\hline Participants & $\begin{array}{l}1838 \text { people not known as belonging to a high-risk group (927 treated and } 911 \text { controls; } 25 \text { and } 22 \\
\text { dropped out, respectively), } 60 \text { years or older }\end{array}$ \\
\hline Interventions & $\begin{array}{l}\text { Parenteral influenza recommended vaccine: A/Singapore/6/86; A/Beijing/357/89; B/Beijing/1/97; B/ } \\
\text { Panama/45/90. Vaccine strains matched the circulating strains. }\end{array}$ \\
\hline Outcomes & $\begin{array}{l}\text { Clinically defined ILI; laboratory-confirmed ILI. Several definitions for clinical and laboratory ILI were } \\
\text { tested; the Dutch Sentinel Stations definition is used (fever } 37.8^{\circ} \mathrm{C} \text { or greater + cough or coryza or sore } \\
\text { throat or headache or myalgia). }\end{array}$ \\
\hline Notes & $\begin{array}{l}\text { The study year was an epidemic one; data were stratified by health status. Intention-to-treat analysis } \\
\text { was performed. }\end{array}$
\end{tabular}

\section{Risk of bias}

\begin{tabular}{lll}
\hline Bias & Authors' judgement & Support for judgement \\
\hline $\begin{array}{l}\text { Random sequence genera- } \\
\text { tion (selection bias) }\end{array}$ & Low risk & Adequate description \\
\hline $\begin{array}{l}\text { Allocation concealment } \\
\text { (selection bias) }\end{array}$ & Low risk & Adequate description \\
\hline $\begin{array}{l}\text { Blinding (performance } \\
\text { bias and detection bias) } \\
\text { All outcomes }\end{array}$ & Low risk & Adequate description \\
\hline $\begin{array}{l}\text { Incomplete outcome data } \\
\text { (attrition bias) }\end{array}$ & Low risk & Adequate description \\
\hline
\end{tabular}


Govaert 1994a (Continued)

All outcomes

Gross 1988

\section{Study characteristics}

\begin{tabular}{ll}
\hline Methods & Prospective cohort study conducted in New York, USA during the 1982 to 1983 influenza season. Au- \\
thors investigated an outbreak in a nursing home; independent blind assessment was conducted. Fol- \\
low-up period was 1 November 1982 to 30 April 1983.305 of the 525 residents volunteered to partici- \\
pate in study; diagnosis was made without knowledge of vaccination status
\end{tabular}

\begin{tabular}{ll}
\hline Participants & $\begin{array}{l}305 \text { nursing home residents, mostly ambulatory (181 treated and 124 controls; } 138 \text { and } 94 \text { had serolog- } \\
\text { ical surveillance, respectively); groups were comparable for health status and drug use; mean age } 85 \\
\text { years }\end{array}$ \\
\hline Interventions & $\begin{array}{l}\text { Parenteral influenza vaccine: A/Bangkok/1/79; A/Brazil/11/78; B/Singapore/222/79. Vaccine strains } \\
\text { matched circulating strains (slight drift) }\end{array}$ \\
\hline Outcomes & $\begin{array}{l}\text { Laboratory-confirmed influenza (4-fold increase in antibody titre), X-ray-confirmed pneumonia, deaths } \\
\text { from all causes }\end{array}$ \\
\hline Notes & $\begin{array}{l}\text { Pneumococcal vaccine was rarely used. Amantadine was not used. The circulating strain was A/Ari- } \\
\text { zona/80, closely related to A/Bangkok/1/79 Laboratory-confirmed cases were analysed by intention-to- } \\
\text { treat }\end{array}$
\end{tabular}

\section{Risk of bias}

\begin{tabular}{lll}
\hline Bias & Authors' judgement & Support for judgement \\
\hline $\begin{array}{l}\text { Allocation concealment } \\
\text { (selection bias) }\end{array}$ & Low risk & A - Adequate \\
\hline
\end{tabular}

Hak 2002a

\section{Study characteristics}

\begin{tabular}{ll}
\hline Methods & $\begin{array}{l}\text { Prospective cohort study conducted in the USA during the } 1996 \text { to } 1997 \text { influenza season, in the com- } \\
\text { munity. Data source was a managed care organisation database. Follow-up period was } 5 \text { October 1996 } \\
\text { to } 3 \text { May } 1997 .\end{array}$ \\
\hline Participants & $\begin{array}{l}122,974 \text { members of a medical care programme continuously enrolled for the 1-year period (71,005 } \\
\text { treated and 51,969 controls, all included in the analysis), } 65 \text { years or older }\end{array}$ \\
\hline Interventions & Parenteral influenza vaccine. Vaccine matched the circulating strain. \\
\hline Outcomes & $\begin{array}{l}\text { Combined outcome: hospitalisation from influenza and pneumonia (ICD 480-487) or death from all } \\
\text { causes }\end{array}$ \\
\hline Notes & $\begin{array}{l}\text { The study controls for confounders in analysis: age, gender, health status. Data were presented by } \\
\text { health status. No information about pneumococcal vaccination. The season was an epidemic one. }\end{array}$ \\
\hline
\end{tabular}

\section{Risk of bias}


Hak 2002a (Continued)

\begin{tabular}{lll} 
Bias & Authors' judgement & Support for judgement \\
\hline $\begin{array}{l}\text { Allocation concealment } \\
\text { (selection bias) }\end{array}$ & Low risk & A-Adequate \\
\hline
\end{tabular}

Hak 2002b

\section{Study characteristics}

\begin{tabular}{ll}
\hline Methods & $\begin{array}{l}\text { Prospective cohort study conducted in the USA during the } 1997 \text { to } 1998 \text { influenza season, in the com- } \\
\text { munity. Data source was a managed care organisation database. Follow-up period was 23 November } \\
1997 \text { to } 4 \text { April } 1998 .\end{array}$ \\
\hline Participants & $\begin{array}{l}158,454 \text { members of a medical care programme continuously enrolled for the 1-year period (92,001 } \\
\text { treated and 66,453 controls, all included in the analysis), } 65 \text { years or older }\end{array}$ \\
\hline Interventions & Parenteral influenza vaccine. Vaccine did not match the circulating strain. \\
\hline Outcomes & \begin{tabular}{l} 
Combined outcome: hospitalisation from influenza and pneumonia (ICD 480-487) or death from all \\
causes \\
health status. No information about pneumococcal vaccination. The season was an epidemic one; cir- \\
\hline culating strain: A/Sydney-like.
\end{tabular} \\
\hline
\end{tabular}

\section{Risk of bias}

\begin{tabular}{lll}
\hline Bias & Authors' judgement & Support for judgement \\
\hline $\begin{array}{l}\text { Allocation concealment } \\
\text { (selection bias) }\end{array}$ & Unclear risk & D - Not used \\
\hline
\end{tabular}

Hara 2006

\section{Study characteristics}

\begin{tabular}{ll}
\hline Methods & $\begin{array}{l}\text { Prospective cohort study conducted in Saga, Japan. 10,000 community-dwelling elderly were random- } \\
\text { ly selected from a population registry and were sent a letter explaining the study with a request for } \\
\text { participation. Eligibility criteria were as follows: not being hospitalised, not being institutionalised, } \\
\text { not having any long-term absence, not living alone, and able to contact by telephone at least once a } \\
\text { month. }\end{array}$ \\
\hline Participants & $\begin{array}{l}\text { Among 10,000 elderly citizens, } 7357 \text { responded, and } 4787 \text { agreed to participate and matched our eligi- } \\
\text { bility criteria. The vaccination status of the study participants was identified by self reporting verifica- } \\
\text { tion and a list of recipients of partially funded vaccination; } 3240 \text { participants (3230 participants were } \\
\text { self reported and } 10 \text { were known with verification) were vaccinated and } 1547 \text { non-vaccinated. The vac- } \\
\text { cination coverage was } 67.7 \% .\end{array}$ \\
\hline
\end{tabular}

\begin{tabular}{ll} 
Interventions & Influenza vaccination versus no vaccination \\
\hline Outcomes & $\begin{array}{l}\text { ILI, clinical influenza, hospitalisation for all causes, hospitalisation for influenza or pneumonia, and to- } \\
\text { tal deaths }\end{array}$
\end{tabular}


Hara 2006 (Continued)

Notes
The author concludes that influenza vaccination was associated with decreased ILI during the epidemic period in community-dwelling elderly. The above risk reduction was greater under low-risk conditions. The results were inconclusive for preventing hospitalisation and death, due to an inadequate sample size. However, our findings support the finding that all elderly individuals substantially benefit from vaccination even in a season of mild influenza activity, and also when the antigenic match between the vaccine strains and the circulating strains is not closely matched.

Horman 1986

\section{Study characteristics}

\begin{tabular}{ll}
\hline Methods & $\begin{array}{l}\text { Authors investigated an outbreak in a nursing home in Maryland, USA during the 1980 to 1981 influenza } \\
\text { season; residents' medical records were reviewed. Follow-up period was 8 December 1980 to 13 Janu- } \\
\text { ary 1981. Throat swab and paired sera specimens were obtained from some residents. }\end{array}$ \\
\hline Participants & $\begin{array}{l}159 \text { nursing home residents, } 62 \text { to } 100 \text { years old (100 treated and 59 controls, all included in the analy- } \\
\text { sis); most of the residents were chronically ill; risk status did not differ between vaccinees and unvacci- } \\
\text { nated. }\end{array}$ \\
\hline Interventions & $\begin{array}{l}\text { Parenteral influenza vaccine: A/Brazil; A/Bangkok; B/Singapore. Vaccine strains matched circulating } \\
\text { strains. }\end{array}$ \\
\hline Outcomes & $\begin{array}{l}\text { Clinically defined ILI (2 case definitions; more specific definition was used: fever + cough or chest con- } \\
\text { gestion), pneumonia without further specification, and case-fatality rate }\end{array}$ \\
\hline Notes & $\begin{array}{l}\text { Vaccination was not offered to staff. 36\% of the observed deaths during the epidemic period occurred } \\
\text { from causes other than flu. Circulating strains: A/Taiwan/1/79-like, very similar to the vaccine strain A/ } \\
\text { Bangkok. Isolation attempts for other pathogens were unsuccessful. }\end{array}$ \\
\hline Risk of bias & $\begin{array}{l}\text { Authors' judgement Support for judgement } \\
\text { Bias }\end{array}$ \\
\hline $\begin{array}{l}\text { Allocation concealment } \\
\text { Unclear risk } \quad \text { B - Unclear }\end{array}$ \\
\hline
\end{tabular}

Howarth 1987a

\section{Study characteristics}

\begin{tabular}{ll}
\hline Methods & $\begin{array}{l}\text { Prospective cohort study conducted in Australia in } 17 \text { nursing homes during the } 1983 \text { influenza season. } \\
\text { Follow-up period was autumn to spring; blinded assessment of illness was performed. }\end{array}$ \\
\hline Participants & $\begin{array}{l}326 \text { residents in } 17 \text { nursing homes (229 treated and } 97 \text { controls, all included in the analysis), } 44 \text { to } 99 \\
\text { years old }\end{array}$ \\
\hline Interventions & $\begin{array}{l}\text { Parenteral influenza vaccine: A/Victoria/186/82; A/Philippines/2/82; B/Singapore/222/79. Vaccine } \\
\text { strains matched circulating strains. }\end{array}$ \\
\hline Outcomes & Laboratory-confirmed influenza (4-fold increase in antibody titre) \\
\hline Notes & $\begin{array}{l}\text { Poor description of methods; part of another study. The circulating strain was A/Philippines/2/82. No } \\
\text { information about flu activity }\end{array}$ \\
\hline
\end{tabular}


Howarth 1987a (Continued)

\section{Risk of bias}

\begin{tabular}{lll}
\hline Bias & Authors' judgement & Support for judgement \\
\hline $\begin{array}{l}\text { Allocation concealment } \\
\text { (selection bias) }\end{array}$ & Unclear risk & B - Unclear \\
\hline
\end{tabular}

Howarth 1987b

\section{Study characteristics}

\begin{tabular}{|c|c|c|}
\hline Methods & \multicolumn{2}{|c|}{$\begin{array}{l}\text { Prospective cohort study conducted in Australia in } 17 \text { nursing homes during the } 1984 \text { influenza season } \\
\text { Follow-up period was autumn to spring; blinded assessment of illness was performed. }\end{array}$} \\
\hline Interventions & \multicolumn{2}{|c|}{$\begin{array}{l}\text { Parenteral influenza vaccine: A/Dunedin/27/83; A/Philippines/2/82; B/Singapore/222/80. Vaccine } \\
\text { strains matched circulating strains. }\end{array}$} \\
\hline Outcomes & \multicolumn{2}{|c|}{ Laboratory-confirmed influenza (4-fold increase in antibody titre) } \\
\hline Notes & \multicolumn{2}{|c|}{$\begin{array}{l}\text { Poor description of methods; part of another study. The circulating strain was A/Philippines/2/82. No } \\
\text { information about flu activity }\end{array}$} \\
\hline Bias & Authors' judgement & Support for judgement \\
\hline $\begin{array}{l}\text { Allocation concealment } \\
\text { (selection bias) }\end{array}$ & Unclear risk & B - Unclear \\
\hline
\end{tabular}

Howells 1975a

\section{Study characteristics}

\begin{tabular}{ll}
\hline Methods & $\begin{array}{l}\text { Prospective cohort study conducted in the UK in several nursing homes during the } 1971 \text { to } 1972 \text { in- } \\
\text { fluenza season; all residents were under constant surveillance. Throat swab and paired sera specimens } \\
\text { were obtained whenever possible. }\end{array}$ \\
\hline Participants & $\begin{array}{l}490 \text { nursing homes residents (134 treated and } 356 \text { controls, all included in the analysis), } 60 \text { years or old- } \\
\text { er }\end{array}$ \\
\hline Interventions & $\begin{array}{l}\text { Parenteral influenza vaccine: A2/HK/68; B/Vic.98926/70. Matching between vaccine and circulating } \\
\text { strains is unknown. }\end{array}$ \\
\hline Outcomes & Respiratory illness and pneumonia without definition, deaths from pneumonia \\
\hline Notes & $\begin{array}{l}\text { Very poor description of methods; groups were roughly comparable as age and general health. No in- } \\
\text { formation about flu activity and laboratory confirmation }\end{array}$
\end{tabular}

\section{Risk of bias}


Howells 1975a (Continued)

\begin{tabular}{lll} 
Bias & Authors' judgement & Support for judgement \\
\hline $\begin{array}{l}\text { Allocation concealment } \\
\text { (selection bias) }\end{array}$ & Unclear risk & D - Not used \\
\hline
\end{tabular}

Howells 1975b

\section{Study characteristics}

\begin{tabular}{|c|c|c|}
\hline Methods & \multicolumn{2}{|c|}{$\begin{array}{l}\text { Prospective cohort study conducted in the UK in several nursing homes during the } 1972 \text { to } 1973 \text { in- } \\
\text { fluenza season; all residents were under constant surveillance. Throat swab and paired sera specimens } \\
\text { were obtained whenever possible. }\end{array}$} \\
\hline Participants & \multicolumn{2}{|c|}{$\begin{array}{l}390 \text { nursing homes residents ( } 123 \text { treated and } 267 \text { controls, all included in the analysis), } 60 \text { years or old- } \\
\text { er }\end{array}$} \\
\hline Interventions & \multicolumn{2}{|c|}{$\begin{array}{l}\text { Parenteral influenza vaccine: A2/HK/68; B/Vic.98926/71. Matching between vaccine and circulating } \\
\text { strains is unknown. }\end{array}$} \\
\hline Outcomes & \multicolumn{2}{|c|}{ Respiratory illness and pneumonia without definition, deaths from pneumonia } \\
\hline Notes & \multicolumn{2}{|c|}{$\begin{array}{l}\text { Very poor description of methods; groups were roughly comparable as age and general health. No in- } \\
\text { formation about flu activity and laboratory confirmation }\end{array}$} \\
\hline \multicolumn{3}{|l|}{ Risk of bias } \\
\hline Bias & Authors' judgement & Support for judgement \\
\hline $\begin{array}{l}\text { Allocation concealment } \\
\text { (selection bias) }\end{array}$ & Unclear risk & D - Not used \\
\hline
\end{tabular}

Howells $1975 \mathrm{c}$

\section{Study characteristics}

\begin{tabular}{ll}
\hline Methods & $\begin{array}{l}\text { Prospective cohort study conducted in the UK in several nursing homes during the } 1973 \text { to } 1974 \text { in- } \\
\text { fluenza season; all residents were under constant surveillance. Throat swab and paired sera specimens } \\
\text { were obtained whenever possible. }\end{array}$ \\
\hline $\begin{array}{l}470 \text { nursing homes residents (183 treated and } 287 \text { controls, all included in the analysis), } 60 \text { years or old- } \\
\text { er }\end{array}$ \\
\hline $\begin{array}{l}\text { Participants } \\
\text { cine and circulating strains is unknown. }\end{array}$ \\
\hline Outcomes & Respiratory illness and pneumonia without definition, deaths from pneumonia \\
\hline Notes & $\begin{array}{l}\text { Very poor description of methods; groups were roughly comparable as age and general health. No in- } \\
\text { formation about flu activity and laboratory confirmation }\end{array}$ \\
\hline
\end{tabular}

\section{Risk of bias}


Howells 1975c (Continued)

\begin{tabular}{lll} 
Bias & Authors' judgement & Support for judgement \\
\hline $\begin{array}{l}\text { Allocation concealment } \\
\text { (selection bias) }\end{array}$ & Unclear risk & D - Not used \\
\hline
\end{tabular}

Isaacs 1997

\section{Study characteristics}

\begin{tabular}{ll}
\hline Methods & $\begin{array}{l}\text { Authors investigated an outbreak in a nursing home in Ontario, Canada during the } 1996 \text { to } 1997 \text { in- } \\
\text { fluenza season. Follow-up period was } 1 \text { January } 1997 \text { to } 11 \text { January 1997. Nasal swabs were obtained } \\
\text { from } 3 \text { ill residents. }\end{array}$ \\
\hline Participants & 172 nursing home residents (149 treated and 23 controls, all included in the analysis) \\
\hline Interventions & Parenteral influenza vaccine. Vaccine strains probably matched circulating strains (other studies). \\
\hline Outcomes & $\begin{array}{l}\text { Clinically defined ILI (fever } 38^{\circ} \mathrm{C} \text { or greater, cough, sore throat, nasal congestion, muscle ache, lethargy, } \\
\text { lasting } 2 \text { days or more) }\end{array}$ \\
\hline Notes & Amantadine was used in all residents. 1 positive result was obtained by rapid testing. Poor reporting \\
\hline Risk of bias & Authors' judgement Support for judgement \\
\hline Bias & High risk C - Inadequate \\
\hline $\begin{array}{l}\text { Allocation concealment } \\
\text { (selection bias) }\end{array}$ & \\
\hline
\end{tabular}

Jordan 2007

\section{Study characteristics}

\begin{tabular}{|c|c|}
\hline Methods & $\begin{array}{l}\text { Case-control study nested within a cohort of older people registered with } 79 \text { participating general prac- } \\
\text { tices in central England. People were included in the identified cohort if aged } 65 \text { to } 89 \text { years and if they } \\
\text { consulted their general practitioner (or other emergency medical services) for an acute episode of res- } \\
\text { piratory infection or acute exacerbation of pre-existing respiratory disease, between } 1 \text { October } 2003 \\
\text { and } 31 \text { March 2004. People with simple upper respiratory tract infections were excluded. }\end{array}$ \\
\hline
\end{tabular}

Participants Cases were defined as all people admitted to hospital with acute respiratory disease. Only the first admission during the study period was included. Surviving cases were invited for interview.

Controls were defined as people presenting with acute respiratory disease but who were managed in the community. 6 controls were invited per case to mitigate for a potential low uptake, in order to achieve 4 controls interviewed per case. Controls were matched to cases for age (within \pm 5 years where possible), sex, and consultation date (within \pm 7 days where possible).

3970 eligible participants were identified. 500 participants were admitted to hospital. Altogether $44.1 \%$ of invited cases and $54.5 \%$ of controls agreed to interview; 157 cases and 639 controls were finally interviewed. The proportion of cases vaccinated against influenza before entry to the study was $74.5 \%$ and in controls was $74.2 \%$.

Interventions Influenza vaccination and admissions to hospital for acute respiratory disease


Jordan 2007 (Continued)

Outcomes

\section{Notes}

The authors conclude that in a winter typical of the current levels of circulating influenza, they were unable to demonstrate that influenza vaccination had a specific effect on preventing hospitalisation among elderly people clinically ill with acute respiratory disease, although there was a possible effect during the peak weeks of influenza activity. Relying solely on the influenza vaccine to control the annual winter bed pressures in hospitals is unlikely to be a sufficiently effective yearly strategy, and continuing attention to other factors (e.g. the effective vaccination of healthcare workers, treatment of comorbidities, indoor housing conditions) is essential.

Kaplan 1982

\section{Study characteristics}

\begin{tabular}{|c|c|c|}
\hline Methods & \multicolumn{2}{|c|}{$\begin{array}{l}\text { Surveillance population-based study conducted in the USA during the } 1979 \text { to } 1980 \text { and } 1980 \text { to } 1981 \\
\text { influenza seasons. Case report for each case was obtained from neurologists. All case reports were in- } \\
\text { cluded. Follow-up period was } 1 \text { September } 1979 \text { to } 31 \text { March } 1980 \text { and } 1 \text { September } 1980 \text { to } 31 \text { March } \\
\text { 1981. }\end{array}$} \\
\hline Participants & \multicolumn{2}{|c|}{ USA (minus Maryland) adult population, 18 years or older } \\
\hline Interventions & \multicolumn{2}{|c|}{ Seasonal trivalent vaccine } \\
\hline Outcomes & \multicolumn{2}{|c|}{$\begin{array}{l}\text { Cases of Guillain-Barré syndrome. Vaccine-associated cases were defined as those with onset within } \\
\text { the 8-week period after influenza vaccination. }\end{array}$} \\
\hline Notes & \multicolumn{2}{|c|}{ Vaccination rates in population were obtained from national immunisation survey. } \\
\hline \multicolumn{3}{|l|}{ Risk of bias } \\
\hline Bias & Authors' judgement & Support for judgement \\
\hline $\begin{array}{l}\text { Allocation concealment } \\
\text { (selection bias) }\end{array}$ & Unclear risk & D - Not used \\
\hline
\end{tabular}

\section{Kawai 2003}

\section{Study characteristics}

\begin{tabular}{ll}
\hline Methods & $\begin{array}{l}\text { Prospective cohort study conducted in Japan during the } 2001 \text { to } 2002 \text { period in the community. Data } \\
\text { sources were the general practitioner database and self administered questionnaire. Follow-up period } \\
\text { was } 31 \text { December } 2001 \text { to } 31 \text { May } 2002 . \text { Unvaccinated participants were matched as closely as possible } \\
\text { for sex and age to the vaccinated participants. Laboratory confirmation was performed in } 60 \% \text { of cases. }\end{array}$ \\
\hline Participants & $\begin{array}{l}4423 \text { mostly community-dwelling ( } 3520 \text { treated and } 903 \text { controls were included in the analysis), } 65 \text { to } \\
104 \text { years old }\end{array}$ \\
\hline Interventions & $\begin{array}{l}\text { Parenteral influenza vaccine: A/New Caledonia/20/99; A/Panama/2007/99; B/Johannesburg/5/99. Vac- } \\
\text { cine strains matched the circulating strain. }\end{array}$ \\
\hline Outcomes & Clinically defined ILI (all of the following symptoms: sudden onset, fever $38^{\circ} \mathrm{C}$ or more, cough) \\
\hline Notes & The influenza season was mild. The study controls for age, sex, and previous vaccinations in analysis. \\
\hline \hline
\end{tabular}


Kawai 2003 (Continued)

Risk of bias

\begin{tabular}{lll}
\hline Bias & Authors' judgement & Support for judgement \\
\hline $\begin{array}{l}\text { Allocation concealment } \\
\text { (selection bias) }\end{array}$ & Unclear risk & B - Unclear \\
\hline
\end{tabular}

Keitel 1996

\section{Study characteristics}

\begin{tabular}{|c|c|c|}
\hline Methods & \multicolumn{2}{|c|}{$\begin{array}{l}\text { Experimental study conducted in Texas, USA during the } 1994 \text { to } 1995 \text { influenza season, randomised, } \\
\text { placebo-controlled trial; randomisation method and allocation concealment were not described. Par- } \\
\text { ticipants were allocated to receive ascending doses ( } 15 \text { ug/45 ug/135 ug) of antigen. Only } 15 \text { ug vaccine } \\
\text { was included in analysis. Follow-up period was } 48 \text { hours after vaccination. }\end{array}$} \\
\hline Participants & \multicolumn{2}{|c|}{21 ambulatory, medically stable people, 65 years or older } \\
\hline Outcomes & \multicolumn{2}{|c|}{ Discomfort, erythema/induration, headache, malaise without further description } \\
\hline Notes & \multicolumn{2}{|c|}{ Different vaccines (haemagglutinin and subvirion) were analysed as a single "treatment group". } \\
\hline Bias & Authors' judgement & Support for judgement \\
\hline $\begin{array}{l}\text { Allocation concealment } \\
\text { (selection bias) }\end{array}$ & Unclear risk & D - Not used \\
\hline
\end{tabular}

Lasky 1998

\section{Study characteristics}

\begin{tabular}{ll}
\hline Methods & $\begin{array}{l}\text { Surveillance population-based study conducted in the USA (4 states: Illinois, Maryland, North Carolina, } \\
\text { Washington) during the } 1992 \text { to } 1993 \text { and } 1993 \text { to } 1994 \text { influenza seasons. Discharge diagnoses data- } \\
\text { base was used to identify cases. Hospital charts were reviewed to confirm diagnosis. Follow-up period } \\
\text { was } 1 \text { September } 1992 \text { to } 28 \text { February } 1993 \text { and } 1 \text { September } 1993 \text { to } 28 \text { February } 1994 .\end{array}$
\end{tabular}

\begin{tabular}{ll}
\hline Participants & About 21 million people, 18 years or older \\
\hline Interventions & Seasonal trivalent vaccine \\
\hline Outcomes & $\begin{array}{l}\text { Cases of Guillain-Barré syndrome. Vaccine-associated cases were defined a priori as those with onset } \\
\text { within the 6-week period after influenza vaccination. }\end{array}$ \\
\hline Notes & $\begin{array}{l}\text { Results were stratified by age and adjusted by season and sex. Vaccination rates in population were es- } \\
\text { timated from a random-digit dialling telephone survey. }\end{array}$
\end{tabular}

\section{Risk of bias}


Lasky 1998 (Continued)

\begin{tabular}{lll} 
Bias & Authors' judgement & Support for judgement \\
\hline $\begin{array}{l}\text { Allocation concealment } \\
\text { (selection bias) }\end{array}$ & Unclear risk & D - Not used \\
\hline
\end{tabular}

Leung 2007

\section{Study characteristics}

Retrospective cohort study conducted in 46 elderly homes in Hong Kong, China to assess the effective-
ness of influenza vaccination on influenza, pneumonia, hospitalisation for influenza, and death. Peo-
ple were eligible if they were age 65 years or above. The exposed group comprised people who had not
received influenza vaccination, while the control group comprised people who had received influen-
za vaccination from the Department of Health or other healthcare providers in 2004. Information re-
garding vaccination was based on its documentation in the elderly home records. A resident having un-
known history of influenza vaccination in the preceding calendar year was regarded as not being vacci-
nated. A standardised questionnaire was used to collect data from the elderly homes once an influen-
za outbreak was defined in the elderly home. The occurrence of influenza was identified by the self ad-
ministered questionnaires. The occurrence of pneumonia, hospitalisation, and death were identified
from the hospital records.

\begin{tabular}{ll}
\hline Participants & $\begin{array}{l}3177 \text { residents participated in the study. The mean age was } 83 \text { years; } 2133 \text { were females and } 1044 \\
\text { males. There were } 2943 \text { vaccinated }(92.6 \%) \text { and } 234(7.4 \%) \text { unvaccinated participants. More females } \\
\text { were vaccinated }(67.7 \%) \text { than males }(59.8 \%) .\end{array}$ \\
\hline Interventions & Influenza vaccination versus no vaccination \\
\hline Outcomes & Influenza, pneumonia, hospitalisation, and death \\
\hline Notes & $\begin{array}{l}\text { The authors conclude that this study failed to demonstrate a protective effect of influenza vaccine } \\
\text { against influenza and its complications during outbreaks. }\end{array}$ \\
\hline
\end{tabular}

Lopez Hernandez 1994

\section{Study characteristics}

\begin{tabular}{ll}
\hline Methods & $\begin{array}{l}\text { Retrospective cohort study conducted in Spain during the } 1991 \text { to } 1992 \text { influenza season, in the com- } \\
\text { munity. Data sources were: the health centre register, death certificate archives, hospital records. Fol- } \\
\text { low-up period was } 7 \text { months after vaccination. People were excluded if they did not approach the cen- } \\
\text { tre in the last 3 years. }\end{array}$ \\
\hline Participants & $\begin{array}{l}1965 \text { community-dwelling elderly enrolled in a health centre (779 treated and } 1186 \text { controls, all includ- } \\
\text { ed in the analysis), } 65 \text { years or older, mean age } 73.5 \text { years }\end{array}$ \\
\hline Interventions & Parenteral influenza vaccine. Vaccine strains probably matched the circulating strain. \\
\hline Outcomes & $\begin{array}{l}\text { Hospitalisation from cardio-respiratory causes, death from all causes. Only deaths from all causes are } \\
\text { included in analysis. }\end{array}$ \\
\hline Notes & $\begin{array}{l}\text { The study controls for confounders in analysis (age, health status, home care). The season had low epi- } \\
\text { demic levels. }\end{array}$ \\
\hline
\end{tabular}

\section{Risk of bias}


Lopez Hernandez 1994 (Continued)

\begin{tabular}{lll} 
Bias & Authors' judgement & Support for judgement \\
\hline $\begin{array}{l}\text { Allocation concealment } \\
\text { (selection bias) }\end{array}$ & Unclear risk & B - Unclear \\
\hline
\end{tabular}

Mangtani 2004a

\section{Study characteristics}

\begin{tabular}{ll}
\hline Methods & $\begin{array}{l}\text { Retrospective cohort study conducted in the UK during the } 1990 \text { to } 1998 \text { influenza season, in the com- } \\
\text { munity. Data source was a managed care organisation database. Follow-up period was the epidemic } \\
\text { period (period with consultation rate for ILI more than 50/100,000 person-weeks). People were iden- } \\
\text { tified and included in the study if they were registered on the first day of the week that included } 1 \\
\text { September each year. }\end{array}$ \\
\hline Participants & $\begin{array}{l}\text { 692,819 person-years in vaccine recipients and 1,534,280 person-years in vaccine non-recipients, } 65 \\
\text { years or older }\end{array}$ \\
\hline Interventions & Parenteral influenza vaccine \\
\hline Outcomes & Hospitalisation for acute respiratory illness (ICD 466, 480-487), respiratory-related deaths \\
\hline Notes & $\begin{array}{l}\text { Most of the seasons were epidemic, with vaccine strains matching the circulating strains. Data were } \\
\text { presented by health status; other strata: year, flu activity, age. Data by health status were extracted by } \\
\text { rates reported in tables. }\end{array}$ \\
\hline Risk of bias & Authors' judgement Support for judgement \\
\hline Bias & $\begin{array}{l}\text { Low risk Adequate } \\
\text { (selection bias) }\end{array}$ \\
\hline
\end{tabular}

Mangtani 2004b

\section{Study characteristics}

\begin{tabular}{ll}
\hline Methods & See Mangtani 2004a. Influenza season 1990 to 1991 \\
\hline Participants & See Mangtani 2004a \\
\hline Interventions & See Mangtani 2004a. Vaccine matched the epidemic strain. \\
\hline Outcomes & See Mangtani 2004a \\
\hline Notes & See Mangtani 2004a. Epidemic year \\
\hline Risk of bias & \\
\hline Bias & Authors' judgement Support for judgement \\
\hline
\end{tabular}


Mangtani 2004b (Continued)

\begin{tabular}{l} 
Allocation concealment $\begin{array}{l}\text { Low risk } \\
\text { (selection bias) }\end{array}$ \\
\hline
\end{tabular}

(selection bias)

Mangtani 2004c

\section{Study characteristics}

\begin{tabular}{ll}
\hline Methods & See Mangtani 2004a. Influenza season 1991 to 1992 \\
\hline Participants & See Mangtani 2004a \\
\hline Interventions & See Mangtani 2004a. Vaccine matched the epidemic strain. \\
\hline Outcomes & See Mangtani 2004a \\
\hline Notes & See Mangtani 2004a. Epidemic year \\
\hline Risk of bias & Authors' judgement Support for judgement \\
\hline Bias & Low risk $\quad$ A - Adequate \\
\hline $\begin{array}{l}\text { Allocation concealment } \\
\text { (selection bias) }\end{array}$ & \\
\hline
\end{tabular}

Mangtani 2004d

\section{Study characteristics}

\begin{tabular}{ll}
\hline Methods & See Mangtani 2004a. Influenza season 1992 to 1993 \\
\hline Participants & See Mangtani 2004a \\
\hline Interventions & See Mangtani 2004a. Vaccine matched the epidemic strain. \\
\hline Outcomes & See Mangtani 2004a \\
\hline Notes & See Mangtani 2004a. Non-epidemic year \\
\hline Risk of bias & Authors' judgement Support for judgement \\
\hline Bias & Low risk $\quad$ A - Adequate \\
\hline $\begin{array}{l}\text { Allocation concealment } \\
\text { (selection bias) }\end{array}$ & \\
\hline
\end{tabular}

Mangtani 2004e

\section{Study characteristics}

Methods See Mangtani 2004a. Influenza season 1993 to 1994


Mangtani 2004e (Continued)

\begin{tabular}{ll} 
Participants & See Mangtani 2004a \\
\hline Interventions & See Mangtani 2004a. Vaccine matched the epidemic strain. \\
\hline Outcomes & See Mangtani 2004a \\
\hline Notes & See Mangtani 2004a. Epidemic year
\end{tabular}

\section{Risk of bias}

\begin{tabular}{lll}
\hline Bias & Authors' judgement & Support for judgement \\
\hline $\begin{array}{l}\text { Allocation concealment } \\
\text { (selection bias) }\end{array}$ & Low risk & A - Adequate \\
\hline
\end{tabular}

Mangtani 2004f

\section{Study characteristics}

\begin{tabular}{|c|c|}
\hline Methods & See Mangtani 2004a. Influenza season 1994 to 1995 \\
\hline Participants & See Mangtani 2004a \\
\hline Interventions & See Mangtani 2004a. Vaccine matched the epidemic strain. \\
\hline Outcomes & See Mangtani $2004 a$ \\
\hline Notes & See Mangtani 2004a. Non-epidemic year \\
\hline \multicolumn{2}{|l|}{ Risk of bias } \\
\hline Bias & Authors' judgement Support for judgement \\
\hline $\begin{array}{l}\text { Allocation concealment } \\
\text { (selection bias) }\end{array}$ & A - Adequate \\
\hline
\end{tabular}

Mangtani $2004 \mathrm{~g}$

\section{Study characteristics}

\begin{tabular}{ll}
\hline Methods & See Mangtani 2004a. Influenza season 1995 to 1996 \\
\hline Participants & See Mangtani 2004a \\
\hline Interventions & See Mangtani 2004a. Vaccine matched the epidemic strain. \\
\hline Outcomes & See Mangtani 2004a \\
\hline Notes & See Mangtani 2004a. Epidemic year \\
\hline
\end{tabular}

\section{Risk of bias}


Mangtani 2004g (Continued)

\begin{tabular}{lll} 
Bias & Authors' judgement & Support for judgement \\
\hline $\begin{array}{l}\text { Allocation concealment } \\
\text { (selection bias) }\end{array}$ & Low risk & A-Adequate \\
\hline
\end{tabular}

\section{Mangtani 2004h}

\section{Study characteristics}

\begin{tabular}{|c|c|c|}
\hline Methods & \multicolumn{2}{|c|}{ See Mangtani 2004a. Influenza season 1996 to 1997} \\
\hline Participants & \multicolumn{2}{|l|}{ See Mangtani 2004a } \\
\hline Interventions & \multicolumn{2}{|c|}{ See Mangtani 2004a. Vaccine matched the epidemic strain. } \\
\hline Outcomes & \multicolumn{2}{|l|}{ See Mangtani 2004a } \\
\hline Notes & \multicolumn{2}{|c|}{ See Mangtani 2004a. Epidemic year } \\
\hline \multicolumn{3}{|l|}{ Risk of bias } \\
\hline Bias & Authors' judgement & Support for judgement \\
\hline $\begin{array}{l}\text { Allocation concealment } \\
\text { (selection bias) }\end{array}$ & Low risk & A - Adequate \\
\hline
\end{tabular}

\section{Mangtani 2004i \\ Study characteristics}

\begin{tabular}{ll}
\hline Methods & See Mangtani 2004a. Influenza season 1997 to 1998 \\
\hline Participants & See Mangtani 2004a \\
\hline Interventions & See Mangtani 2004a. Vaccine did not match the epidemic strain. \\
\hline Outcomes & See Mangtani 2004a \\
\hline Notes & See Mangtani 2004a. Non-epidemic year \\
\hline Risk of bias & Authors' judgement Support for judgement \\
\hline Bias & Low risk $\quad$ A - Adequate \\
\hline $\begin{array}{l}\text { Allocation concealment } \\
\text { (selection bias) }\end{array}$ & \\
\hline
\end{tabular}

\section{Study characteristics}

Vaccines for preventing influenza in the elderly (Review) 
Mangtani 2004j (Continued)

\begin{tabular}{ll} 
Methods & See Mangtani 2004a. Influenza season 1998 to 1999 \\
\hline Participants & See Mangtani 2004a \\
\hline Interventions & See Mangtani 2004a. Vaccine matched the epidemic strain. \\
\hline Outcomes & See Mangtani 2004a \\
\hline Notes & See Mangtani 2004a. Epidemic year
\end{tabular}

\section{Risk of bias}

\begin{tabular}{lll}
\hline Bias & Authors' judgement & Support for judgement \\
\hline $\begin{array}{l}\text { Allocation concealment } \\
\text { (selection bias) }\end{array}$ & Low risk & A-Adequate \\
\hline
\end{tabular}

Margolis 1990a

\section{Study characteristics}

\begin{tabular}{ll}
\hline Methods & $\begin{array}{l}\text { Experimental study conducted in Minneapolis, USA during the } 1988 \text { to } 1989 \text { influenza season, ran- } \\
\text { domised, double-blind, placebo-controlled cross-over trial. Follow-up period was } 7 \text { days after vaccina- } \\
\text { tion. Symptoms were assessed by phone interview. }\end{array}$ \\
\hline Participants & 672 outpatients (336 treated and 336 controls were included in the analysis), 65 years or older \\
\hline Interventions & Parenteral influenza recommended vaccine: A/Taiwan/1/86; A/Sichuan/2/87; B/Victoria/2/87 \\
\hline Outcomes & $\begin{array}{l}\text { Cough, coryza, fatigue, malaise, myalgia, headache, nausea, sore arm, disability, feverish without fur- } \\
\text { ther description }\end{array}$ \\
\hline Notes & Placebo was saline injection.
\end{tabular}

\section{Risk of bias}

\begin{tabular}{|c|c|c|}
\hline Bias & Authors' judgement & Support for judgement \\
\hline $\begin{array}{l}\text { Random sequence genera- } \\
\text { tion (selection bias) }\end{array}$ & Unclear risk & Randomisation method described. \\
\hline $\begin{array}{l}\text { Allocation concealment } \\
\text { (selection bias) }\end{array}$ & Unclear risk & Allocation concealment not described. \\
\hline $\begin{array}{l}\text { Blinding (performance } \\
\text { bias and detection bias) } \\
\text { All outcomes }\end{array}$ & Low risk & Probably acceptable since placebo was a saline injection \\
\hline $\begin{array}{l}\text { Incomplete outcome data } \\
\text { (attrition bias) } \\
\text { All outcomes }\end{array}$ & Unclear risk & $\begin{array}{l}\text { Short-term follow-up for most outcomes was by phone, but unclear how com- } \\
\text { plete data were for longer-term outcomes. }\end{array}$ \\
\hline
\end{tabular}


Meiklejohn 1987

\section{Study characteristics}

Methods Authors investigated an outbreak in a nursing home in Wyoming, USA during the 1984 to 1985 influenza season. Follow-up period was 2 January 1985 to 3 March 1985. Throat washing and convalescent sera were obtained from some residents.

\begin{tabular}{ll}
\hline Participants & 55 nursing home residents (36 treated and 19 controls, all included in the analysis), 60 to 98 years old \\
\hline Interventions & $\begin{array}{l}\text { Parenteral influenza vaccine: A/Philippines/82; A/Chile/83; B/USSR/84. Vaccine strains probably } \\
\text { matched circulating strains. }\end{array}$ \\
\hline Outcomes & $\begin{array}{l}\text { Clinically defined URI (upper respiratory illness: fever, chills, myalgia, respiratory symptoms), radiologi- } \\
\text { cally confirmed pneumonia, hospitalisation, and death without further specification }\end{array}$ \\
\hline Notes & $\begin{array}{l}\text { Amantadine was used in cases. The circulating strain that year was of A/Philippines type. No virus strain } \\
\text { was isolated from participants, but serologic tests confirmed influenza A virus infections. Poor descrip- } \\
\text { tion of methods }\end{array}$ \\
\hline
\end{tabular}

\section{Risk of bias}

\begin{tabular}{lll}
\hline Bias & Authors' judgement & Support for judgement \\
\hline $\begin{array}{l}\text { Allocation concealment } \\
\text { (selection bias) }\end{array}$ & High risk & C-Inadequate \\
\hline
\end{tabular}

Monto 2001

\section{Study characteristics}

Prospective cohort study conducted in Michigan, USA during the 1991 to 1992 influenza season. Au-
thors investigated 26 skilled nursing homes with evidence of flu activity; nursing homes with high rates
of immunisation (herd immunity) were excluded from the study; data on ILI or pneumonia were record-
ed prospectively under supervision of a nurse co-ordinator. Follow-up period was 1 November 1991 to
29 February 1992.

\begin{tabular}{ll}
\hline Participants & $\begin{array}{l}2351 \text { residents in } 26 \text { nursing homes (1728 treated and } 623 \text { controls, all included in the analysis), } 65 \\
\text { years or older, for whom vaccination status was known }\end{array}$ \\
\hline Interventions & Parenteral influenza vaccine. Vaccine strains matched circulating strains. \\
\hline Outcomes & $\begin{array}{l}\text { Clinically defined ILI (fever } 37.8^{\circ} \mathrm{C} \text { or greater + cough, sore throat, or nasal congestion), clinical pneu- } \\
\text { monia, deaths occurring within } 3 \text { months of the onset of respiratory illness. Influenza was considered } \\
\text { to have been introduced into a nursing home when a least } 2 \% \text { of residents developed ILI within a } 7 \text {-day } \\
\text { period during community-documented virus circulation or when virus was isolated from cases. }\end{array}$ \\
\hline Notes & $\begin{array}{l}\text { Both influenza A (H3N2) and A (H1N1) co-circulated with influenza A (H3N2) predominantly. The circu- } \\
\text { lating strains were closely related to the vaccine strain. Rate ratio estimates were adjusted by sex, age, } \\
\text { home size and presented by "peak period". Groups were comparable as age and chronic conditions. }\end{array}$ \\
\hline
\end{tabular}

\section{Risk of bias}

\begin{tabular}{lll}
\hline Bias & Authors' judgement & Support for judgement \\
\hline $\begin{array}{l}\text { Allocation concealment } \\
\text { (selection bias) }\end{array}$ & Low risk & A - Adequate \\
\hline
\end{tabular}


Morens 1995

\section{Study characteristics}

\begin{tabular}{ll}
\hline Methods & $\begin{array}{l}\text { Authors investigated an outbreak in a nursing home in Honolulu, USA during the 1989 to 1990 influen- } \\
\text { za season; vaccination records, hospital records, resident records were reviewed. Follow-up period was } \\
\text { 15 December 1989 to 28 January 1990. Specimens for virus isolation were obtained from } 9 \text { ill residents, } \\
\text { and paired sera specimens were obtained from } 34 \text { case and non-case residents. }\end{array}$ \\
\hline Participants & $\begin{array}{l}39 \text { nursing home residents with multiple chronic conditions (36 treated and 3 controls, all included in } \\
\text { the analysis), } 36 \text { to } 102 \text { years (mean age } 80 \text { years) }\end{array}$ \\
\hline Interventions & $\begin{array}{l}\text { Parenteral influenza vaccine; pneumococcal vaccine was also used. Vaccine strains matched circulat- } \\
\text { ing strains. }\end{array}$ \\
\hline Outcomes & $\begin{array}{l}\text { Clinically defined ILI (fever 37.8 }{ }^{\circ} \mathrm{C} \text { or greater + cough, coryza, or sore throat), laboratory-confirmed in- } \\
\text { fluenza, pneumonia, deaths from ILI or pneumonia }\end{array}$ \\
\hline Notes & $\begin{array}{l}\text { Amantadine was administered to all participants over a 1-week period (January 4 to 12, 1990). The cir- } \\
\text { culating strain was indistinguishable from the vaccine strain A/England/4/27/88. Lack of serologic evi- } \\
\text { dence for other respiratory agents }\end{array}$ \\
\hline Risk of bias & $\begin{array}{l}\text { Authors' judgement Support for judgement } \\
\text { Bias }\end{array}$ \\
\hline Allocation concealment & \begin{tabular}{l} 
Unclear risk - Unclear \\
\hline
\end{tabular} \\
\hline
\end{tabular}

Mukerjee 1994

\section{Study characteristics}

\begin{tabular}{|c|c|c|}
\hline Methods & \multicolumn{2}{|c|}{$\begin{array}{l}\text { Authors investigated outbreaks in } 14 \text { nursing homes in Wales, UK during the } 1991 \text { to } 1992 \text { influenza sea- } \\
\text { son. Follow-up period was } 15 \text { December } 1991 \text { to } 28 \text { February 1992. Paired sera specimens were collect- } \\
\text { ed from } 7 \text { cases in } 2 \text { homes. }\end{array}$} \\
\hline Participants & \multicolumn{2}{|c|}{466 residents in 14 nursing homes (104 treated and 362 controls, all included in the analysis) } \\
\hline Interventions & \multicolumn{2}{|c|}{ Parenteral influenza vaccine. Vaccine strains probably matched circulating strains. } \\
\hline Outcomes & \multicolumn{2}{|c|}{ Clinically defined URI (upper respiratory illness: fever, chills, myalgia, cough) } \\
\hline Notes & \multicolumn{2}{|c|}{$\begin{array}{l}\text { Very poor reporting. Vaccine strain was assumed to match the circulating strain according to literature } \\
\text { data. }\end{array}$} \\
\hline \multicolumn{3}{|l|}{ Risk of bias } \\
\hline Bias & Authors' judgement & Support for judgement \\
\hline $\begin{array}{l}\text { Allocation concealment } \\
\text { (selection bias) }\end{array}$ & Unclear risk & D - Not used \\
\hline
\end{tabular}


Mullooly 1994

\section{Study characteristics}

\begin{tabular}{ll}
\hline Methods & $\begin{array}{l}\text { Case-control study conducted in the USA during the } 1981 \text { to } 1989 \text { period, in the community. Data } \\
\text { source was a managed care organisation database. Follow-up period was the epidemic period accord- } \\
\text { ing to surveillance data. Cases were admitted to services with pneumonia or influenza or died in hospi- } \\
\text { tal from pneumonia or influenza; community controls were matched for high-risk status. }\end{array}$ \\
\hline Participants & 251,034 members of a medical care programme, 65 years or older \\
\hline Interventions & $\begin{array}{l}\text { Parenteral influenza vaccine; participants also received pneumococcal vaccination. Vaccine strains } \\
\text { matched the circulating strain. }\end{array}$ \\
\hline Outcomes & $\begin{array}{l}\text { Pneumonia and influenza without hospitalisation, hospitalisation from pneumonia and influenza (ICD } \\
\text { 480-487), hospitalised death }\end{array}$ \\
\hline Notes & $\begin{array}{l}\text { Most of the seasons were epidemic, and vaccine strains did not match the circulating strains. The study } \\
\text { controls for confounders in analysis (age, sex, pneumococcal vaccination). Data are stratified by health } \\
\text { status, but allow only quantitative analysis. The odds ratio adjusted by risk status was obtained by } \\
\text { pooling the data reported in the paper using Wolf method. }\end{array}$
\end{tabular}

\section{Risk of bias}

\begin{tabular}{lll}
\hline Bias & Authors' judgement & Support for judgement \\
\hline $\begin{array}{l}\text { Allocation concealment } \\
\text { (selection bias) }\end{array}$ & Low risk & A - Adequate \\
\hline
\end{tabular}

Murayama 1999

\section{Study characteristics}

Methods

Authors investigated 2 consecutive outbreaks in the same nursing home in Japan during the 1996 to 1997 influenza season; patients' records were reviewed. Follow-up period was 25 December 1996 to 14 January 1997 and 19 February 1997 to 26 February 1997. Throat swab and paired sera specimens were obtained from ill residents.

\begin{tabular}{ll}
\hline Participants & $\begin{array}{l}128 \text { nursing home residents ( } 60 \text { treated and } 68 \text { controls, all included in the analysis), } 70 \text { years or ol } \\
\text { None of the residents was previously vaccinated. }\end{array}$ \\
\hline Interventions & $\begin{array}{l}2 \text { doses of parenteral influenza vaccine: A/Yamagata/32/89; A/Wuhan/359/95; B/Mie/1/93. Vaccine } \\
\text { strains matched circulating strains. }\end{array}$
\end{tabular}

Outcomes ICHPP-2 defined ILI (laboratory evidence or epidemiological criteria or 6 of the following symptoms: sudden onset, fever, cough, prostration, chills, weakness, myalgia, widespread aches), hospitalisations, and deaths without definition

Notes Epidemic reoccurrence of influenza A outbreak was observed. Both outbreaks were investigated; vaccinated and control groups were comparable as age or risk status. The circulating strain was A/ Wuhan/359/95. Amantadine was not used. Other respiratory viruses were not isolated.

\section{Risk of bias}

Bias Authors' judgement Support for judgement


Murayama 1999 (Continued)

\begin{tabular}{l}
$\begin{array}{l}\text { Allocation concealment } \\
\text { (selection bias) }\end{array}$ Low risk Adequate \\
\hline
\end{tabular}

Nichol 1994a

\section{Study characteristics}

\begin{tabular}{ll}
\hline Methods & $\begin{array}{l}\text { Prospective cohort study conducted in Minneapolis, USA during the 1990 to 1991 influenza season, in } \\
\text { the community. Data source was the managed care organisation database. Follow-up period was 1 Oc- } \\
\text { tober } 1990 \text { to 31 March 1991. The rate was adjusted for age, sex, health status, pneumococcal vaccina- } \\
\text { tion. }\end{array}$ \\
\hline Participants & $\begin{array}{l}25,532 \text { members of a medical care programme continuously enrolled for the 1-year period (11,483 } \\
\text { treated and 14,049 controls, all included in the analysis), 65 years or older }\end{array}$ \\
\hline Interventions & $\begin{array}{l}\text { Parenteral influenza vaccine. 3\% of vaccinees and 1\% of unvaccinated received pneumococcal vacci- } \\
\text { nation. Vaccine strains matched the circulating strain. }\end{array}$ \\
\hline Outcomes & $\begin{array}{l}\text { Hospitalisation from pneumonia and influenza (ICD 480-487), hospitalisation from all respiratory con- } \\
\text { ditions (ICD 460, 462, 465-466, 480-487, 490-96, 500-518), hospitalisation from congestive heart failure } \\
\text { (ICD 428), death from all causes (not reported) }\end{array}$ \\
\hline Notes & $\begin{array}{l}\text { The season was an epidemic one. Data were extracted by rates reported in tables. Quantitative analysis } \\
\text { with adjusted rates was not performed because data reported and statistical model used were not ho- } \\
\text { mogeneous to those reported in the other studies. }\end{array}$ \\
\hline Risk of bias & $\begin{array}{l}\text { Allocation concealment } \\
\text { (selection bias) }\end{array}$ \\
\hline Bias & \begin{tabular}{l} 
Unclear risk Support for judgement \\
\hline
\end{tabular} \\
\hline
\end{tabular}

Nichol 1994b

\section{Study characteristics}

\begin{tabular}{ll}
\hline Methods & $\begin{array}{l}\text { Prospective cohort study conducted in Minneapolis, USA during the } 1991 \text { to } 1992 \text { influenza season, in } \\
\text { the community. Data source was the managed care organisation database. Follow-up period was } 1 \text { Oc- } \\
\text { tober } 1991 \text { to } 31 \text { March 1992. The rate was adjusted for age, sex, health status, pneumococcal vaccina- } \\
\text { tion. }\end{array}$ \\
\hline Participants & $\begin{array}{l}26,369 \text { members of a medical care programme continuously enrolled for the 1-year period (15,288 } \\
\text { treated and } 11,081 \text { controls, all included in the analysis), } 65 \text { years or older }\end{array}$ \\
\hline Interventions & $\begin{array}{l}\text { Parenteral influenza vaccine. } 5 \% \text { of vaccinees and } 2 \% \text { of unvaccinated received pneumococcal vacci- } \\
\text { nation. Vaccine strains matched the circulating strain. }\end{array}$ \\
\hline Outcomes & $\begin{array}{l}\text { Hospitalisation from pneumonia and influenza (ICD 480-487), hospitalisation from all respiratory con- } \\
\text { ditions (ICD 460, 462, 465-466, 480-487, 490-496, 500-518), hospitalisation from congestive heart failure } \\
\text { (ICD 428), death from all causes (not reported) }\end{array}$ \\
\hline
\end{tabular}


Nichol 1994b (Continued)

Notes
The season was an epidemic one. Data were extracted by rates reported in tables. Quantitative analysis with adjusted rates was not performed because data reported and statistical model used were not homogeneous to those reported in the other studies.

\section{Risk of bias}

\begin{tabular}{lll}
\hline Bias & Authors' judgement & Support for judgement \\
\hline $\begin{array}{l}\text { Allocation concealment } \\
\text { (selection bias) }\end{array}$ & Unclear risk & B - Unclear \\
\hline
\end{tabular}

\section{Nichol 1994c}

\begin{tabular}{ll}
\hline Study characteristics & $\begin{array}{l}\text { Prospective cohort study conducted in Minneapolis, USA during the } 1992 \text { to } 1993 \text { influenza season, in } \\
\text { the community. Data source was the managed care organisation database. Follow-up period was } 1 \text { Oc- } \\
\text { tober } 1992 \text { to } 31 \text { March 1993. The rate was adjusted for age, sex, health status, pneumococcal vaccina- } \\
\text { tion. }\end{array}$ \\
\hline Participants & $\begin{array}{l}26,626 \text { members of a medical care programme continuously enrolled for the 1-year period (14,647 } \\
\text { treated and 11,979 controls, all included in the analysis), 65 years or older }\end{array}$ \\
\hline Interventions & $\begin{array}{l}\text { Parenteral influenza vaccine. 6\% of vaccinees and 3\% of unvaccinated received pneumococcal vacci- } \\
\text { nation. Vaccine strains did not match the circulating strain. }\end{array}$ \\
\hline Outcomes & $\begin{array}{l}\text { Hospitalisation from pneumonia and influenza (ICD 480-487), hospitalisation from all respiratory con- } \\
\text { ditions (ICD 460, 462, 465-466, 480-487, 490-496, 500-518), hospitalisation from congestive heart failure } \\
\text { (ICD 428), death from all causes (not reported) }\end{array}$ \\
\hline Notes & $\begin{array}{l}\text { The season was an epidemic one. Data were extracted by rates reported in tables. Quantitative analysis } \\
\text { with adjusted rates was not performed because data reported and statistical model used were not ho- } \\
\text { mogeneous to those reported in the other studies. }\end{array}$
\end{tabular}

\section{Risk of bias}

\begin{tabular}{lll}
\hline Bias & Authors' judgement & Support for judgement \\
\hline $\begin{array}{l}\text { Allocation concealment } \\
\text { (selection bias) }\end{array}$ & Unclear risk & B - Unclear \\
\hline
\end{tabular}

\section{Nichol 1998a}

\section{Study characteristics}

Methods $\begin{aligned} & \text { Prospective cohort study conducted in Minneapolis, USA during the } 1990 \text { to } 1995 \text { period, in the com- } \\ & \text { munity. Data source was the managed care organisation database. Follow-up period was } 15 \text { November } \\ & \text { to } 31 \text { February. A subgroup analysis by health status was performed. The rate was adjusted for age, sex, } \\ & \text { health status, vaccination status. }\end{aligned}$

Participants

147,551 members of a medical care programme continuously enrolled for the 1 -year period $(87,898$ treated and 59,653 controls included in the analysis), 64 years or older 
Nichol 1998a (Continued)

Interventions

Parenteral influenza vaccine. $11.3 \%$ of vaccinees and $4.5 \%$ of unvaccinated received pneumococcal vaccination, on average.

Outcomes

Hospitalisation from pneumonia and influenza (ICD 480-487), hospitalisation from all respiratory conditions, hospitalisation from congestive heart failure, death from all causes (deaths were not reported)

\section{Notes}

Most of the seasons were epidemic, with vaccine strains matching the circulating strains. Data were extracted by rates reported in tables. Only data stratified by health status were included in the analysis.

Quantitative analysis was also performed.

\section{Risk of bias}

\begin{tabular}{lll}
\hline Bias & Authors' judgement & Support for judgement \\
\hline $\begin{array}{l}\text { Allocation concealment } \\
\text { (selection bias) }\end{array}$ & Low risk & A - Adequate \\
\hline
\end{tabular}

Nichol 1998b

\section{Study characteristics}

Prospective cohort study conducted in Minneapolis, USA during the 1993 to 1995 period, in the com-
munity. Data source was the managed care organisation database. Follow-up period was 15 November
to 31 March. The rate was adjusted for age, sex, health status, vaccination status.

\begin{tabular}{ll} 
Participants & $\begin{array}{l}69,024 \text { members of a medical care programme continuously enrolled for the 1-year period (46,480 } \\
\text { treated and 22,544 controls included in the analysis), } 65 \text { years or older }\end{array}$ \\
\hline Interventions & $\begin{array}{l}\text { Parenteral influenza vaccine. } 11.3 \% \text { of vaccinees and } 4.5 \% \text { of unvaccinated received pneumococcal } \\
\text { vaccination, on average. }\end{array}$ \\
\hline Outcomes & $\begin{array}{l}\text { Hospitalisation from pneumonia and influenza (ICD 480-487), hospitalisation from all respiratory condi- } \\
\text { tions, hospitalisation from congestive heart failure, death from all causes (deaths were not reported) }\end{array}$ \\
\hline Notes & $\begin{array}{l}\text { All the seasons were epidemic, with vaccine strains matching the circulating strains. Data were extract- } \\
\text { ed by rates reported in tables and calculated by difference with data reported in previous studies. }\end{array}$
\end{tabular}

\section{Risk of bias}

\begin{tabular}{lll}
\hline Bias & Authors' judgement & Support for judgement \\
\hline $\begin{array}{l}\text { Allocation concealment } \\
\text { (selection bias) }\end{array}$ & Unclear risk & B - Unclear \\
\hline
\end{tabular}

Nichol 2003a

\section{Study characteristics}

Methods

Prospective cohort study conducted in the USA, during the 1998 to 1999 influenza season, in the community. Data source was the managed care organisation database. Follow-up period was 15 November to 31 February. The rate was adjusted for age, sex, health status. 
Nichol 2003a (Continued)

Participants

140,055 members of a medical care programme continuously enrolled for the 1-year period $(77,738$ treated and 62,317 controls, all included in the analysis), 65 years or older

\begin{tabular}{ll}
\hline Interventions & Parenteral influenza vaccine. Vaccine strains matched the circulating strain. \\
\hline Outcomes & $\begin{array}{l}\text { Hospitalisation from pneumonia and influenza (ICD 480-487), hospitalisation from cerebrovascular dis- } \\
\text { ease (ICD 431-437), hospitalisation from heart disease (ICD 410-414, 428), death from all causes }\end{array}$
\end{tabular}

Notes The season probably was an epidemic one. Quantitative analysis was also performed.

\section{Risk of bias}

\begin{tabular}{lll}
\hline Bias & Authors' judgement & Support for judgement \\
\hline $\begin{array}{l}\text { Allocation concealment } \\
\text { (selection bias) }\end{array}$ & Unclear risk & B - Unclear \\
\hline
\end{tabular}

Nichol 2003b

\section{Study characteristics}

Methods

Prospective cohort study conducted in the USA during the 1999 to 2000 influenza season, in the community. Data source was the managed care organisation database. Follow-up period was 15 November to 31 March. The rate was adjusted for age, sex, health status.

Participants $\quad 146,328$ members of a medical care programme continuously enrolled for the 1-year period (87,357 treated and 58,971 controls, all included in the analysis), 65 years or older

\begin{tabular}{ll}
\hline Interventions & Parenteral influenza vaccine. Vaccine strains matched the circulating strain. \\
\hline Outcomes & $\begin{array}{l}\text { Hospitalisation from pneumonia and influenza (ICD 480-487), hospitalisation from cerebrovascular dis- } \\
\text { ease (ICD 431-437), hospitalisation from heart disease (ICD 410-414, 428), death from all causes }\end{array}$ \\
\hline
\end{tabular}

Notes The season probably was an epidemic one. Quantitative analysis was also performed.

\section{Risk of bias}

\begin{tabular}{lll}
\hline Bias & Authors' judgement & Support for judgement \\
\hline $\begin{array}{l}\text { Allocation concealment } \\
\text { (selection bias) }\end{array}$ & Unclear risk & B - Unclear \\
\hline
\end{tabular}

Nicholson 1999

\section{Study characteristics}

$\begin{array}{ll}\text { Methods } & \text { Prospective cohort study conducted in Leicester, UK during the } 1993 \text { to } 1994 \text { influenza season, in the } \\ \text { community. Data source was weekly phone interviews. Follow-up period was } 18 \text { October } 1993 \text { to } 19 \text { De- } \\ \text { cember 1993. The sample was randomly selected. Symptomatic participants were checked for labora- } \\ \text { tory confirmation. }\end{array}$


Nicholson 1999 (Continued)

Participants

427 community-dwelling elderly (223 treated and 216 controls; 218 and 209 included in the analysis, respectively), 63 to 89 years old

\begin{tabular}{ll}
\hline Interventions & Parenteral influenza vaccine. Vaccine strains matched the circulating strain. \\
\hline Outcomes & Laboratory-confirmed influenza (4-fold increase in antibody titre) \\
\hline Notes & $\begin{array}{l}\text { The study was conducted throughout an outbreak of influenza. The study controls for age, health sta- } \\
\text { tus, and smoking habits in analysis. Data are presented by smoking habits. }\end{array}$
\end{tabular}

\section{Risk of bias}

\begin{tabular}{lll}
\hline Bias & Authors' judgement & Support for judgement \\
\hline $\begin{array}{l}\text { Allocation concealment } \\
\text { (selection bias) }\end{array}$ & Unclear risk & B - Unclear \\
\hline
\end{tabular}

Nordin 2001a

\section{Study characteristics}

\begin{tabular}{ll}
\hline Methods & $\begin{array}{l}\text { Prospective cohort study conducted in the USA during the 1996 to } 1997 \text { influenza season, in the com- } \\
\text { munity. Data source was a } 3 \text { managed care organisation database. Follow-up period was } 5 \text { October } \\
1996 \text { to } 3 \text { May } 1997 .\end{array}$ \\
\hline Participants & $\begin{array}{l}\text { 122,974 members of a medical care programme continuously enrolled for the 1-year period (71,005 } \\
\text { treated and 51,969 controls, all included in the analysis), } 65 \text { years or older }\end{array}$ \\
\hline Interventions & Parenteral influenza vaccine. Vaccine matched the circulating strain. \\
\hline Outcomes & Hospitalisation from influenza and pneumonia (ICD 480-487), death from all causes \\
\hline Notes & $\begin{array}{l}\text { Identical to Hak 1. Odds ratios adjusted for age, sex, site, health status were presented. Frequencies da- } \\
\text { ta were not available. To perform quantitative analysis adjusted data were used. }\end{array}$ \\
\hline Risk of bias & Authors' judgement Support for judgement \\
\hline Bias & Low risk Adequate \\
\hline $\begin{array}{l}\text { Allocation concealment } \\
\text { (selection bias) }\end{array}$ \\
\hline
\end{tabular}

Nordin 2001b

\section{Study characteristics}

Methods

Prospective cohort study conducted in the USA during the 1997 to 1998 influenza season, in the community. Data source was the managed care organisation database. Follow-up period was 23 November 1997 to 4 April 1998.

Participants

158,454 members of a medical care programme continuously enrolled for the 1-year period (92,001 treated and 66,453 controls, all included in the analysis), 65 years or older 
Nordin 2001b (Continued)

Interventions Parenteral influenza vaccine. Vaccine did not match the circulating strain.

\begin{tabular}{ll}
\hline Outcomes & Hospitalisation from influenza and pneumonia (ICD 480-487), death from all causes \\
\hline Notes & $\begin{array}{l}\text { Identical to Hak 2. Odds ratios adjusted for age, sex, site, health status were presented. Frequencies da- } \\
\text { ta were not available. To perform quantitative analysis adjusted data were used }\end{array}$
\end{tabular}

\section{Risk of bias}

\begin{tabular}{lll}
\hline Bias & Authors' judgement & Support for judgement \\
\hline $\begin{array}{l}\text { Allocation concealment } \\
\text { (selection bias) }\end{array}$ & Low risk & A - Adequate \\
\hline
\end{tabular}

Ohmit 1995a

\section{Study characteristics}

Case-control study conducted in Michigan, USA during the 1990 to 1991 influenza season, in the com-
munity. Data sources were: database discharge diagnoses, mailed questionnaire. Follow-up period was
1 November 1990 to 30 April 1991. Cases were people discharged from hospital with pneumonia or in-
fluenza; community controls were matched for age, sex, and residence.

\begin{tabular}{ll}
\hline Participants & $\begin{array}{l}2197 \text { non-institutionalised elderly (860 cases and } 1828 \text { controls were identified; } 667 \text { and } 1530 \text { were in- } \\
\text { cluded in analysis, respectively), } 65 \text { years or older }\end{array}$ \\
\hline Interventions & $\begin{array}{l}\text { Parenteral influenza vaccine, participants were also offered pneumococcal vaccine. Vaccine strains } \\
\text { matched the circulating strain. }\end{array}$ \\
\hline Outcomes & Hospitalisation from pneumonia and influenza (ICD 480-487) \\
\hline Notes & $\begin{array}{l}41 \% \text { of cases and } 28 \% \text { of controls received pneumococcal vaccination. The season probably had low } \\
\text { epidemic levels. The study controls for confounders in analysis: influenza activity, health status, age, } \\
\text { sex, region. Quantitative analysis was also performed. }\end{array}$
\end{tabular}

\section{Risk of bias}

\begin{tabular}{lll}
\hline Bias & Authors' judgement & Support for judgement \\
\hline $\begin{array}{l}\text { Allocation concealment } \\
\text { (selection bias) }\end{array}$ & Unclear risk & B - Unclear \\
\hline
\end{tabular}

Ohmit 1995b

\section{Study characteristics}

\begin{tabular}{|c|c|}
\hline Methods & $\begin{array}{l}\text { Case-control study conducted in Michigan, USA during the } 1991 \text { to } 1992 \text { influenza season, in the com- } \\
\text { munity. Data sources were: database discharge diagnoses, mailed questionnaire. Follow-up period was } \\
1 \text { November } 1991 \text { to } 30 \text { April 1992. Cases were people discharged from hospital with pneumonia or in- } \\
\text { fluenza; community controls were matched for age, sex, and residence. }\end{array}$ \\
\hline
\end{tabular}

Participants

2761 non-institutionalised elderly (1186 cases and 2345 controls were identified; 890 and 1871 were included in analysis, respectively), 65 years or older 
Ohmit 1995b (Continued)

Interventions Parenteral influenza vaccine, participants were also offered pneumococcal vaccine. Vaccine strains matched the circulating strain.

\begin{tabular}{ll}
\hline Outcomes & Hospitalisation from pneumonia and influenza (ICD 480-487) \\
\hline Notes & $\begin{array}{l}\text { 44\% of cases and } 32 \% \text { of controls received pneumococcal vaccination. The season was probably an } \\
\text { epidemic one. The study controls for confounders in analysis: influenza activity, health status, age, sex, } \\
\text { region. Quantitative analysis was also performed. }\end{array}$
\end{tabular}

\section{Risk of bias}

\begin{tabular}{lll}
\hline Bias & Authors' judgement & Support for judgement \\
\hline $\begin{array}{l}\text { Allocation concealment } \\
\text { (selection bias) }\end{array}$ & Unclear risk & B - Unclear \\
\hline
\end{tabular}

Ohmit 1999

\section{Study characteristics}

\begin{tabular}{ll}
\hline Methods & $\begin{array}{l}\text { Case-control study conducted in Michigan, USA during the } 1989 \text { to } 1990 \text { influenza season, in } 23 \text { nursing } \\
\text { homes. Data sources were: patients specific logs, vaccination records. Follow-up period was the epi- } \\
\text { demic period according to surveillance data. Cases developed ILI during the period of laboratory-con- } \\
\text { firmed community influenza activity; controls resided in the same facility and were matched for age. }\end{array}$ \\
\hline Participants & $\begin{array}{l}1198 \text { residents in } 23 \text { nursing homes that experienced outbreaks or with virus isolation (361 cases and } \\
837 \text { controls, all included in analysis), } 65 \text { years or older }\end{array}$ \\
\hline Interventions & $\begin{array}{l}\text { Parenteral influenza vaccine; } 17 \% \text { of cases and } 17 \% \text { of controls received pneumococcal vaccination. } \\
\text { Vutcomes }\end{array}$ \\
\hline Clinically defined ILI (fever $37.8^{\circ} \mathrm{C}$ or greater and 1 or more of the following: cough, sore throat, coryza)
\end{tabular}

\section{Risk of bias}

\begin{tabular}{lll}
\hline Bias & Authors' judgement & Support for judgement \\
\hline $\begin{array}{l}\text { Allocation concealment } \\
\text { (selection bias) }\end{array}$ & Low risk & A - Adequate \\
\hline
\end{tabular}

Patriarca 1985a

\section{Study characteristics}

Methods

\begin{abstract}
Retrospective cohort study conducted in Michigan, USA during the 1982 to 1983 influenza season. Authors investigated 7 nursing homes with evidence of flu activity. Throat swab and paired sera specimens were obtained from some residents; medical records. Follow-up period was 10 December 1982 to 4 March 1983.
\end{abstract}


Patriarca 1985a (Continued)

Participants

1018 residents in 7 nursing homes with outbreak ( 548 treated and 470 controls, all included in the analysis)

Interventions

Parenteral influenza vaccine: A/Bangkok/79; A/Brazil/78; B/Singapore/79. Vaccine strains probably matched circulating strains.

\section{Outcomes}

Clinically defined ILI (fever $37.8^{\circ} \mathrm{C}$ or greater + cough, coryza, or sore throat), X-ray-confirmed pneumonia, hospitalisation for ILI, deaths occurring within 2 weeks of onset of ILI. An outbreak was defined by a number of ILI per week that exceeded $10 \%$ of the residents.

Notes

Cohorts were comparable as age and level of nursing care. Amantadine was not used. The circulating strain was A/Bangkok/1/79-like. Laboratory confirmation of influenza A infection was obtained in 3 homes.

\section{Risk of bias}

\begin{tabular}{lll}
\hline Bias & Authors' judgement & Support for judgement \\
\hline $\begin{array}{l}\text { Allocation concealment } \\
\text { (selection bias) }\end{array}$ & Low risk & A - Adequate \\
\hline
\end{tabular}

\section{Patriarca 1985b}

\section{Study characteristics}

\begin{tabular}{ll}
\hline Methods & $\begin{array}{l}\text { Retrospective cohort study conducted in Michigan, USA during the } 1982 \text { to } 1983 \text { influenza season, in } 6 \\
\text { nursing homes. Throat swab and paired sera specimens were obtained from some residents; medical } \\
\text { records were reviewed. Follow-up period was } 10 \text { December } 1982 \text { to } 4 \text { March } 1983 .\end{array}$
\end{tabular}

\begin{tabular}{|c|c|}
\hline Participants & $\begin{array}{l}458 \text { residents in } 6 \text { nursing homes without outbreak ( } 339 \text { treated and } 119 \text { controls, all included in the } \\
\text { analysis) }\end{array}$ \\
\hline Interventions & $\begin{array}{l}\text { Parenteral influenza vaccine: A/Bangkok/79; A/Brazil/78; B/Singapore/79. Vaccine strains matched cir- } \\
\text { culating strains. }\end{array}$ \\
\hline Outcomes & $\begin{array}{l}\text { Clinically defined ILI (fever } 37.8^{\circ} \mathrm{C} \text { or greater + cough, coryza, or sore throat), deaths occurring within } 2 \\
\text { weeks of onset of ILI }\end{array}$ \\
\hline Notes & $\begin{array}{l}\text { Cohorts were comparable as age and level of nursing care. Amantadine was not used. The circulating } \\
\text { strain in the community was A/Bangkok/1/79-like, but laboratory confirmation was not available in the } \\
\text { homes. }\end{array}$ \\
\hline
\end{tabular}

\section{Risk of bias}

\begin{tabular}{lll}
\hline Bias & Authors' judgement & Support for judgement \\
\hline $\begin{array}{l}\text { Allocation concealment } \\
\text { (selection bias) }\end{array}$ & Low risk & A - Adequate \\
\hline
\end{tabular}

\section{Study characteristics}


Pregliasco 2002 (Continued)

Methods

Prospective cohort study conducted in Milan, Italy during the 2000 to 2001 influenza season, in the community. Data sources were: monthly phone interviews and self administered questionnaires. Follow-up period was 30 November 2000 to 31 March 2001. Participants $\begin{aligned} & 363 \text { community-dwelling elderly (264 treated and } 99 \text { controls; } 184 \text { and } 79 \text { included in the analysis, re- } \\ & \text { spectively), mean age } 75 \text { years }\end{aligned}$

\begin{tabular}{ll}
\hline Interventions & Adjuvant virosomal vaccine. Vaccine strains probably matched the circulating strain. \\
\hline Outcomes & Clinically defined ILI (fever + at least 1 systemic symptom: headache, myalgia, chills, weakness + at \\
& least 1 respiratory symptom: cough, sore throat, congestion); acute respiratory infection (respiratory \\
& symptoms without immediate fever); hospitalisation for pulmonary infection
\end{tabular}

Notes

Low viral circulation. Cohorts were not significantly different as comorbidity.

\section{Risk of bias}

\begin{tabular}{lll}
\hline Bias & Authors' judgement & Support for judgement \\
\hline $\begin{array}{l}\text { Allocation concealment } \\
\text { (selection bias) }\end{array}$ & High risk & C-Inadequate \\
\hline
\end{tabular}

Puig-Barberà 1997

\begin{tabular}{ll}
\hline Study characteristics & \\
\hline Methods & $\begin{array}{l}\text { Case-control study conducted in Spain during the } 1994 \text { to } 1995 \text { influenza season, in the community. } \\
\text { Data sources were: hospital emergency logs and records; structured interview. Follow-up period was } \\
15 \text { November } 1994 \text { to } 31 \text { March 1995. Cases were people admitted to hospital for pneumonia; controls } \\
\text { were admitted to hospital in the same week for acute abdominal surgical condition or trauma. }\end{array}$ \\
\hline Participants & $\begin{array}{l}249 \text { non-institutionalised people (94 cases and } 166 \text { controls were identified; } 83 \text { and } 166 \text { were included } \\
\text { in analysis, respectively), } 65 \text { years or older }\end{array}$ \\
\hline Interventions & Parenteral influenza vaccine. Vaccine strains matched the circulating strain. \\
\hline Outcomes & Hospitalisation for pneumonia; pneumonia was clinically defined and radiologically confirmed \\
\hline Notes & $\begin{array}{l}\text { The study controls for confounders in analysis: health status, age, socio-economic factors. The season } \\
\text { probably had low epidemic levels. Quantitative analysis was also performed. }\end{array}$
\end{tabular}

\section{Risk of bias}

\begin{tabular}{lll}
\hline Bias & Authors' judgement & Support for judgement \\
\hline $\begin{array}{l}\text { Allocation concealment } \\
\text { (selection bias) }\end{array}$ & Unclear risk & B - Unclear \\
\hline
\end{tabular}

\section{Study characteristics}


Puig-Barberà 2004 (Continued)

Methods

Case-control study conducted in Valencia, Spain during the 2002 to 2003 influenza season, in the community. Data sources were: hospital records; structured interview by trained field investigator. Follow-up period was 15 November 2002 to 31 March 2003. Cases were people admitted to hospital for pneumonia; controls were admitted to hospital in the same week for acute abdominal surgical condition or trauma. $\begin{array}{ll}\text { Participants } & 815 \text { non-institutionalised people (325 cases and } 525 \text { controls were identified; } 290 \text { and } 525 \text { were includ- } \\ \text { ed in analysis, respectively), } 65 \text { years or older }\end{array}$

Interventions

Parenteral influenza MF59 adjuvant vaccine. $42 \%$ of cases and $34 \%$ of controls received pneumococcal vaccination. Vaccine strains matched the circulating strain.

Outcomes $\quad \begin{aligned} & \text { Hospitalisation for pneumonia (ICD-9 code 480-487); pneumonia was clinically defined and radiologi- } \\ & \text { cally confirmed }\end{aligned}$
cally confirmed

Notes

The study controls for confounders in analysis: health status, smoking habits, pneumococcal vaccination. The season had low epidemic levels. Quantitative analysis was also performed.

\section{Risk of bias}

\begin{tabular}{lll}
\hline Bias & Authors' judgement & Support for judgement \\
\hline $\begin{array}{l}\text { Allocation concealment } \\
\text { (selection bias) }\end{array}$ & Low risk & A - Adequate \\
\hline
\end{tabular}

Puig-Barbera 2007

\section{Study characteristics}

\begin{tabular}{l} 
Methods $\begin{array}{l}3 \text { case-control studies were performed in the elderly population (>64 years of age) of } 3 \text { health districts } \\
\text { in the Valencia Autonomous Region, Spain (total number of elderly residents in these districts: } n= \\
105,454 \text { at } 31 \text { December 2004), where MF59-adjuvanted subunit influenza vaccine was used. The risk of } \\
\text { hospitalisation for ACS, CVA, or pneumonia was evaluated for people who had received influenza vac- } \\
\text { cine and for those who had not received influenza vaccine. }\end{array}$ \\
\hline
\end{tabular}

Participants Description of cases

Incident cases for each disease were identified from all consecutive emergency hospitalisations following their admission between 15 November 2004 and 31 March 2005. Diagnoses were made according to the International Classification of Diseases, 9th version, Clinical Modification for ACS (410-411.89 and 413), CVA (431-436), or pneumonia (480-487). Only non-institutionalised patients who were $>64$ years of age, had lived in the hospital catchment area for the previous 6 months, were able to give informed consent, and remained in hospital for at least 72 hours were included in the study. After consideration of the exclusion criteria, 144 cases admitted for ACS, 134 for CVA, and 198 for pneumonia were included in the study.

\section{Description of controls}

Each case was paired with 1 or 2 controls, matched for hospital and gender. Controls were recruited based on the same inclusion criteria as cases, following emergency hospitalisations for an acute surgical process or trauma. The admission date for controls was matched to the case admission date, preferably being the same day, and with a maximum interval of 10 days. 258 controls were admitted for ACS, 246 for CVA, and 321 for pneumonia.

A total of $75.2 \%$ and $78.1 \%$ of vaccinated cases and controls, respectively $(P=0.314)$ were vaccinated and on the population register. Of these, all cases and $99.73 \%$ of controls had received MF59-adjuvanted subunit influenza vaccine. 
Puig-Barbera 2007 (Continued)

Interventions Influenza vaccination and hospitalisation for ACS, CVA, and pneumonia

Outcomes

Notes

The authors conclude that the results suggest that MF59-adjuvanted influenza vaccination is associated with a significant reduction in the risk of hospitalisation for ACS, CVA, and pneumonia during the period of influenza virus circulation.

\section{Ruben 1974}

\section{Study characteristics}

\begin{tabular}{ll}
\hline Methods & $\begin{array}{l}\text { Authors investigated an outbreak in a nursing home in California, USA during the } 1972 \text { to } 1973 \text { influen- } \\
\text { za season; independent blind assessment was conducted. Follow-up period was } 20 \text { December } 1972 \text { to } \\
\text { 28 January 1973. Throat swabs were obtained from ill residents. }\end{array}$ \\
\hline Participants & $\begin{array}{l}392 \text { nursing home residents (204 treated and } 192 \text { controls, all included in the analysis). Participants } \\
\text { were both ambulatory and bedridden. }\end{array}$ \\
\hline Interventions & $\begin{array}{l}\text { Parenteral influenza vaccine: A/Aichi/2/62; B/Mass/1/71. Vaccine strains did not match circulating } \\
\text { strains. }\end{array}$ \\
\hline Outcomes & $\begin{array}{l}\text { Clinically defined ILI (fever } 37.7{ }^{\circ} \mathrm{C}+\text { upper respiratory symptoms), laboratory-confirmed ILI (positive } \\
\text { swab culture), deaths from outbreak-related respiratory illness }\end{array}$ \\
\hline Notes & Data stratified by nurse floor. The circulating strain was A/ENG/42/72. \\
\hline Risk of bias & Authors' judgement Support for judgement \\
\hline Bias & Unclear risk \\
\hline $\begin{array}{l}\text { Allocation concealment } \\
\text { selection bias) }\end{array}$ & B - Unclear \\
\hline
\end{tabular}

Rudenko 2001

\section{Study characteristics}

Methods

Experimental study conducted in Russia during the 1996 to 1997 influenza season, randomised, double-blind, placebo controlled; random sample stratified by age and underlying health conditions. Follow-up period was 20 January 1997 to 2 March 1997

Participants $\begin{aligned} & 602 \text { nursing home residents (93 vaccinated with parenteral vaccine, } 111 \text { vaccinated with aerosol vac- } \\ & \text { cine, and } 109 \text { controls); severely debilitated and immunosuppressed people were excluded; } 41 \text { to } 95 \\ & \text { years, median } 73 \text { years }\end{aligned}$

Interventions Live cold-adapted vaccine aerosol administered: A/Leningrad/134/17/57; B/Ann Arbor/60/69 parenteral vaccine: A/Texas/36/91; A/Nanchang/933/95; B/Harbin/7/94. Vaccine strains matched the circulating strains

\section{Outcomes}

Laboratory-confirmed influenza: positive swab or 4-fold or greater increase in antibody titre 
Rudenko 2001 (Continued)

Notes

No description of methods; 1 or 2 doses' efficacy was tested; data were extracted irrespective of the number of doses administered

\section{Risk of bias}

\begin{tabular}{lll}
\hline Bias & Authors' judgement & Support for judgement \\
\hline $\begin{array}{l}\text { Random sequence genera- } \\
\text { tion (selection bias) }\end{array}$ & High risk & $\begin{array}{l}\text { Random allocation sequence not described and the six groups have uneveven } \\
\text { denominators }\end{array}$ \\
\hline $\begin{array}{l}\text { Allocation concealment } \\
\text { (selection bias) }\end{array}$ & Unclear risk & Not described \\
\hline $\begin{array}{l}\text { Blinding (performance } \\
\text { bias and detection bias) } \\
\text { All outcomes }\end{array}$ & Unclear risk & Not described \\
\hline $\begin{array}{l}\text { Incomplete outcome data } \\
\text { (attrition bias) }\end{array}$ & High risk & $\begin{array}{l}\text { Unexplained attrition both for efficacy and serological outcomes. Harms are } \\
\text { not mentioned at all in the report. This is a particular problem in the use of live } \\
\text { attenuated vaccines in elderly or infirm people }\end{array}$ \\
\hline
\end{tabular}

\section{Saah 1986}

\section{Study characteristics}

$\begin{array}{ll}\text { Methods } & \text { Prospective cohort study conducted in New York, USA during the } 1979 \text { to } 1980 \text { influenza season. Au- } \\ \text { thors investigated a nursing home with evidence of flu activity; medical records were reviewed. Compa- } \\ \text { rability between cohorts was assessed by analysis of the underlying conditions of a sample of the pop- } \\ \text { ulation; } 62 \text { people with severe organic brain syndrome were excluded. Follow-up period was } 1 \text { Novem- } \\ \text { ber } 1979 \text { to } 30 \text { April } 1980 .\end{array}$

\begin{tabular}{ll} 
Participants & $\begin{array}{l}453 \text { residents in nursing home for healthy and ill elderly (219 treated and } 234 \text { controls, all included in } \\
\text { the analysis); most patients required skilled nursing home care }\end{array}$ \\
\hline Interventions & $\begin{array}{l}\text { Parenteral influenza vaccine: A/Brazil/78; A/Texas/77; B/Hong Kong/72. Matching between vaccine and } \\
\text { circulating strains is unknown. }\end{array}$ \\
\hline Outcomes & $\begin{array}{l}\text { Symptoms defined and radiologically confirmed pneumonia; death from pneumonia within } 60 \text { days } \\
\text { from the onset of pneumonia }\end{array}$ \\
\hline Notes & $\begin{array}{l}\text { Vaccinated participants had very slight excess of underlying conditions; smokers were rare; pneumo- } \\
\text { coccal vaccine was rarely used. Specific viral diagnosis was not attempted, but the circulating strain in } \\
\text { the community was B/Singapore/79-like. }\end{array}$
\end{tabular}

Risk of bias

\begin{tabular}{lll}
\hline Bias & Authors' judgement & Support for judgement \\
\hline $\begin{array}{l}\text { Allocation concealment } \\
\text { (selection bias) }\end{array}$ & Unclear risk & B - Unclear \\
\hline
\end{tabular}


Saah 1986b

\section{Study characteristics}

Methods Prospective cohort study conducted in New York, USA during the 1980 to 1981 influenza season. Authors investigated a nursing home with evidence of flu activity; medical records were reviewed. Comparability between cohorts was assessed by analysis of the underlying conditions of a sample of the population; 62 people with severe organic brain syndrome were excluded. Follow-up period was 1 November 1980 to 30 April 1981.

\begin{tabular}{ll} 
Participants & $\begin{array}{l}458 \text { residents in nursing home for healthy and ill elderly (244 treated and } 214 \text { controls, all included in } \\
\text { the analysis); most patients required skilled nursing home care }\end{array}$ \\
\hline Interventions & $\begin{array}{l}\text { Parenteral influenza vaccine: A/Brazil/78; A/Bangkok/79; B/Singapore/79. Vaccine strains matched cir- } \\
\text { culating strains. }\end{array}$ \\
\hline Outcomes & $\begin{array}{l}\text { Symptoms defined and radiologically confirmed pneumonia; death from pneumonia within } 60 \text { days } \\
\text { from the onset of pneumonia }\end{array}$ \\
\hline Notes & $\begin{array}{l}\text { Vaccinated participants had very slight excess of underlying conditions; smokers were rare; pneumo- } \\
\text { coccal vaccine was rarely used. Specific viral diagnosis was not attempted, but the circulating strain in } \\
\text { the community was A/Bangkok/79-like. }\end{array}$
\end{tabular}

\section{Risk of bias}

\begin{tabular}{lll}
\hline Bias & Authors' judgement & Support for judgement \\
\hline $\begin{array}{l}\text { Allocation concealment } \\
\text { (selection bias) }\end{array}$ & Unclear risk & B - Unclear \\
\hline
\end{tabular}

\section{Saah $1986 c$}

\section{Study characteristics}

$\begin{array}{ll}\text { Methods } & \text { Prospective cohort study conducted in New York, USA during the } 1981 \text { to } 1982 \text { influenza season in } 26 \\ \text { nursing homes. Comparability between cohorts was assessed by analysis of the underlying conditions } \\ \text { of a sample of the population; } 62 \text { people with severe organic brain syndrome were excluded; medical } \\ \text { records were reviewed. Follow-up period was } 1 \text { November } 1981 \text { to } 30 \text { April } 1982 .\end{array}$

Participants

451 residents in nursing home for healthy and ill elderly ( 225 treated and 226 controls, all included in the analysis); most patients required skilled nursing home care

\begin{tabular}{ll}
\hline Interventions & $\begin{array}{l}\text { Parenteral influenza vaccine: A/Brazil/78; A/Bangkok/79; B/Singapore/80. Matching between vaccine } \\
\text { and circulating strains is unknown. }\end{array}$ \\
\hline Outcomes & $\begin{array}{l}\text { Symptoms defined and radiologically confirmed pneumonia; death from pneumonia within } 60 \text { days } \\
\text { from the onset of pneumonia }\end{array}$ \\
\hline Notes & $\begin{array}{l}\text { Vaccinated participants had very slight excess of underlying conditions; smokers were rare; pneumo- } \\
\text { coccal vaccine was rarely used. The circulating strain was not identified. }\end{array}$ \\
\hline
\end{tabular}

\section{Risk of bias}

\begin{tabular}{lll}
\hline Bias & Authors' judgement & Support for judgement \\
\hline $\begin{array}{l}\text { Allocation concealment } \\
\text { (selection bias) }\end{array}$ & Unclear risk & B - Unclear \\
\hline
\end{tabular}


Saito 2002a

\section{Study characteristics}

\begin{tabular}{ll}
\hline Methods & $\begin{array}{l}\text { Prospective cohort study conducted in Japan during the } 1998 \text { to } 1999 \text { influenza season in } 9 \text { nursing } \\
\text { homes. Follow-up period was the epidemic period. Efficacy assessment was also performed by vaccina- } \\
\text { tion rate in residents and HCWs, physical impairment, sex, age, and health status of residents. Throat } \\
\text { swabs were obtained from ill individuals; medical charts were reviewed. }\end{array}$ \\
\hline Participants & $\begin{array}{l}699 \text { residents in } 9 \text { nursing homes (331 treated and } 368 \text { controls, all included in the analysis). The vacci- } \\
\text { nated group had more underlying diseases. }\end{array}$ \\
\hline Interventions & $\begin{array}{l}\text { Parenteral influenza vaccine: A/Beijing/262/95; A/Sydney/5/97; B/Mie/1/93. Vaccine strains matched } \\
\text { circulating strains (good match). }\end{array}$ \\
\hline Outcomes & Clinically defined ILI (fever + cough or coryza or sore throat) occurring during the epidemic period \\
\hline Notes & $\begin{array}{l}\text { The circulating strain was A/Sydney. Influenza virus exposure was confirmed in all } 9 \text { facilities. Out- } \\
\text { breaks were demonstrated in only } 4 \text { homes. No other respiratory viruses were isolated. Data were ex- } \\
\text { tracted by RRs reported in tables. }\end{array}$
\end{tabular}

\section{Risk of bias}

\begin{tabular}{lll}
\hline Bias & Authors' judgement & Support for judgement \\
\hline $\begin{array}{l}\text { Allocation concealment } \\
\text { (selection bias) }\end{array}$ & Unclear risk & B - Unclear \\
\hline
\end{tabular}

\section{Saito 2002b}

\section{Study characteristics}

\begin{tabular}{ll} 
Methods & $\begin{array}{l}\text { Prospective cohort study conducted in Japan during the } 1999 \text { to } 2000 \text { influenza season in } 11 \text { nursing } \\
\text { homes. Follow-up period was the epidemic period. Efficacy assessment was also performed by vaccina- } \\
\text { tion rate in residents and HCWs, physical impairment, sex, age, and health status of residents. Throat } \\
\text { swabs were obtained from ill individuals; medical charts were reviewed. }\end{array}$ \\
\hline Participants & $\begin{array}{l}930 \text { residents in } 11 \text { nursing homes (743 treated and } 187 \text { controls, all included in the analysis). The vacci- } \\
\text { nated group had more physical impairment of daily living. }\end{array}$ \\
\hline Interventions & $\begin{array}{l}\text { Parenteral influenza vaccine: A/Beijing/262/95; A/Sydney/5/97; B/Shandon/7/97. Vaccine strains } \\
\text { matched circulating strains (good match). }\end{array}$ \\
\hline Outcomes & Clinically defined ILI (fever + cough or coryza or sore throat) occurring during the epidemic period \\
\hline Notes & $\begin{array}{l}\text { The circulating strain was A/Sydney. Influenza virus exposure was confirmed in only } 4 / 11 \text { facilities. No } \\
\text { outbreaks were detected. No other respiratory viruses were isolated. Data were extracted by RRs re- } \\
\text { ported in tables. }\end{array}$ \\
\hline
\end{tabular}

\section{Risk of bias}

\begin{tabular}{lll}
\hline Bias & Authors' judgement & Support for judgement \\
\hline $\begin{array}{l}\text { Allocation concealment } \\
\text { (selection bias) }\end{array}$ & Unclear risk & B - Unclear \\
\hline
\end{tabular}


Schonberger 1979

\section{Study characteristics}

\begin{tabular}{|c|c|c|}
\hline Methods & \multicolumn{2}{|c|}{$\begin{array}{l}\text { Surveillance population-based study conducted in the USA during the } 1976 \text { to } 1977 \text { influenza season. } \\
\text { Neurologists were directly contacted; physician and hospital records were reviewed. Suspected cases } \\
\text { reported to the Centers for Disease Control and Prevention directly by patients or medical personnel } \\
\text { were included only if accepted by a state health department. Follow-up period was } 1 \text { October } 1976 \text { to } \\
31 \text { January } 1977 \text {. }\end{array}$} \\
\hline Participants & \multicolumn{2}{|l|}{ USA population } \\
\hline Interventions & \multicolumn{2}{|c|}{ Monovalent $\mathrm{A} / \mathrm{New}$ Jersey/76 or bivalent $\mathrm{A} / \mathrm{New}$ Jersey/76 and A/Victoria/75 parenteral vaccine } \\
\hline Outcomes & \multicolumn{2}{|c|}{ Cases of Guillain-Barré syndrome } \\
\hline Notes & \multicolumn{2}{|c|}{$\begin{array}{l}\text { Results were stratified by age group and vaccine type. Vaccination rates in population were obtained } \\
\text { from national immunisation survey. }\end{array}$} \\
\hline \multicolumn{3}{|l|}{ Risk of bias } \\
\hline Bias & Authors' judgement & Support for judgement \\
\hline $\begin{array}{l}\text { Allocation concealment } \\
\text { (selection bias) }\end{array}$ & Unclear risk & D - Not used \\
\hline
\end{tabular}

\section{Shapiro 2003}

\section{Study characteristics}

\begin{tabular}{ll}
\hline Methods & $\begin{array}{l}\text { Retrospective cohort study conducted in Israel during the 2000 to 2001 influenza season, in the com- } \\
\text { munity. Data source was managed care organisation database. Follow-up period was the entire in- } \\
\text { fluenza season. }\end{array}$ \\
\hline Participants & $\begin{array}{l}84,640 \text { community-dwelling elderly (36,596 treated and 48,044 controls included in the analysis), } 65 \\
\text { years or older }\end{array}$ \\
\hline Interventions & Parenteral influenza vaccine. Vaccine strain probably matched the circulating strain (literature). \\
\hline Outcomes & Hospitalisation for any reason; deaths from all causes \\
\hline Notes & $\begin{array}{l}\text { Very poor description of methods; no information about flu activity: probably not epidemic year. Data } \\
\text { were presented by health status. Only deaths were included in the analysis. }\end{array}$ \\
\hline Risk of bias & Authors' judgement Support for judgement \\
\hline Bias & Unclear risk $\quad$ B - Unclear \\
\hline $\begin{array}{l}\text { Allocation concealment } \\
\text { (selection bias) }\end{array}$ & \\
\hline
\end{tabular}


Strassburg 1986

\section{Study characteristics}

Methods
fluenza season; patients records were reviewed. Follow-up period was 1 February 1983 to 31 March
1983. Virus circulation was confirmed with throat swab from ill people.

\begin{tabular}{ll}
\hline Participants & $\begin{array}{l}87 \text { nursing home residents, } 59 \text { to } 94 \text { years old, most of them suffering from dementia (65 treated and } 19 \\
\text { controls were included in the analysis; vaccination status could not be determined for } 3 \text { residents) }\end{array}$ \\
\hline Interventions & $\begin{array}{l}\text { Parenteral influenza vaccine: A/Bangkok/79; A/Brazil/78; B/Singapore/79. Vaccine strains probably } \\
\text { matched circulating strains. }\end{array}$ \\
\hline Outcomes & $\begin{array}{l}\text { Clinically defined ILI (fever or fever + respiratory symptoms) occurring during the epidemic period, } \\
\text { deaths from ILI }\end{array}$ \\
\hline Notes & $\begin{array}{l}\text { Age, sex ratio, and health status were similar in vaccinated and unvaccinated people. The circulating } \\
\text { strain was A/Bangkok/79-like. No other positive laboratory findings were found. Amantadine was not } \\
\text { used. }\end{array}$
\end{tabular}

\section{Risk of bias}

\begin{tabular}{lll}
\hline Bias & Authors' judgement & Support for judgement \\
\hline $\begin{array}{l}\text { Allocation concealment } \\
\text { (selection bias) }\end{array}$ & Low risk & A - Adequate \\
\hline
\end{tabular}

\section{Stuart 1969}

\section{Study characteristics}

\begin{tabular}{ll}
\hline Methods & $\begin{array}{l}\text { Experimental study conducted in California, USA during the } 1965 \text { to } 1966 \text { influenza season; the control } \\
\text { group received influenza B vaccine, placebo, or no vaccine; laboratory samples were obtained from ill } \\
\text { people to confirm the infection active surveillance. Follow-up period was } 1 \text { February } 1966 \text { to } 30 \text { April } \\
1966 .\end{array}$ \\
\hline Participants & $\begin{array}{l}4180 \text { residents in the nursing home, healthy (1561 treated and } 2619 \text { controls were included in the } \\
\text { analysis), } 52 \text { years or older }\end{array}$ \\
\hline Interventions & $\begin{array}{l}\text { Monovalent A2 parenteral influenza vaccine: A2/Taiwan/1/64. Vaccine strains matched the circulating } \\
\text { strains }\end{array}$ \\
\hline Outcomes & $\begin{array}{l}\text { Clinically defined febrile illness (fever + cough or malaise or coryza or myalgia or headache), clinically } \\
\text { defined afebrile illness, hospitalisation and deaths without definition. } \\
\text { Harms were reported, but they were excluded from analysis, as they refer to an old oil adjuvant vaccine }\end{array}$ \\
\hline Notes & $\begin{array}{l}\text { Participants randomised the previous year but not vaccinated (reason not explained) in the current } \\
\text { year were added in the control group; the study year was an epidemic one }\end{array}$ \\
\hline Risk of bias & Authors' judgement Support for judgement \\
\hline Random sequence genera- & Unclear risk Insufficient details available to permit judgement \\
\hline tion (selection bias) &
\end{tabular}


Stuart 1969 (Continued)

$\begin{aligned} & \text { Allocation concealment } \\ & \text { (selection bias) }\end{aligned}$ Unclear risk Insufficient details available to permit judgement

Blinding (performance

High risk

Open-label design

bias and detection bias)

All outcomes

Incomplete outcome data Low risk Data available for most participants in the study
(attrition bias)

(attrition bias)

All outcomes

Taylor 1992

\section{Study characteristics}

\begin{tabular}{ll}
\hline Methods & $\begin{array}{l}\text { Authors investigated an outbreak in a nursing home in Washington, USA during the } 1988 \text { to } 1989 \text { in- } \\
\text { fluenza season; residents' records and hospital charts were reviewed. Follow-up period was } 29 \text { January } \\
1989 \text { to } 1 \text { March 1989. Throat swabs were obtained from a sample of acutely ill residents; paired sera } \\
\text { were obtained from } 63 \% \text { of both ill and well residents. }\end{array}$ \\
\hline Participants & $\begin{array}{l}109 \text { nursing home residents (48 treated and } 61 \text { controls; } 45 \text { and } 52 \text { included in the analysis, respective- } \\
\text { ly), } 58 \text { to } 105 \text { years old. Groups were similar in age, gender, and level of care required. }\end{array}$ \\
\hline Interventions & $\begin{array}{l}\text { Parenteral influenza vaccine: A/Taiwan; A/Sichuan; B/Victoria. Vaccine strains probably matched circu- } \\
\text { lating strains. }\end{array}$ \\
\hline Outcomes & $\begin{array}{l}\text { Outbreak-associated cases: clinically defined ILI (fever + cough) or laboratory-confirmed influenza (4- } \\
\text { fold increase in antibody titre), pneumonia, hospitalisation from ILI or pneumonia, deaths from ILI or } \\
\text { pneumonia }\end{array}$ \\
\hline Notes & $\begin{array}{l}\text { Vaccination was not offered to staff. Positive specimens showed a diagnostic titre rise to A/Sichuan, but } \\
\text { no virus was isolated; matching was only hypothetic. Amantadine was not used. Laboratory-confirmed } \\
\text { cases were analysed by intention-to-treat. }\end{array}$ \\
\hline
\end{tabular}

\section{Risk of bias}

\begin{tabular}{lll}
\hline Bias & Authors' judgement & Support for judgement \\
\hline $\begin{array}{l}\text { Allocation concealment } \\
\text { (selection bias) }\end{array}$ & Low risk & A - Adequate \\
\hline
\end{tabular}

\section{Treanor 1994}

\section{Study characteristics}

$\begin{array}{ll}\text { Methods } & \text { Experimental study conducted in New York, USA during the } 1990 \text { to } 1991 \text { influenza season, randomised, } \\ \text { double-blind, placebo-controlled study. } 34 \text { participants received live vaccine; } 30 \text { participants received } \\ \text { trivalent vaccine; } 11 \text { participants received placebo. Follow-up period was for } 7 \text { days after vaccination. } \\ \text { Participants filled self administered diary card. }\end{array}$

Participants

75 outpatients with chronic disease or elderly, mostly 65 years or older 
Treanor 1994 (Continued)

Interventions

Live cold-adapted influenza B virus vaccine, aerosol administered; parenteral trivalent influenza vaccine

Outcomes

Upper respiratory symptoms (coryza or sore throat), lower respiratory symptoms (cough, hoarseness, or dyspnoea), systemic symptoms (malaise and myalgia), sore arm, fever

Notes

Participants experiencing symptoms within 1 week of vaccination were considered.

\section{Risk of bias}

\begin{tabular}{lll}
\hline Bias & Authors' judgement & Support for judgement \\
\hline $\begin{array}{l}\text { Random sequence genera- } \\
\text { tion (selection bias) }\end{array}$ & Unclear risk & Randomisation method not described. \\
\hline $\begin{array}{l}\text { Allocation concealment } \\
\text { (selection bias) }\end{array}$ & Unclear risk & Allocation concealment not described. \\
\hline $\begin{array}{l}\text { Blinding (performance } \\
\text { bias and detection bias) } \\
\text { All outcomes }\end{array}$ & Unclear risk & Described as placebo controlled, but no further details available \\
\hline $\begin{array}{l}\text { Incomplete outcome data } \\
\text { (attrition bias) }\end{array}$ & Low risk & No attrition \\
$\begin{array}{l}\text { All outcomes } \\
\end{array}$ & \\
\hline
\end{tabular}

Voordouw 2003

\section{Study characteristics}

Retrospective cohort study conducted in the Netherlands during the 1996 to 1997 influenza season,
in the community. Data source was the managed care organisation database. Follow-up period was 1
September 1996 to 1 June 1997 . For every individual who had received an influenza vaccination, 1 age-
sex matched unvaccinated control participant was randomly selected.

Participants 17,822 community-dwelling elderly with a permanent status in 1 of the practices (8911 treated and 8911 controls, all included in the analysis), 65 years or older

\begin{tabular}{ll}
\hline Interventions & Parenteral influenza vaccine. Vaccine strain matched the circulating strain. \\
\hline Outcomes & $\begin{array}{l}\text { Influenza as defined by International Classification of Primary Care (R80: proven influenza without } \\
\text { pneumonia), pneumonia, deaths from all causes }\end{array}$ \\
\hline Notes & $\begin{array}{l}\text { The influenza season was relatively mild. Data were stratified by age and health status. Quantitative } \\
\text { analysis was also performed only for the outcome 'deaths from all causes'. }\end{array}$ \\
\hline
\end{tabular}

\section{Risk of bias}

\begin{tabular}{lll}
\hline Bias & Authors' judgement & Support for judgement \\
\hline $\begin{array}{l}\text { Allocation concealment } \\
\text { (selection bias) }\end{array}$ & Low risk & A - Adequate \\
\hline
\end{tabular}

ACS = acute coronary syndromes

$\mathrm{CAP}=$ community-acquired pneumonia 
CVA = cerebrovascular accident

$\mathrm{HCWs}=$ healthcare workers

$I C D=$ International Classification of Diseases

ILI = influenza-like illness

$\mathrm{NI}=$ neuroaminidase inhibitor

$\mathrm{OR}=$ odds ratio

$\mathrm{RR}=$ risk ratio

$\mathrm{URI}=$ upper respiratory infection

WHO $=$ World Health Organization

Characteristics of excluded studies [ordered by study ID]

\begin{tabular}{|c|c|}
\hline Study & Reason for exclusion \\
\hline Allsup 2001 & Elderly denominator 19 and no breakdown of cases by age groups is given \\
\hline Allsup 2003 & See Allsup 2004 \\
\hline Anonymous 1995 & Comment \\
\hline Anonymous 2004b & No data presented. \\
\hline Ansaldi 2002 & Cross-sectional study \\
\hline Arden 1986 & Review \\
\hline Armstrong 2004 & $\begin{array}{l}\text { Data presented cannot be used in the analysis; the statistical model is not comparable with } \\
\text { that used in the other studies. }\end{array}$ \\
\hline Arroyo 1988 & Description of epidemic \\
\hline Arya 2003 & No data presented. \\
\hline Ayala-Montiel 2004 & No placebo/do nothing comparator: influenza + pneumococcus versus influenza vaccine \\
\hline Baldo 1999 & Lack of a control group \\
\hline Barker 1980 & Cross-sectional study \\
\hline Bektimirov 1993 & No original data presented. \\
\hline Belshe 2004 & Children and adults \\
\hline Ben-Yehuda 2003 & No placebo/do nothing comparator \\
\hline Berg 2004 & The study does not investigate the vaccine efficacy. \\
\hline Buxton 2001 & Lack of a control group \\
\hline Carman 2000 & Data are not presented by vaccine condition. \\
\hline Castilla 2006 & $\begin{array}{l}\text { Retrospective paper looking at vaccination cover in }>65 \text { and relations with effectiveness } \\
\text { claimed as efficacy. Only } 60 \text { influenza-like illness cases were tested out of a total of } 2300 \text {. }\end{array}$ \\
\hline Chen 2004 & The study does not investigate the vaccine efficacy. \\
\hline Chlibek 2002 & This could be a cohort study to be considered for the adults review. \\
\hline
\end{tabular}




\begin{tabular}{|c|c|}
\hline Study & Reason for exclusion \\
\hline Christenson 2002 & Same cohorts of Christenson 2001 \\
\hline Chumakov 1992 & High-risk groups \\
\hline Cohen 2004 & Does not present original data \\
\hline Conne 1997 & Lack of a control group \\
\hline Cruijff 1999 & Same cohorts of Govaert 1994a \\
\hline D'Alessandro 2004 & Both arms administered influenza vaccine, no placebo/do nothing comparator. \\
\hline de Bernardi 2002 & Healthy adults; lack of a control group \\
\hline de Bruijn 2004 & Serological outcome only \\
\hline Deguchi 2000a & Same cohorts of Deguchi 2001 \\
\hline Deguchi 2000b & Same cohorts of Deguchi 2001 \\
\hline Deguchi $2000 c$ & Same cohorts of Deguchi 2001 \\
\hline Deibel 1970 & The study does not investigate the vaccine efficacy. \\
\hline De Serres 2004 & Same data set as Skowronski - high-risk group \\
\hline Elder 1996 & Healthy adults \\
\hline Ender 2001 & Assessment of vitamins before vaccination as immunomodulators \\
\hline Erofeeva 2001 & Frequency data are not reported; outcome is not clearly defined. \\
\hline Fedson 1992 & The study does not investigate the vaccine efficacy. \\
\hline Fedson 1993 & Comment \\
\hline Fitzner 2001 & Economic study without original data \\
\hline Fukumi 1969 & The study does not investigate the vaccine efficacy. \\
\hline Fukushima 1999 & Serological outcome only \\
\hline Galanti 1976 & Data presented cannot be estimated for the analysis. \\
\hline Galasso 1977 & Healthy adults \\
\hline Garcia-Doval 2001 & Case report \\
\hline Garcia-Garcia 2009 & Only $16 \%$ of participants are over the age of 60. \\
\hline Gasparini 2002 & Economic study; data source not described \\
\hline Gavira 1990 & Economic evaluation \\
\hline Gendon 1988 & No original data presented. \\
\hline
\end{tabular}




\begin{tabular}{|c|c|}
\hline Study & Reason for exclusion \\
\hline Giglio 1994 & Unclear study design; probably retrospective cohort based only on individual recall of disease \\
\hline Glass 1978 & The study does not investigate the vaccine efficacy. \\
\hline Glezen 1987 & The study does not investigate the vaccine efficacy. \\
\hline Gomez de Caso 1996 & The study does not investigate the vaccine efficacy. \\
\hline Govaert 1994b & Antibody outcomes only \\
\hline Gowda 1979 & The study does not investigate the vaccine efficacy. \\
\hline Grigor'eva 1994 & Study population is children. \\
\hline Grigor'eva 2002 & Study population is children. \\
\hline Gross 1977 & Study population is children. \\
\hline Gross 1995 & Review \\
\hline Guarino 1977 & Serological survey \\
\hline Guillevin 1983 & The study does not investigate the vaccine efficacy. \\
\hline Gutierrez 2001 & $\begin{array}{l}\text { Unclear study design; probably retrospective cohort based only on individual recall of dis- } \\
\text { ease; 1-year follow-up }\end{array}$ \\
\hline Hak 1998 & High-risk groups \\
\hline Hall 1981 & The study does not investigate the vaccine efficacy. \\
\hline Hampson 1997 & Economic review \\
\hline Hara 2008 & Redundant publication of Hara 2006 \\
\hline Harling 2004 & NI used \\
\hline Harper 1985 & Comment \\
\hline Hedlund 2003 & Same cohorts of Christenson 2001 \\
\hline Helliwell 1988 & Economic evaluation \\
\hline Hennessen 1978 & Cross-sectional study \\
\hline Herzog 2003 & The study does not investigate the vaccine efficacy. \\
\hline Heymann 2004 & Same cohorts of Shapiro 2003 \\
\hline Hirota 1997 & Healthy adults \\
\hline Hoberman 2003 & Study population is children. \\
\hline Hope-Simpson 1970 & The study does not investigate the vaccine efficacy. \\
\hline
\end{tabular}




\begin{tabular}{|c|c|}
\hline Study & Reason for exclusion \\
\hline Howell 1967 & Not elderly \\
\hline Hurwitz 1983 & Non-comparative data \\
\hline Icardi 2002 & Unclear study design; probably cross-sectional \\
\hline Ikematsu 1998 & $\begin{array}{l}\text { Poorly described study. Influenza-like illness was defined only as "fever". Deaths from all } \\
\text { causes referred to too long a period (from January to September). }\end{array}$ \\
\hline Ikematsu 2000 & $\begin{array}{l}\text { Poorly described study. Influenza-like illness was defined only as "fever". Asymptomatic infec- } \\
\text { tions were indistinguishable from symptomatic ones. }\end{array}$ \\
\hline Isahak 2007 & Inadequate comparator \\
\hline Jackson 1999 & High-risk groups \\
\hline Jackson 2002 & High-risk groups \\
\hline Jahnz-Rozyk 2003 & Economic evaluation \\
\hline Jani 1994 & Case report \\
\hline Jarstrand 1974 & The study does not investigate the vaccine efficacy. \\
\hline Jovanovic 1977 & Lack of a control group; high-risk groups \\
\hline Kaplan 1983 & Non-comparative design \\
\hline Keavey 1999 & No data \\
\hline King 1997 & Comment \\
\hline Knight 1984 & Case report \\
\hline Knottnerus 1996 & Cost-of-illness study \\
\hline Kurland 1984 & Non-comparative study \\
\hline Landi 2003 & 1-year follow-up in a population with important diseases \\
\hline Landi 2006 & Same data set as Landi 2003 \\
\hline Lavergne 1980 & No placebo/do nothing comparator, serological responses and age group? \\
\hline Lawson 2000 & Frequency data not reported. \\
\hline Lindahl 1999 & Case report \\
\hline Lohse 1999 & Case report \\
\hline Luce 2001 & Economic evaluation \\
\hline Mair 1974 & Lack of a control group \\
\hline Mandal 1973 & Descriptive \\
\hline
\end{tabular}




\begin{tabular}{|c|c|}
\hline Study & Reason for exclusion \\
\hline Manzano 2000 & Case report \\
\hline Manzoli 2007 & Feasibility study of general practice reporting method to assess vaccine effectiveness \\
\hline Margolis 1990b & No placebo/do nothing comparator \\
\hline Marine 1973 & Serological outcome only \\
\hline Marinich 1997 & Serological outcome only \\
\hline Martin 1997 & Lack of a control group \\
\hline Marwick 1995 & Comment \\
\hline Masurel 1979 & Antibody only \\
\hline Maxim 1998 & No data presented. \\
\hline Mayon-White 1994 & No data presented. \\
\hline McCall 1996 & No data presented. \\
\hline McCarthy 1978 & No data presented. \\
\hline McElhaney 2002 & No data presented. \\
\hline McGuffey 1993 & No data presented. \\
\hline Meiklejohn 1989 & Interruption study \\
\hline Mendelman 2001 & Study population is children and adults. \\
\hline Meynaar 1991 & Comment \\
\hline Mignogna 2000 & Case report \\
\hline Miller 1975 & Lack of a control group \\
\hline Modlin 1977 & Children \\
\hline Monto 1994 & No data presented. \\
\hline Moreno 2009 & Non-systematic review and meta-analysis with metaviews back to front \\
\hline Mostow 1969 & Lack of a control group \\
\hline Mostow 1988 & No data presented. \\
\hline Nguyen-van-Tam 1992 & Unclear study design \\
\hline Nichol 1996 & Same cohorts of Nichol 1994 \\
\hline Nichol 1999a & No original effectiveness data presented. \\
\hline Nichol 1999b & Same cohorts of Nichol 1994 \\
\hline
\end{tabular}




\begin{tabular}{|c|c|}
\hline Study & Reason for exclusion \\
\hline Nichol 1999c & High-risk groups \\
\hline Nichol 1999d & Adult population \\
\hline Nichol 2002 & Same cohorts of Nichol 1998 \\
\hline Nichol 2007 & Data already included in review from other publication by the same author \\
\hline Nicholson 1979 & No placebo/do nothing comparator \\
\hline Nicholson 1983 & Lack of a control group \\
\hline Nicholson 1990a & Unclear study design; symptomatic participants only \\
\hline Nicholson 1990b & No data presented. \\
\hline Nicholson 1992 & Unclear study design; symptomatic participants only \\
\hline Nielsen 1996 & No data presented. \\
\hline Nygaard 1999 & No data presented. \\
\hline Odelin 1993 & Lack of a control group \\
\hline Odelin 2003 & Lack of a control group \\
\hline Ohmit 1995 & Same population as Ohmit 1995 \\
\hline Ortqvist 2007 & Data already included in the 2005 review; re-analysis of the same data set \\
\hline Oshitani 2000 & Ecological study \\
\hline Parkin 1978 & Case series \\
\hline Parsons 1997 & No data \\
\hline Patel 1988 & Case report \\
\hline Patriarca 1985 & The study does not investigate the vaccine efficacy. \\
\hline Patriarca 1994 & Comment \\
\hline Pena-Rey 2003 & The study does not investigate the vaccine efficacy. \\
\hline Perez 2000 & Case report \\
\hline Perez-Tirse 1992 & Review of economic evaluations \\
\hline Perucchini 2004 & Lack of a control group \\
\hline Peters 1988 & Serological outcomes \\
\hline Philip 1969 & Data are not presented by age. \\
\hline Phillips 1970 & Lack of a control group \\
\hline
\end{tabular}




\begin{tabular}{|c|c|}
\hline Study & Reason for exclusion \\
\hline Phillips 1971 & Comment \\
\hline Piedra 2002 & Study population is children. \\
\hline Poe 1977 & Not about vaccine effectiveness \\
\hline Poland 2002 & Review \\
\hline Potter 1997 & Data are not presented by vaccine condition. \\
\hline Powers 1991 & Serological outcome only \\
\hline Pregliasco 1997 & Not about vaccine effectiveness \\
\hline Pregliasco 1999 & The study does not investigate the vaccine efficacy. \\
\hline Profeta 1987 & Serological outcome only \\
\hline Provinciali 1994 & Unclear study design \\
\hline Puig Barberà 1995 & Review \\
\hline Puretz 1979 & Review \\
\hline Pyhala 1997 & Guideline \\
\hline Quinlisk 1990 & Not about vaccines \\
\hline Quinnan 1983 & Does not report safety outcomes by age group \\
\hline Rao 1982 & Not about vaccines \\
\hline Read 2000 & No outcome data by vaccine status, uncertain denominators \\
\hline Reedy 2000 & Review \\
\hline Ruben 1973 & Serological outcome only \\
\hline Rubin 1973 & No data \\
\hline Rudenko 1981 & Review \\
\hline Rudenko 1993 & Children \\
\hline Ruel 2002 & Only 1 participant was unvaccinated. \\
\hline Ruf 2004 & Antibody titres and no placebo/do nothing comparator \\
\hline Runehagen 2002 & Not about vaccines \\
\hline Russell 2001 & Not about vaccines \\
\hline Ryan 1984 & No placebo/do nothing comparator \\
\hline Sadler 2000 & Not about vaccines \\
\hline
\end{tabular}




\begin{tabular}{|c|c|}
\hline Study & Reason for exclusion \\
\hline Sandrini 1997 & Data only in graphs \\
\hline Saslaw 1966 & Antibody responses \\
\hline Satsuta 1985 & Not about vaccines \\
\hline Schoenbaum 1969 & Poor description; data do not fit the comparison of this review \\
\hline Schwartz 1995 & Comment \\
\hline Selvaraj 1998 & Case report \\
\hline Serie 1977 & $\begin{array}{l}\text { Very poor description; absence of definitions, incoherence between data reported in text anc } \\
\text { data reported in tables }\end{array}$ \\
\hline Sethi 2002 & Not about vaccines \\
\hline Sharbaugh 1997 & Descriptive study \\
\hline Shinkawa 2002 & No data \\
\hline Shoji 2003 & Comment \\
\hline Siewert 1988 & The study does not investigate the vaccine efficacy. \\
\hline Simonsen 2005 & Ecological study \\
\hline Skowronski 2003 & High-risk groups \\
\hline Skull 2009 & $\begin{array}{l}\text { Study assessing risk factors for community-acquired pneumonia. Insufficient data presented } \\
\text { for evaluation of influenza vaccine effectiveness. }\end{array}$ \\
\hline Slepuskin 1967 & Ecological study \\
\hline Sloan 1993 & Comment \\
\hline Socan 2004 & Lack of a control group \\
\hline Solomon 1984 & Case report \\
\hline Solomon 1996 & Case report \\
\hline Solomon 1999 & Case report \\
\hline Spencer 1979 & Healthy adults \\
\hline Sprenger 1990 & The study does not investigate the vaccine efficacy. \\
\hline Squarcione 2003 & No placebo/do nothing comparator \\
\hline Stamboulian 1999 & Unclear study design \\
\hline Stott 2001 & Letter with no data \\
\hline Tamblyn 1997 & Comment \\
\hline
\end{tabular}




\begin{tabular}{|c|c|}
\hline Study & Reason for exclusion \\
\hline Thompson 1988 & Review \\
\hline Treanor 1992 & Lack of a control group \\
\hline Treanor 1998 & Lack of a control group \\
\hline Tsai 2007 & Model based on aspecific outcomes \\
\hline Upshur 2000 & Descriptive study \\
\hline Urquhart 1974 & Antibody titres \\
\hline Uyeki 2003 & The study does not investigate the vaccine efficacy. \\
\hline Vallee 2000 & No data presented. \\
\hline Van Horren 1976 & Not about effectiveness \\
\hline van Vuuren 2009 & Insufficient data \\
\hline Verde 1973 & Serological outcomes \\
\hline Verweij 2002 & Ethical study \\
\hline Vila-Corcoles 2005 & Insufficient data reported. \\
\hline Visconti 1973 & Serological outcomes \\
\hline Voordouw 2004 & Lack of a control group \\
\hline Voordouw 2006 & Insufficient data reported (denominators are not reported). \\
\hline Vu 2002 & Review \\
\hline Wagner 1993 & Lacks controls \\
\hline Wagner 1994 & Comment \\
\hline Wakefield 1990 & The study does not investigate the vaccine efficacy. \\
\hline Wang 1986 & Comment \\
\hline Wang 2002 & 1-year follow-up \\
\hline Warburton 1972 & Ecological study \\
\hline Wareing 2001 & Review \\
\hline Watson 1997 & Review \\
\hline Weaver 2001 & The study does not investigate the vaccine efficacy. \\
\hline Wiehl 2001 & Comment \\
\hline Williams 1980 & Comment \\
\hline
\end{tabular}




\begin{tabular}{|c|c|}
\hline Study & Reason for exclusion \\
\hline Wilson 1994 & Comment \\
\hline Winer 1984 & Survey of cases \\
\hline Wise 1977 & Healthy adults \\
\hline Wood 2000 & Review \\
\hline Woratz 1984 & Methodological paper \\
\hline Yassi 1993 & Vaccine and amantadine were used to control outbreak: amantadine acts as confounder. \\
\hline Zambon 2001 & The study does not investigate the vaccine efficacy. \\
\hline Zimmerman 2004 & Not about vaccine effectiveness \\
\hline Zoffmann 1977 & Not about vaccine effectiveness \\
\hline Zourbas 1973 & Serological outcome only \\
\hline Zuckerman 1990 & Serological outcome only \\
\hline Zuckerman 1992 & Serological outcome only \\
\hline Zuckerman 1993 & Serological outcome only \\
\hline
\end{tabular}

NI: neuoraminidase inhibitors

\section{DATA AND ANALYSES}

Comparison 1. Influenza vaccines versus placebo: randomised controlled trials - parenteral vaccine

\begin{tabular}{|c|c|c|c|c|}
\hline Outcome or subgroup title & No. of studies & $\begin{array}{l}\text { No. of partici- } \\
\text { pants }\end{array}$ & Statistical method & Effect size \\
\hline 1.1 Influenza & 3 & 2217 & $\begin{array}{l}\text { Risk Ratio (M-H, Random, } \\
95 \% \mathrm{Cl})\end{array}$ & $0.42[0.27,0.66]$ \\
\hline $\begin{array}{l}\text { 1.1.1 Outbreak - vaccine matching - } \\
\text { community - healthy and ill }\end{array}$ & 1 & 1838 & $\begin{array}{l}\text { Risk Ratio (M-H, Random, } \\
95 \% \mathrm{Cl} \text { ) }\end{array}$ & $0.41[0.23,0.74]$ \\
\hline $\begin{array}{l}\text { 1.1.2 Outbreak - vaccine matching - } \\
\text { psychiatric hospital }\end{array}$ & 1 & 177 & $\begin{array}{l}\text { Risk Ratio (M-H, Random, } \\
95 \% \mathrm{Cl} \text { ) }\end{array}$ & $0.35[0.12,1.06]$ \\
\hline $\begin{array}{l}\text { 1.1.3 No outbreak - vaccine matching - } \\
\text { nursing home - healthy and ill }\end{array}$ & 1 & 202 & $\begin{array}{l}\text { Risk Ratio (M-H, Random, } \\
95 \% \mathrm{Cl} \text { ) }\end{array}$ & $0.50[0.20,1.25]$ \\
\hline 1.2 Influenza-like illness & 4 & 6894 & $\begin{array}{l}\text { Risk Ratio (M-H, Random, } \\
95 \% \mathrm{Cl} \text { ) }\end{array}$ & $0.59[0.47,0.73]$ \\
\hline $\begin{array}{l}\text { 1.2.1 Outbreak - vaccine matching (cir- } \\
\text { culating strains) - community - healthy }\end{array}$ & 2 & 2047 & $\begin{array}{l}\text { Risk Ratio (M-H, Random, } \\
95 \% \mathrm{Cl})\end{array}$ & $0.57[0.42,0.79]$ \\
\hline
\end{tabular}




\begin{tabular}{|c|c|c|c|c|}
\hline Outcome or subgroup title & No. of studies & $\begin{array}{l}\text { No. of partici- } \\
\text { pants }\end{array}$ & Statistical method & Effect size \\
\hline $\begin{array}{l}\text { 1.2.2 Outbreak - vaccine matching - } \\
\text { community - risk groups }\end{array}$ & 1 & 490 & $\begin{array}{l}\text { Risk Ratio (M-H, Random, } \\
95 \% \mathrm{Cl})\end{array}$ & $0.87[0.49,1.53]$ \\
\hline $\begin{array}{l}\text { 1.2.3 Outbreak - vaccine matching - } \\
\text { nursing home - healthy }\end{array}$ & 1 & 4180 & $\begin{array}{l}\text { Risk Ratio (M-H, Random, } \\
95 \% \mathrm{Cl})\end{array}$ & $0.54[0.37,0.80]$ \\
\hline $\begin{array}{l}\text { 1.2.4 Outbreak - vaccine matching - } \\
\text { psychiatric hospital }\end{array}$ & 1 & 177 & $\begin{array}{l}\text { Risk Ratio (M-H, Random, } \\
95 \% \mathrm{Cl})\end{array}$ & $0.35[0.13,0.92]$ \\
\hline 1.3 Pneumonia & 1 & & $\begin{array}{l}\text { Risk Ratio (M-H, Random, } \\
95 \% \mathrm{Cl})\end{array}$ & $\begin{array}{l}\text { Totals not select- } \\
\text { ed }\end{array}$ \\
\hline $\begin{array}{l}\text { 1.3.1 Outbreak - vaccine matching - } \\
\text { community - healthy }\end{array}$ & 1 & & $\begin{array}{l}\text { Risk Ratio (M-H, Random, } \\
95 \% \mathrm{Cl})\end{array}$ & $\begin{array}{l}\text { Totals not select- } \\
\text { ed }\end{array}$ \\
\hline 1.4 All deaths & 1 & & $\begin{array}{l}\text { Risk Ratio (M-H, Random, } \\
95 \% \mathrm{Cl})\end{array}$ & $\begin{array}{l}\text { Totals not select- } \\
\text { ed }\end{array}$ \\
\hline $\begin{array}{l}\text { 1.4.1 Outbreak - vaccine matching - } \\
\text { community - healthy }\end{array}$ & 1 & & $\begin{array}{l}\text { Risk Ratio (M-H, Random, } \\
95 \% \mathrm{Cl} \text { ) }\end{array}$ & $\begin{array}{l}\text { Totals not select- } \\
\text { ed }\end{array}$ \\
\hline
\end{tabular}


Analysis 1.1. Comparison 1: Influenza vaccines versus placebo: randomised controlled trials - parenteral vaccine, Outcome 1: Influenza

\begin{tabular}{|c|c|c|c|c|c|c|}
\hline \multirow[b]{2}{*}{ Study or Subgroup } & \multicolumn{2}{|c|}{ Vaccine } & \multicolumn{2}{|c|}{ Placebo } & \multirow[b]{2}{*}{ Weight } & \multirow{2}{*}{$\begin{array}{c}\text { Risk Ratio } \\
\text { M-H, Random, 95\% CI }\end{array}$} \\
\hline & Events & Total & Events & Total & & \\
\hline \multicolumn{7}{|c|}{ 1.1.1 Outbreak - vaccine matching - community - healthy and ill } \\
\hline Govaert 1994a & 16 & 927 & 38 & 911 & $59.9 \%$ & $0.41[0.23,0.74]$ \\
\hline Subtotal $(95 \% \mathrm{CI})$ & & 927 & & 911 & $59.9 \%$ & $0.41[0.23,0.74]$ \\
\hline Total events: & 16 & & 38 & & & \\
\hline
\end{tabular}

Heterogeneity: Not applicable

Test for overall effect: $\mathrm{Z}=3.00(\mathrm{P}=0.003)$

1.1.2 Outbreak - vaccine matching - psychiatric hospital

$\begin{array}{lcccccc}\text { Edmondson } 1971 & 4 & 90 & 11 & 87 & 16.3 \% & 0.35[0.12,1.06] \\ \text { Subtotal (95\% CI) } & & \mathbf{9 0} & & \mathbf{8 7} & \mathbf{1 6 . 3 \%} & \mathbf{0 . 3 5}[\mathbf{0 . 1 2}, \mathbf{1 . 0 6}] \\ \text { Total events: } & 4 & & 11 & & & \end{array}$

Heterogeneity: Not applicable

Test for overall effect: $\mathrm{Z}=1.85(\mathrm{P}=0.06)$

1.1.3 No outbreak - vaccine matching - nursing home - healthy and ill

$\begin{array}{lcccccc}\text { Rudenko 2001 } & 6 & 93 & 14 & 109 & 23.8 \% & 0.50[0.20,1.25] \\ \text { Subtotal (95\% CI) } & & \mathbf{9 3} & & \mathbf{1 0 9} & \mathbf{2 3 . 8 \%} & \mathbf{0 . 5 0}[\mathbf{0 . 2 0}, \mathbf{1 . 2 5}] \\ \text { Total events: } & 6 & & 14 & & & \end{array}$

$\begin{array}{lll}\text { Total events: } & 6 & 14\end{array}$

Heterogeneity: Not applicable

Test for overall effect: $\mathrm{Z}=1.47(\mathrm{P}=0.14)$

$\begin{array}{lcccccc}\text { Total (95\% CI) } & & \mathbf{1 1 1 0} & & \mathbf{1 1 0 7} & \mathbf{1 0 0 . 0 \%} & \mathbf{0 . 4 2}[\mathbf{0 . 2 7}, \mathbf{0 . 6 6}] \\ \text { Total events: } & 26 & & 63 & & & \end{array}$

Heterogeneity: $\mathrm{Tau}^{2}=0.00 ; \mathrm{Chi}^{2}=0.25, \mathrm{df}=2(\mathrm{P}=0.88) ; \mathrm{I}^{2}=0 \%$

Test for overall effect: $\mathrm{Z}=3.79(\mathrm{P}=0.0002)$

Test for subgroup differences: $\mathrm{Chi}^{2}=0.25, \mathrm{df}=2(\mathrm{P}=0.88), \mathrm{I}^{2}=0 \%$ 
Analysis 1.2. Comparison 1: Influenza vaccines versus placebo: randomised controlled trials - parenteral vaccine, Outcome 2: Influenza-like illness

\begin{tabular}{|c|c|c|c|c|c|c|c|}
\hline & \multicolumn{2}{|c|}{ Vaccine } & \multicolumn{2}{|c|}{ Placebo } & \multicolumn{2}{|r|}{ Risk Ratio } & Risk Ratio \\
\hline Study or Subgroup & Events & Total & Events & Total & Weight & M-H, Random, 95\% CI & M-H, Random, 95\% CI \\
\hline
\end{tabular}

\begin{tabular}{|c|c|c|c|c|c|c|}
\hline Allsup 2004 & 24 & 522 & 17 & 177 & $13.5 \%$ & $0.48[0.26,0.87]$ \\
\hline Govaert 1994a & 41 & 676 & 66 & 672 & $34.3 \%$ & $0.62[0.42,0.90]$ \\
\hline Subtotal (95\% CI) & & 1198 & & 849 & $47.8 \%$ & $0.57[0.42,0.79]$ \\
\hline
\end{tabular}

Total events: $65 \quad 83$

Heterogeneity: $\mathrm{Tau}^{2}=0.00 ; \mathrm{Chi}^{2}=0.50, \mathrm{df}=1(\mathrm{P}=0.48) ; \mathrm{I}^{2}=0 \%$

Test for overall effect: $\mathrm{Z}=3.42(\mathrm{P}=0.0006)$

1.2.2 Outbreak - vaccine matching - community - risk groups

$\begin{array}{lcccccc}\text { Govaert 1994a } & 21 & 251 & 23 & 239 & 15.1 \% & 0.87[0.49,1.53] \\ \text { Subtotal (95\% CI) } & & \mathbf{2 5 1} & & \mathbf{2 3 9} & \mathbf{1 5 . 1 \%} & \mathbf{0 . 8 7}[\mathbf{0 . 4 9}, \mathbf{1 . 5 3}] \\ \text { Total events: } & 21 & & 23 & & & \end{array}$

Total events:
Heterogeneity: Not applicable

Test for overall effect: $\mathrm{Z}=0.49(\mathrm{P}=0.63)$

1.2.3 Outbreak - vaccine matching - nursing home - healthy

$\begin{array}{lcccccc}\text { Stuart } 1969 & 33 & 1561 & 102 & 2619 & 32.1 \% & 0.54[0.37,0.80] \\ \text { Subtotal (95\% CI) } & & \mathbf{1 5 6 1} & & \mathbf{2 6 1 9} & \mathbf{3 2 . 1 \%} & \mathbf{0 . 5 4}[\mathbf{0 . 3 7 , \mathbf { 0 . 8 0 } ]} \\ \text { Total events: } & 33 & & 102 & & & \end{array}$

Heterogeneity: Not applicable

Test for overall effect: $\mathrm{Z}=3.09(\mathrm{P}=0.002)$

1.2.4 Outbreak - vaccine matching - psychiatric hospital

$\begin{array}{lcccccc}\text { Edmondson } 1971 & 5 & 90 & 14 & 87 & 5.0 \% & 0.35[0.13,0.92] \\ \text { Subtotal (95\% CI) } & & \mathbf{9 0} & & \mathbf{8 7} & \mathbf{5 . 0 \%} & \mathbf{0 . 3 5}[\mathbf{0 . 1 3}, \mathbf{0 . 9 2}] \\ \text { Total events: } & 5 & & 14 & & & \end{array}$

Heterogeneity: Not applicable

Test for overall effect: $\mathrm{Z}=2.13(\mathrm{P}=0.03)$

$\begin{array}{lllll}\text { Total }(95 \% \text { CI) } & 3100 & 3794 & 100.0 \% & 0.59[0.47,0.73]\end{array}$

Total events:
Heterogeneity: $\mathrm{Tau}^{2}=0.00 ; \mathrm{Chi}^{2}=3.67, \mathrm{df}=4(\mathrm{P}=0.45) ; \mathrm{I}^{2}=0 \%$

Test for overall effect: $\mathrm{Z}=4.78(\mathrm{P}<0.00001)$

Test for subgroup differences: $\mathrm{Chi}^{2}=3.17 \mathrm{df}=3(\mathrm{P}=0.37), \mathrm{I}^{2}=5.2 \%$

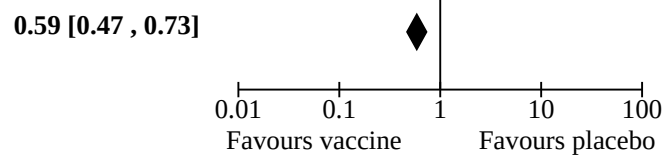

Analysis 1.3. Comparison 1: Influenza vaccines versus placebo: randomised controlled trials - parenteral vaccine, Outcome 3: Pneumonia

\begin{tabular}{|c|c|c|c|c|c|c|}
\hline & Va & & Pla & & Risk Ratio & Risk Ratio \\
\hline Study or Subgroup & Events & Total & Events & Total & M-H, Random, 95\% CI & M-H, Random, 95\% CI \\
\hline
\end{tabular}

1.3.1 Outbreak - vaccine matching - community - healthy

$\begin{array}{llllll}\text { Allsup } 2004 & 0 & 522 & 0 & 177 & \text { Not estimable }\end{array}$

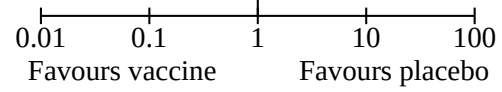


Analysis 1.4. Comparison 1: Influenza vaccines versus placebo: randomised controlled trials - parenteral vaccine, Outcome 4: All deaths

\begin{tabular}{|c|c|c|c|c|c|c|}
\hline \multirow[b]{2}{*}{ Stu } & \multicolumn{2}{|c|}{ Vaccine } & \multicolumn{2}{|c|}{ Placebo } & Risk Ratio & Risk Ratio \\
\hline & Events & Total & Events & Total & M-H, Random, 95\% CI & M-H, Random, 95\% CI \\
\hline
\end{tabular}

1.4.1 Outbreak - vaccine matching - community - healthy

$\begin{array}{llllll}\text { Allsup } 2004 & 3 & 522 & 1 & 177 & 1.02[0.11,9.72]\end{array}$

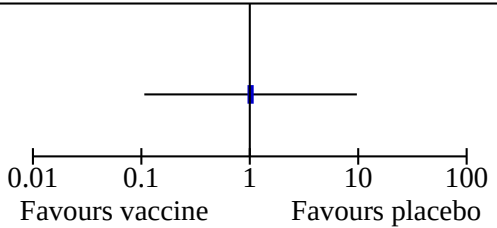

Comparison 2. Influenza vaccines versus placebo: randomised controlled trials - parenteral vaccine - adverse events

\begin{tabular}{lllll}
\hline $\begin{array}{l}\text { Outcome or subgroup ti- } \\
\text { tle }\end{array}$ & No. of studies & $\begin{array}{l}\text { No. of partici- } \\
\text { pants }\end{array}$ & Statistical method & Effect size \\
\hline 2.1 General malaise & 4 & 2560 & Risk Ratio (M-H, Random, 95\% Cl) & $1.18[0.87,1.61]$ \\
\hline 2.2 Nausea & 1 & 672 & Risk Ratio (M-H, Random, 95\% Cl) & $1.75[0.74,4.12]$ \\
\hline $\begin{array}{l}2.3 \text { Upper respiratory tract } \\
\text { symptoms }\end{array}$ & 2 & 713 & Risk Ratio (M-H, Random, 95\% Cl) & $1.35[0.90,2.01]$ \\
\hline $\begin{array}{l}2.4 \text { Headache } \\
2.5 \text { Fever }\end{array}$ & 3 & 2519 & Risk Ratio (M-H, Random, 95\% Cl) & $1.10[0.76,1.58]$ \\
\hline $\begin{array}{l}2.6 \text { Local tenderness/sore } \\
\text { arm }\end{array}$ & 4 & 2519 & Risk Ratio (M-H, Random, 95\% Cl) & $1.57[0.92,2.71]$ \\
\hline $\begin{array}{l}2.7 \text { Swelling - erythema - } \\
\text { induration }\end{array}$ & 2 & 2560 & Risk Ratio (M-H, Random, 95\% Cl) & $3.56[2.61,4.87]$ \\
\hline
\end{tabular}

Analysis 2.1. Comparison 2: Influenza vaccines versus placebo: randomised controlled trials - parenteral vaccine - adverse events, Outcome 1: General malaise

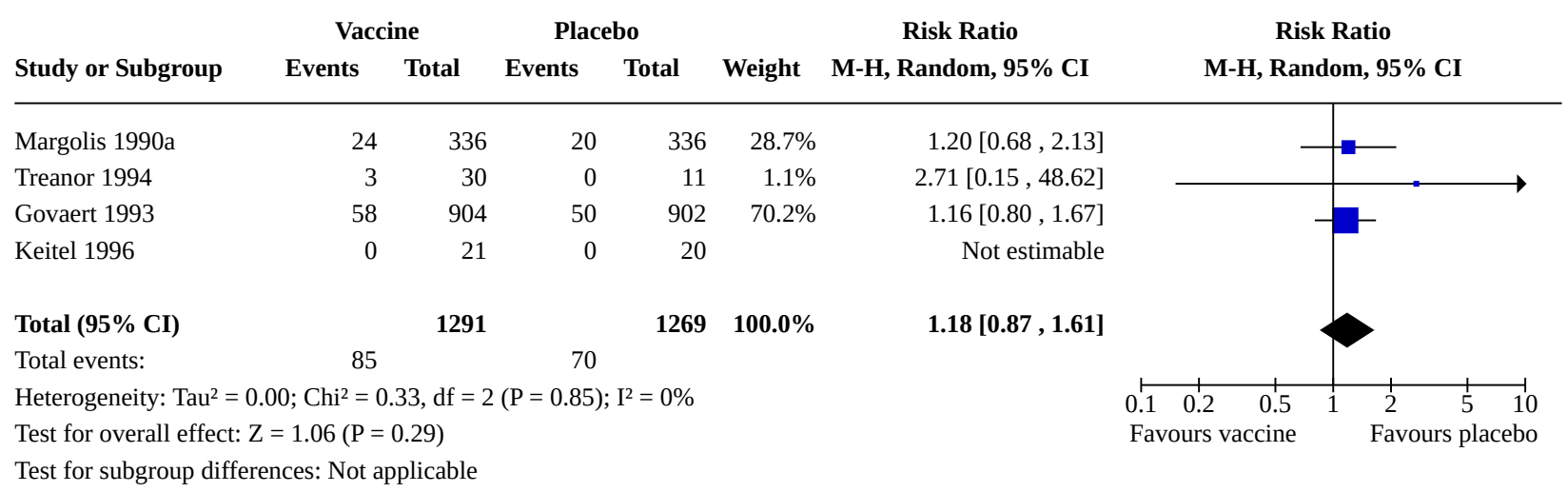


Analysis 2.2. Comparison 2: Influenza vaccines versus placebo: randomised controlled trials - parenteral vaccine - adverse events, Outcome 2: Nausea

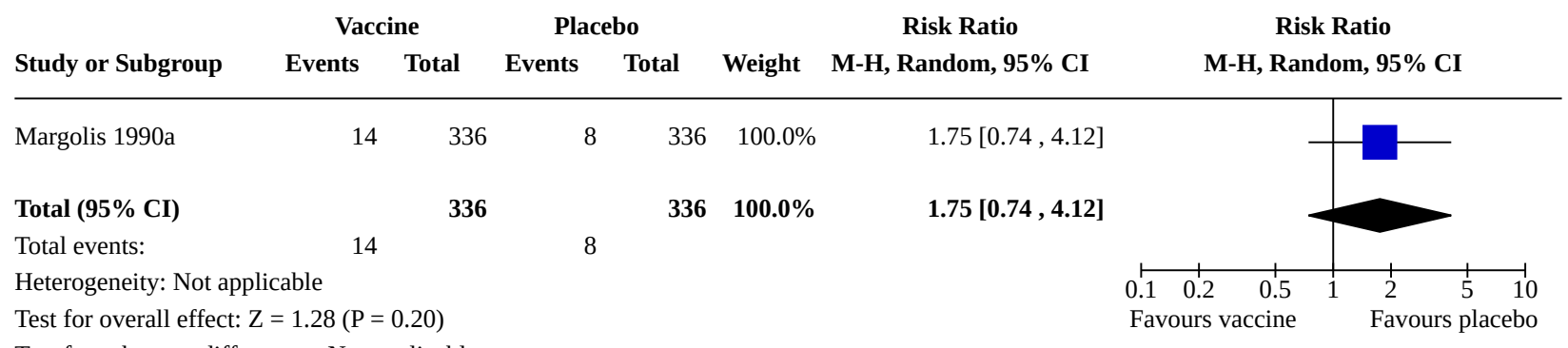

Test for subgroup differences: Not applicable

Analysis 2.3. Comparison 2: Influenza vaccines versus placebo: randomised controlled trials - parenteral vaccine - adverse events, Outcome 3: Upper respiratory tract symptoms

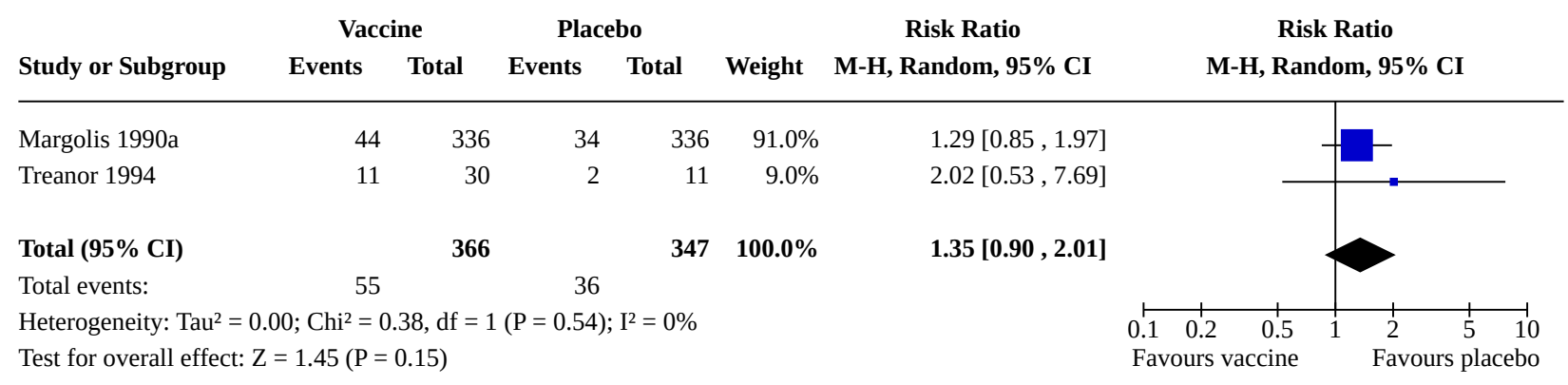

Test for subgroup differences: Not applicable

Analysis 2.4. Comparison 2: Influenza vaccines versus placebo: randomised controlled trials - parenteral vaccine - adverse events, Outcome 4: Headache

\begin{tabular}{|c|c|c|c|c|c|c|c|}
\hline \multirow[b]{2}{*}{ Study or Subgroup } & \multicolumn{2}{|c|}{ Vaccine } & \multicolumn{2}{|c|}{ Placebo } & \multirow[b]{2}{*}{ Weight } & \multirow{2}{*}{$\begin{array}{c}\text { Risk Ratio } \\
\text { M-H, Random, 95\% CI }\end{array}$} & \multirow{2}{*}{$\begin{array}{c}\text { Risk Ratio } \\
\text { M-H, Random, 95\% CI }\end{array}$} \\
\hline & Events & Total & Events & Total & & & \\
\hline Margolis 1990a & 22 & 336 & 26 & 336 & $39.6 \%$ & $0.85[0.49,1.46]$ & \\
\hline Govaert 1993 & 44 & 904 & 35 & 902 & $58.8 \%$ & $1.25[0.81,1.94]$ & \\
\hline Keitel 1996 & 2 & 21 & 0 & 20 & $1.5 \%$ & $4.77[0.24,93.67]$ & \\
\hline Total $(95 \%$ CI) & & 1261 & & 1258 & $100.0 \%$ & $1.10[0.76,1.58]$ & \\
\hline Total events: & 68 & & 61 & & & & \\
\hline \multicolumn{7}{|c|}{ Heterogeneity: $\mathrm{Tau}^{2}=0.01 ; \mathrm{Chi}^{2}=2.17, \mathrm{df}=2(\mathrm{P}=0.34) ; \mathrm{I}^{2}=8 \%$} & $0.1 \quad 0.2 \quad 0.5$ \\
\hline \multicolumn{5}{|c|}{ Test for overall effect: $\mathrm{Z}=0.48(\mathrm{P}=0.63)$} & & & Favours vaccine \\
\hline
\end{tabular}


Analysis 2.5. Comparison 2: Influenza vaccines versus placebo: randomised controlled trials - parenteral vaccine - adverse events, Outcome 5: Fever

\begin{tabular}{|c|c|c|c|c|c|c|c|}
\hline \multirow[b]{2}{*}{ Study or Subgroup } & \multicolumn{2}{|c|}{ Vaccine } & \multicolumn{2}{|c|}{ Placebo } & \multirow[b]{2}{*}{ Weight } & \multirow{2}{*}{$\begin{array}{c}\text { Risk Ratio } \\
\text { M-H, Random, 95\% CI }\end{array}$} & \multirow{2}{*}{$\begin{array}{c}\text { Risk Ratio } \\
\text { M-H, Random, 95\% CI }\end{array}$} \\
\hline & Events & Total & Events & Total & & & \\
\hline Margolis 1990a & 20 & 336 & 14 & 336 & $66.2 \%$ & $1.43[0.73,2.78]$ & \\
\hline Treanor 1994 & 1 & 30 & 0 & 11 & $3.0 \%$ & $1.16[0.05,26.58]$ & $\longleftarrow$ \\
\hline Govaert 1993 & 12 & 904 & 6 & 902 & $30.8 \%$ & $2.00[0.75,5.29]$ & - \\
\hline Total (95\% CI) & & 1270 & & 1249 & $100.0 \%$ & $1.57[0.92,2.71]$ & \\
\hline Total events: & 33 & & 20 & & & & \\
\hline \multicolumn{7}{|c|}{ Heterogeneity: $\mathrm{Tau}^{2}=0.00 ; \mathrm{Chi}^{2}=0.35, \mathrm{df}=2(\mathrm{P}=0.84) ; \mathrm{I}^{2}=0 \%$} & $\begin{array}{ll}\vdash & 1 \\
0.1 & 0.2\end{array}$ \\
\hline \multicolumn{7}{|c|}{ Test for overall effect: $\mathrm{Z}=1.64(\mathrm{P}=0.10)$} & Favours vaccine \\
\hline
\end{tabular}

Test for subgroup differences: Not applicable

Analysis 2.6. Comparison 2: Influenza vaccines versus placebo: randomised controlled trials - parenteral vaccine - adverse events, Outcome 6: Local tenderness/sore arm

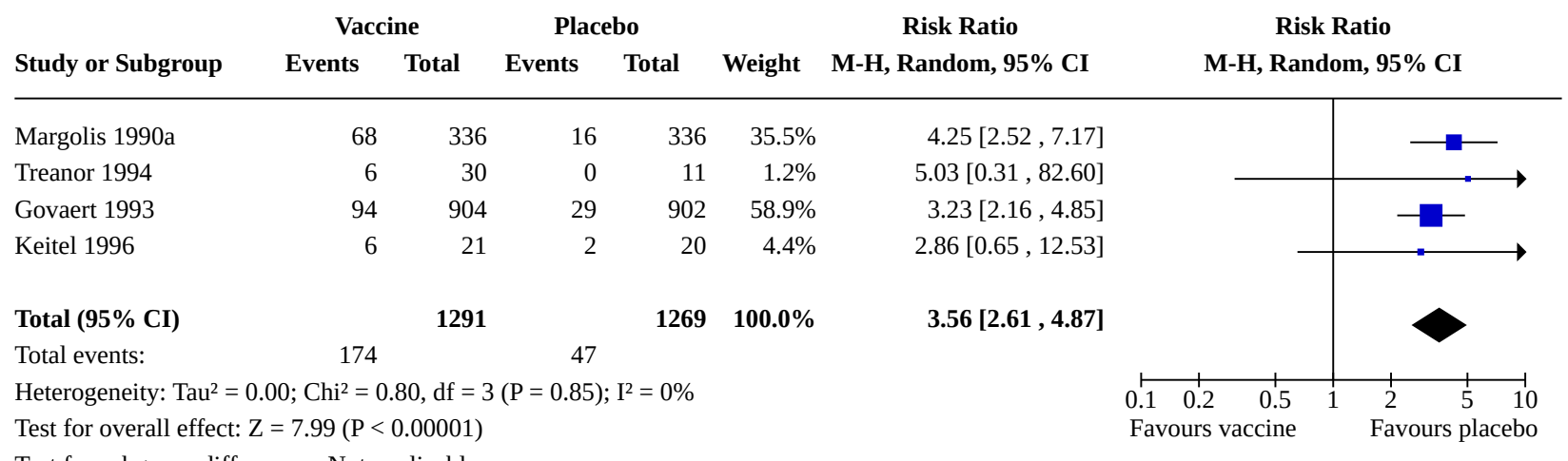

Test for subgroup differences: Not applicable

Analysis 2.7. Comparison 2: Influenza vaccines versus placebo: randomised controlled trials - parenteral vaccine - adverse events, Outcome 7: Swelling - erythema - induration

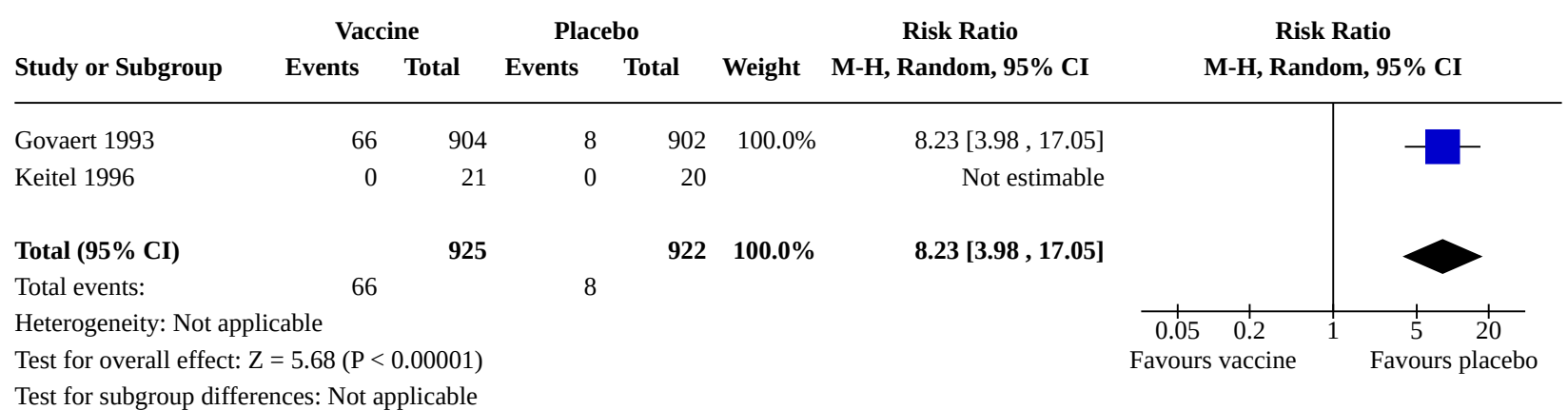


Comparison 3. Influenza vaccines versus placebo: randomised controlled trials - inactivated aerosol vaccine

\begin{tabular}{|c|c|c|c|c|}
\hline Outcome or subgroup title & No. of studies & $\begin{array}{l}\text { No. of partici- } \\
\text { pants }\end{array}$ & Statistical method & Effect size \\
\hline 3.1 Influenza & 1 & 176 & $\begin{array}{l}\text { Risk Ratio (M-H, Random, } \\
95 \% \mathrm{Cl})\end{array}$ & $0.89[0.40,1.99]$ \\
\hline $\begin{array}{l}\text { 3.1.1 Outbreak - vaccine matching - } \\
\text { psychiatric hospital }\end{array}$ & 1 & 176 & $\begin{array}{l}\text { Risk Ratio (M-H, Random, } \\
95 \% \mathrm{Cl})\end{array}$ & $0.89[0.40,1.99]$ \\
\hline 3.2 Influenza-like illness & 1 & 176 & $\begin{array}{l}\text { Risk Ratio (M-H, Random, } \\
95 \% \mathrm{Cl})\end{array}$ & $0.84[0.41,1.71]$ \\
\hline $\begin{array}{l}\text { 3.2.1 Outbreak - vaccine matching - } \\
\text { psychiatric hospital }\end{array}$ & 1 & 176 & $\begin{array}{l}\text { Risk Ratio (M-H, Random, } \\
95 \% \mathrm{Cl})\end{array}$ & $0.84[0.41,1.71]$ \\
\hline
\end{tabular}

Analysis 3.1. Comparison 3: Influenza vaccines versus placebo: randomised controlled trials - inactivated aerosol vaccine, Outcome 1: Influenza

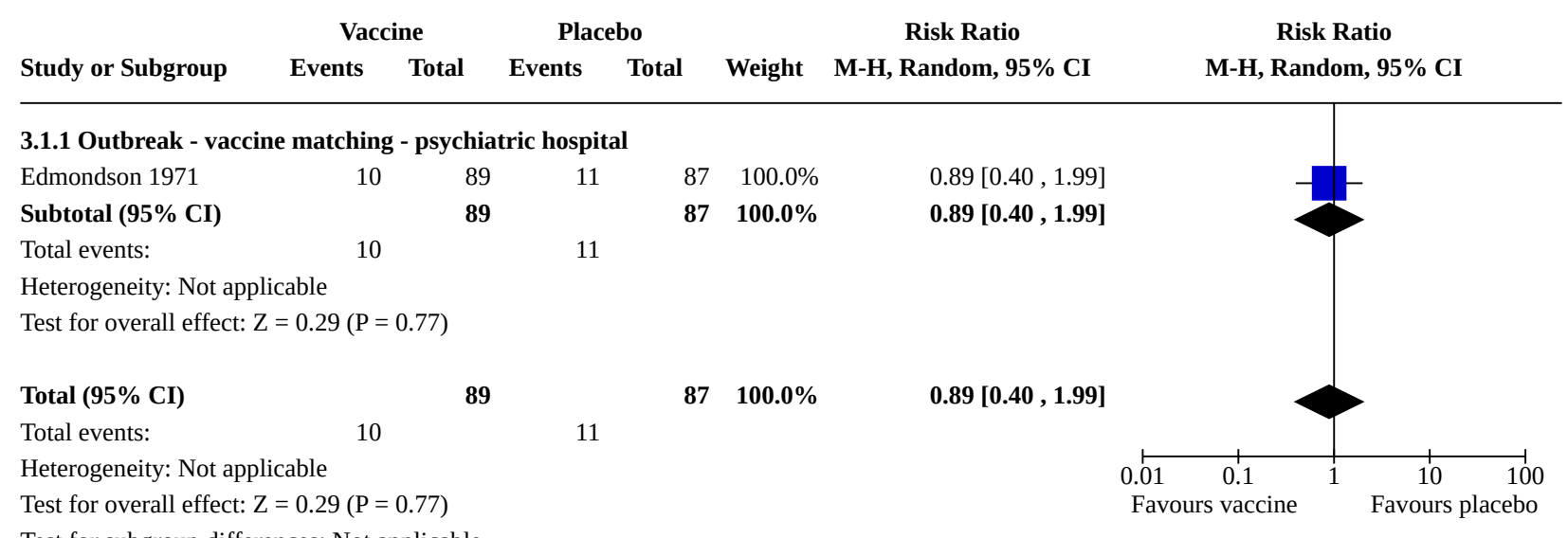

Test for subgroup differences: Not applicable

Analysis 3.2. Comparison 3: Influenza vaccines versus placebo: randomised controlled trials - inactivated aerosol vaccine, Outcome 2: Influenza-like illness

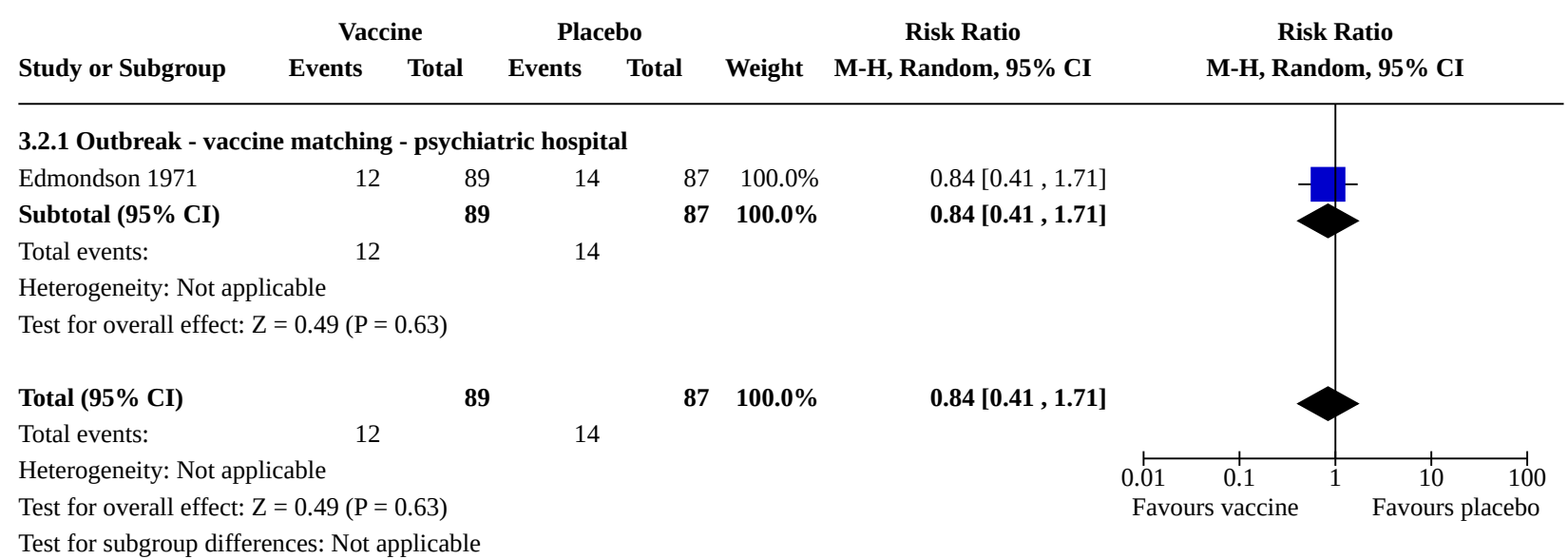


Comparison 4. Influenza vaccines versus placebo: randomised controlled trials - live aerosol vaccine

\begin{tabular}{lllll}
\hline Outcome or subgroup title & No. of studies & $\begin{array}{l}\text { No. of partici- } \\
\text { pants }\end{array}$ & Statistical method & Effect size \\
\hline 4.1 Influenza & 1 & 220 & $\begin{array}{l}\text { Risk Ratio (M-H, Random, } \\
95 \% \mathrm{Cl})\end{array}$ & $0.49[0.21,1.17]$ \\
\hline $\begin{array}{l}\text { 4.1.1 No outbreak - vaccine matching - } \\
\text { nursing home - healthy and ill }\end{array}$ & 1 & 220 & $\begin{array}{l}\text { Risk Ratio (M-H, Random, } \\
95 \% \mathrm{Cl})\end{array}$ & $0.49[0.21,1.17]$ \\
\hline
\end{tabular}

Analysis 4.1. Comparison 4: Influenza vaccines versus placebo: randomised controlled trials - live aerosol vaccine, Outcome 1: Influenza

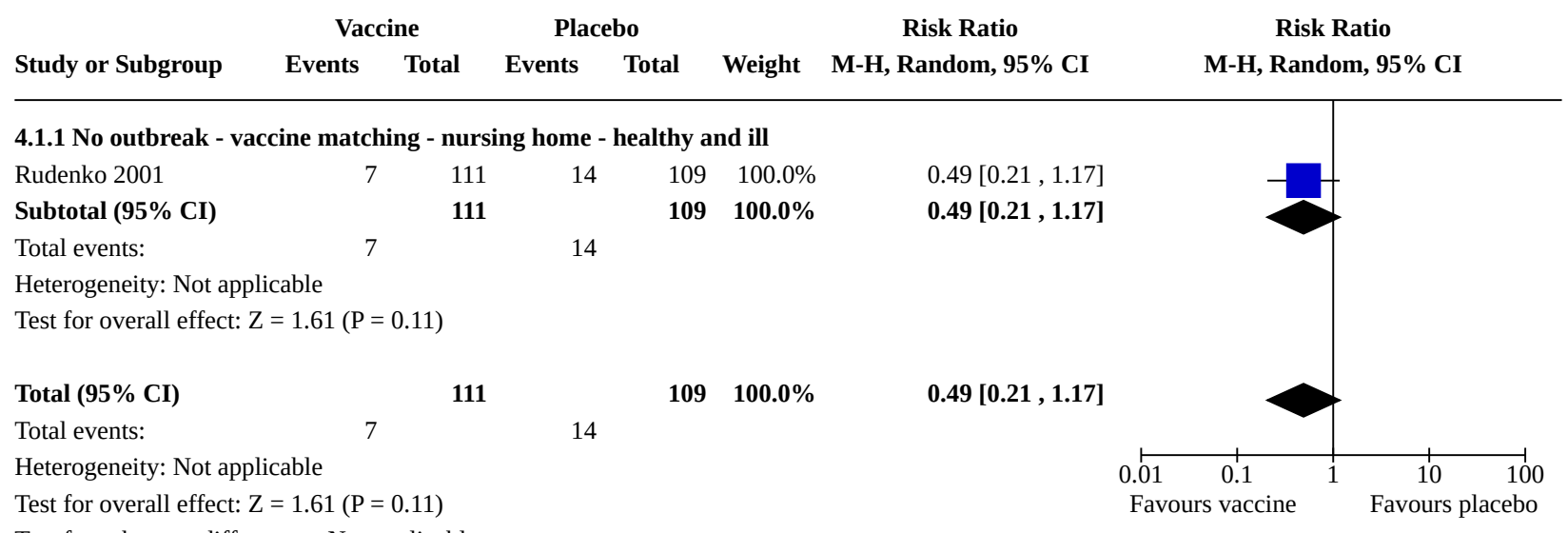

Comparison 5. Influenza vaccines versus placebo: randomised controlled trials - live aerosol vaccine - adverse events

\begin{tabular}{lllll}
\hline Outcome or subgroup title & No. of studies & $\begin{array}{l}\text { No. of partici- } \\
\text { pants }\end{array}$ & Statistical method & Effect size \\
\hline 5.1 General malaise & 1 & 45 & Risk Ratio (M-H, Random, 95\% Cl) & $3.09[0.18,53.20]$ \\
\hline 5.2 Fever & 1 & 45 & Risk Ratio (M-H, Random, 95\% Cl) & $1.71[0.09,33.24]$ \\
\hline $\begin{array}{l}5.3 \text { Upper respiratory tract } \\
\text { symptoms }\end{array}$ & 1 & 45 & Risk Ratio (M-H, Random, 95\% Cl) & $1.62[0.42,6.29]$ \\
\hline $\begin{array}{l}5.4 \text { Lower respiratory tract } \\
\text { symptoms }\end{array}$ & 1 & 45 & Risk Ratio (M-H, Random, 95\% Cl) & $2.91[0.41,20.48]$ \\
\hline
\end{tabular}


Analysis 5.1. Comparison 5: Influenza vaccines versus placebo: randomised controlled trials - live aerosol vaccine - adverse events, Outcome 1: General malaise

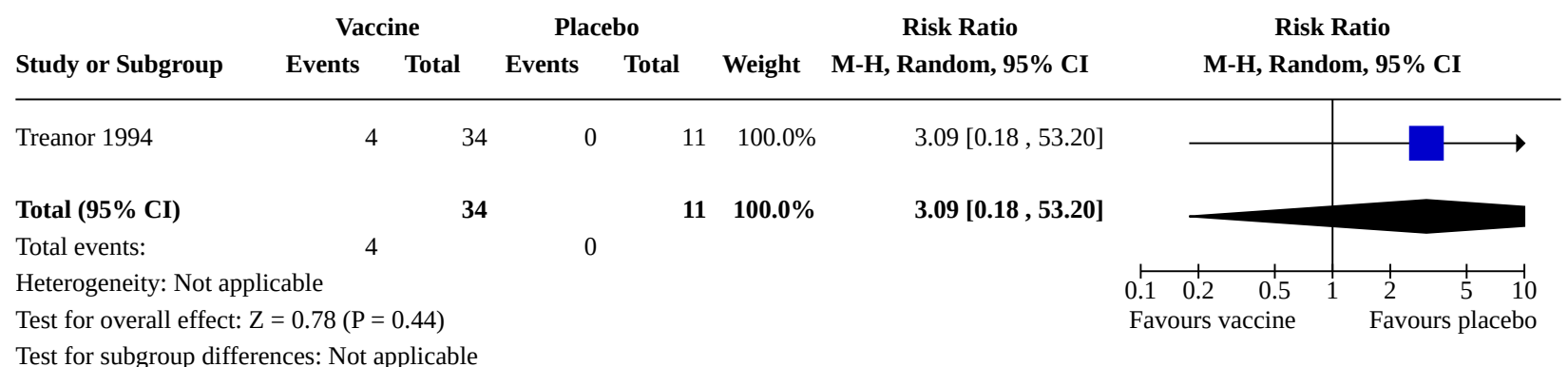

Analysis 5.2. Comparison 5: Influenza vaccines versus placebo: randomised controlled trials - live aerosol vaccine - adverse events, Outcome 2: Fever

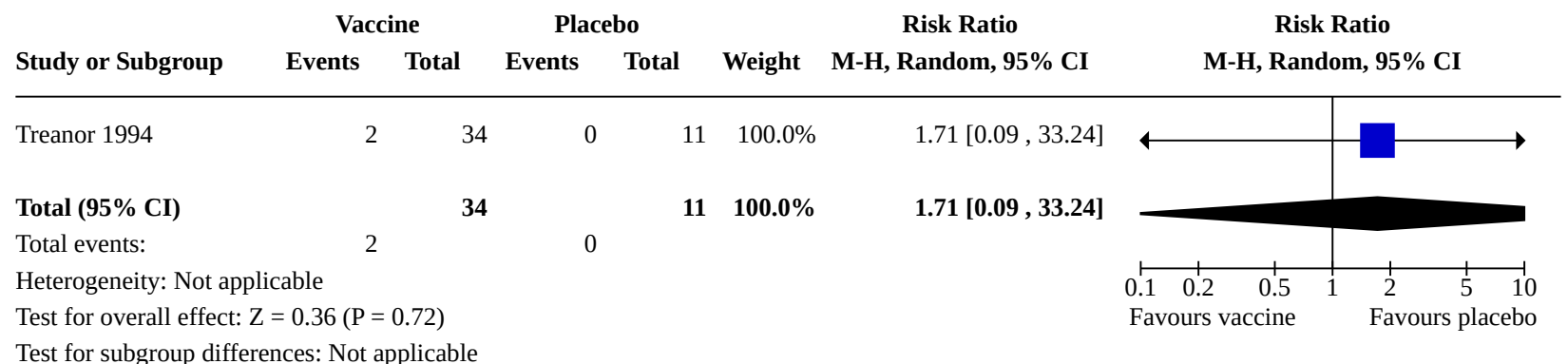

Analysis 5.3. Comparison 5: Influenza vaccines versus placebo: randomised controlled trials - live aerosol vaccine - adverse events, Outcome 3: Upper respiratory tract symptoms

\begin{tabular}{|c|c|c|c|c|c|c|c|c|}
\hline \multirow[b]{2}{*}{ Study or Subgroup } & \multicolumn{2}{|c|}{ Vaccine } & \multicolumn{2}{|c|}{ Placebo } & \multirow[b]{2}{*}{ Weight } & \multirow{2}{*}{$\begin{array}{c}\text { Risk Ratio } \\
\text { M-H, Random, 95\% CI }\end{array}$} & \multirow{2}{*}{\multicolumn{2}{|c|}{$\begin{array}{c}\text { Risk Ratio } \\
\text { M-H, Random, 95\% CI }\end{array}$}} \\
\hline & Events & Total & Events & Total & & & & \\
\hline Treanor 1994 & 10 & 34 & 2 & 11 & $100.0 \%$ & $1.62[0.42,6.29]$ & & \\
\hline Total (95\% CI) & & 34 & & 11 & $100.0 \%$ & $1.62[0.42,6.29]$ & & \\
\hline Total events: & 10 & & 2 & & & & & \\
\hline \multirow{2}{*}{\multicolumn{3}{|c|}{$\begin{array}{l}\text { Heterogeneity: Not applicable } \\
\text { Test for overall effect: } \mathrm{Z}=0.69(\mathrm{P}=0.49)\end{array}$}} & & & & & $\begin{array}{lll}0.1 & 0.2 & 0.5\end{array}$ & 2 \\
\hline & & & & & & & Favours vaccine & Favours $\mathrm{F}$ \\
\hline
\end{tabular}


Analysis 5.4. Comparison 5: Influenza vaccines versus placebo: randomised controlled trials - live aerosol vaccine - adverse events, Outcome 4: Lower respiratory tract symptoms

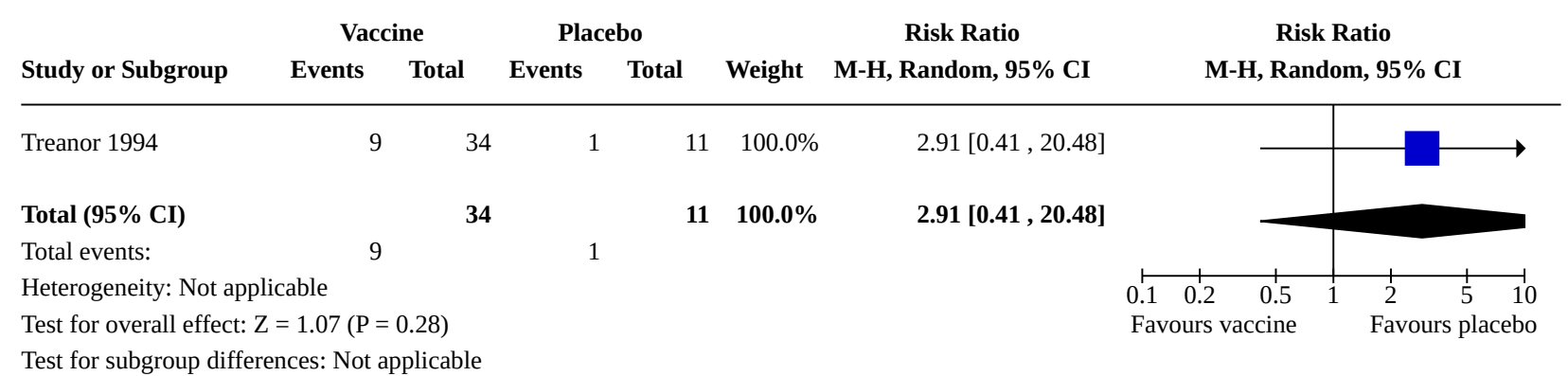

Comparison 6. Influenza vaccines versus no vaccination: cohort studies in nursing homes

\begin{tabular}{|c|c|c|c|c|}
\hline Outcome or subgroup title & No. of studies & $\begin{array}{l}\text { No. of partici- } \\
\text { pants }\end{array}$ & Statistical method & Effect size \\
\hline 6.1 Influenza & 8 & 1941 & $\begin{array}{l}\text { Risk Ratio (M-H, Random, } \\
95 \% \mathrm{Cl})\end{array}$ & $0.65[0.32,1.29]$ \\
\hline 6.1.1 Outbreak - vaccine matching & 4 & 658 & $\begin{array}{l}\text { Risk Ratio (M-H, Random, } \\
95 \% \mathrm{Cl} \text { ) }\end{array}$ & $1.04[0.43,2.51]$ \\
\hline $\begin{array}{l}\text { 6.1.2 Outbreak - vaccine matching } \\
\text { absent or unknown }\end{array}$ & 2 & 592 & $\begin{array}{l}\text { Risk Ratio (M-H, Random, } \\
95 \% \mathrm{Cl} \text { ) }\end{array}$ & $0.47[0.22,1.04]$ \\
\hline 6.1.3 No outbreak - vaccine matching & 2 & 691 & $\begin{array}{l}\text { Risk Ratio (M-H, Random, } \\
95 \% \mathrm{Cl})\end{array}$ & $0.23[0.05,1.03]$ \\
\hline $\begin{array}{l}\text { 6.1.4 No outbreak - vaccine matching } \\
\text { absent or unknown }\end{array}$ & 0 & 0 & $\begin{array}{l}\text { Risk Ratio (M-H, Random, } \\
95 \% \mathrm{Cl})\end{array}$ & Not estimable \\
\hline 6.2 Influenza-like illness & 26 & 12388 & $\begin{array}{l}\text { Risk Ratio (M-H, Random, } \\
95 \% \mathrm{Cl})\end{array}$ & $0.76[0.66,0.88]$ \\
\hline $\begin{array}{l}\text { 6.2.1 Outbreak - vaccine matching } \\
\text { (circulating strains) }\end{array}$ & 16 & 5963 & $\begin{array}{l}\text { Risk Ratio (M-H, Random, } \\
95 \% \mathrm{Cl})\end{array}$ & $0.77[0.64,0.94]$ \\
\hline $\begin{array}{l}\text { 6.2.2 Outbreak - vaccine matching } \\
\text { absent or unknown }\end{array}$ & 6 & 4096 & $\begin{array}{l}\text { Risk Ratio (M-H, Random, } \\
95 \% \mathrm{Cl})\end{array}$ & $0.80[0.60,1.05]$ \\
\hline 6.2.3 No outbreak - vaccine matching & 4 & 2329 & $\begin{array}{l}\text { Risk Ratio (M-H, Random, } \\
95 \% \mathrm{Cl})\end{array}$ & $0.67[0.46,0.98]$ \\
\hline $\begin{array}{l}\text { 6.2.4 No outbreak - vaccine matching } \\
\text { absent or unknown }\end{array}$ & 0 & 0 & $\begin{array}{l}\text { Risk Ratio (M-H, Random, } \\
95 \% \mathrm{Cl} \text { ) }\end{array}$ & Not estimable \\
\hline 6.3 Pneumonia & 17 & 10274 & $\begin{array}{l}\text { Risk Ratio (M-H, Random, } \\
95 \% \mathrm{Cl} \text { ) }\end{array}$ & $0.53[0.43,0.66]$ \\
\hline 6.3.1 Outbreak - vaccine matching & 8 & 4482 & $\begin{array}{l}\text { Risk Ratio (M-H, Random, } \\
95 \% \mathrm{Cl} \text { ) }\end{array}$ & $0.54[0.42,0.70]$ \\
\hline $\begin{array}{l}\text { 6.3.2 Outbreak - vaccine matching } \\
\text { absent or unknown }\end{array}$ & 5 & 3991 & $\begin{array}{l}\text { Risk Ratio (M-H, Random, } \\
95 \% \mathrm{Cl} \text { ) }\end{array}$ & $0.68[0.39,1.21]$ \\
\hline
\end{tabular}




\begin{tabular}{|c|c|c|c|c|}
\hline Outcome or subgroup title & No. of studies & $\begin{array}{l}\text { No. of partici- } \\
\text { pants }\end{array}$ & Statistical method & Effect size \\
\hline 6.3.3 No outbreak - vaccine matching & 0 & 0 & $\begin{array}{l}\text { Risk Ratio (M-H, Random, } \\
95 \% \mathrm{Cl})\end{array}$ & Not estimable \\
\hline $\begin{array}{l}\text { 6.3.4 No outbreak - matching absent } \\
\text { or unknown }\end{array}$ & 4 & 1801 & $\begin{array}{l}\text { Risk Ratio (M-H, Random, } \\
95 \% \mathrm{Cl})\end{array}$ & $0.35[0.18,0.68]$ \\
\hline $\begin{array}{l}6.4 \text { Hospitalisation for influenza-like } \\
\text { illness or pneumonia }\end{array}$ & 12 & 28032 & $\begin{array}{l}\text { Risk Ratio (M-H, Random, } \\
95 \% \mathrm{Cl})\end{array}$ & $0.51[0.32,0.81]$ \\
\hline 6.4.1 Outbreak - vaccine matching & 8 & 2027 & $\begin{array}{l}\text { Risk Ratio (M-H, Random, } \\
95 \% \mathrm{Cl} \text { ) }\end{array}$ & $0.55[0.36,0.84]$ \\
\hline $\begin{array}{l}\text { 6.4.2 Outbreak - vaccine matching } \\
\text { absent or unknown }\end{array}$ & 2 & 3301 & $\begin{array}{l}\text { Risk Ratio (M-H, Random, } \\
95 \% \mathrm{Cl})\end{array}$ & $0.82[0.43,1.58]$ \\
\hline 6.4.3 No outbreak - vaccine matching & 2 & 22704 & $\begin{array}{l}\text { Risk Ratio (M-H, Random, } \\
95 \% \mathrm{Cl})\end{array}$ & $0.32[0.14,0.76]$ \\
\hline $\begin{array}{l}\text { 6.4.4 No outbreak - vaccine matching } \\
\text { absent or unknown }\end{array}$ & 0 & 0 & $\begin{array}{l}\text { Risk Ratio (M-H, Random, } \\
95 \% \mathrm{Cl})\end{array}$ & Not estimable \\
\hline 6.5 Deaths from flu or pneumonia & 27 & 32179 & $\begin{array}{l}\text { Risk Ratio (M-H, Random, } \\
95 \% \mathrm{Cl})\end{array}$ & $0.46[0.33,0.63]$ \\
\hline 6.5.1 Outbreak - vaccine matching & 16 & 6127 & $\begin{array}{l}\text { Risk Ratio (M-H, Random, } \\
95 \% \mathrm{Cl})\end{array}$ & $0.58[0.41,0.83]$ \\
\hline $\begin{array}{l}\text { 6.5.2 Outbreak - vaccine matching } \\
\text { absent or unknown }\end{array}$ & 4 & 1089 & $\begin{array}{l}\text { Risk Ratio (M-H, Random, } \\
95 \% \mathrm{Cl})\end{array}$ & $0.34[0.11,1.02]$ \\
\hline 6.5.3 No outbreak - vaccine matching & 3 & 23162 & $\begin{array}{l}\text { Risk Ratio (M-H, Random, } \\
95 \% \mathrm{Cl})\end{array}$ & $0.27[0.09,0.87]$ \\
\hline $\begin{array}{l}\text { 6.5.4 No outbreak - vaccine matching } \\
\text { absent or unknown }\end{array}$ & 4 & 1801 & $\begin{array}{l}\text { Risk Ratio (M-H, Random, } \\
95 \% \mathrm{Cl})\end{array}$ & $0.30[0.14,0.67]$ \\
\hline 6.6 All deaths & 1 & 305 & $\begin{array}{l}\text { Risk Ratio (M-H, Random, } \\
95 \% \mathrm{Cl})\end{array}$ & $0.40[0.21,0.77]$ \\
\hline 6.6.1 Outbreak - vaccine matching & 1 & 305 & $\begin{array}{l}\text { Risk Ratio (M-H, Random, } \\
95 \% \mathrm{Cl})\end{array}$ & $0.40[0.21,0.77]$ \\
\hline $\begin{array}{l}\text { 6.6.2 Outbreak - vaccine matching } \\
\text { absent or unknown }\end{array}$ & 0 & 0 & $\begin{array}{l}\text { Risk Ratio (M-H, Random, } \\
95 \% \mathrm{Cl})\end{array}$ & Not estimable \\
\hline 6.6.3 No outbreak - vaccine matching & 0 & 0 & $\begin{array}{l}\text { Risk Ratio (M-H, Random, } \\
95 \% \mathrm{Cl})\end{array}$ & Not estimable \\
\hline $\begin{array}{l}\text { 6.6.4 No outbreak - vaccine matching } \\
\text { absent or unknown }\end{array}$ & 0 & 0 & $\begin{array}{l}\text { Risk Ratio (M-H, Random, } \\
95 \% \mathrm{Cl})\end{array}$ & Not estimable \\
\hline $\begin{array}{l}6.7 \text { Influenza cases (clinically defined } \\
\text { without clear definition) }\end{array}$ & 7 & 24238 & $\begin{array}{l}\text { Risk Ratio (M-H, Random, } \\
95 \% \mathrm{Cl})\end{array}$ & $0.52[0.27,1.02]$ \\
\hline
\end{tabular}




\begin{tabular}{|c|c|c|c|c|}
\hline Outcome or subgroup title & No. of studies & $\begin{array}{l}\text { No. of partici- } \\
\text { pants }\end{array}$ & Statistical method & Effect size \\
\hline 6.7.1 Outbreak - vaccine matching & 2 & 271 & $\begin{array}{l}\text { Risk Ratio (M-H, Random, } \\
95 \% \mathrm{Cl} \text { ) }\end{array}$ & $0.70[0.11,4.56]$ \\
\hline $\begin{array}{l}\text { 6.7.2 Outbreak - vaccine matching } \\
\text { absent or unknown }\end{array}$ & 1 & 155 & $\begin{array}{l}\text { Risk Ratio (M-H, Random, } \\
95 \% \mathrm{Cl} \text { ) }\end{array}$ & $0.23[0.09,0.59]$ \\
\hline 6.7.3 No outbreak - vaccine matching & 1 & 22462 & $\begin{array}{l}\text { Risk Ratio (M-H, Random, } \\
95 \% \mathrm{Cl} \text { ) }\end{array}$ & $0.40[0.35,0.46]$ \\
\hline $\begin{array}{l}\text { 6.7.4 No outbreak - vaccine matching } \\
\text { absent or unknown }\end{array}$ & 3 & 1350 & $\begin{array}{l}\text { Risk Ratio (M-H, Random, } \\
95 \% \mathrm{Cl} \text { ) }\end{array}$ & $0.72[0.41,1.28]$ \\
\hline
\end{tabular}




\section{Analysis 6.1. Comparison 6: Influenza vaccines versus no vaccination: cohort studies in nursing homes, Outcome 1: Influenza}

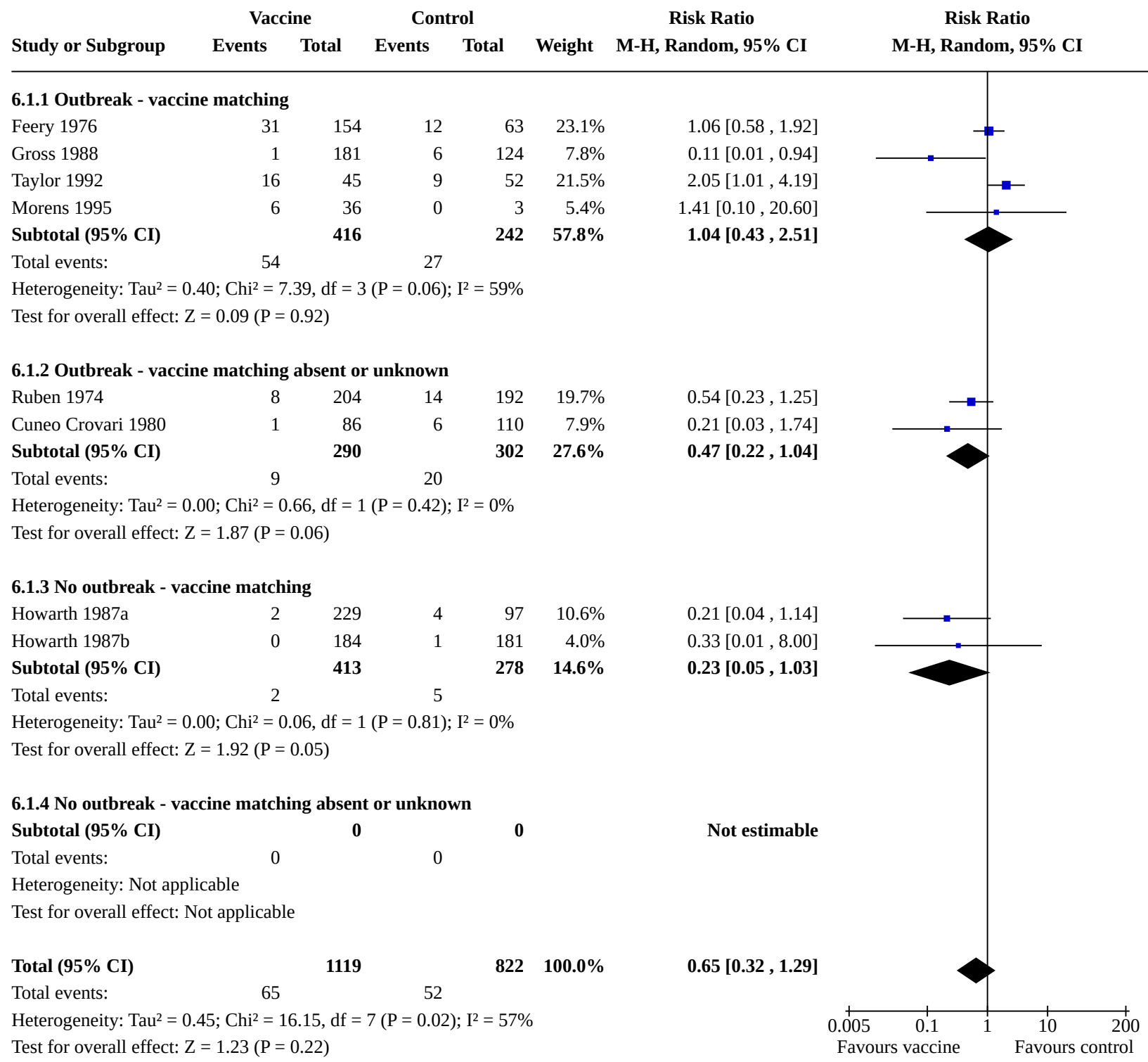


Analysis 6.2. Comparison 6: Influenza vaccines versus no vaccination: cohort studies in nursing homes, Outcome 2: Influenza-like illness

\begin{tabular}{lrrrrr}
\multicolumn{7}{c}{ Vaccine } & \multicolumn{2}{c}{ Control } \\
Study or Subgroup & Events & Total & Events & Total & Weight \\
\hline 6.2.1 Outbreak - vaccine matching (circulating strains) & & \\
Goodman 1982 & 6 & 36 & 24 & 84 & $2.2 \%$ \\
Horman 1986 & 22 & 100 & 12 & 59 & $3.1 \%$ \\
Patriarca 1985a & 113 & 548 & 155 & 470 & $6.5 \%$ \\
Strassburg 1986 & 34 & 65 & 11 & 19 & $4.3 \%$ \\
Fyson 1983a & 23 & 321 & 29 & 224 & $3.8 \%$ \\
Meiklejohn 1987 & 14 & 36 & 16 & 19 & $4.3 \%$ \\
Cartter 1990c & 75 & 332 & 25 & 126 & $4.7 \%$ \\
Cartter 1990b & 12 & 30 & 14 & 55 & $3.1 \%$ \\
Cartter 1990a & 15 & 96 & 3 & 35 & $1.2 \%$ \\
Arden 1988 & 6 & 31 & 8 & 24 & $1.8 \%$ \\
Taylor 1992 & 25 & 45 & 27 & 52 & $5.0 \%$ \\
Morens 1995 & 10 & 36 & 1 & 3 & $0.7 \%$ \\
Mukerjee 1994 & 62 & 250 & 121 & 216 & $6.2 \%$ \\
Monto 2001 & 247 & 1728 & 98 & 623 & $6.5 \%$ \\
Isaacs 1997 & 57 & 149 & 12 & 23 & $4.4 \%$ \\
Murayama 1999 & 25 & 60 & 38 & 68 & $5.1 \%$ \\
Subtotal (95\% CI) & & $\mathbf{3 8 6 3}$ & & $\mathbf{2 1 0 0}$ & $\mathbf{6 2 . 9 \%}$ \\
Total events: & 746 & & 594 & &
\end{tabular}

Risk Ratio

Risk Ratio

Heterogeneity: Tau $^{2}=0.09 ; \mathrm{Chi}^{2}=46.72, \mathrm{df}=15(\mathrm{P}<0.0001) ; \mathrm{I}^{2}=68 \%$

Test for overall effect: $\mathrm{Z}=2.64(\mathrm{P}=0.008)$

6.2.2 Outbreak - vaccine matching absent or unknown

$\begin{array}{lrrrrr}\text { Leung 2007 } & 194 & 2943 & 16 & 234 & 4.0 \% \\ \text { D'Alessio 1969 } & 29 & 131 & 7 & 31 & 2.5 \% \\ \text { Ruben 1974 } & 38 & 204 & 70 & 192 & 5.3 \% \\ \text { Arroyo 1984 } & 10 & 26 & 44 & 90 & 3.7 \% \\ \text { Currier 1988 } & 36 & 87 & 15 & 34 & 4.3 \% \\ \text { Coles 1992 } & 34 & 112 & 3 & 12 & 1.5 \% \\ \text { Subtotal (95\% CI) } & & \mathbf{3 5 0 3} & & \mathbf{5 9 3} & \mathbf{2 1 . 4 \%} \\ \text { Total events: } & 341 & & 155 & & \end{array}$

$0.96[0.59,1.58]$ $0.98[0.47,2.03]$ $0.51[0.36,0.72]$ $0.79[0.46,1.34]$ $0.94[0.60,1.48]$ $1.21[0.44,3.37]$ $0.80[0.60,1.05]$

Heterogeneity: $\mathrm{Tau}^{2}=0.04 ; \mathrm{Chi}^{2}=8.18, \mathrm{df}=5(\mathrm{P}=0.15) ; \mathrm{I}^{2}=39 \%$

Test for overall effect: $\mathrm{Z}=1.62(\mathrm{P}=0.11)$

6.2.3 No outbreak - vaccine matching

$\begin{array}{lrrrrr}\text { Patriarca 1985b } & 37 & 339 & 20 & 119 & 3.9 \% \\ \text { Caminiti 1994 } & 12 & 169 & 12 & 73 & 2.4 \% \\ \text { Saito 2002a } & 58 & 331 & 112 & 368 & 5.9 \% \\ \text { Saito 2002b } & 68 & 743 & 14 & 187 & 3.5 \% \\ \text { Subtotal (95\% CI) } & & \mathbf{1 5 8 2} & & \mathbf{7 4 7} & \mathbf{1 5 . 8 \%} \\ \text { Total events: } & 175 & & 158 & & \end{array}$

$0.65[0.39,1.07]$ $0.43[0.20,0.92]$ $0.58[0.44,0.76]$ $1.22[0.70,2.12]$ $0.67[0.46,0.98]$

Heterogeneity: $\mathrm{Tau}^{2}=0.08 ; \mathrm{Chi}^{2}=6.91, \mathrm{df}=3(\mathrm{P}=0.07) ; \mathrm{I}^{2}=57 \%$ Test for overall effect: $\mathrm{Z}=2.09(\mathrm{P}=0.04)$

6.2.4 No outbreak - vaccine matching absent or unknown Subtotal (95\% CI)

o 0

Not estimable

Total events: 0 0

Heterogeneity: Not applicable

Test for overall effect: Not applicable

Total (95\% CI)

Total events:

8948 1262 907

$3440 \quad 100.0 \%$

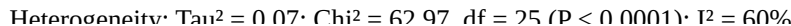

$1.08[0.58,2.02]$

$63[0.51,0.77]$

$0.55[0.33,0.93]$

$6[0.29,0.73]$

$1.57[0.84,2.95]$

$82[0.56,5.92]$

$1.07[0.74,1.55]$

$0.91[0.73,1.13]$

$0.73[0.47,1.14]$

$0.77[0.64,0.94]$ 


\section{Analysis 6.2. (Continued)}

Total events: 1262

907

Heterogeneity: Tau $^{2}=0.07 ; \mathrm{Chi}^{2}=62.97, \mathrm{df}=25(\mathrm{P}<0.0001) ; \mathrm{I}^{2}=60 \%$

Test for overall effect: $\mathrm{Z}=3.79(\mathrm{P}=0.0002)$

Test for subgroup differences: $\mathrm{Chi}^{2}=0.54, \mathrm{df}=2(\mathrm{P}=0.76), \mathrm{I}^{2}=0 \%$

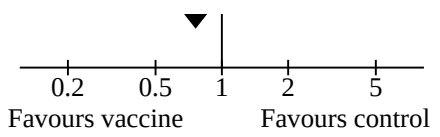




\section{Analysis 6.3. Comparison 6: Influenza vaccines versus no vaccination: cohort studies in nursing homes, Outcome 3: Pneumonia}

\begin{tabular}{lrrrrr}
\multicolumn{2}{c}{ Vaccine } & \multicolumn{2}{c}{ Control } \\
Study or Subgroup & Events & Total & Events & Total & Weight \\
\hline 6.3.1 Outbreak - vaccine matching & & & & & \\
Saah 1986b & 12 & 244 & 11 & 214 & $7.2 \%$ \\
Horman 1986 & 6 & 100 & 5 & 59 & $3.5 \%$ \\
Gross 1988 & 6 & 181 & 8 & 124 & $4.3 \%$ \\
Patriarca 1985a & 22 & 548 & 45 & 470 & $18.7 \%$ \\
Meiklejohn 1987 & 4 & 36 & 8 & 19 & $4.0 \%$ \\
Taylor 1992 & 3 & 45 & 3 & 52 & $1.9 \%$ \\
Morens 1995 & 5 & 36 & 1 & 3 & $1.4 \%$ \\
Monto 2001 & 65 & 1728 & 41 & 623 & $31.7 \%$ \\
Subtotal (95\% CI) & & $\mathbf{2 9 1 8}$ & & $\mathbf{1 5 6 4}$ & $\mathbf{7 2 . 7 \%}$ \\
Total events: & 123 & & 122 & &
\end{tabular}

Risk Ratio

Risk Ratio

M-H, Random, 95\% CI

M-H, Random, 95\% CI

Heterogeneity: $\mathrm{Tau}^{2}=0.00 ; \mathrm{Chi}^{2}=6.04, \mathrm{df}=7(\mathrm{P}=0.54) ; \mathrm{I}^{2}=0 \%$

Test for overall effect: $\mathrm{Z}=4.80(\mathrm{P}<0.00001)$

6.3.2 Outbreak - vaccine matching absent or unknown

$\begin{array}{lrrrrr}\text { Leung 2007 } & 18 & 2943 & 1 & 234 & 1.1 \% \\ \text { Saah 1986a } & 11 & 219 & 20 & 234 & 9.0 \% \\ \text { Arroyo 1984 } & 2 & 26 & 14 & 90 & 2.3 \% \\ \text { Currier 1988 } & 4 & 87 & 1 & 34 & 1.0 \% \\ \text { Coles 1992 } & 6 & 112 & 0 & 12 & 0.6 \% \\ \text { Subtotal (95\% CI) } & & \mathbf{3 3 8 7} & & \mathbf{6 0 4} & \mathbf{1 4 . 0 \%} \\ \text { Total events: } & 41 & & 36 & & \end{array}$

Heterogeneity: $\mathrm{Tau}^{2}=0.00 ; \mathrm{Chi}^{2}=1.76, \mathrm{df}=4(\mathrm{P}=0.78) ; \mathrm{I}^{2}=0 \%$

Test for overall effect: $\mathrm{Z}=1.30(\mathrm{P}=0.19)$

6.3.3 No outbreak - vaccine matching

Subtotal (95\% CI)

$\mathbf{0}$

$\mathbf{0}$

Total events:

0

0

Heterogeneity: Not applicable

Test for overall effect: Not applicable

6.3.4 No outbreak - matching absent or unknown

Howells 1975a

Howells $1975 b$

2134

134
123

18

356

$2.2 \%$

Howells 1975c

183

28

267

$3.3 \%$

Saah $1986 c$

$\begin{array}{ll}0 & 183 \\ 9 & 225\end{array}$

287

$0.6 \%$

Subtotal (95\% CI)

665

1136

$13.3 \%$

Total events:

14

73

Heterogeneity: $\mathrm{Tau}^{2}=0.06$; $\mathrm{Chi}^{2}=3.44, \mathrm{df}=3(\mathrm{P}=0.33) ; \mathrm{I}^{2}=13 \%$

Test for overall effect: $\mathrm{Z}=3.10(\mathrm{P}=0.002)$

\section{Total (95\% CI)}

6970

178

231

Heterogeneity: $\mathrm{Tau}^{2}=0.00 ; \mathrm{Chi}^{2}=13.29, \mathrm{df}=16(\mathrm{P}=0.65) ; \mathrm{I}^{2}=0 \%$

Test for overall effect: $\mathrm{Z}=5.79(\mathrm{P}<0.00001)$

Test for subgroup differences: $\mathrm{Chi}^{2}=2.24, \mathrm{df}=2(\mathrm{P}=0.33), \mathrm{I}^{2}=10.7 \%$
$0.96[0.43,2.12]$

$0.51[0.18,1.44]$

$0.42[0.26,0.69]$

$0.26[0.09,0.76]$

$[0.25,5.44]$

$0.57[0.39,0.84]$

$0.54[0.42,0.70]$

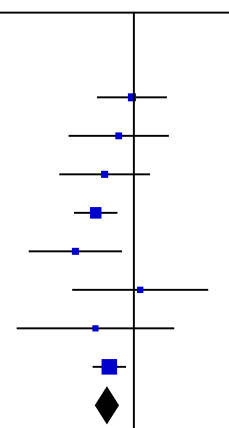

$1.43[0.19,10.67]$

$0.59[0.29,1.20]$

$0.49[0.12,2.04]$

$1.56[0.18,13.49]$

$1.50[0.09,25.06]$

0.68 [0.39, 1.21]

Not estimable

$0.30[0.07,1.26]$

$0.23[0.07,0.75]$

$0.07[0.00,1.15]$

$0.56[0.26,1.25]$

0.35 [0.18, 0.68]

4
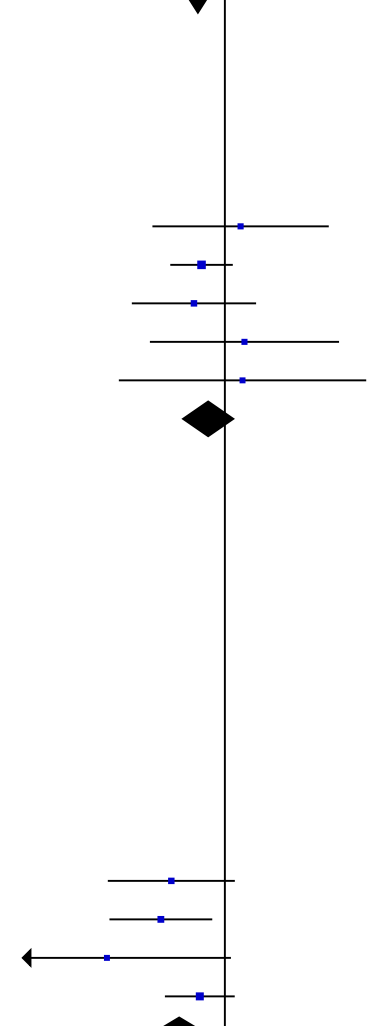
Analysis 6.4. Comparison 6: Influenza vaccines versus no vaccination: cohort studies in nursing homes, Outcome 4: Hospitalisation for influenza-like illness or pneumonia

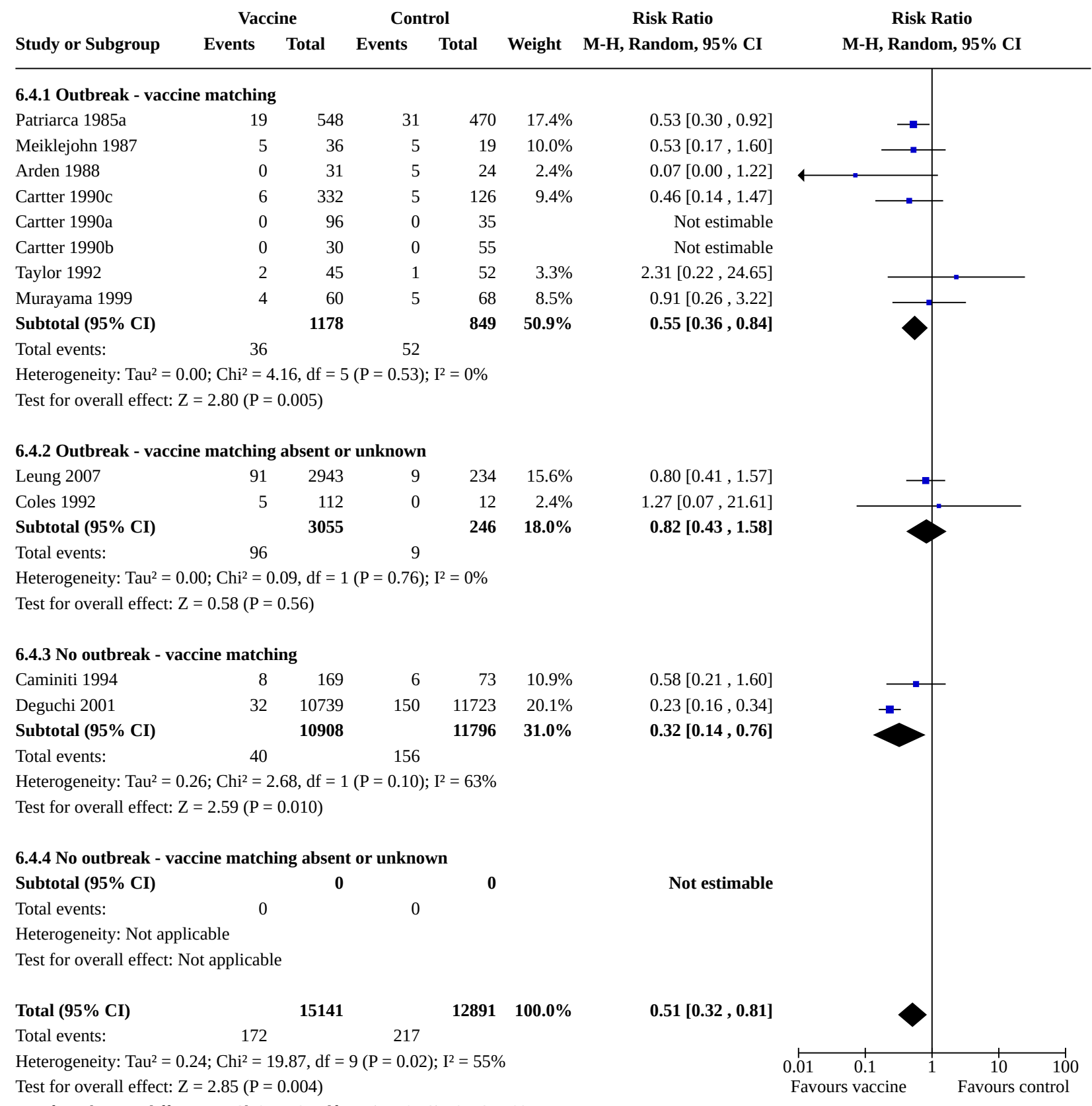


Analysis 6.5. Comparison 6: Influenza vaccines versus no vaccination: cohort studies in nursing homes, Outcome 5: Deaths from flu or pneumonia

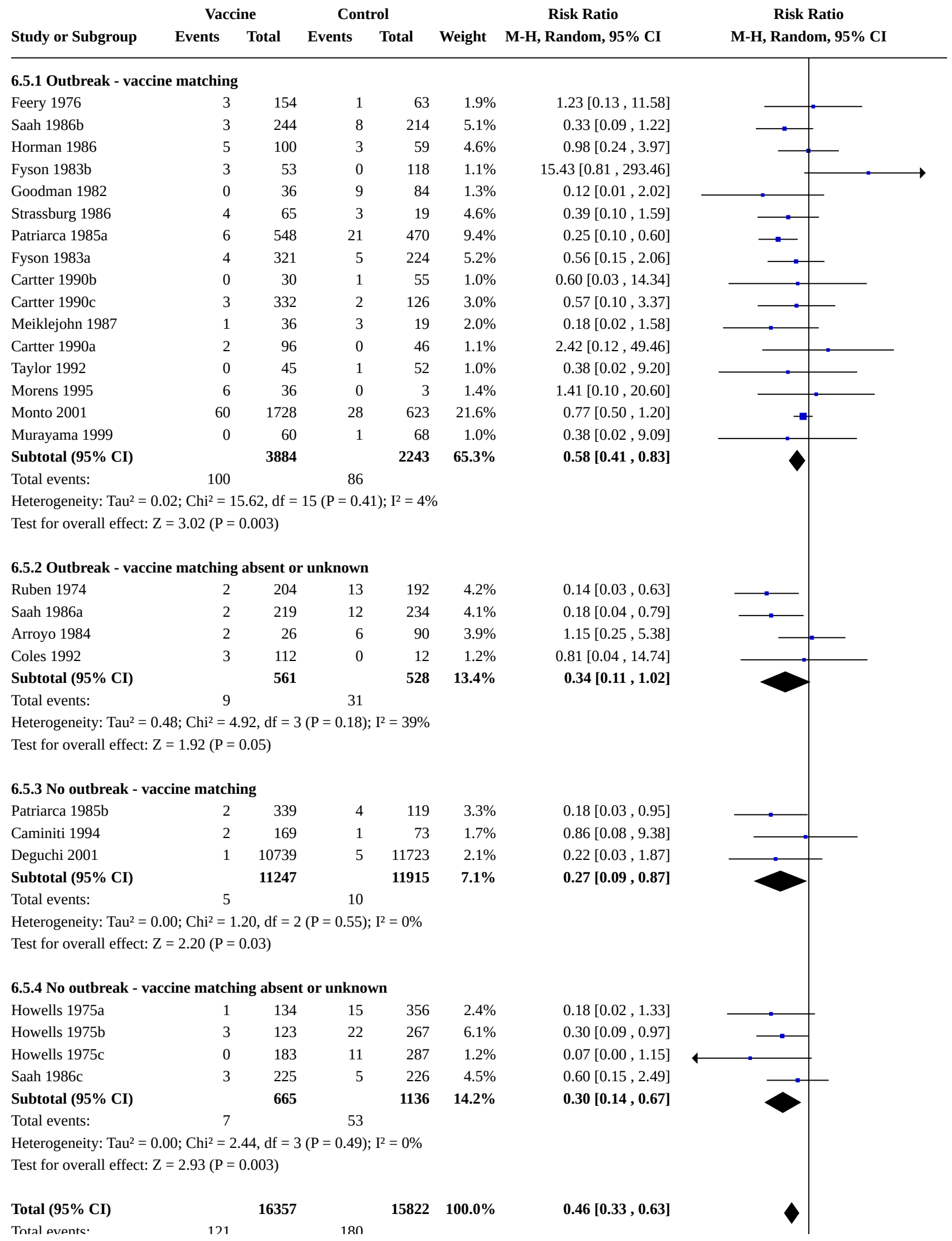




\section{Analysis 6.5. (Continued)}

Total (95\% CI)

Total events:

16357

Heterogeneity: $\mathrm{Tau}^{2}=0.07 ; \mathrm{Chi}^{2}=29.31, \mathrm{df}=26(\mathrm{P}=0.30) ; \mathrm{I}^{2}=11 \%$

Test for overall effect: $\mathrm{Z}=4.79(\mathrm{P}<0.00001)$

Test for subgroup differences: $\mathrm{Chi}^{2}=3.78, \mathrm{df}=3(\mathrm{P}=0.29), \mathrm{I}^{2}=20.6 \%$
$15822 \quad 100.0 \% \quad 0.46[0.33,0.63]$

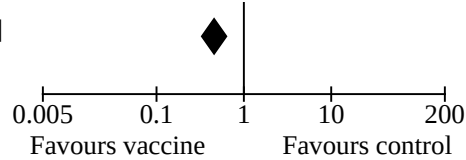

Favours vaccine

Favours control

Analysis 6.6. Comparison 6: Influenza vaccines versus no vaccination: cohort studies in nursing homes, Outcome 6: All deaths

\begin{tabular}{|c|c|c|c|c|c|c|}
\hline \multirow[b]{2}{*}{ Study or Subgroup } & \multicolumn{2}{|c|}{ Vaccine } & \multicolumn{2}{|c|}{ Control } & \multirow[b]{2}{*}{ Weight } & Risk Ratio \\
\hline & Events & Total & Events & Total & & M-H, Random, 95\% CI \\
\hline \multicolumn{7}{|c|}{ 6.6.1 Outbreak - vaccine matching } \\
\hline Gross 1988 & 13 & 181 & 22 & 124 & $100.0 \%$ & $0.40[0.21,0.77]$ \\
\hline Subtotal (95\% CI) & & 181 & & 124 & $100.0 \%$ & $0.40[0.21,0.77]$ \\
\hline Total events: & 13 & & 22 & & & \\
\hline
\end{tabular}

Heterogeneity: Not applicable

Test for overall effect: $\mathrm{Z}=2.74(\mathrm{P}=0.006)$

6.6.2 Outbreak - vaccine matching absent or unknown

Subtotal (95\% CI)

0

Total events:

0

0

Not estimable

Heterogeneity: Not applicable

Test for overall effect: Not applicable

6.6.3 No outbreak - vaccine matching

Subtotal (95\% CI)

$\mathbf{0}$

0

Total events:

0

Not estimable

Heterogeneity: Not applicable

Test for overall effect: Not applicable

6.6.4 No outbreak - vaccine matching absent or unknown

Subtotal (95\% CI)

0

$\mathbf{0}$

Not estimable

Total events:

0

0

Heterogeneity: Not applicable

Test for overall effect: Not applicable

Total (95\% CI)

181

Total events: 13

Heterogeneity: Not applicable

Test for overall effect: $\mathrm{Z}=2.74(\mathrm{P}=0.006)$

Test for subgroup differences: Not applicable
Risk Ratio M-H, Random, 95\% CI 
Analysis 6.7. Comparison 6: Influenza vaccines versus no vaccination: cohort studies in nursing homes, Outcome 7: Influenza cases (clinically defined without clear definition)

\begin{tabular}{|c|c|c|c|c|c|c|c|c|}
\hline \multirow[b]{2}{*}{ Study or Subgroup } & \multicolumn{2}{|c|}{ Vaccine } & \multicolumn{2}{|c|}{ Control } & \multirow[b]{2}{*}{ Weight } & \multirow{2}{*}{$\begin{array}{c}\text { Risk Ratio } \\
\text { M-H, Random, 95\% CI }\end{array}$} & \multirow{2}{*}{\multicolumn{2}{|c|}{$\begin{array}{c}\text { Risk Ratio } \\
\text { M-H, Random, 95\% CI }\end{array}$}} \\
\hline & Events & Total & Events & Total & & & & \\
\hline \multicolumn{9}{|c|}{ 6.7.1 Outbreak - vaccine matching } \\
\hline Aymard 1979a & 5 & 50 & 18 & 50 & $13.6 \%$ & $0.28[0.11,0.69]$ & & \\
\hline Fyson 1983b & 35 & 53 & 48 & 118 & $17.7 \%$ & $1.62[1.21,2.17]$ & & $\rightarrow$ \\
\hline Subtotal $(95 \% \mathrm{CI})$ & & 103 & & 168 & $31.3 \%$ & $0.70[0.11,4.56]$ & & \\
\hline Total events: & 40 & & 66 & & & & & \\
\hline \multicolumn{9}{|c|}{ Heterogeneity: $\mathrm{Tau}^{2}=1.70 ; \mathrm{Chi}^{2}=15.33, \mathrm{df}=1(\mathrm{P}<0.0001) ; \mathrm{I}^{2}=93 \%$} \\
\hline \multicolumn{9}{|c|}{ Test for overall effect: $\mathrm{Z}=0.37(\mathrm{P}=0.71)$} \\
\hline \multicolumn{9}{|c|}{ 6.7.2 Outbreak - vaccine matching absent or unknown } \\
\hline Aymard 1979b & 5 & 85 & 18 & 70 & $13.4 \%$ & $0.23[0.09,0.59]$ & & \\
\hline Subtotal $(95 \% \mathrm{CI})$ & & 85 & & 70 & $13.4 \%$ & $0.23[0.09,0.59]$ & & \\
\hline Total events: & 5 & & 18 & & & & & \\
\hline \multicolumn{9}{|c|}{ Heterogeneity: Not applicable } \\
\hline \multicolumn{9}{|c|}{ Test for overall effect: $\mathrm{Z}=3.08(\mathrm{P}=0.002)$} \\
\hline \multicolumn{9}{|c|}{ 6.7.3 No outbreak - vaccine matching } \\
\hline Deguchi 2001 & 256 & 10739 & 694 & 11723 & $18.2 \%$ & $0.40[0.35,0.46]$ & . & \\
\hline Subtotal $(95 \% \mathrm{CI})$ & & 10739 & & 11723 & $18.2 \%$ & $0.40[0.35,0.46]$ & $\theta$ & \\
\hline Total events: & 256 & & 694 & & & & & \\
\hline \multicolumn{9}{|c|}{ Heterogeneity: Not applicable } \\
\hline \multicolumn{9}{|c|}{ Test for overall effect: $\mathrm{Z}=12.65(\mathrm{P}<0.00001)$} \\
\hline \multicolumn{9}{|c|}{ 6.7.4 No outbreak - vaccine matching absent or unknown } \\
\hline Howells 1975a & 17 & 134 & 57 & 356 & $16.6 \%$ & $0.79[0.48,1.31]$ & & \\
\hline Howells 1975b & 16 & 123 & 43 & 267 & $16.4 \%$ & $0.81[0.47,1.38]$ & & \\
\hline Howells $1975 \mathrm{c}$ & 0 & 183 & 13 & 287 & $4.2 \%$ & $0.06[0.00,0.97]$ & $\leftarrow$ & \\
\hline Subtotal $(95 \% \mathrm{CI})$ & & 440 & & 910 & $37.2 \%$ & $0.72[0.41,1.28]$ & & \\
\hline Total events: & 33 & & 113 & & & & & \\
\hline \multicolumn{9}{|c|}{ Heterogeneity: $\mathrm{Tau}^{2}=0.11 ; \mathrm{Chi}^{2}=3.63, \mathrm{df}=2(\mathrm{P}=0.16) ; \mathrm{I}^{2}=45 \%$} \\
\hline \multicolumn{9}{|c|}{ Test for overall effect: $\mathrm{Z}=1.12(\mathrm{P}=0.26)$} \\
\hline Total $(95 \% \mathrm{CI})$ & & 11367 & & 12871 & $100.0 \%$ & $0.52[0.27,1.02]$ & & \\
\hline Total events: & 334 & & 891 & & & & & \\
\hline \multirow{2}{*}{\multicolumn{7}{|c|}{$\begin{array}{l}\text { Heterogeneity: } \mathrm{Tau}^{2}=0.62 ; \mathrm{Chi}^{2}=88.75, \mathrm{df}=6(\mathrm{P}<0.00001) ; \mathrm{I}^{2}=93 \% \\
\text { Test for overall effect: } \mathrm{Z}=1.91(\mathrm{P}=0.06)\end{array}$}} & $0.01 \quad 0.1$ & $\begin{array}{ll}+ & 1 \\
1 & 10\end{array}$ \\
\hline & & & & & & & Favours vaccine & Favours C \\
\hline
\end{tabular}

Comparison 7. Influenza and pneumococcal vaccines versus no vaccination: case-control studies in nursing homes

\begin{tabular}{lllll}
\hline Outcome or subgroup title & No. of studies & $\begin{array}{l}\text { No. of partici- } \\
\text { pants }\end{array}$ & Statistical method & Effect size \\
\hline 7.1 Influenza-like illness & 1 & 1198 & $\begin{array}{l}\text { Odds Ratio (M-H, Random, 95\% } \\
\text { Cl) }\end{array}$ & $0.52[0.40,0.68]$ \\
\hline 7.1 .1 Outbreak - vaccine matching & 1 & 1198 & $\begin{array}{l}\text { Odds Ratio (M-H, Random, 95\% } \\
\text { Cl) }\end{array}$ & $0.52[0.40,0.68]$ \\
\hline
\end{tabular}


Analysis 7.1. Comparison 7: Influenza and pneumococcal vaccines versus no vaccination: case-control studies in nursing homes, Outcome 1: Influenza-like illness

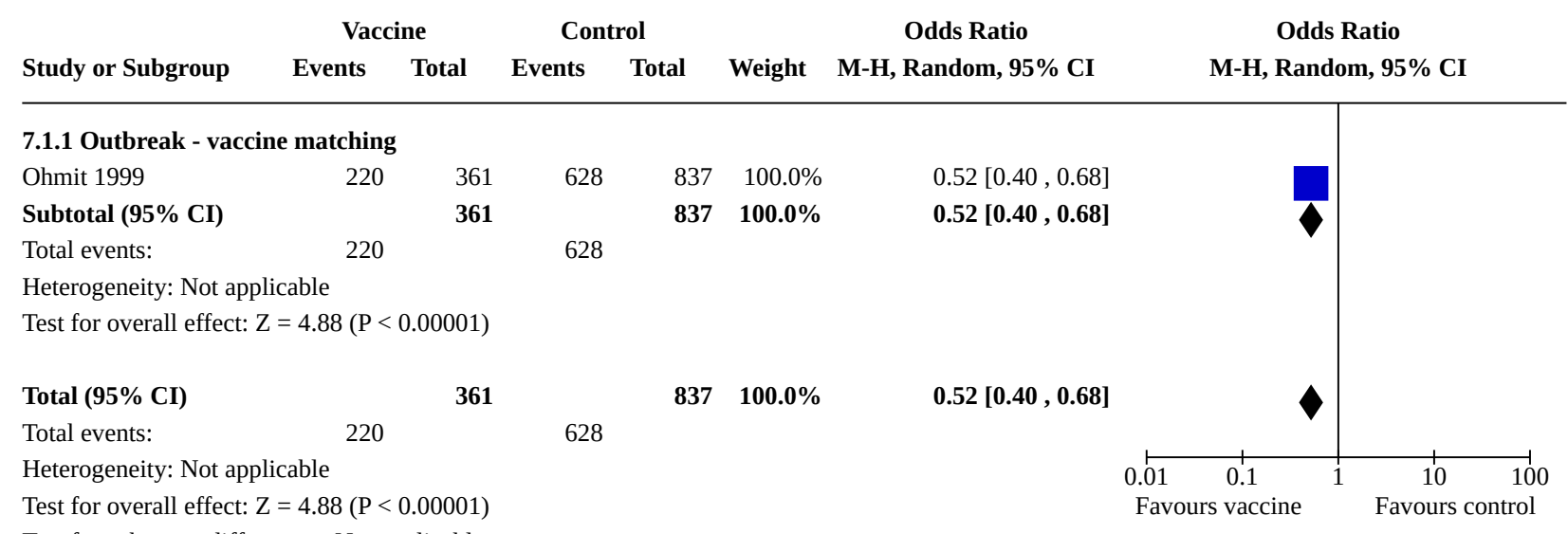

Comparison 8. Influenza vaccines versus no vaccination: cohort studies in community-dwellers

\begin{tabular}{|c|c|c|c|c|}
\hline Outcome or subgroup title & No. of studies & $\begin{array}{l}\text { No. of partici- } \\
\text { pants }\end{array}$ & Statistical method & Effect size \\
\hline 8.1 Influenza & 2 & 18249 & $\begin{array}{l}\text { Risk Ratio (M-H, Random, } \\
95 \% \mathrm{Cl} \text { ) }\end{array}$ & $0.19[0.02,2.01]$ \\
\hline 8.1.1 Epidemic year - vaccine matching & 1 & 427 & $\begin{array}{l}\text { Risk Ratio (M-H, Random, } \\
95 \% \mathrm{Cl})\end{array}$ & $0.05[0.01,0.37]$ \\
\hline $\begin{array}{l}\text { 8.1.2 Epidemic year - vaccine matching } \\
\text { absent or unknown }\end{array}$ & 0 & 0 & $\begin{array}{l}\text { Risk Ratio (M-H, Random, } \\
95 \% \mathrm{Cl})\end{array}$ & Not estimable \\
\hline $\begin{array}{l}\text { 8.1.3 Non-epidemic year - vaccine } \\
\text { matching }\end{array}$ & 1 & 17822 & $\begin{array}{l}\text { Risk Ratio (M-H, Random, } \\
95 \% \mathrm{Cl})\end{array}$ & $0.50[0.27,0.91]$ \\
\hline $\begin{array}{l}\text { 8.1.4 Non-epidemic year - vaccine } \\
\text { matching absent or unknown }\end{array}$ & 0 & 0 & $\begin{array}{l}\text { Risk Ratio (M-H, Random, } \\
95 \% \mathrm{Cl})\end{array}$ & Not estimable \\
\hline 8.2 Influenza-like illness & 4 & 9613 & $\begin{array}{l}\text { Risk Ratio (M-H, Random, } \\
95 \% \mathrm{Cl})\end{array}$ & $0.75[0.42,1.33]$ \\
\hline 8.2.1 Epidemic year - vaccine matching & 0 & 0 & $\begin{array}{l}\text { Risk Ratio (M-H, Random, } \\
95 \% \mathrm{Cl} \text { ) }\end{array}$ & Not estimable \\
\hline $\begin{array}{l}\text { 8.2.2 Epidemic year - vaccine matching } \\
\text { absent or unknown }\end{array}$ & 0 & 0 & $\begin{array}{l}\text { Risk Ratio (M-H, Random, } \\
95 \% \mathrm{Cl})\end{array}$ & Not estimable \\
\hline $\begin{array}{l}\text { 8.2.3 Non-epidemic year - vaccine } \\
\text { matching }\end{array}$ & 2 & 4636 & $\begin{array}{l}\text { Risk Ratio (M-H, Random, } \\
95 \% \mathrm{Cl})\end{array}$ & $1.08[0.58,2.03]$ \\
\hline $\begin{array}{l}\text { 8.2.4 Non-epidemic year - vaccine } \\
\text { matching absent or unknown }\end{array}$ & 1 & 268 & $\begin{array}{l}\text { Risk Ratio (M-H, Random, } \\
95 \% \mathrm{Cl})\end{array}$ & $0.85[0.16,4.55]$ \\
\hline $\begin{array}{l}\text { 8.2.5 Epidemic year - vaccine not } \\
\text { matching }\end{array}$ & 1 & 4709 & $\begin{array}{l}\text { Risk Ratio (M-H, Random, } \\
95 \% \mathrm{Cl})\end{array}$ & $0.44[0.24,0.81]$ \\
\hline
\end{tabular}




\begin{tabular}{|c|c|c|c|c|}
\hline Outcome or subgroup title & No. of studies & $\begin{array}{l}\text { No. of partici- } \\
\text { pants }\end{array}$ & Statistical method & Effect size \\
\hline 8.3 Pneumonia & 2 & 18090 & $\begin{array}{l}\text { Risk Ratio (M-H, Random, } \\
95 \% \mathrm{Cl})\end{array}$ & $0.88[0.64,1.20]$ \\
\hline 8.3.1 Epidemic year - vaccine matching & 0 & 0 & $\begin{array}{l}\text { Risk Ratio (M-H, Random, } \\
95 \% \mathrm{Cl})\end{array}$ & Not estimable \\
\hline $\begin{array}{l}\text { 8.3.2 Epidemic year - vaccine matching } \\
\text { absent or unknown }\end{array}$ & 0 & 0 & $\begin{array}{l}\text { Risk Ratio (M-H, Random, } \\
95 \% \mathrm{Cl})\end{array}$ & Not estimable \\
\hline $\begin{array}{l}\text { 8.3.3 Non-epidemic year - vaccine } \\
\text { matching }\end{array}$ & 1 & 17822 & $\begin{array}{l}\text { Risk Ratio (M-H, Random, } \\
95 \% \mathrm{Cl})\end{array}$ & $0.87[0.63,1.19]$ \\
\hline $\begin{array}{l}\text { 8.3.4 Non-epidemic year - vaccine } \\
\text { matching absent or unknown }\end{array}$ & 1 & 268 & $\begin{array}{l}\text { Risk Ratio (M-H, Random, } \\
95 \% \mathrm{Cl})\end{array}$ & $3.00[0.16,57.42]$ \\
\hline $\begin{array}{l}\text { 8.4 Hospitalisation for flu or pneumo- } \\
\text { nia }\end{array}$ & 9 & 784643 & $\begin{array}{l}\text { Risk Ratio (M-H, Random, } \\
95 \% \mathrm{Cl})\end{array}$ & $0.73[0.62,0.85]$ \\
\hline 8.4.1 Epidemic year - vaccine matching & 6 & 727776 & $\begin{array}{l}\text { Risk Ratio (M-H, Random, } \\
95 \% \mathrm{Cl})\end{array}$ & $0.74[0.62,0.88]$ \\
\hline $\begin{array}{l}\text { 8.4.2 Epidemic year - vaccine matching } \\
\text { absent or unknown }\end{array}$ & 0 & 0 & $\begin{array}{l}\text { Risk Ratio (M-H, Random, } \\
95 \% \mathrm{Cl})\end{array}$ & Not estimable \\
\hline $\begin{array}{l}\text { 8.4.3 Non-epidemic year - vaccine } \\
\text { matching }\end{array}$ & 1 & 25532 & $\begin{array}{l}\text { Risk Ratio (M-H, Random, } \\
95 \% \mathrm{Cl})\end{array}$ & $0.55[0.37,0.83]$ \\
\hline $\begin{array}{l}\text { 8.4.4 Non-epidemic year - vaccine } \\
\text { matching absent or unknown }\end{array}$ & 1 & 26626 & $\begin{array}{l}\text { Risk Ratio (M-H, Random, } \\
95 \% \mathrm{Cl})\end{array}$ & $0.73[0.54,0.99]$ \\
\hline $\begin{array}{l}\text { 8.4.5 Epidemic year - vaccine not } \\
\text { matching }\end{array}$ & 1 & 4709 & $\begin{array}{l}\text { Risk Ratio (M-H, Random, } \\
95 \% \mathrm{Cl})\end{array}$ & $0.89[0.33,2.40]$ \\
\hline $\begin{array}{l}\text { 8.5 Hospitalisation for any respiratory } \\
\text { disease }\end{array}$ & 5 & 567299 & $\begin{array}{l}\text { Risk Ratio (M-H, Random, } \\
95 \% \mathrm{Cl})\end{array}$ & $0.88[0.54,1.43]$ \\
\hline 8.5.1 Epidemic year - vaccine matching & 3 & 515141 & $\begin{array}{l}\text { Risk Ratio (M-H, Random, } \\
95 \% \mathrm{Cl})\end{array}$ & $0.78[0.37,1.64]$ \\
\hline $\begin{array}{l}\text { 8.5.2 Epidemic year - vaccine matching } \\
\text { absent or unknown }\end{array}$ & 0 & 0 & $\begin{array}{l}\text { Risk Ratio (M-H, Random, } \\
95 \% \mathrm{Cl})\end{array}$ & Not estimable \\
\hline $\begin{array}{l}\text { 8.5.3 Non-epidemic year - vaccine } \\
\text { matching }\end{array}$ & 1 & 25532 & $\begin{array}{l}\text { Risk Ratio (M-H, Random, } \\
95 \% \mathrm{Cl})\end{array}$ & $0.94[0.79,1.12]$ \\
\hline $\begin{array}{l}\text { 8.5.4 Non-epidemic year - vaccine } \\
\text { matching absent or unknown }\end{array}$ & 1 & 26626 & $\begin{array}{l}\text { Risk Ratio (M-H, Random, } \\
95 \% \mathrm{Cl})\end{array}$ & $1.16[1.01,1.34]$ \\
\hline 8.6 Deaths from flu or pneumonia & 1 & 163391 & $\begin{array}{l}\text { Risk Ratio (M-H, Random, } \\
95 \% \mathrm{Cl})\end{array}$ & $0.87[0.70,1.09]$ \\
\hline 8.6.1 Epidemic year - vaccine matching & 1 & 163391 & $\begin{array}{l}\text { Risk Ratio (M-H, Random, } \\
95 \% \mathrm{Cl})\end{array}$ & $0.87[0.70,1.09]$ \\
\hline
\end{tabular}




\begin{tabular}{|c|c|c|c|c|}
\hline Outcome or subgroup title & No. of studies & $\begin{array}{l}\text { No. of partici- } \\
\text { pants }\end{array}$ & Statistical method & Effect size \\
\hline $\begin{array}{l}\text { 8.6.2 Epidemic year - vaccine matching } \\
\text { absent or unknown }\end{array}$ & 0 & 0 & $\begin{array}{l}\text { Risk Ratio (M-H, Random, } \\
95 \% \mathrm{Cl})\end{array}$ & Not estimable \\
\hline $\begin{array}{l}\text { 8.6.3 Non-epidemic year - vaccine } \\
\text { matching }\end{array}$ & 0 & 0 & $\begin{array}{l}\text { Risk Ratio (M-H, Random, } \\
95 \% \mathrm{Cl})\end{array}$ & Not estimable \\
\hline $\begin{array}{l}\text { 8.6.4 Non-epidemic year - vaccine } \\
\text { matching absent or unknown }\end{array}$ & 0 & 0 & $\begin{array}{l}\text { Risk Ratio (M-H, Random, } \\
95 \% \mathrm{Cl})\end{array}$ & Not estimable \\
\hline 8.7 Deaths from respiratory disease & 1 & 426668 & $\begin{array}{l}\text { Risk Ratio (M-H, Random, } \\
95 \% \mathrm{Cl})\end{array}$ & $1.32[1.25,1.39]$ \\
\hline 8.7.1 Epidemic year - vaccine matching & 1 & 426668 & $\begin{array}{l}\text { Risk Ratio (M-H, Random, } \\
95 \% \mathrm{Cl})\end{array}$ & $1.32[1.25,1.39]$ \\
\hline 8.8 All deaths & 8 & 409468 & $\begin{array}{l}\text { Risk Ratio (M-H, Random, } \\
95 \% \mathrm{Cl})\end{array}$ & $0.61[0.47,0.80]$ \\
\hline 8.8.1 Epidemic year - vaccine matching & 4 & 300332 & $\begin{array}{l}\text { Risk Ratio (M-H, Random, } \\
95 \% \mathrm{Cl})\end{array}$ & $0.59[0.50,0.70]$ \\
\hline $\begin{array}{l}\text { 8.8.2 Epidemic year - vaccine matching } \\
\text { absent or unknown }\end{array}$ & 0 & 0 & $\begin{array}{l}\text { Risk Ratio (M-H, Random, } \\
95 \% \mathrm{Cl})\end{array}$ & Not estimable \\
\hline $\begin{array}{l}\text { 8.8.3 Non-epidemic year - vaccine } \\
\text { matching }\end{array}$ & 3 & 104427 & $\begin{array}{l}\text { Risk Ratio (M-H, Random, } \\
95 \% \mathrm{Cl})\end{array}$ & $0.65[0.30,1.39]$ \\
\hline $\begin{array}{l}\text { 8.8.4 Non-epidemic year - vaccine } \\
\text { matching absent or unknown }\end{array}$ & 0 & 0 & $\begin{array}{l}\text { Risk Ratio (M-H, Random, } \\
95 \% \mathrm{Cl})\end{array}$ & Not estimable \\
\hline $\begin{array}{l}\text { 8.8.5 Epidemic year - vaccine not } \\
\text { matching }\end{array}$ & 1 & 4709 & $\begin{array}{l}\text { Risk Ratio (M-H, Random, } \\
95 \% \mathrm{Cl})\end{array}$ & $3.89[0.90,16.89]$ \\
\hline 8.9 Hospitalisation for heart disease & 6 & 433934 & $\begin{array}{l}\text { Risk Ratio (M-H, Random, } \\
95 \% \mathrm{Cl})\end{array}$ & $0.87[0.67,1.12]$ \\
\hline 8.9.1 Epidemic year - vaccine matching & 4 & 381776 & $\begin{array}{l}\text { Risk Ratio (M-H, Random, } \\
95 \% \mathrm{Cl})\end{array}$ & $0.74[0.56,0.97]$ \\
\hline $\begin{array}{l}\text { 8.9.2 Epidemic year - vaccine matching } \\
\text { absent or unknown }\end{array}$ & 0 & 0 & $\begin{array}{l}\text { Risk Ratio (M-H, Random, } \\
95 \% \mathrm{Cl})\end{array}$ & Not estimable \\
\hline $\begin{array}{l}\text { 8.9.3 Non-epidemic year - vaccine } \\
\text { matching }\end{array}$ & 1 & 25532 & $\begin{array}{l}\text { Risk Ratio (M-H, Random, } \\
95 \% \mathrm{Cl})\end{array}$ & $1.06[0.81,1.38]$ \\
\hline $\begin{array}{l}\text { 8.9.4 Non-epidemic year - vaccine } \\
\text { matching absent or unknown }\end{array}$ & 1 & 26626 & $\begin{array}{l}\text { Risk Ratio (M-H, Random, } \\
95 \% \mathrm{Cl})\end{array}$ & $1.59[1.07,2.36]$ \\
\hline $\begin{array}{l}8.10 \text { Combined outcome: all deaths or } \\
\text { severe respiratory illness }\end{array}$ & 3 & 290819 & $\begin{array}{l}\text { Risk Ratio (M-H, Random, } \\
95 \% \mathrm{Cl})\end{array}$ & $0.71[0.58,0.85]$ \\
\hline $\begin{array}{l}\text { 8.10.1 Epidemic year - vaccine match- } \\
\text { ing }\end{array}$ & 2 & 132365 & $\begin{array}{l}\text { Risk Ratio (M-H, Random, } \\
95 \% \mathrm{CI})\end{array}$ & $0.80[0.42,1.55]$ \\
\hline
\end{tabular}




\begin{tabular}{lllll}
\hline Outcome or subgroup title & No. of studies & $\begin{array}{l}\text { No. of partici- } \\
\text { pants }\end{array}$ & Statistical method & Effect size \\
\hline $\begin{array}{l}\text { 8.10.2 Epidemic year - vaccine match- } \\
\text { ing absent or unknown }\end{array}$ & 1 & 158454 & $\begin{array}{l}\text { Risk Ratio (M-H, Random, } \\
95 \% \mathrm{Cl})\end{array}$ & $0.74[0.69,0.80]$ \\
\hline
\end{tabular}

\section{Analysis 8.1. Comparison 8: Influenza vaccines versus no vaccination: cohort studies in community-dwellers, Outcome 1: Influenza}

\begin{tabular}{|c|c|c|c|c|c|c|c|}
\hline & & & & & & Risk Ratio & Risk Ratio \\
\hline Study or Subgroup & Events & Total & Events & Total & Weight & M-H, Random, $95 \%$ CI & M-H, Random, 95\% CI \\
\hline
\end{tabular}

\subsubsection{Epidemic year - vaccine matching} Nicholson 1999 1218

19

$0.05[0.01,0.37]$

Total events: 1

$209 \quad 42.0 \%$ $0.05[0.01,0.37]$

Heterogeneity: Not applicable

Test for overall effect: $\mathrm{Z}=2.92(\mathrm{P}=0.003)$

8.1.2 Epidemic year - vaccine matching absent or unknown Subtotal $(95 \% \mathrm{CI})$

o o Total events: 0 0

Not estimable

Heterogeneity: Not applicable

Test for overall effect: Not applicable

8.1.3 Non-epidemic year - vaccine matching

$\begin{array}{lll}\text { Voordouw } 2003 & 16 & 8911 \\ \text { Subtotal (95\% CI) } & & \mathbf{8 9 1 1}\end{array}$

8911

Total events: 16

Heterogeneity: Not applicable

Test for overall effect: $\mathrm{Z}=2.27(\mathrm{P}=0.02)$

8.1.4 Non-epidemic year - vaccine matching absent or unknown Subtotal (95\% CI)

$\mathbf{0}$ 32

Heterogeneity: Not applicable

Test for overall effect: Not applicable

\begin{tabular}{|c|c|c|c|c|}
\hline Total (95\% CI) & 9129 & 9120 & $100.0 \%$ & $0.19[0.02,2.01]$ \\
\hline Total events: & 17 & & & \\
\hline
\end{tabular}

Heterogeneity: $\mathrm{Tau}^{2}=2.40 ; \mathrm{Chi}^{2}=5.22, \mathrm{df}=1(\mathrm{P}=0.02) ; \mathrm{I}^{2}=81 \%$

Test for overall effect: $\mathrm{Z}=1.38(\mathrm{P}=0.17)$

Test for subgroup differences: $\mathrm{Chi}^{2}=4.63, \mathrm{df}=1(\mathrm{P}=0.03), \mathrm{I}^{2}=78.4 \%$

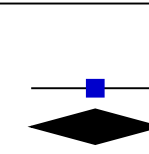


Analysis 8.2. Comparison 8: Influenza vaccines versus no vaccination: cohort studies in community-dwellers, Outcome 2: Influenza-like illness

\begin{tabular}{lccccccc} 
& \multicolumn{2}{c}{ Vaccine } & \multicolumn{2}{c}{ Control } & \multicolumn{2}{c}{ Risk Ratio } & \multicolumn{2}{c}{ Risk Ratio } \\
Study or Subgroup & Events & Total & Events & Total & Weight & M-H, Random, 95\% CI & M-H, Random, 95\% CI
\end{tabular}

8.2.1 Epidemic year - vaccine matching Subtotal (95\% CI)

Total events: 0

Heterogeneity: Not applicable

Test for overall effect: Not applicable

8.2.2 Epidemic year - vaccine matching absent or unknown Subtotal (95\% CI) $\mathbf{0}$

Total events: 0 0

Heterogeneity: Not applicable

Test for overall effect: Not applicable

8.2.3 Non-epidemic year - vaccine matching

Comeri 1995

Kawai 2003

Subtotal (95\% CI)

$20 \quad 150$

150
3520

6

$63 \quad 26.7 \%$

3670

6

$903 \quad 24.8 \%$

Total events:

12

Heterogeneity: $\mathrm{Tau}^{2}=0.00 ; \mathrm{Chi}^{2}=0.72, \mathrm{df}=1(\mathrm{P}=0.40) ; \mathrm{I}^{2}=0 \%$

Test for overall effect: $\mathrm{Z}=0.25(\mathrm{P}=0.80)$

8.2.4 Non-epidemic year - vaccine matching absent or unknown

Gavira Iglesias 1987

4

188

2

Subtotal (95\% CI)

4

188

2

$10.0 \%$

$\mathbf{1 0 . 0 \%}$

Total events:

applicable

Test for overall effect: $\mathrm{Z}=0.19(\mathrm{P}=0.85)$

8.2.5 Epidemic year - vaccine not matching

Hara $2006 \quad 20 \quad 3169$

Subtotal (95\% CI)

3169

22

$1540 \quad 38.4 \%$

$1540 \quad 38.4 \%$

Total events:

20

22

Heterogeneity: Not applicable

Test for overall effect: $\mathrm{Z}=2.66(\mathrm{P}=0.008)$

Total (95\% CI)

Total events:

7027

63

$2586 \quad 100.0 \%$

Heterogeneity: Tau $^{2}=0.13 ; \mathrm{Chi}^{2}=4.87, \mathrm{df}=3(\mathrm{P}=0.18) ; \mathrm{I}^{2}=38 \%$

Test for overall effect: $\mathrm{Z}=0.99(\mathrm{P}=0.32)$

Test for subgroup differences: $\mathrm{Chi}^{2}=4.15, \mathrm{df}=2(\mathrm{P}=0.13), \mathrm{I}^{2}=51.8 \%$
$1.40[0.59,3.32]$

Not estimable

Not estimable

$0.81[0.33,2.03]$

$1.08[0.58,2.03]$

$0.85[0.16,4.55]$

$0.85[0.16,4.55]$

$0.44[0.24,0.81]$

$0.44[0.24,0.81]$

$0.75[0.42,1.33]$

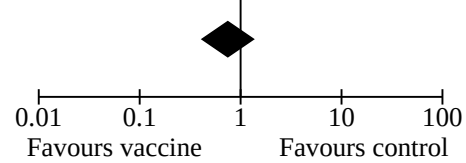




\section{Analysis 8.3. Comparison 8: Influenza vaccines versus no vaccination: cohort studies in community-dwellers, Outcome 3: Pneumonia}

\begin{tabular}{lccccccc} 
& \multicolumn{2}{c}{ Vaccine } & \multicolumn{2}{c}{ Control } & \multicolumn{2}{c}{ Risk Ratio } & \multicolumn{2}{c}{ Risk Ratio } \\
Study or Subgroup & Events & Total & Events & Total & Weight & M-H, Random, 95\% CI & M-H, Random, 95\% CI
\end{tabular}

\subsubsection{Epidemic year - vaccine matching} Subtotal (95\% CI)

Total events:

0

$\mathbf{0}$

Not estimable

Heterogeneity: Not applicable

Test for overall effect: Not applicable

8.3.2 Epidemic year - vaccine matching absent or unknown Subtotal (95\% CI)

0

Total events:

0

Heterogeneity: Not applicable

Test for overall effect: Not applicable

8.3.3 Non-epidemic year - vaccine matching

Voordouw $2003 \quad 72 \quad 8911$

Subtotal (95\% CI)

8911

83

$891198.9 \%$

Total events:

72

$8911 \quad 98.9 \%$

83

Heterogeneity: Not applicable

Test for overall effect: $\mathrm{Z}=0.89(\mathrm{P}=0.38)$

8.3.4 Non-epidemic year - vaccine matching absent or unknown

Gavira Iglesias 1987

3

188

80

$1.1 \%$

$3.00[0.16,57.42]$

3

0

Heterogeneity: Not applicable

Test for overall effect: $\mathrm{Z}=0.73(\mathrm{P}=0.47)$

Total (95\% CI)

9099

$8991 \quad 100.0 \%$

Total events: 75 83

Heterogeneity: $\mathrm{Tau}^{2}=0.00 ; \mathrm{Chi}^{2}=0.67, \mathrm{df}=1(\mathrm{P}=0.41) ; \mathrm{I}^{2}=0 \%$

Test for overall effect: $\mathrm{Z}=0.80(\mathrm{P}=0.42)$

Test for subgroup differences: $\mathrm{Chi}^{2}=0.67, \mathrm{df}=1(\mathrm{P}=0.41), \mathrm{I}^{2}=0 \%$
$0.87[0.63,1.19]$

Not estimable

$0.87[0.63,1.19]$ 
Analysis 8.4. Comparison 8: Influenza vaccines versus no vaccination: cohort studies in community-dwellers, Outcome 4: Hospitalisation for flu or pneumonia

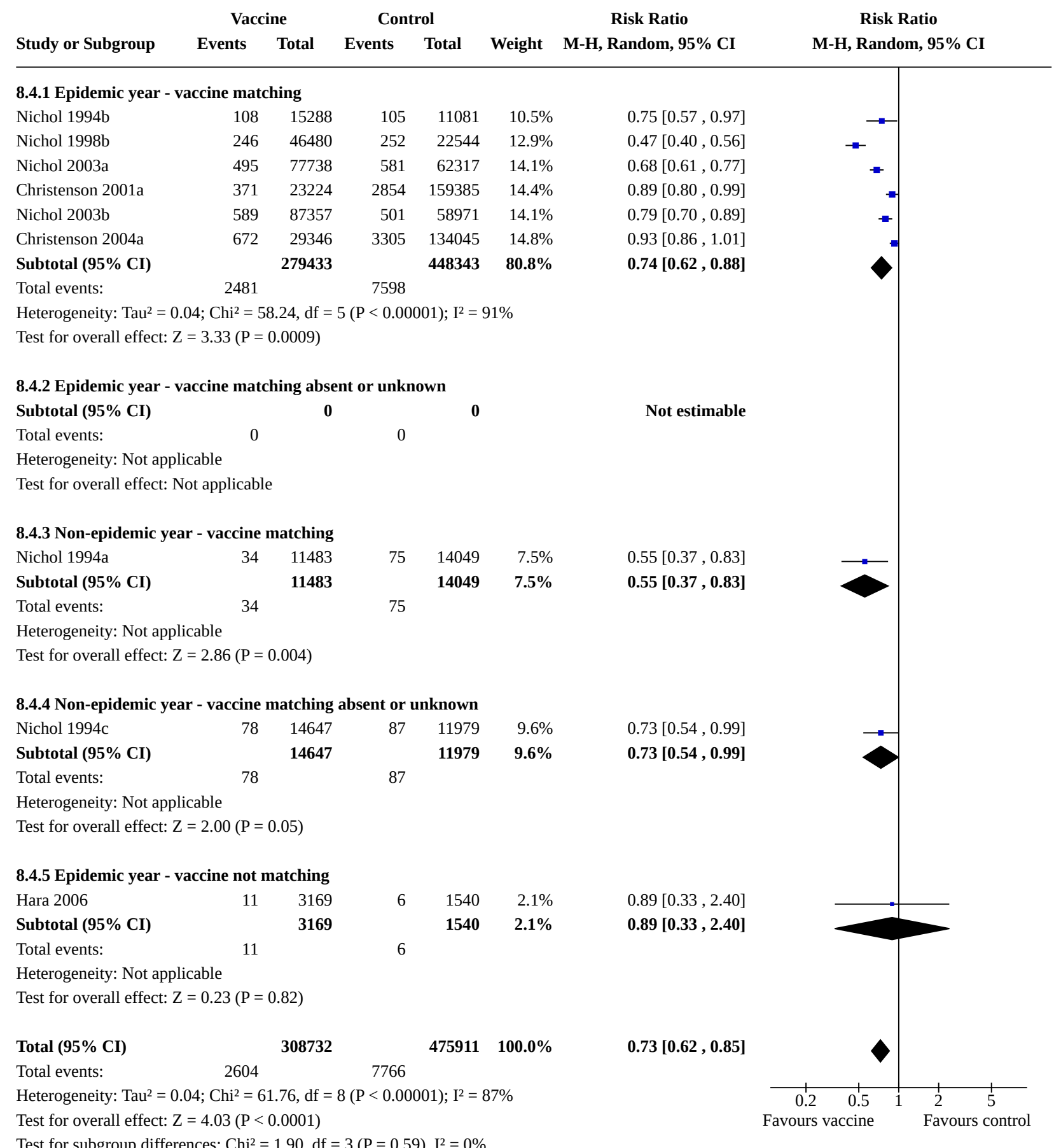


Analysis 8.5. Comparison 8: Influenza vaccines versus no vaccination: cohort studies in community-dwellers, Outcome 5: Hospitalisation for any respiratory disease

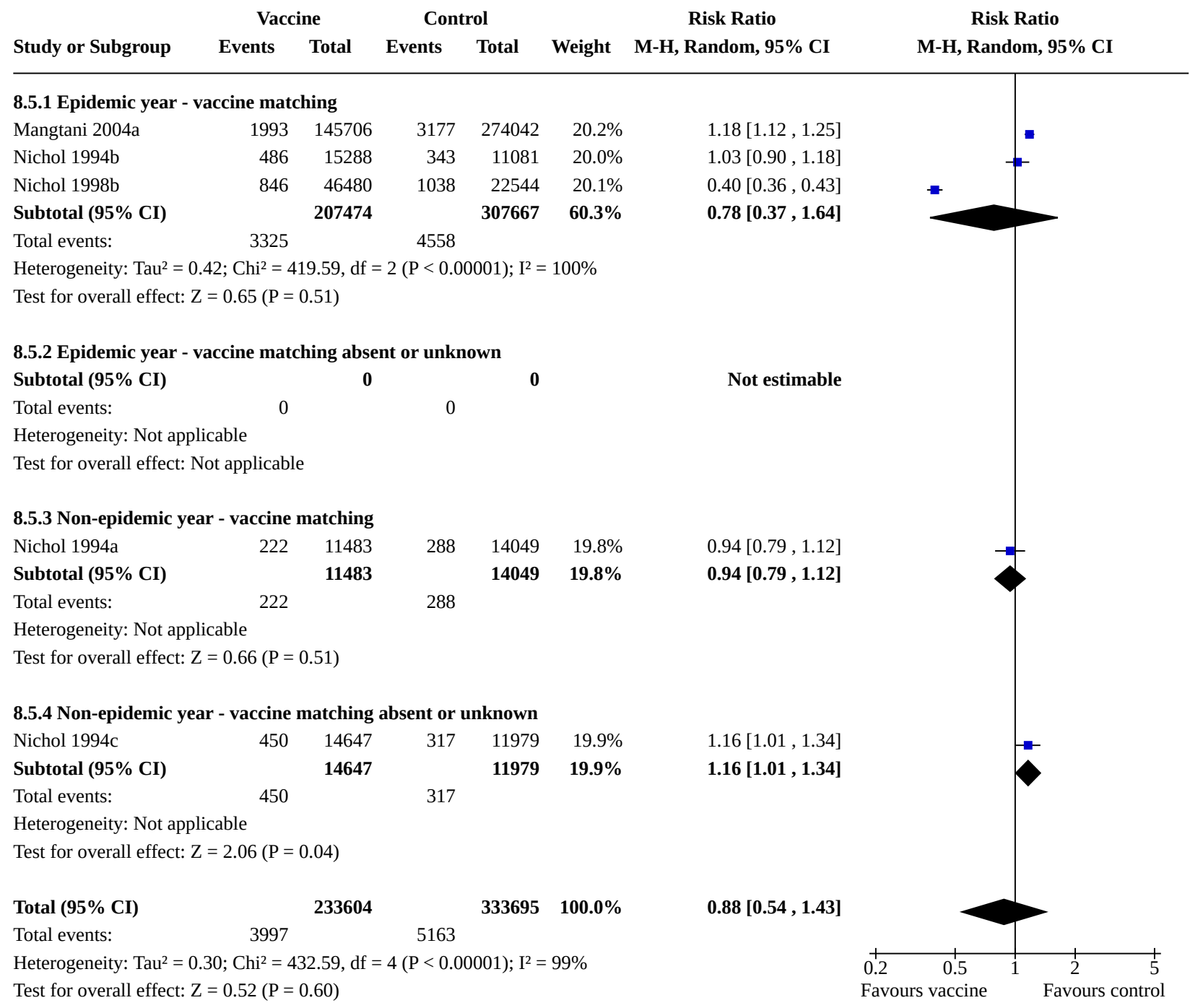


Analysis 8.6. Comparison 8: Influenza vaccines versus no vaccination: cohort studies in community-dwellers, Outcome 6: Deaths from flu or pneumonia

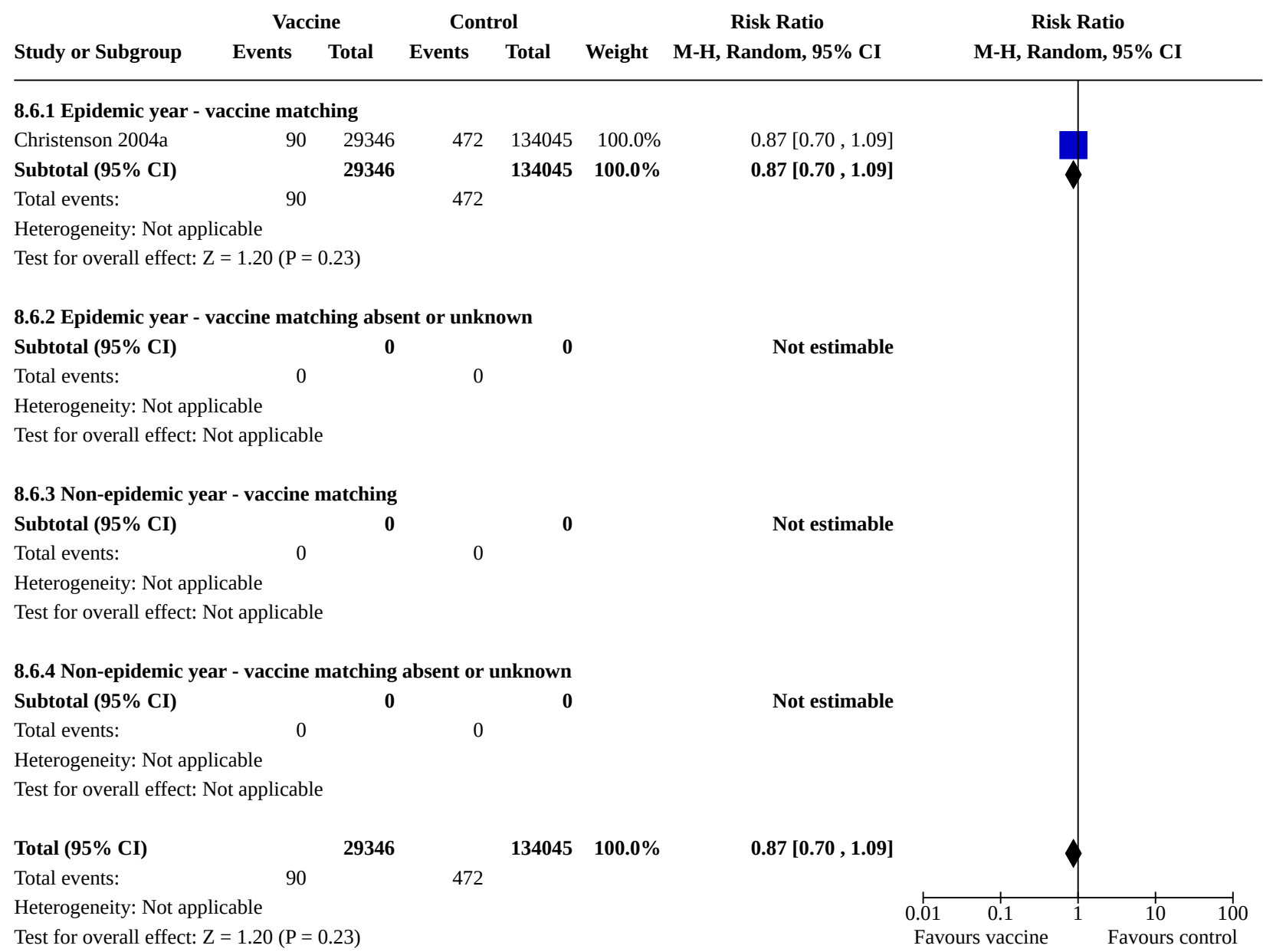

\section{Analysis 8.7. Comparison 8: Influenza vaccines versus no vaccination: cohort studies in community-dwellers, Outcome 7: Deaths from respiratory disease}

\begin{tabular}{|c|c|c|c|c|c|c|c|}
\hline & Vac & & Co & & & Risk Ratio & Risk Ratio \\
\hline Study or Subgroup & Events & Total & Events & Total & Weight & M-H, Random, 95\% CI & M-H, Random, 95\% CI \\
\hline
\end{tabular}

8.7.1 Epidemic year - vaccine matching

Mangtani 2004a $\quad 2585 \quad 147294$

$3720 \quad 279374 \quad 100.0 \%$

Subtotal (95\% CI)

147294

$279374 \quad 100.0 \%$

3720

Heterogeneity: Not applicable

Test for overall effect: $\mathrm{Z}=10.87(\mathrm{P}<0.00001)$

\section{Total (95\% CI)}

147294

Total events: 2585

Heterogeneity: Not applicable

Test for overall effect: $\mathrm{Z}=10.87(\mathrm{P}<0.00001)$

Test for subgroup differences: Not applicable 


\section{Analysis 8.8. Comparison 8: Influenza vaccines versus no vaccination: cohort studies in community-dwellers, Outcome 8: All deaths}

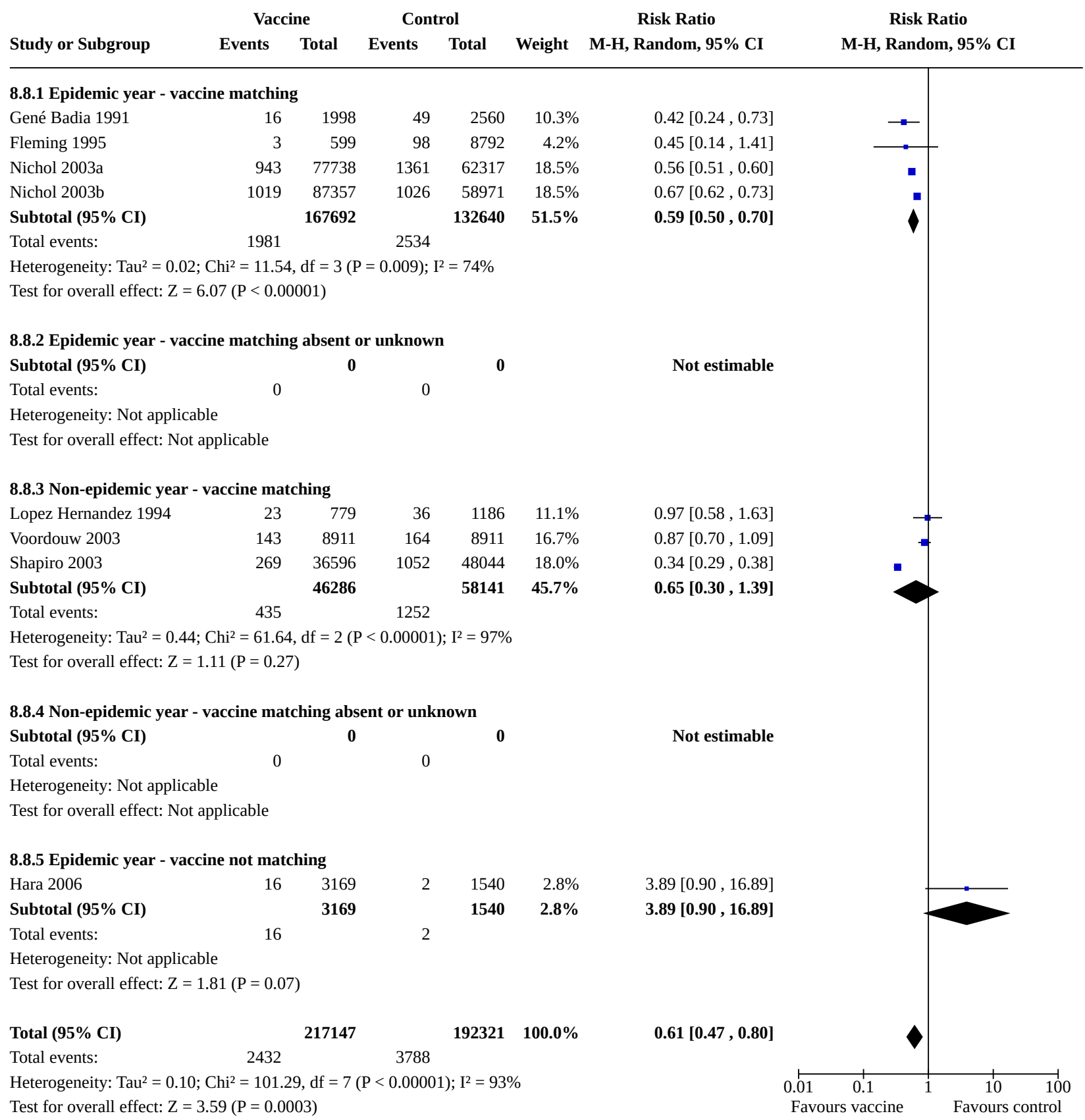


Analysis 8.9. Comparison 8: Influenza vaccines versus no vaccination: cohort studies in community-dwellers, Outcome 9: Hospitalisation for heart disease

\begin{tabular}{|c|c|c|c|c|c|c|}
\hline \multirow[b]{2}{*}{ Study or Subgroup } & \multicolumn{2}{|c|}{ Vaccine } & \multicolumn{2}{|c|}{ Control } & \multirow[b]{2}{*}{ Weight } & \multirow{2}{*}{$\begin{array}{c}\text { Risk Ratio } \\
\text { H, Random, 95\% CI }\end{array}$} \\
\hline & Events & Total & Events & Total & & \\
\hline \multicolumn{7}{|c|}{ 8.9.1 Epidemic year - vaccine matching } \\
\hline Nichol 1994b & 81 & 15288 & 50 & 11081 & $14.2 \%$ & $1.17[0.83,1.67]$ \\
\hline Nichol 1998b & 554 & 46480 & 553 & 22544 & $18.6 \%$ & $0.49[0.43,0.55]$ \\
\hline Nichol 2003a & 888 & 77738 & 1026 & 62317 & $18.9 \%$ & $0.69[0.63,0.76]$ \\
\hline Nichol 2003b & 1029 & 87357 & 819 & 58971 & $18.9 \%$ & $0.85[0.77,0.93]$ \\
\hline Subtotal $(95 \%$ CI) & & 226863 & & 154913 & $70.7 \%$ & $0.74[0.56,0.97]$ \\
\hline Total events: & 2552 & & 2448 & & & \\
\hline
\end{tabular}

Heterogeneity: $\mathrm{Tau}^{2}=0.07 ; \mathrm{Chi}^{2}=62.97, \mathrm{df}=3(\mathrm{P}<0.00001) ; \mathrm{I}^{2}=95 \%$

Test for overall effect: $\mathrm{Z}=2.16(\mathrm{P}=0.03)$

8.9.2 Epidemic year - vaccine matching absent or unknown

Subtotal (95\% CI)

Total events:

0

0

Heterogeneity: Not applicable

Test for overall effect: Not applicable

8.9.3 Non-epidemic year - vaccine matching

$\begin{array}{lccccc}\text { Nichol 1994a } & 102 & 11483 & 118 & 14049 & 16.1 \% \\ \text { Subtotal (95\% CI) } & & \mathbf{1 1 4 8 3} & & \mathbf{1 4 0 4 9} & \mathbf{1 6 . 1 \%} \\ \text { Total events: } & 102 & & 118 & & \end{array}$

Heterogeneity: Not applicable

Test for overall effect: $\mathrm{Z}=0.42(\mathrm{P}=0.68)$

8.9.4 Non-epidemic year - vaccine matching absent or unknown

$\begin{array}{lccccc}\text { Nichol 1994c } & 72 & 14647 & 37 & 11979 & 13.2 \% \\ \text { Subtotal (95\% CI) } & & \mathbf{1 4 6 4 7} & & \mathbf{1 1 9 7 9} & \mathbf{1 3 . 2 \%} \\ \text { Total events: } & 72 & & 37 & & \end{array}$

Heterogeneity: Not applicable

Test for overall effect: $\mathrm{Z}=2.30(\mathrm{P}=0.02)$

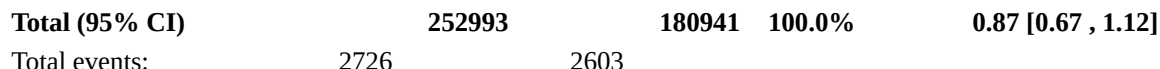

Heterogeneity: $\mathrm{Tau}^{2}=0.09 ; \mathrm{Chi}^{2}=87.72, \mathrm{df}=5(\mathrm{P}<0.00001) ; \mathrm{I}^{2}=94 \%$

Test for overall effect: $\mathrm{Z}=1.08(\mathrm{P}=0.28)$

Test for subgroup differences: $\mathrm{Chi}^{2}=10.12, \mathrm{df}=2(\mathrm{P}=0.006), \mathrm{I}^{2}=80.2 \%$
Not estimable

$1.06[0.81,1.38]$

$1.06[0.81,1.38]$

$1.59[1.07,2.36]$

$1.59[1.07,2.36]$ 
Analysis 8.10. Comparison 8: Influenza vaccines versus no vaccination: cohort studies in community-dwellers, Outcome 10: Combined outcome: all deaths or severe respiratory illness

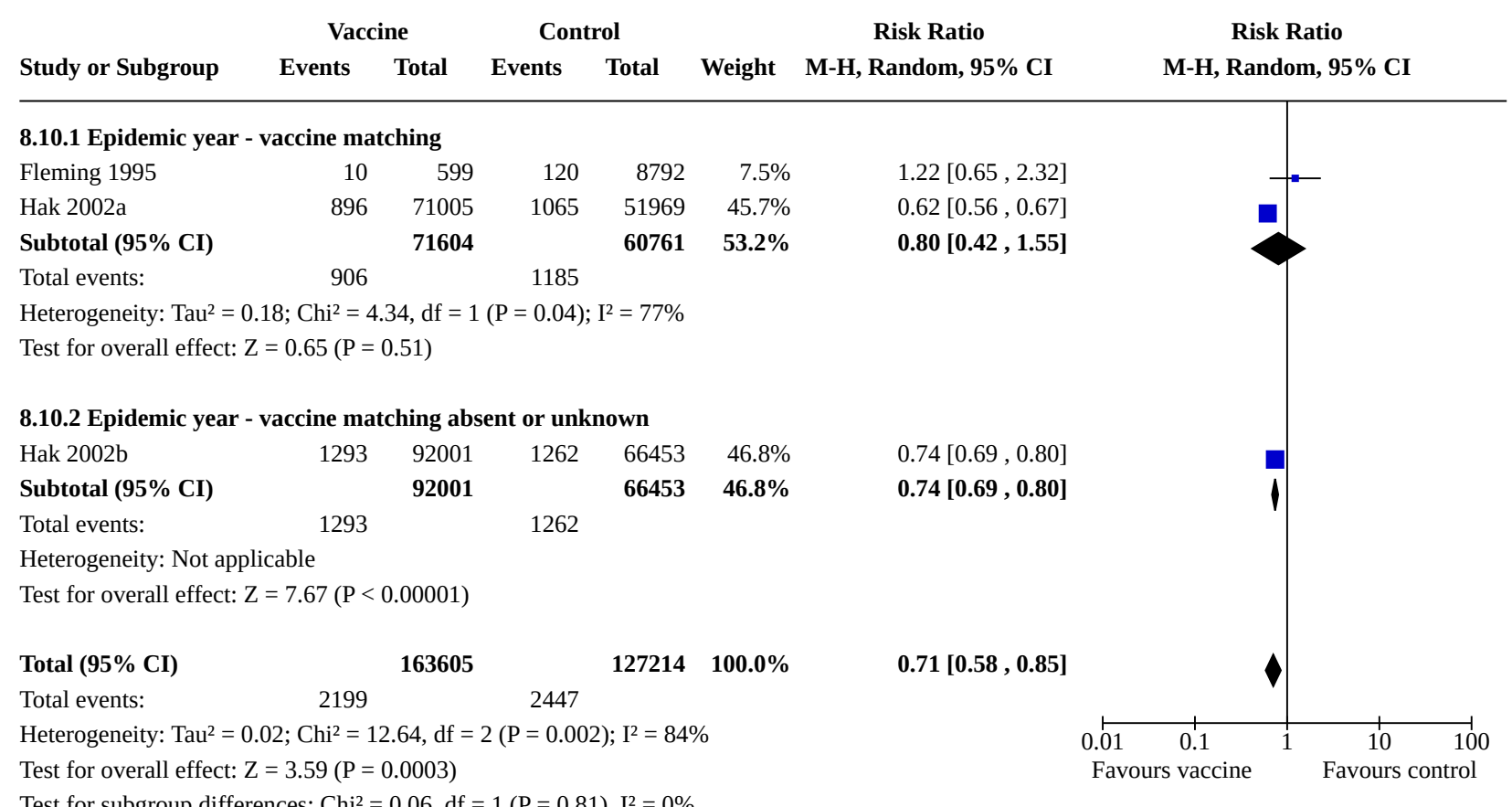

Comparison 9. Influenza vaccines versus no vaccination: cohort studies in community - adjusted rates

\begin{tabular}{|c|c|c|c|c|}
\hline Outcome or subgroup title & No. of studies & $\begin{array}{l}\text { No. of partici- } \\
\text { pants }\end{array}$ & Statistical method & Effect size \\
\hline $\begin{array}{l}9.1 \text { Hospitalisation for influenza or } \\
\text { pneumonia }\end{array}$ & 8 & & $\begin{array}{l}\text { Odds Ratio (IV, Random, 95\% } \\
\mathrm{Cl} \text { ) }\end{array}$ & $0.73[0.67,0.79]$ \\
\hline 9.1.1 Epidemic - vaccine matching & 6 & & $\begin{array}{l}\text { Odds Ratio (IV, Random, 95\% } \\
\mathrm{Cl} \text { ) }\end{array}$ & $0.71[0.65,0.77]$ \\
\hline $\begin{array}{l}\text { 9.1.2 Non-epidemic-vaccine not } \\
\text { matching }\end{array}$ & 1 & & $\begin{array}{l}\text { Odds Ratio (IV, Random, 95\% } \\
\mathrm{CI} \text { ) }\end{array}$ & $0.90[0.58,1.38]$ \\
\hline $\begin{array}{l}\text { 9.1.3 Epidemic year - vaccine match- } \\
\text { ing absent or unknown }\end{array}$ & 1 & & $\begin{array}{l}\text { Odds Ratio (IV, Random, 95\% } \\
\mathrm{CI} \text { ) }\end{array}$ & $0.82[0.68,0.98]$ \\
\hline $\begin{array}{l}9.2 \text { Hospitalisation for any respiratory } \\
\text { disease }\end{array}$ & 13 & & $\begin{array}{l}\text { Odds Ratio (IV, Random, 95\% } \\
\mathrm{Cl} \text { ) }\end{array}$ & $0.78[0.72,0.85]$ \\
\hline 9.2.1 Epidemic - vaccine matching & 9 & & $\begin{array}{l}\text { Odds Ratio (IV, Random, 95\% } \\
\mathrm{Cl} \text { ) }\end{array}$ & $0.71[0.67,0.74]$ \\
\hline $\begin{array}{l}\text { 9.2.2 Non-epidemic - vaccine not } \\
\text { matching }\end{array}$ & 2 & & $\begin{array}{l}\text { Odds Ratio (IV, Random, 95\% } \\
\mathrm{Cl} \text { ) }\end{array}$ & $0.91[0.76,1.08]$ \\
\hline $\begin{array}{l}\text { 9.2.3 Non-epidemic year - vaccine } \\
\text { matching }\end{array}$ & 2 & & $\begin{array}{l}\text { Odds Ratio (IV, Random, 95\% } \\
\mathrm{Cl} \text { ) }\end{array}$ & $0.94[0.84,1.06]$ \\
\hline
\end{tabular}




\begin{tabular}{|c|c|c|c|c|}
\hline Outcome or subgroup title & No. of studies & $\begin{array}{l}\text { No. of partici- } \\
\text { pants }\end{array}$ & Statistical method & Effect size \\
\hline 9.3 Hospitalisation for heart disease & 6 & & $\begin{array}{l}\text { Odds Ratio (IV, Random, 95\% } \\
\mathrm{Cl} \text { ) }\end{array}$ & $0.76[0.70,0.82]$ \\
\hline $\begin{array}{l}\text { 9.3.1 Epidemic year - vaccine match- } \\
\text { ing }\end{array}$ & 5 & & $\begin{array}{l}\text { Odds Ratio (IV, Random, 95\% } \\
\mathrm{Cl} \text { ) }\end{array}$ & $0.75[0.70,0.82]$ \\
\hline $\begin{array}{l}\text { 9.3.2 Non-epidemic - vaccine not } \\
\text { matching }\end{array}$ & 1 & & $\begin{array}{l}\text { Odds Ratio (IV, Random, 95\% } \\
\mathrm{CI} \text { ) }\end{array}$ & $0.80[0.55,1.16]$ \\
\hline 9.4 All deaths & 7 & & $\begin{array}{l}\text { Odds Ratio (IV, Random, 95\% } \\
\mathrm{Cl} \text { ) }\end{array}$ & $0.53[0.46,0.61]$ \\
\hline $\begin{array}{l}\text { 9.4.1 Epidemic year - vaccine match- } \\
\text { ing }\end{array}$ & 5 & & $\begin{array}{l}\text { Odds Ratio (IV, Random, 95\% } \\
\mathrm{Cl} \text { ) }\end{array}$ & $0.47[0.42,0.53]$ \\
\hline $\begin{array}{l}\text { 9.4.2 Epidemic year - vaccine match- } \\
\text { ing absent or unknown }\end{array}$ & 1 & & $\begin{array}{l}\text { Odds Ratio (IV, Random, 95\% } \\
\mathrm{Cl} \text { ) }\end{array}$ & $0.65[0.57,0.75]$ \\
\hline $\begin{array}{l}\text { 9.4.3 Non-epidemic year - vaccine } \\
\text { matching }\end{array}$ & 1 & & $\begin{array}{l}\text { Odds Ratio (IV, Random, 95\% } \\
\mathrm{Cl} \text { ) }\end{array}$ & $0.76[0.60,0.97]$ \\
\hline $\begin{array}{l}\text { 9.5 Combined outcome: all deaths or } \\
\text { severe respiratory illness }\end{array}$ & 1 & & $\begin{array}{l}\text { Odds Ratio (IV, Random, 95\% } \\
\mathrm{Cl} \text { ) }\end{array}$ & $0.70[0.37,1.34]$ \\
\hline $\begin{array}{l}\text { 9.5.1 Epidemic year - vaccine match- } \\
\text { ing }\end{array}$ & 1 & & $\begin{array}{l}\text { Odds Ratio (IV, Random, 95\% } \\
\mathrm{Cl} \text { ) }\end{array}$ & $0.70[0.37,1.34]$ \\
\hline
\end{tabular}


Analysis 9.1. Comparison 9: Influenza vaccines versus no vaccination: cohort studies in community - adjusted rates, Outcome 1: Hospitalisation for influenza or pneumonia

Odds Ratio

Study or Subgroup $\quad \log [\mathrm{OR}] \quad$ SE $\quad$ Weight $\quad$ IV, Random, 95\% CI
Odds Ratio

IV, Random, 95\% CI

\begin{tabular}{lrrrr}
\hline 9.1.1 Epidemic - vaccine matching & & & \\
Nichol 1998a & -0.4943 & 0.1104 & $11.8 \%$ & $0.61[0.49,0.76]$ \\
Davis 2001b & -0.11 & 0.2 & $4.2 \%$ & $0.90[0.61,1.33]$ \\
Nordin 2001a & -0.2107 & 0.097 & $14.4 \%$ & $0.81[0.67,0.98]$ \\
Davis 2001c & -0.51 & 0.24 & $3.0 \%$ & $0.60[0.38,0.96]$ \\
Nichol 2003a & -0.3857 & 0.0669 & $23.5 \%$ & $0.68[0.60,0.78]$ \\
Nichol 2003b & -0.3425 & 0.065 & $24.3 \%$ & $0.71[0.63,0.81]$ \\
Subtotal (95\% CI) & & & $\mathbf{8 1 . 2 \%}$ & $\mathbf{0 . 7 1}[\mathbf{0 . 6 5}, \mathbf{0 . 7 7}]$
\end{tabular}

Heterogeneity: $\mathrm{Tau}^{2}=0.00 ; \mathrm{Chi}^{2}=5.95, \mathrm{df}=5(\mathrm{P}=0.31) ; \mathrm{I}^{2}=16 \%$

Test for overall effect: $\mathrm{Z}=7.97(\mathrm{P}<0.00001)$

9.1.2 Non-epidemic - vaccine not matching

\begin{tabular}{|c|c|c|c|c|}
\hline Davis 2001a & -0.11 & 0.22 & $3.5 \%$ & $0.90[0.58,1.38]$ \\
\hline Subtotal (95\% CI) & & & $3.5 \%$ & $0.90[0.58,1.38]$ \\
\hline
\end{tabular}

Heterogeneity: Not applicable

Test for overall effect: $\mathrm{Z}=0.50(\mathrm{P}=0.62)$

9.1.3 Epidemic year - vaccine matching absent or unknown

$\begin{array}{lllll}\text { Nordin 2001b } & -0.1985 & 0.0932 & 15.3 \% & 0.82[0.68,0.98] \\ \text { Subtotal (95\% CI) } & & & \mathbf{1 5 . 3 \%} & \mathbf{0 . 8 2}[\mathbf{0 . 6 8 , 0 . 9 8}]\end{array}$

Heterogeneity: Not applicable

Test for overall effect: $\mathrm{Z}=2.13(\mathrm{P}=0.03)$

Total (95\% CI)

$100.0 \%$

$0.73[0.67,0.79]$

Heterogeneity: $\mathrm{Tau}^{2}=0.00 ; \mathrm{Chi}^{2}=9.18, \mathrm{df}=7(\mathrm{P}=0.24) ; \mathrm{I}^{2}=24 \%$

Test for overall effect: $\mathrm{Z}=7.40(\mathrm{P}<0.00001)$

Test for subgroup differences: $\mathrm{Chi}^{2}=3.02, \mathrm{df}=2(\mathrm{P}=0.22), \mathrm{I}^{2}=33.8 \%$

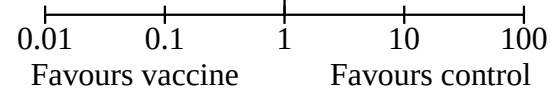


Analysis 9.2. Comparison 9: Influenza vaccines versus no vaccination: cohort studies in community - adjusted rates, Outcome 2: Hospitalisation for any respiratory disease

Odds Ratio

Study or Subgroup
SE
Weight IV, Random, 95\% CI

\subsubsection{Epidemic - vaccine matching}

Nichol 1998a

Mangtani 2004b

Mangtani 2004c

Mangtani 2004e

Davis 2001b

Mangtani 2004g

Mangtani 2004h

Davis 2001c

Mangtani 2004j

$-0.3857$

$-0.1744$

0.0429

$11.6 \%$

0.68 [0.63, 0.74]

$-0.3567$

0.1209

$6.4 \%$

0.84 [0.66, 1.06]

$-0.2744$

0.084

$8.7 \%$

0.70 [0.59, 0.83]

$-0.22$

0.1062

$7.3 \%$

$0.76[0.62,0.94]$

$-0.3711$

0.15

$5.1 \%$

$0.80[0.60,1.08]$

$-0.4155$

0.0777

$9.2 \%$

$0.69[0.59,0.80]$

$-0.36$

0.0656

$10.0 \%$

0.66 [0.58, 0.75]

$-0.1985$

0.18

$4.0 \%$

0.70 [0.49, 0.99]

0.82 [0.68, 0.99]

$0.71[0.67,0.74]$

Subtotal (95\% CI)

Heterogeneity: $\mathrm{Tau}^{2}=0.00 ; \mathrm{Chi}^{2}=7.64, \mathrm{df}=8(\mathrm{P}=0.47) ; \mathrm{I}^{2}=0 \%$

Test for overall effect: $\mathrm{Z}=13.17(\mathrm{P}<0.00001)$

9.2.2 Non-epidemic - vaccine not matching

$\begin{array}{lrrrr}\text { Davis 2001a } & -0.22 & 0.15 & 5.1 \% & 0.80[0.60,1.08] \\ \text { Mangtani 2004i } & -0.0305 & 0.1018 & 7.6 \% & 0.97[0.79,1.18] \\ \text { Subtotal (95\% CI) } & & & \mathbf{1 2 . 6 \%} & \mathbf{0 . 9 1}[\mathbf{0 . 7 6}, \mathbf{1 . 0 8}]\end{array}$

Heterogeneity: $\mathrm{Tau}^{2}=0.00 ; \mathrm{Chi}^{2}=1.09, \mathrm{df}=1(\mathrm{P}=0.30) ; \mathrm{I}^{2}=8 \%$

Test for overall effect: $\mathrm{Z}=1.05(\mathrm{P}=0.30)$

9.2.3 Non-epidemic year - vaccine matching

$\begin{array}{lrrrr}\text { Mangtani 2004d } & -0.0726 & 0.1003 & 7.7 \% & 0.93[0.76,1.13] \\ \text { Mangtani 2004f } & -0.0513 & 0.0726 & 9.5 \% & 0.95[0.82,1.10] \\ \text { Subtotal (95\% CI) } & & & \mathbf{1 7 . 2 \%} & \mathbf{0 . 9 4}[\mathbf{0 . 8 4}, \mathbf{1 . 0 6}]\end{array}$

Heterogeneity: $\mathrm{Tau}^{2}=0.00 ; \mathrm{Chi}^{2}=0.03, \mathrm{df}=1(\mathrm{P}=0.86) ; \mathrm{I}^{2}=0 \%$

Test for overall effect: $\mathrm{Z}=1.00(\mathrm{P}=0.32)$

Total (95\% CI)

$100.0 \%$

$0.78[0.72,0.85]$

Heterogeneity: $\mathrm{Tau}^{2}=0.01 ; \mathrm{Chi}^{2}=34.73, \mathrm{df}=12(\mathrm{P}=0.0005) ; \mathrm{I}^{2}=65 \%$

Test for overall effect: $\mathrm{Z}=5.74(\mathrm{P}<0.00001)$

Test for subgroup differences: $\mathrm{Chi}^{2}=25.25, \mathrm{df}=2(\mathrm{P}<0.00001), \mathrm{I}^{2}=92.1 \%$
Odds Ratio

IV, Random, 95\% CI 
Analysis 9.3. Comparison 9: Influenza vaccines versus no vaccination: cohort studies in community - adjusted rates, Outcome 3: Hospitalisation for heart disease

Study or Subgroup $\log [\mathrm{OR}]$

\section{SE}

\author{
Odds Ratio \\ Weight IV, Random, 95\% CI
}

Odds Ratio

IV, Random, 95\% CI

9.3.1 Epidemic year - vaccine matching

$\begin{array}{lrrrr}\text { Nichol 1998a } & -0.3147 & 0.0846 & 22.3 \% & 0.73[0.62,0.86] \\ \text { Davis 2001b } & -0.36 & 0.21 & 3.6 \% & 0.70[0.46,1.05] \\ \text { Davis 2001c } & -0.36 & 0.21 & 3.6 \% & 0.70[0.46,1.05] \\ \text { Nichol 2003a } & -0.2107 & 0.0697 & 32.9 \% & 0.81[0.71,0.93] \\ \text { Nichol 2003b } & -0.3147 & 0.0694 & 33.2 \% & 0.73[0.64,0.84] \\ \text { Subtotal (95\% CI) } & & & \mathbf{9 5 . 6 \%} & \mathbf{0 . 7 5}[\mathbf{0 . 7 0 , 0 . 8 2}]\end{array}$

Heterogeneity: $\mathrm{Tau}^{2}=0.00 ; \mathrm{Chi}^{2}=1.69, \mathrm{df}=4(\mathrm{P}=0.79) ; \mathrm{I}^{2}=0 \%$

Test for overall effect: $\mathrm{Z}=6.91(\mathrm{P}<0.00001)$

9.3.2 Non-epidemic - vaccine not matching

$\begin{array}{lllll}\text { Davis 2001a } & -0.22 & 0.19 & 4.4 \% & 0.80[0.55,1.16] \\ \text { Subtotal (95\% CI) } & & & \mathbf{4 . 4 \%} & \mathbf{0 . 8 0}[\mathbf{0 . 5 5 , \mathbf { 1 . 1 6 }}]\end{array}$

Heterogeneity: Not applicable

Test for overall effect: $\mathrm{Z}=1.16(\mathrm{P}=0.25)$

Total (95\% CI)

$100.0 \%$

$0.76[0.70,0.82]$

Heterogeneity: $\mathrm{Tau}^{2}=0.00 ; \mathrm{Chi}^{2}=1.80, \mathrm{df}=5(\mathrm{P}=0.88) ; \mathrm{I}^{2}=0 \%$ Test for overall effect: $\mathrm{Z}=7.00(\mathrm{P}<0.00001)$

Test for subgroup differences: $\mathrm{Chi}^{2}=0.10, \mathrm{df}=1(\mathrm{P}=0.75), \mathrm{I}^{2}=0 \%$

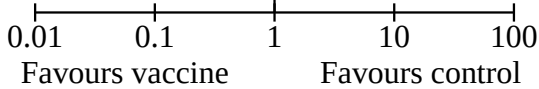




\section{Analysis 9.4. Comparison 9: Influenza vaccines versus no vaccination:} cohort studies in community - adjusted rates, Outcome 4: All deaths

\section{Odds Ratio}

$\log [\mathrm{OR}] \quad$ SE Weight IV, Random, 95\% CI
Odds Ratio

IV, Random, 95\% CI

9.4.1 Epidemic year - vaccine matching

$\begin{array}{lrrrr}\text { Fleming 1995 } & -1.3863 & 0.5842 & 1.4 \% & 0.25[0.08,0.79] \\ \text { Nichol 1998a } & -0.6931 & 0.0615 & 17.0 \% & 0.50[0.44,0.56] \\ \text { Nordin 2001a } & -0.9416 & 0.0658 & 16.7 \% & 0.39[0.34,0.44] \\ \text { Nichol 2003a } & -0.6539 & 0.0492 & 17.8 \% & 0.52[0.47,0.57] \\ \text { Nichol 2003b } & -0.6931 & 0.0456 & 18.1 \% & 0.50[0.46,0.55] \\ \text { Subtotal (95\% CI) } & & & \mathbf{7 1 . 1 \%} & \mathbf{0 . 4 7}[\mathbf{0 . 4 2}, \mathbf{0 . 5 3}]\end{array}$

Heterogeneity: $\mathrm{Tau}^{2}=0.01 ; \mathrm{Chi}^{2}=14.96, \mathrm{df}=4(\mathrm{P}=0.005) ; \mathrm{I}^{2}=73 \%$

Test for overall effect: $\mathrm{Z}=12.72(\mathrm{P}<0.00001)$

9.4.2 Epidemic year - vaccine matching absent or unknown

$\begin{array}{lllll}\text { Nordin 2001b } & -0.4308 & 0.07 & 16.4 \% & 0.65[0.57,0.75] \\ \text { Subtotal (95\% CI) } & & & \mathbf{1 6 . 4 \%} & \mathbf{0 . 6 5}[\mathbf{0 . 5 7}, \mathbf{0 . 7 5}]\end{array}$

Heterogeneity: Not applicable

Test for overall effect: $\mathrm{Z}=6.15(\mathrm{P}<0.00001)$

9.4.3 Non-epidemic year - vaccine matching
Voordouw 2003
$-0.2744 \quad 0.1225$
$12.5 \%$
$0.76[0.60,0.97]$
Subtotal (95\% CI)
$12.5 \%$
$0.76[0.60,0.97]$

Heterogeneity: Not applicable

Test for overall effect: $\mathrm{Z}=2.24(\mathrm{P}=0.03)$

Total (95\% CI)

$100.0 \%$

$0.53[0.46,0.61]$

Heterogeneity: Tau $^{2}=0.03 ; \mathrm{Chi}^{2}=41.15, \mathrm{df}=6(\mathrm{P}<0.00001) ; \mathrm{I}^{2}=85 \%$

Test for overall effect: $\mathrm{Z}=8.92(\mathrm{P}<0.00001)$

Test for subgroup differences: $\mathrm{Chi}^{2}=18.78, \mathrm{df}=2(\mathrm{P}<0.0001), \mathrm{I}^{2}=89.4 \%$

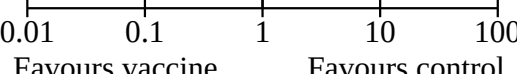

\section{Analysis 9.5. Comparison 9: Influenza vaccines versus no vaccination: cohort studies in community - adjusted rates, Outcome 5: Combined outcome: all deaths or severe respiratory illness}

Odds Ratio

Study or Subgroup $\quad \log [\mathrm{OR}] \quad$ SE $\quad$ Weight $\quad$ IV, Random, $95 \%$ CI

9.5.1 Epidemic year - vaccine matching

Fleming 1995

$-0.3567$

0.3321

Subtotal (95\% CI)

Heterogeneity: Not applicable

Test for overall effect: $\mathrm{Z}=1.07(\mathrm{P}=0.28)$

Total (95\% CI)

$100.0 \%$

Heterogeneity: Not applicable

Test for overall effect: $\mathrm{Z}=1.07(\mathrm{P}=0.28)$

Test for subgroup differences: Not applicable
Odds Ratio

IV, Random, 95\% CI 
Comparison 10. Influenza vaccines versus no vaccination: cohort studies in community-dwellers - risk groups

\begin{tabular}{|c|c|c|c|c|}
\hline Outcome or subgroup title & No. of studies & $\begin{array}{l}\text { No. of partici- } \\
\text { pants }\end{array}$ & Statistical method & Effect size \\
\hline 10.1 Influenza & 1 & 6423 & $\begin{array}{l}\text { Risk Ratio (M-H, Random, } \\
95 \% \mathrm{Cl})\end{array}$ & $0.40[0.14,1.17]$ \\
\hline $\begin{array}{l}\text { 10.1.1 Epidemic year - vaccine match- } \\
\text { ing }\end{array}$ & 0 & 0 & $\begin{array}{l}\text { Risk Ratio (M-H, Random, } \\
95 \% \mathrm{Cl})\end{array}$ & Not estimable \\
\hline $\begin{array}{l}\text { 10.1.2 Epidemic year - vaccine match- } \\
\text { ing absent or unknown }\end{array}$ & 0 & 0 & $\begin{array}{l}\text { Risk Ratio (M-H, Random, } \\
95 \% \mathrm{Cl})\end{array}$ & Not estimable \\
\hline $\begin{array}{l}\text { 10.1.3 Non-epidemic year - vaccine } \\
\text { matching }\end{array}$ & 1 & 6423 & $\begin{array}{l}\text { Risk Ratio (M-H, Random, } \\
95 \% \mathrm{Cl})\end{array}$ & $0.40[0.14,1.17]$ \\
\hline $\begin{array}{l}\text { 10.1.4 Non-epidemic year - vaccine } \\
\text { matching absent or unknown }\end{array}$ & 0 & 0 & $\begin{array}{l}\text { Risk Ratio (M-H, Random, } \\
95 \% \mathrm{Cl} \text { ) }\end{array}$ & Not estimable \\
\hline 10.2 Pneumonia & 1 & 6423 & $\begin{array}{l}\text { Risk Ratio (M-H, Random, } \\
95 \% \mathrm{Cl})\end{array}$ & $1.22[0.76,1.94]$ \\
\hline $\begin{array}{l}\text { 10.2.1 Epidemic year - vaccine match- } \\
\text { ing }\end{array}$ & 0 & 0 & $\begin{array}{l}\text { Risk Ratio (M-H, Random, } \\
95 \% \mathrm{Cl})\end{array}$ & Not estimable \\
\hline $\begin{array}{l}\text { 10.2.2 Epidemic year - vaccine match- } \\
\text { ing absent or unknown }\end{array}$ & 0 & 0 & $\begin{array}{l}\text { Risk Ratio (M-H, Random, } \\
95 \% \mathrm{Cl})\end{array}$ & Not estimable \\
\hline $\begin{array}{l}\text { 10.2.3 Non-epidemic year - vaccine } \\
\text { matching }\end{array}$ & 1 & 6423 & $\begin{array}{l}\text { Risk Ratio (M-H, Random, } \\
95 \% \mathrm{Cl})\end{array}$ & $1.22[0.76,1.94]$ \\
\hline $\begin{array}{l}\text { 10.2.4 Non-epidemic year - vaccine } \\
\text { matching absent or unknown }\end{array}$ & 0 & 0 & $\begin{array}{l}\text { Risk Ratio (M-H, Random, } \\
95 \% \mathrm{Cl})\end{array}$ & Not estimable \\
\hline $\begin{array}{l}10.3 \text { Hospitalisation for influenza or } \\
\text { pneumonia }\end{array}$ & 1 & 45932 & $\begin{array}{l}\text { Risk Ratio (M-H, Random, } \\
95 \% \mathrm{CI})\end{array}$ & $0.74[0.63,0.86]$ \\
\hline $\begin{array}{l}\text { 10.3.1 Epidemic year - vaccine match- } \\
\text { ing }\end{array}$ & 1 & 45932 & $\begin{array}{l}\text { Risk Ratio (M-H, Random, } \\
95 \% \mathrm{Cl} \text { ) }\end{array}$ & $0.74[0.63,0.86]$ \\
\hline $\begin{array}{l}\text { 10.3.2 Epidemic year - vaccine match- } \\
\text { ing absent or unknown }\end{array}$ & 0 & 0 & $\begin{array}{l}\text { Risk Ratio (M-H, Random, } \\
95 \% \mathrm{Cl} \text { ) }\end{array}$ & Not estimable \\
\hline $\begin{array}{l}\text { 10.3.3 Non-epidemic year - vaccine } \\
\text { matching }\end{array}$ & 0 & 0 & $\begin{array}{l}\text { Risk Ratio (M-H, Random, } \\
95 \% \mathrm{Cl} \text { ) }\end{array}$ & Not estimable \\
\hline $\begin{array}{l}\text { 10.3.4 Non-epidemic year - vaccine } \\
\text { matching absent or unknown }\end{array}$ & 0 & 0 & $\begin{array}{l}\text { Risk Ratio (M-H, Random, } \\
95 \% \mathrm{Cl})\end{array}$ & Not estimable \\
\hline $\begin{array}{l}\text { 10.4 Hospitalisation for any respiratory } \\
\text { disease }\end{array}$ & 2 & 189004 & $\begin{array}{l}\text { Risk Ratio (M-H, Random, } \\
95 \% \mathrm{Cl})\end{array}$ & $0.85[0.80,0.92]$ \\
\hline $\begin{array}{l}\text { 10.4.1 Epidemic year - vaccine match- } \\
\text { ing }\end{array}$ & 2 & 189004 & $\begin{array}{l}\text { Risk Ratio (M-H, Random, } \\
95 \% \mathrm{Cl} \text { ) }\end{array}$ & $0.85[0.80,0.92]$ \\
\hline $\begin{array}{l}\text { 10.4.2 Epidemic year - vaccine match- } \\
\text { ing absent or unknown }\end{array}$ & 0 & 0 & $\begin{array}{l}\text { Risk Ratio (M-H, Random, } \\
95 \% \mathrm{Cl} \text { ) }\end{array}$ & Not estimable \\
\hline
\end{tabular}




\begin{tabular}{|c|c|c|c|c|}
\hline Outcome or subgroup title & No. of studies & $\begin{array}{l}\text { No. of partici- } \\
\text { pants }\end{array}$ & Statistical method & Effect size \\
\hline $\begin{array}{l}\text { 10.4.3 Non-epidemic year - vaccine } \\
\text { matching }\end{array}$ & 0 & 0 & $\begin{array}{l}\text { Risk Ratio (M-H, Random, } \\
95 \% \mathrm{Cl})\end{array}$ & Not estimable \\
\hline $\begin{array}{l}\text { 10.4.4 Non-epidemic year - vaccine } \\
\text { matching absent or unknown }\end{array}$ & 0 & 0 & $\begin{array}{l}\text { Risk Ratio (M-H, Random, } \\
95 \% \mathrm{Cl})\end{array}$ & Not estimable \\
\hline 10.5 Deaths from respiratory disease & 1 & 142464 & $\begin{array}{l}\text { Risk Ratio (M-H, Random, } \\
95 \% \mathrm{Cl})\end{array}$ & $0.92[0.86,0.98]$ \\
\hline $\begin{array}{l}\text { 10.5.1 Epidemic year - vaccine match- } \\
\text { ing }\end{array}$ & 1 & 142464 & $\begin{array}{l}\text { Risk Ratio (M-H, Random, } \\
95 \% \mathrm{Cl})\end{array}$ & $0.92[0.86,0.98]$ \\
\hline 10.6 All deaths & 3 & 68032 & $\begin{array}{l}\text { Risk Ratio (M-H, Random, } \\
95 \% \mathrm{Cl})\end{array}$ & $0.39[0.16,0.97]$ \\
\hline $\begin{array}{l}\text { 10.6.1 Epidemic year - vaccine match- } \\
\text { ing }\end{array}$ & 1 & 2344 & $\begin{array}{l}\text { Risk Ratio (M-H, Random, } \\
95 \% \mathrm{Cl})\end{array}$ & $0.13[0.02,0.92]$ \\
\hline $\begin{array}{l}\text { 10.6.2 Epidemic year - vaccine match- } \\
\text { ing absent or unknown }\end{array}$ & 0 & 0 & $\begin{array}{l}\text { Risk Ratio (M-H, Random, } \\
95 \% \mathrm{Cl})\end{array}$ & Not estimable \\
\hline $\begin{array}{l}\text { 10.6.3 Non-epidemic year - vaccine } \\
\text { matching }\end{array}$ & 2 & 65688 & $\begin{array}{l}\text { Risk Ratio (M-H, Random, } \\
95 \% \mathrm{Cl})\end{array}$ & $0.47[0.17,1.28]$ \\
\hline $\begin{array}{l}\text { 10.6.4 Non-epidemic year - vaccine } \\
\text { matching absent or unknown }\end{array}$ & 0 & 0 & $\begin{array}{l}\text { Risk Ratio (M-H, Random, } \\
95 \% \mathrm{CI})\end{array}$ & Not estimable \\
\hline 10.7 Hospitalisation for heart disease & 1 & 45932 & $\begin{array}{l}\text { Risk Ratio (M-H, Random, } \\
95 \% \mathrm{Cl})\end{array}$ & $0.92[0.83,1.03]$ \\
\hline $\begin{array}{l}\text { 10.7.1 Epidemic year - vaccine match- } \\
\text { ing }\end{array}$ & 1 & 45932 & $\begin{array}{l}\text { Risk Ratio (M-H, Random, } \\
95 \% \mathrm{Cl})\end{array}$ & $0.92[0.83,1.03]$ \\
\hline $\begin{array}{l}\text { 10.7.2 Epidemic year - vaccine match- } \\
\text { ing absent or unknown }\end{array}$ & 0 & 0 & $\begin{array}{l}\text { Risk Ratio (M-H, Random, } \\
95 \% \mathrm{Cl})\end{array}$ & Not estimable \\
\hline $\begin{array}{l}\text { 10.7.3 Non-epidemic year - vaccine } \\
\text { matching }\end{array}$ & 0 & 0 & $\begin{array}{l}\text { Risk Ratio (M-H, Random, } \\
95 \% \mathrm{Cl})\end{array}$ & Not estimable \\
\hline $\begin{array}{l}\text { 10.7.4 Non-epidemic year - vaccine } \\
\text { matching absent or unknown }\end{array}$ & 0 & 0 & $\begin{array}{l}\text { Risk Ratio (M-H, Random, } \\
95 \% \mathrm{Cl})\end{array}$ & Not estimable \\
\hline $\begin{array}{l}10.8 \text { Combined outcome: all deaths or } \\
\text { severe respiratory illness }\end{array}$ & 2 & 146248 & $\begin{array}{l}\text { Risk Ratio (M-H, Random, } \\
95 \% \mathrm{Cl} \text { ) }\end{array}$ & $0.60[0.49,0.74]$ \\
\hline $\begin{array}{l}\text { 10.8.1 Epidemic year - vaccine match- } \\
\text { ing }\end{array}$ & 1 & 54438 & $\begin{array}{l}\text { Risk Ratio (M-H, Random, } \\
95 \% \mathrm{Cl})\end{array}$ & $0.54[0.49,0.60]$ \\
\hline $\begin{array}{l}\text { 10.8.2 Epidemic year - vaccine match- } \\
\text { ing absent or unknown }\end{array}$ & 1 & 91810 & $\begin{array}{l}\text { Risk Ratio (M-H, Random, } \\
95 \% \mathrm{Cl} \text { ) }\end{array}$ & $0.67[0.61,0.72]$ \\
\hline
\end{tabular}


Analysis 10.1. Comparison 10: Influenza vaccines versus no vaccination: cohort studies in community-dwellers - risk groups, Outcome 1: Influenza

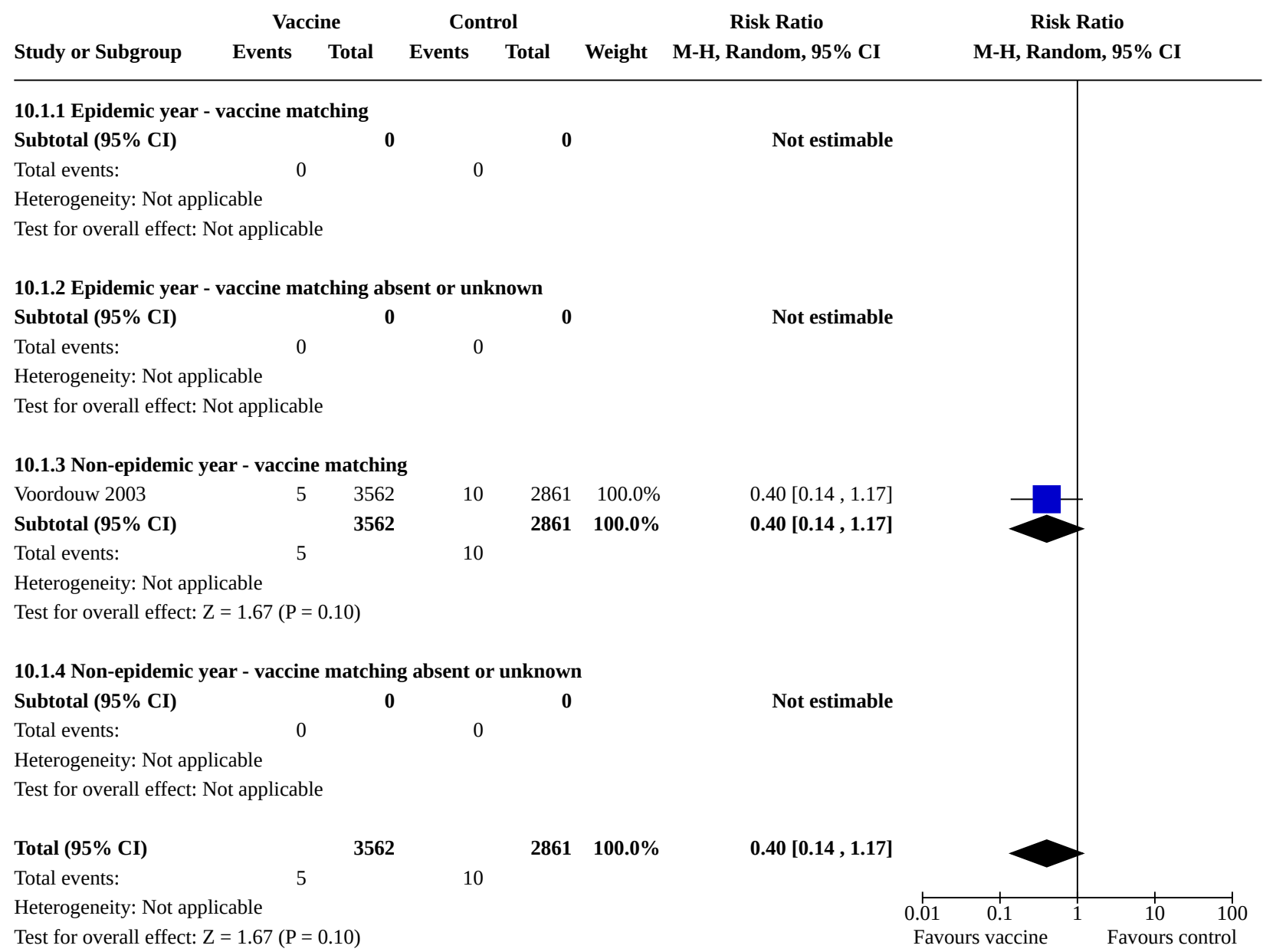


Analysis 10.2. Comparison 10: Influenza vaccines versus no vaccination: cohort studies in community-dwellers - risk groups, Outcome 2: Pneumonia

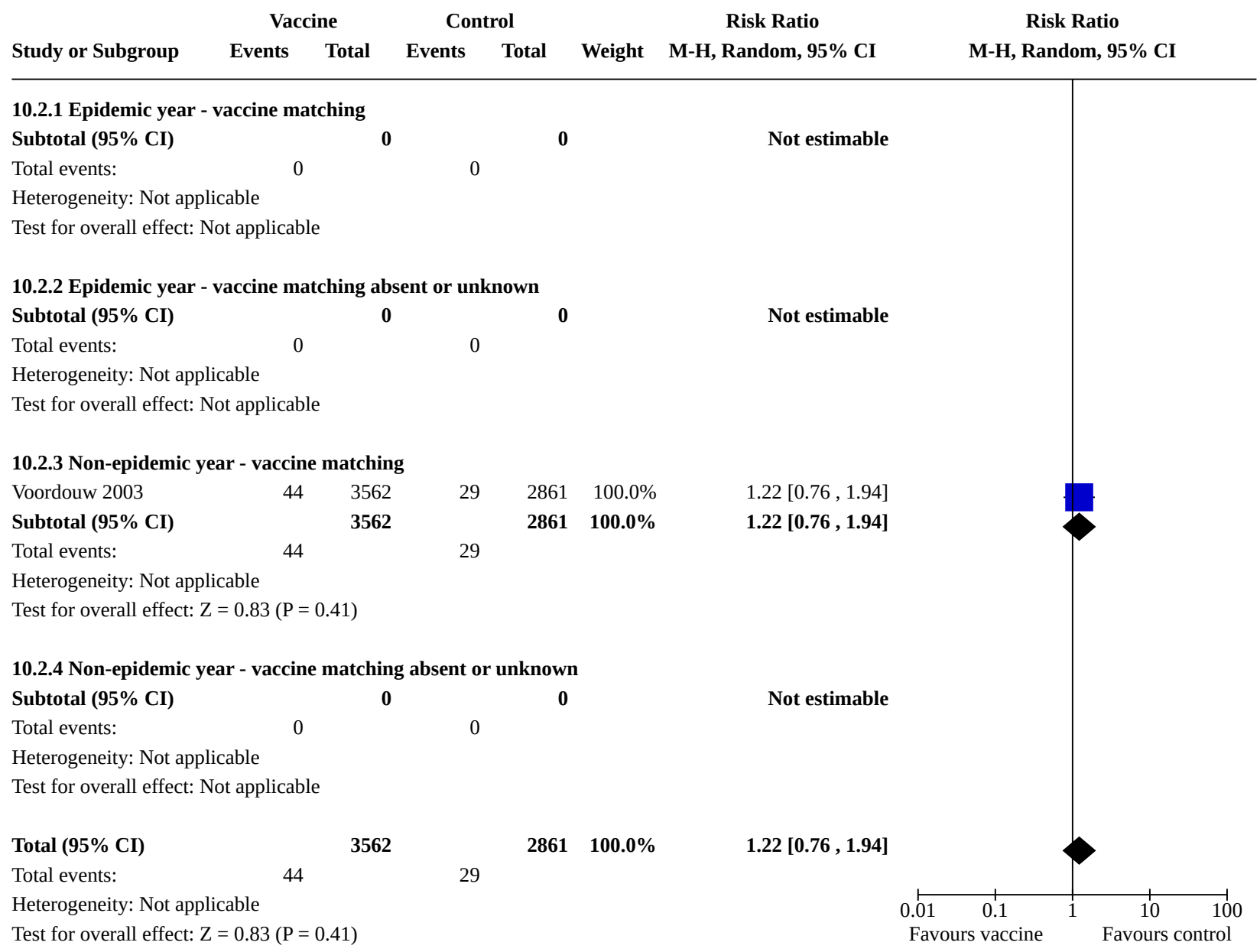


Analysis 10.3. Comparison 10: Influenza vaccines versus no vaccination: cohort studies in community-dwellers - risk groups, Outcome 3: Hospitalisation for influenza or pneumonia

\begin{tabular}{|c|c|c|c|c|c|c|c|c|}
\hline \multirow[b]{2}{*}{ Study or Subgroup } & \multicolumn{2}{|c|}{ Vaccine } & \multicolumn{2}{|c|}{ Control } & \multirow[b]{2}{*}{ Weight } & \multirow{2}{*}{$\begin{array}{c}\text { Risk Ratio } \\
\text { M-H, Random, 95\% CI }\end{array}$} & \multirow{2}{*}{\multicolumn{2}{|c|}{$\begin{array}{c}\text { Risk Ratio } \\
\text { M-H, Random, 95\% CI }\end{array}$}} \\
\hline & Events & Total & Events & Total & & & & \\
\hline \multicolumn{9}{|c|}{ 10.3.1 Epidemic year - vaccine matching } \\
\hline Nichol 1998a & 419 & 30840 & 278 & 15092 & $100.0 \%$ & $0.74[0.63,0.86]$ & & \\
\hline Subtotal (95\% CI) & & 30840 & & 15092 & $100.0 \%$ & $0.74[0.63,0.86]$ & $\Delta$ & \\
\hline Total events: & 419 & & 278 & & & & & \\
\hline \multicolumn{9}{|c|}{ Heterogeneity: Not applicable } \\
\hline \multicolumn{9}{|c|}{ Test for overall effect: $\mathrm{Z}=3.97(\mathrm{P}<0.0001)$} \\
\hline \multicolumn{9}{|c|}{ 10.3.2 Epidemic year - vaccine matching absent or unknown } \\
\hline Subtotal (95\% CI) & & $\mathbf{0}$ & & $\mathbf{0}$ & & Not estimable & & \\
\hline Total events: & 0 & & 0 & & & & & \\
\hline \multicolumn{9}{|c|}{ Heterogeneity: Not applicable } \\
\hline \multicolumn{9}{|c|}{ Test for overall effect: Not applicable } \\
\hline \multicolumn{9}{|c|}{ 10.3.3 Non-epidemic year - vaccine matching } \\
\hline Subtotal (95\% CI) & & $\mathbf{0}$ & & $\mathbf{0}$ & & Not estimable & & \\
\hline Total events: & 0 & & 0 & & & & & \\
\hline \multicolumn{9}{|c|}{ Heterogeneity: Not applicable } \\
\hline \multicolumn{9}{|c|}{ Test for overall effect: Not applicable } \\
\hline \multicolumn{9}{|c|}{ 10.3.4 Non-epidemic year - vaccine matching absent or unknown } \\
\hline Subtotal $(95 \% \mathrm{CI})$ & & $\mathbf{0}$ & & $\mathbf{0}$ & & Not estimable & & \\
\hline Total events: & 0 & & 0 & & & & & \\
\hline \multicolumn{9}{|c|}{ Heterogeneity: Not applicable } \\
\hline \multicolumn{9}{|c|}{ Test for overall effect: Not applicable } \\
\hline Total $(95 \%$ CI) & & 30840 & & 15092 & $100.0 \%$ & $0.74[0.63,0.86]$ & $\Delta$ & \\
\hline Total events: & 419 & & 278 & & & & & \\
\hline Heterogeneity: Not ap & icable & & & & & 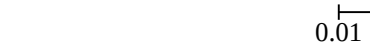 & 0.1 & 10 \\
\hline Test for overall effect: & $=3.97(\mathrm{P}<$ & $0.0001)$ & & & & Fav & vaccine & Favours c \\
\hline
\end{tabular}


Analysis 10.4. Comparison 10: Influenza vaccines versus no vaccination: cohort studies in community-dwellers - risk groups, Outcome 4: Hospitalisation for any respiratory disease

\begin{tabular}{lccrrrr} 
& \multicolumn{2}{c}{ Vaccine } & \multicolumn{2}{c}{ Control } & \multicolumn{2}{c}{ Risk Ratio } \\
Study or Subgroup & Events & Total & Events & Total & Weight & M-H, Random, 95\% CI \\
\hline $\begin{array}{l}\text { 10.4.1 Epidemic year } \\
\text { - vaccine matching }\end{array}$ & 1937 & 30840 & 1150 & 15092 & $49.5 \%$ & $0.82[0.77,0.88]$ \\
Nichol 1998a & 1426 & 67877 & 1785 & 75195 & $50.5 \%$ & $0.89[0.83,0.95]$ \\
Mangtani 2004a & & $\mathbf{9 8 7 1 7}$ & & $\mathbf{9 0 2 8 7}$ & $\mathbf{1 0 0 . 0 \%}$ & $\mathbf{0 . 8 5}[\mathbf{0 . 8 0 , 0 . 9 2}]$ \\
Subtotal (95\% CI) & 3363 & & 2935 & & &
\end{tabular}

Heterogeneity: $\mathrm{Tau}^{2}=0.00 ; \mathrm{Chi}^{2}=2.01, \mathrm{df}=1(\mathrm{P}=0.16) ; \mathrm{I}^{2}=50 \%$

Test for overall effect: $\mathrm{Z}=4.42(\mathrm{P}<0.00001)$

10.4.2 Epidemic year - vaccine matching absent or unknown

Subtotal (95\% CI)

0

0

Total events: $\quad 0 \quad 0$

Not estimable

Heterogeneity: Not applicable

Test for overall effect: Not applicable

10.4.3 Non-epidemic year - vaccine matching

Subtotal (95\% CI)

Total events: $\quad 0$

0

0

Heterogeneity: Not applicable

Test for overall effect: Not applicable

10.4.4 Non-epidemic year - vaccine matching absent or unknown

Subtotal (95\% CI)

0

Total events: $\quad 0 \quad 0$

Not estimable

Heterogeneity: Not applicable

Test for overall effect: Not applicable

$\begin{array}{lllll}\text { Total (95\% CI) } & 98717 & 90287 & 100.0 \% & 0.85[0.80,0.92]\end{array}$ 3363 2935

Heterogeneity: $\mathrm{Tau}^{2}=0.00 ; \mathrm{Chi}^{2}=2.01, \mathrm{df}=1(\mathrm{P}=0.16) ; \mathrm{I}^{2}=50 \%$

Test for overall effect: $\mathrm{Z}=4.42(\mathrm{P}<0.00001)$

Test for subgroup differences: Not applicable

Risk Ratio

M-H, Random, 95\% CI

\section{Analysis 10.5. Comparison 10: Influenza vaccines versus no vaccination: cohort studies in community-dwellers - risk groups, Outcome 5: Deaths from respiratory disease}

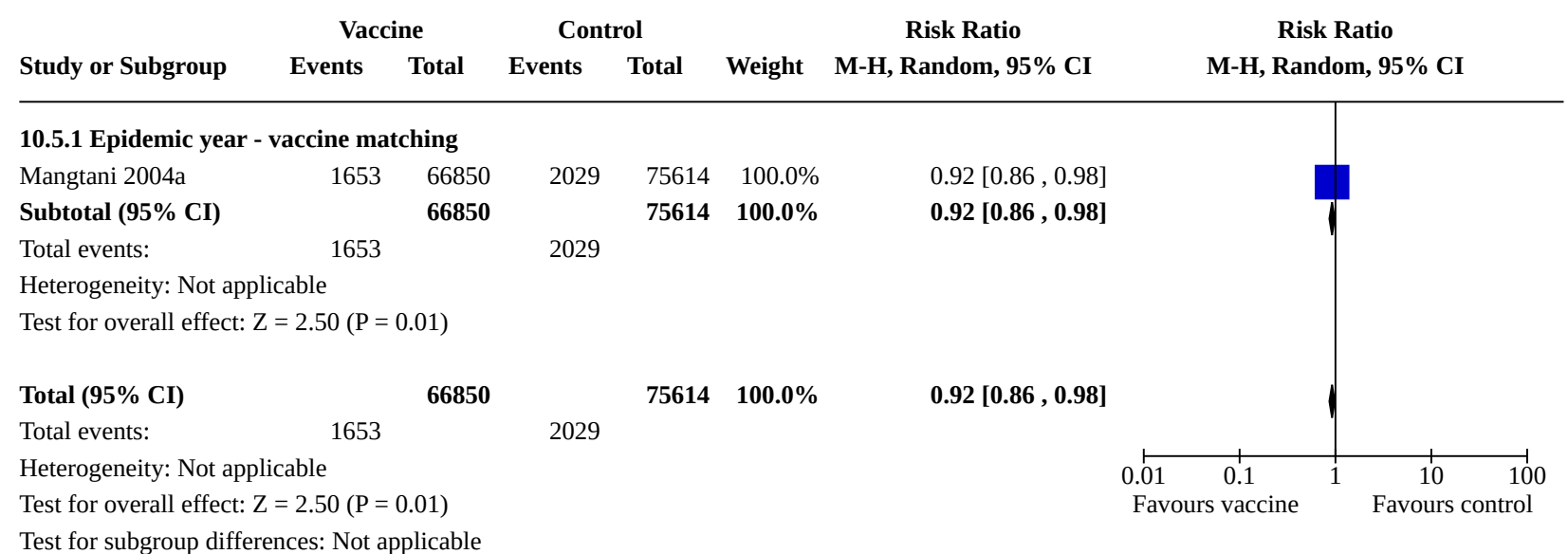


Analysis 10.6. Comparison 10: Influenza vaccines versus no vaccination: cohort studies in community-dwellers - risk groups, Outcome 6: All deaths

\begin{tabular}{|c|c|c|c|c|c|c|c|}
\hline & & & Con & & & Risk Ratio & Risk Ratio \\
\hline Study or Subgroup & Events & Total & Events & Total & Weight & M-H, Random, 95\% CI & M-H, Random, 95\% CI \\
\hline
\end{tabular}

10.6.1 Epidemic year - vaccine matching

Fleming 1995

Subtotal (95\% CI)

1265

Total events: 265

Heterogeneity: Not applicable

Test for overall effect: $\mathrm{Z}=2.04(\mathrm{P}=0.04)$

10.6.2 Epidemic year - vaccine matching absent or unknown

Subtotal (95\% CI)

Total events: 0 0

Heterogeneity: Not applicable

Test for overall effect: Not applicable

10.6.3 Non-epidemic year - vaccine matching

$\begin{array}{lrrrrr}\text { Voordouw 2003 } & 75 & 3562 & 76 & 2861 & 41.9 \% \\ \text { Shapiro 2003 } & 238 & 28853 & 872 & 30412 & 43.7 \% \\ \text { Subtotal (95\% CI) } & & \mathbf{3 2 4 1 5} & & \mathbf{3 3 2 7 3} & \mathbf{8 5 . 6 \%} \\ \text { Total events: } & 313 & & 948 & & \end{array}$

Heterogeneity: Tau $^{2}=0.50 ; \mathrm{Chi}^{2}=33.12, \mathrm{df}=1(\mathrm{P}<0.00001) ; \mathrm{I}^{2}=97 \%$

Test for overall effect: $\mathrm{Z}=1.48(\mathrm{P}=0.14)$

10.6.4 Non-epidemic year - vaccine matching absent or unknown Subtotal (95\% CI)

o 0

Total events: 0

0

Heterogeneity: Not applicable

Test for overall effect: Not applicable

Total (95\% CI)

32680

$35352100.0 \%$

Total events: 314 1009

Heterogeneity: $\mathrm{Tau}^{2}=0.49 ; \mathrm{Chi}^{2}=34.12, \mathrm{df}=2(\mathrm{P}<0.00001) ; \mathrm{I}^{2}=94 \%$

Test for overall effect: $\mathrm{Z}=2.02(\mathrm{P}=0.04)$

Test for subgroup differences: $\mathrm{Chi}^{2}=1.33, \mathrm{df}=1(\mathrm{P}=0.25), \mathrm{I}^{2}=25.1 \%$
$0.13[0.02,0.92]$

$0.13[0.02,0.92]$

Not estimable

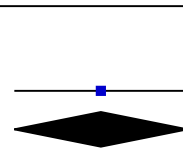

$0.79[0.58,1.09]$

$0.29[0.25,0.33]$

$0.47[0.17,1.28]$

Not estimable

$0.39[0.16,0.97]$

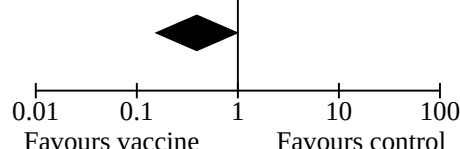




\section{Analysis 10.7. Comparison 10: Influenza vaccines versus no vaccination: cohort studies} in community-dwellers - risk groups, Outcome 7: Hospitalisation for heart disease

\begin{tabular}{|c|c|c|c|c|c|c|c|c|c|}
\hline \multirow{2}{*}{ Study or Subgroup } & \multicolumn{2}{|c|}{ Vaccine } & \multicolumn{2}{|c|}{ Control } & \multirow[b]{2}{*}{ Weight } & \multirow{2}{*}{$\begin{array}{c}\text { Risk Ratio } \\
\text { M-H, Random, 95\% CI }\end{array}$} & \multirow{2}{*}{\multicolumn{2}{|c|}{$\begin{array}{c}\text { Risk Ratio } \\
\text { M-H, Random, 95\% CI }\end{array}$}} & \\
\hline & Events & Total & Events & Total & & & & & \\
\hline \multicolumn{10}{|c|}{ 10.7.1 Epidemic year - vaccine matching } \\
\hline Nichol 1998a & 917 & 30840 & 487 & 15092 & $100.0 \%$ & $0.92[0.83,1.03]$ & & & \\
\hline Subtotal $(95 \%$ CI $)$ & & 30840 & & 15092 & $100.0 \%$ & $0.92[0.83,1.03]$ & & & \\
\hline Total events: & 917 & & 487 & & & & & & \\
\hline \multicolumn{10}{|c|}{ Heterogeneity: Not applicable } \\
\hline \multicolumn{10}{|c|}{ Test for overall effect: $\mathrm{Z}=1.48(\mathrm{P}=0.14)$} \\
\hline \multicolumn{10}{|c|}{ 10.7.2 Epidemic year - vaccine matching absent or unknown } \\
\hline Subtotal (95\% CI) & & $\mathbf{0}$ & & $\mathbf{0}$ & & Not estimable & & & \\
\hline Total events: & 0 & & 0 & & & & & & \\
\hline \multicolumn{10}{|c|}{ Heterogeneity: Not applicable } \\
\hline \multicolumn{10}{|c|}{ Test for overall effect: Not applicable } \\
\hline \multicolumn{10}{|c|}{ 10.7.3 Non-epidemic year - vaccine matching } \\
\hline Subtotal $(95 \%$ CI $)$ & & $\mathbf{0}$ & & $\mathbf{0}$ & & Not estimable & & & \\
\hline Total events: & 0 & & 0 & & & & & & \\
\hline \multicolumn{10}{|c|}{ Heterogeneity: Not applicable } \\
\hline \multicolumn{10}{|c|}{ Test for overall effect: Not applicable } \\
\hline \multicolumn{10}{|c|}{ 10.7.4 Non-epidemic year - vaccine matching absent or unknown } \\
\hline Subtotal $(95 \% \mathrm{CI})$ & & $\mathbf{0}$ & & $\mathbf{0}$ & & Not estimable & & & \\
\hline Total events: & 0 & & 0 & & & & & & \\
\hline \multicolumn{10}{|c|}{ Heterogeneity: Not applicable } \\
\hline \multicolumn{10}{|c|}{ Test for overall effect: Not applicable } \\
\hline Total (95\% CI) & & 30840 & & 15092 & $100.0 \%$ & $0.92[0.83,1.03]$ & & & \\
\hline Total events: & 917 & & 487 & & & & & & \\
\hline Heterogeneity: Not ap & cable & & & & & 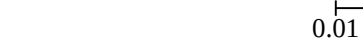 & 0.1 & 10 & $\stackrel{100}{100}$ \\
\hline Test for overall effect: & $=1.48(\mathrm{P}=$ & $0.14)$ & & & & Fav & Irs vaccine & Favours & trol \\
\hline
\end{tabular}


Analysis 10.8. Comparison 10: Influenza vaccines versus no vaccination: cohort studies in communitydwellers - risk groups, Outcome 8: Combined outcome: all deaths or severe respiratory illness

\begin{tabular}{|c|c|c|c|c|c|c|c|c|c|}
\hline \multirow[b]{2}{*}{ Study or Subgroup } & \multicolumn{2}{|c|}{ Vaccine } & \multicolumn{2}{|c|}{ Control } & \multirow[b]{2}{*}{ Weight } & \multirow{2}{*}{$\begin{array}{c}\text { Risk Ratio } \\
\text { M-H, Random, 95\% CI }\end{array}$} & \multirow{2}{*}{\multicolumn{2}{|c|}{$\begin{array}{c}\text { Risk Ratio } \\
\text { M-H, Random, 95\% CI }\end{array}$}} & \\
\hline & Events & Total & Events & Total & & & & & \\
\hline \multicolumn{10}{|c|}{ 10.8.1 Epidemic year - vaccine matching } \\
\hline Hak 2002a & 695 & 33312 & 811 & 21126 & $49.1 \%$ & $0.54[0.49,0.60]$ & $\mathbf{\square}$ & & \\
\hline Subtotal (95\% CI) & & 33312 & & 21126 & $49.1 \%$ & $0.54[0.49,0.60]$ & 1 & & \\
\hline Total events: & 695 & & 811 & & & & & & \\
\hline \multicolumn{10}{|c|}{ Heterogeneity: Not applicable } \\
\hline \multicolumn{10}{|c|}{ Test for overall effect: $\mathrm{Z}=11.97(\mathrm{P}<0.00001)$} \\
\hline \multicolumn{10}{|c|}{ 10.8.2 Epidemic year - vaccine matching absent or unknown } \\
\hline Hak 2002b & 1129 & 57846 & 995 & 33964 & $50.9 \%$ & $0.67[0.61,0.72]$ & $\mathbf{\square}$ & & \\
\hline Subtotal $(95 \%$ CI $)$ & & 57846 & & 33964 & $50.9 \%$ & $0.67[0.61,0.72]$ & 1 & & \\
\hline Total events: & 1129 & & 995 & & & & & & \\
\hline \multicolumn{10}{|c|}{ Heterogeneity: Not applicable } \\
\hline \multicolumn{10}{|c|}{ Test for overall effect: $\mathrm{Z}=9.46(\mathrm{P}<0.00001)$} \\
\hline Total (95\% CI) & & 91158 & & 55090 & $100.0 \%$ & $0.60[0.49,0.74]$ & $\Delta$ & & \\
\hline Total events: & 1824 & & 1806 & & & & & & \\
\hline \multicolumn{6}{|c|}{ Heterogeneity: $\mathrm{Tau}^{2}=0.02 ; \mathrm{Chi}^{2}=9.34, \mathrm{df}=1(\mathrm{P}=0.002) ; \mathrm{I}^{2}=89 \%$} & $0 . \stackrel{\bullet}{0}$ & 0.1 & 10 & 100 \\
\hline \multicolumn{6}{|c|}{ Test for overall effect: $\mathrm{Z}=4.97(\mathrm{P}<0.00001)$} & Fav & Irs vaccine & Favours & trol \\
\hline
\end{tabular}

Comparison 11. Influenza vaccines versus no vaccination: cohort studies in community-dwellers - no risk groups

\begin{tabular}{|c|c|c|c|c|}
\hline Outcome or subgroup title & No. of studies & $\begin{array}{l}\text { No. of partici- } \\
\text { pants }\end{array}$ & Statistical method & Effect size \\
\hline 11.1 Influenza & 1 & 11399 & $\begin{array}{l}\text { Risk Ratio (M-H, Random, } \\
95 \% \mathrm{Cl})\end{array}$ & $0.57[0.27,1.17]$ \\
\hline $\begin{array}{l}\text { 11.1.1 Epidemic year - vaccine match- } \\
\text { ing }\end{array}$ & 0 & 0 & $\begin{array}{l}\text { Risk Ratio (M-H, Random, } \\
95 \% \mathrm{Cl})\end{array}$ & Not estimable \\
\hline $\begin{array}{l}\text { 11.1.2 Epidemic year - vaccine match- } \\
\text { ing absent or unknown }\end{array}$ & 0 & 0 & $\begin{array}{l}\text { Risk Ratio (M-H, Random, } \\
95 \% \mathrm{Cl})\end{array}$ & Not estimable \\
\hline $\begin{array}{l}\text { 11.1.3 Non-epidemic year - vaccine } \\
\text { matching }\end{array}$ & 1 & 11399 & $\begin{array}{l}\text { Risk Ratio (M-H, Random, } \\
95 \% \mathrm{Cl})\end{array}$ & $0.57[0.27,1.17]$ \\
\hline $\begin{array}{l}\text { 11.1.4 Non-epidemic year - vaccine } \\
\text { matching absent or unknown }\end{array}$ & 0 & 0 & $\begin{array}{l}\text { Risk Ratio (M-H, Random, } \\
95 \% \mathrm{Cl})\end{array}$ & Not estimable \\
\hline 11.2 Pneumonia & 1 & 11399 & $\begin{array}{l}\text { Risk Ratio (M-H, Random, } \\
95 \% \mathrm{Cl})\end{array}$ & $0.59[0.37,0.92]$ \\
\hline $\begin{array}{l}\text { 11.2.1 Epidemic year - vaccine match- } \\
\text { ing }\end{array}$ & 0 & 0 & $\begin{array}{l}\text { Risk Ratio (M-H, Random, } \\
95 \% \mathrm{Cl})\end{array}$ & Not estimable \\
\hline $\begin{array}{l}\text { 11.2.2 Epidemic year - vaccine match- } \\
\text { ing absent or unknown }\end{array}$ & 0 & 0 & $\begin{array}{l}\text { Risk Ratio (M-H, Random, } \\
95 \% \mathrm{Cl})\end{array}$ & Not estimable \\
\hline $\begin{array}{l}\text { 11.2.3 Non-epidemic year - vaccine } \\
\text { matching }\end{array}$ & 1 & 11399 & $\begin{array}{l}\text { Risk Ratio (M-H, Random, } \\
95 \% \mathrm{Cl})\end{array}$ & $0.59[0.37,0.92]$ \\
\hline
\end{tabular}




\begin{tabular}{|c|c|c|c|c|}
\hline Outcome or subgroup title & No. of studies & $\begin{array}{l}\text { No. of partici- } \\
\text { pants }\end{array}$ & Statistical method & Effect size \\
\hline $\begin{array}{l}\text { 11.2.4 Non-epidemic year - vaccine } \\
\text { matching absent or unknown }\end{array}$ & 0 & 0 & $\begin{array}{l}\text { Risk Ratio (M-H, Random, } \\
95 \% \mathrm{Cl} \text { ) }\end{array}$ & Not estimable \\
\hline $\begin{array}{l}11.3 \text { Hospitalisation for influenza or } \\
\text { pneumonia }\end{array}$ & 1 & 101619 & $\begin{array}{l}\text { Risk Ratio (M-H, Random, } \\
95 \% \mathrm{Cl} \text { ) }\end{array}$ & $0.50[0.40,0.63]$ \\
\hline $\begin{array}{l}\text { 11.3.1 Epidemic year - vaccine match- } \\
\text { ing }\end{array}$ & 1 & 101619 & $\begin{array}{l}\text { Risk Ratio (M-H, Random, } \\
95 \% \mathrm{Cl} \text { ) }\end{array}$ & $0.50[0.40,0.63]$ \\
\hline $\begin{array}{l}\text { 11.3.2 Epidemic year - vaccine match- } \\
\text { ing absent or unknown }\end{array}$ & 0 & 0 & $\begin{array}{l}\text { Risk Ratio (M-H, Random, } \\
95 \% \mathrm{Cl} \text { ) }\end{array}$ & Not estimable \\
\hline $\begin{array}{l}\text { 11.3.3 Non-epidemic year - vaccine } \\
\text { matching }\end{array}$ & 0 & 0 & $\begin{array}{l}\text { Risk Ratio (M-H, Random, } \\
95 \% \mathrm{Cl})\end{array}$ & Not estimable \\
\hline $\begin{array}{l}\text { 11.3.4 Non-epidemic year - vaccine } \\
\text { matching absent or unknown }\end{array}$ & 0 & 0 & $\begin{array}{l}\text { Risk Ratio (M-H, Random, } \\
95 \% \mathrm{Cl})\end{array}$ & Not estimable \\
\hline $\begin{array}{l}\text { 11.4 Hospitalisation for any respiratory } \\
\text { disease }\end{array}$ & 2 & 376324 & $\begin{array}{l}\text { Risk Ratio (M-H, Random, } \\
95 \% \mathrm{Cl})\end{array}$ & $0.84[0.55,1.27]$ \\
\hline $\begin{array}{l}\text { 11.4.1 Epidemic year - vaccine match- } \\
\text { ing }\end{array}$ & 2 & 376324 & $\begin{array}{l}\text { Risk Ratio (M-H, Random, } \\
95 \% \mathrm{Cl})\end{array}$ & $0.84[0.55,1.27]$ \\
\hline $\begin{array}{l}\text { 11.4.2 Epidemic year - vaccine match- } \\
\text { ing absent or unknown }\end{array}$ & 0 & 0 & $\begin{array}{l}\text { Risk Ratio (M-H, Random, } \\
95 \% \mathrm{Cl})\end{array}$ & Not estimable \\
\hline $\begin{array}{l}\text { 11.4.3 Non-epidemic year - vaccine } \\
\text { matching }\end{array}$ & 0 & 0 & $\begin{array}{l}\text { Risk Ratio (M-H, Random, } \\
95 \% \mathrm{Cl})\end{array}$ & Not estimable \\
\hline $\begin{array}{l}\text { 11.4.4 Non-epidemic year - vaccine } \\
\text { matching absent or unknown }\end{array}$ & 0 & 0 & $\begin{array}{l}\text { Risk Ratio (M-H, Random, } \\
95 \% \mathrm{Cl})\end{array}$ & Not estimable \\
\hline 11.5 Deaths from respiratory disease & 1 & 281424 & $\begin{array}{l}\text { Risk Ratio (M-H, Random, } \\
95 \% \mathrm{Cl} \text { ) }\end{array}$ & $1.41[1.31,1.53]$ \\
\hline $\begin{array}{l}\text { 11.5.1 Epidemic year - vaccine match- } \\
\text { ing }\end{array}$ & 1 & 281424 & $\begin{array}{l}\text { Risk Ratio (M-H, Random, } \\
95 \% \mathrm{Cl})\end{array}$ & $1.41[1.31,1.53]$ \\
\hline 11.6 All deaths & 3 & 43821 & $\begin{array}{l}\text { Risk Ratio (M-H, Random, } \\
95 \% \mathrm{Cl} \text { ) }\end{array}$ & $0.65[0.33,1.29]$ \\
\hline $\begin{array}{l}\text { 11.6.1 Epidemic year - vaccine match- } \\
\text { ing }\end{array}$ & 1 & 7047 & $\begin{array}{l}\text { Risk Ratio (M-H, Random, } \\
95 \% \mathrm{Cl})\end{array}$ & $1.09[0.26,4.49]$ \\
\hline $\begin{array}{l}\text { 11.6.2 Epidemic year - vaccine match- } \\
\text { ing absent or unknown }\end{array}$ & 0 & 0 & $\begin{array}{l}\text { Risk Ratio (M-H, Random, } \\
95 \% \mathrm{CI})\end{array}$ & Not estimable \\
\hline $\begin{array}{l}\text { 11.6.3 Non-epidemic year - vaccine } \\
\text { matching }\end{array}$ & 2 & 36774 & $\begin{array}{l}\text { Risk Ratio (M-H, Random, } \\
95 \% \mathrm{Cl} \text { ) }\end{array}$ & $0.59[0.27,1.30]$ \\
\hline $\begin{array}{l}\text { 11.6.4 Non-epidemic year - vaccine } \\
\text { matching absent or unknown }\end{array}$ & 0 & 0 & $\begin{array}{l}\text { Risk Ratio (M-H, Random, } \\
95 \% \mathrm{Cl})\end{array}$ & Not estimable \\
\hline
\end{tabular}




\begin{tabular}{|c|c|c|c|c|}
\hline Outcome or subgroup title & No. of studies & $\begin{array}{l}\text { No. of partici- } \\
\text { pants }\end{array}$ & Statistical method & Effect size \\
\hline 11.7 Hospitalisation for heart disease & 1 & 101619 & $\begin{array}{l}\text { Risk Ratio (M-H, Random, } \\
95 \% \mathrm{Cl})\end{array}$ & $0.79[0.61,1.01]$ \\
\hline $\begin{array}{l}\text { 11.7.1 Epidemic year - vaccine match- } \\
\text { ing }\end{array}$ & 1 & 101619 & $\begin{array}{l}\text { Risk Ratio (M-H, Random, } \\
95 \% \mathrm{Cl})\end{array}$ & $0.79[0.61,1.01]$ \\
\hline $\begin{array}{l}\text { 11.7.2 Epidemic year - vaccine match- } \\
\text { ing absent or unknown }\end{array}$ & 0 & 0 & $\begin{array}{l}\text { Risk Ratio (M-H, Random, } \\
95 \% \mathrm{CI})\end{array}$ & Not estimable \\
\hline $\begin{array}{l}\text { 11.7.3 Non-epidemic year - vaccine } \\
\text { matching }\end{array}$ & 0 & 0 & $\begin{array}{l}\text { Risk Ratio (M-H, Random, } \\
95 \% \mathrm{Cl})\end{array}$ & Not estimable \\
\hline $\begin{array}{l}\text { 11.7.4 Non-epidemic year - vaccine } \\
\text { matching absent or unknown }\end{array}$ & 0 & 0 & $\begin{array}{l}\text { Risk Ratio (M-H, Random, } \\
95 \% \mathrm{Cl})\end{array}$ & Not estimable \\
\hline $\begin{array}{l}11.8 \text { Combined outcome: all deaths or } \\
\text { severe respiratory illness }\end{array}$ & 2 & 135180 & $\begin{array}{l}\text { Risk Ratio (M-H, Random, } \\
95 \% \mathrm{CI})\end{array}$ & $0.62[0.54,0.70]$ \\
\hline $\begin{array}{l}\text { 11.8.1 Epidemic year - vaccine match- } \\
\text { ing }\end{array}$ & 1 & 68536 & $\begin{array}{l}\text { Risk Ratio (M-H, Random, } \\
95 \% \mathrm{Cl})\end{array}$ & $0.65[0.54,0.78]$ \\
\hline $\begin{array}{l}\text { 11.8.2 Epidemic year - vaccine match- } \\
\text { ing absent or unknown }\end{array}$ & 1 & 66644 & $\begin{array}{l}\text { Risk Ratio (M-H, Random, } \\
95 \% \mathrm{Cl})\end{array}$ & $0.58[0.48,0.71]$ \\
\hline
\end{tabular}


Analysis 11.1. Comparison 11: Influenza vaccines versus no vaccination: cohort studies in community-dwellers - no risk groups, Outcome 1: Influenza

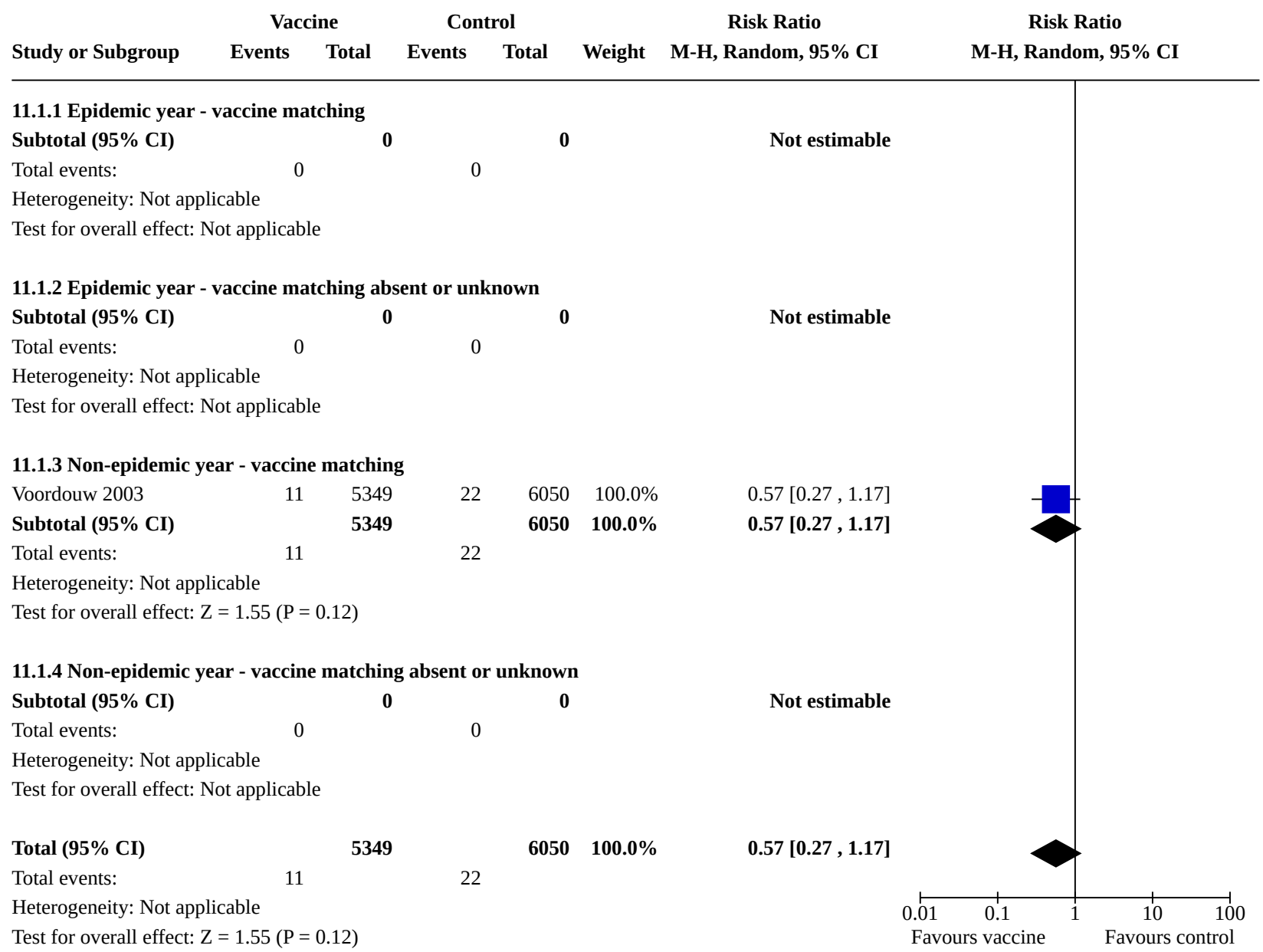


Analysis 11.2. Comparison 11: Influenza vaccines versus no vaccination: cohort studies in community-dwellers - no risk groups, Outcome 2: Pneumonia

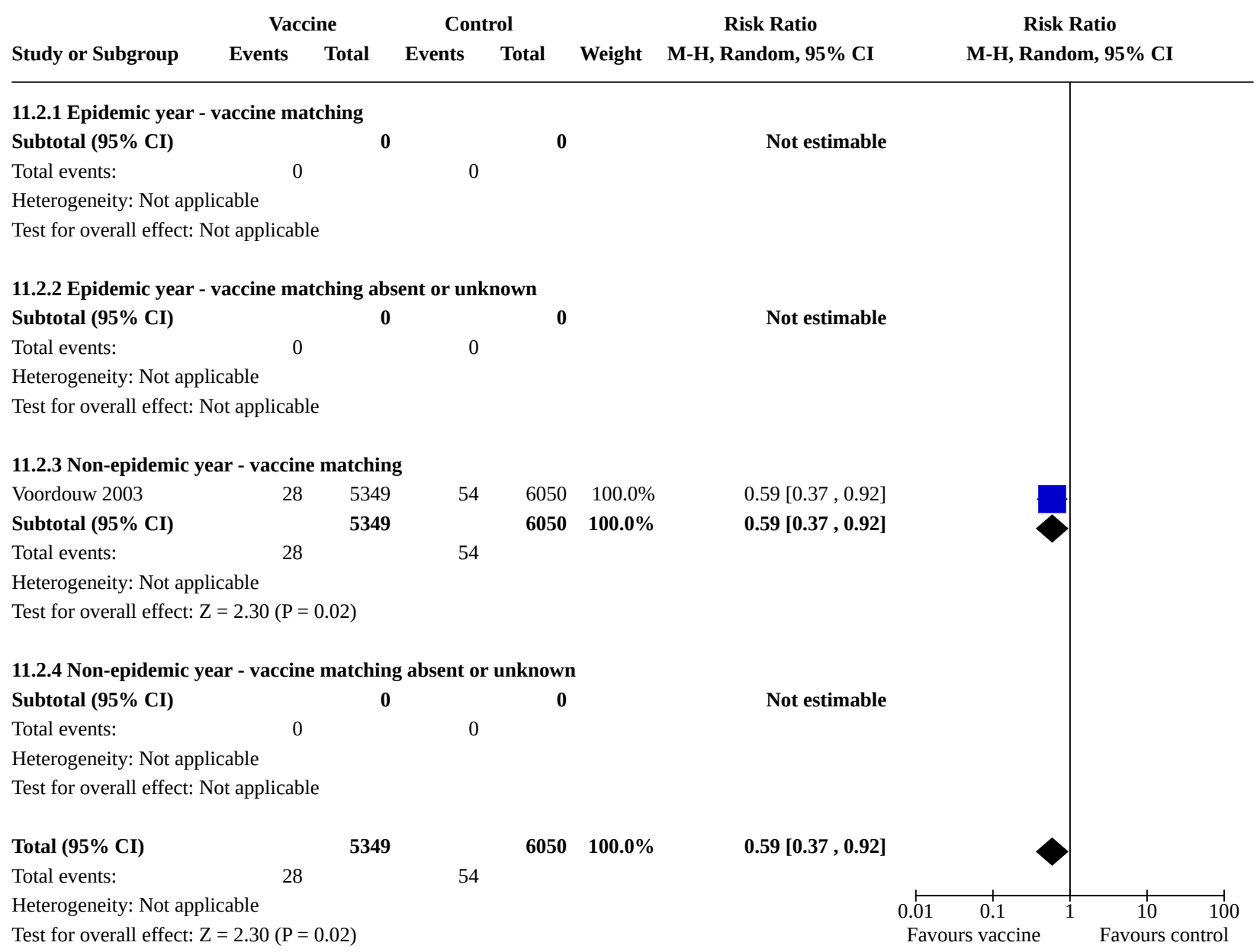


Analysis 11.3. Comparison 11: Influenza vaccines versus no vaccination: cohort studies in community-dwellers - no risk groups, Outcome 3: Hospitalisation for influenza or pneumonia

\begin{tabular}{|c|c|c|c|c|c|c|c|c|}
\hline \multirow[b]{2}{*}{ Study or Subgroup } & \multicolumn{2}{|c|}{ Vaccine } & \multicolumn{2}{|c|}{ Control } & \multicolumn{2}{|r|}{ Risk Ratio } & \multirow{2}{*}{\multicolumn{2}{|c|}{$\begin{array}{c}\text { Risk Ratio } \\
\text { M-H, Random, 95\% CI }\end{array}$}} \\
\hline & Events & Total & Events & Total & Weight & M-H, Random, 95\% CI & & \\
\hline \multicolumn{9}{|c|}{ 11.3.1 Epidemic year - vaccine matching } \\
\hline Nichol 1998a & 126 & 57058 & 196 & 44561 & $100.0 \%$ & $0.50[0.40,0.63]$ & & \\
\hline Subtotal (95\% CI) & & 57058 & & 44561 & $100.0 \%$ & $0.50[0.40,0.63]$ & 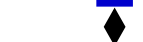 & \\
\hline Total events: & 126 & & 196 & & & & & \\
\hline \multicolumn{9}{|c|}{ Heterogeneity: Not applicable } \\
\hline \multicolumn{9}{|c|}{ Test for overall effect: $\mathrm{Z}=6.04(\mathrm{P}<0.00001)$} \\
\hline \multicolumn{9}{|c|}{ 11.3.2 Epidemic year - vaccine matching absent or unknown } \\
\hline Subtotal (95\% CI) & & $\mathbf{0}$ & & $\mathbf{0}$ & & Not estimable & & \\
\hline Total events: & 0 & & 0 & & & & & \\
\hline \multicolumn{9}{|c|}{ Heterogeneity: Not applicable } \\
\hline \multicolumn{9}{|c|}{ Test for overall effect: Not applicable } \\
\hline \multicolumn{9}{|c|}{ 11.3.3 Non-epidemic year - vaccine matching } \\
\hline Subtotal (95\% CI) & & $\mathbf{0}$ & & $\mathbf{0}$ & & Not estimable & & \\
\hline Total events: & 0 & & 0 & & & & & \\
\hline \multicolumn{9}{|c|}{ Heterogeneity: Not applicable } \\
\hline \multicolumn{9}{|c|}{ Test for overall effect: Not applicable } \\
\hline \multicolumn{9}{|c|}{ 11.3.4 Non-epidemic year - vaccine matching absent or unknown } \\
\hline Subtotal $(95 \% \mathrm{CI})$ & & $\mathbf{0}$ & & $\mathbf{0}$ & & Not estimable & & \\
\hline Total events: & 0 & & 0 & & & & & \\
\hline \multicolumn{9}{|c|}{ Heterogeneity: Not applicable } \\
\hline \multicolumn{9}{|c|}{ Test for overall effect: Not applicable } \\
\hline Total (95\% CI) & & 57058 & & 44561 & $100.0 \%$ & $0.50[0.40,0.63]$ & 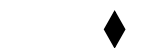 & \\
\hline Total events: & 126 & & 196 & & & & & \\
\hline Heterogeneity: Not ap & cable & & & & & $0 . \stackrel{\circ}{0}$ & 0.1 & 10 \\
\hline Test for overall effect & $=6.04(\mathrm{P}<$ & $0.00001)$ & & & & & rs vaccine & Favours c \\
\hline
\end{tabular}


Analysis 11.4. Comparison 11: Influenza vaccines versus no vaccination: cohort studies in community-dwellers - no risk groups, Outcome 4: Hospitalisation for any respiratory disease

\begin{tabular}{|c|c|c|c|c|c|c|}
\hline \multirow[b]{2}{*}{ Study or Subgroup } & \multicolumn{2}{|c|}{ Vaccine } & \multicolumn{2}{|c|}{ Control } & \multirow[b]{2}{*}{ Weight } & \multirow{2}{*}{$\begin{array}{c}\text { Risk Ratio } \\
\text { M-H, Random, } 95 \% \text { CI }\end{array}$} \\
\hline & Events & Total & Events & Total & & \\
\hline \multicolumn{7}{|c|}{ 11.4.1 Epidemic year - vaccine matching } \\
\hline Nichol 1998a & 491 & 57058 & 566 & 44561 & $49.6 \%$ & $0.68[0.60,0.76]$ \\
\hline Mangtani 2004a & 567 & 77722 & 1392 & 196983 & $50.4 \%$ & $1.03[0.94,1.14]$ \\
\hline Subtotal $(95 \%$ CI) & & 134780 & & 241544 & $100.0 \%$ & $0.84[0.55,1.27]$ \\
\hline Total events: & 1058 & & 1958 & & & \\
\hline
\end{tabular}

Heterogeneity: Tau $^{2}=0.09 ; \mathrm{Chi}^{2}=28.49, \mathrm{df}=1(\mathrm{P}<0.00001) ; \mathrm{I}^{2}=96 \%$

Test for overall effect: $\mathrm{Z}=0.84(\mathrm{P}=0.40)$

11.4.2 Epidemic year - vaccine matching absent or unknown

Subtotal (95\% CI)

$\mathbf{0}$

Total events: $\quad 0 \quad 0$

Not estimable

Heterogeneity: Not applicable

Test for overall effect: Not applicable

11.4.3 Non-epidemic year - vaccine matching

Subtotal (95\% CI)

Total events: $\quad 0$

0

0

Heterogeneity: Not applicable

Test for overall effect: Not applicable

11.4.4 Non-epidemic year - vaccine matching absent or unknown

Subtotal (95\% CI)

0

Total events: 0

0

Heterogeneity: Not applicable

Test for overall effect: Not applicable

Total (95\% CI)

$241544 \quad 100.0 \%$

$0.84[0.55,1.27]$

$\begin{array}{lcc}1058 & 1958 \\ \text { Heterogeneity: } \mathrm{Tau}^{2}=0.09 ; \mathrm{Chi}^{2}=28.49, \mathrm{df}=1 & (\mathrm{P}<0.00001) ; \mathrm{I}^{2}=96 \%\end{array}$

Test for overall effect: $\mathrm{Z}=0.84(\mathrm{P}=0.40)$

Test for subgroup differences: Not applicable

Risk Ratio

M-H, Random, 95\% CI

\section{Analysis 11.5. Comparison 11: Influenza vaccines versus no vaccination: cohort studies in community-dwellers - no risk groups, Outcome 5: Deaths from respiratory disease}

\begin{tabular}{|c|c|c|c|c|c|c|c|c|}
\hline \multirow[b]{2}{*}{ Study or Subgroup } & \multicolumn{2}{|c|}{ Vaccine } & \multicolumn{2}{|c|}{ Control } & \multirow[b]{2}{*}{ Weight } & \multirow{2}{*}{$\begin{array}{c}\text { Risk Ratio } \\
\text { M-H, Random, 95\% CI }\end{array}$} & \multirow{2}{*}{\multicolumn{2}{|c|}{$\begin{array}{c}\text { Risk Ratio } \\
\text { M-H, Random, 95\% CI }\end{array}$}} \\
\hline & Events & Total & Events & Total & & & & \\
\hline \multicolumn{9}{|c|}{ 11.5.1 Epidemic year - vaccine matching } \\
\hline Mangtani 2004a & 932 & 78912 & 1691 & 202512 & $100.0 \%$ & $1.41[1.31,1.53]$ & & \\
\hline Subtotal (95\% CI) & & 78912 & & 202512 & $100.0 \%$ & $1.41[1.31,1.53]$ & & \\
\hline Total events: & 932 & & 1691 & & & & & \\
\hline \multicolumn{9}{|c|}{ Heterogeneity: Not applicable } \\
\hline \multicolumn{9}{|c|}{ Test for overall effect: $\mathrm{Z}=8.54(\mathrm{P}<0.00001)$} \\
\hline Total (95\% CI) & & 78912 & & 202512 & $100.0 \%$ & $1.41[1.31,1.53]$ & & 1 \\
\hline Total events: & 932 & & 1691 & & & & & \\
\hline \multicolumn{3}{|c|}{ Heterogeneity: Not applicable } & & & & $0 . \stackrel{\vdash}{01}$ & 0.1 & 10 \\
\hline Test for overall effect: & $=8.54(\mathrm{P}<$ & $0.00001)$ & & & & Fave & Irs vaccine & Favours c \\
\hline
\end{tabular}


Analysis 11.6. Comparison 11: Influenza vaccines versus no vaccination: cohort studies in community-dwellers - no risk groups, Outcome 6: All deaths

\begin{tabular}{|c|c|c|c|c|c|c|c|}
\hline \multirow[b]{2}{*}{ Study or Subgroup } & \multicolumn{2}{|c|}{ Vaccine } & \multicolumn{2}{|c|}{ Control } & \multicolumn{2}{|r|}{ Risk Ratio } & Risk Ratio \\
\hline & Events & Total & Events & Total & Weight & M-H, Random, 95\% CI & M-H, Random, 95\% CI \\
\hline
\end{tabular}

11.6.1 Epidemic year - vaccine matching

$\begin{array}{lcccccc}\text { Fleming } 1995 & 2 & 334 & 37 & 6713 & 15.6 \% & 1.09[0.26,4.49] \\ \text { Subtotal (95\% CI) } & & \mathbf{3 3 4} & & \mathbf{6 7 1 3} & \mathbf{1 5 . 6 \%} & \mathbf{1 . 0 9}[\mathbf{0 . 2 6}, \mathbf{4 . 4 9 ]} \\ \text { Total events: } & 2 & & 37 & & & \end{array}$

Heterogeneity: Not applicable

Test for overall effect: $\mathrm{Z}=0.11(\mathrm{P}=0.91)$

11.6.2 Epidemic year - vaccine matching absent or unknown

Subtotal (95\% CI)

0

Total events:

0

Heterogeneity: Not applicable

Test for overall effect: Not applicable

11.6.3 Non-epidemic year - vaccine matching

$\begin{array}{lccrrrr}\text { Voordouw 2003 } & 68 & 5349 & 88 & 6050 & 43.1 \% & 0.87[0.64,1.20] \\ \text { Shapiro 2003 } & 31 & 7743 & 180 & 17632 & 41.3 \% & 0.39[0.27,0.57] \\ \text { Subtotal (95\% CI) } & & \mathbf{1 3 0 9 2} & & \mathbf{2 3 6 8 2} & \mathbf{8 4 . 4 \%} & \mathbf{0 . 5 9}[\mathbf{0 . 2 7 , \mathbf { 1 . 3 0 } ]} \\ \text { Total events: } & 99 & & 268 & & & \end{array}$

Heterogeneity: Tau$^{2}=0.30 ; \mathrm{Chi}^{2}=10.32, \mathrm{df}=1(\mathrm{P}=0.001) ; \mathrm{I}^{2}=90 \%$

Test for overall effect: $\mathrm{Z}=1.31(\mathrm{P}=0.19)$

11.6.4 Non-epidemic year - vaccine matching absent or unknown Subtotal (95\% CI)

0

Total events:

0

Heterogeneity: Not applicable

Test for overall effect: Not applicable

Total (95\% CI)

$101 \quad 305$

$30395 \quad 100.0 \%$

Total events:

$\mathrm{i}^{2}=10.88, \mathrm{df}=2(\mathrm{P}=0.004) ; \mathrm{I}^{2}=82 \%$

Heterogeneity: $\mathrm{Tau}^{2}=0.26$; $\mathrm{Chi}^{2}=10.88$,
Test for overall effect: $\mathrm{Z}=1.24(\mathrm{P}=0.22)$

Test for subgroup differences: $\mathrm{Chi}^{2}=0.54, \mathrm{df}=1(\mathrm{P}=0.46), \mathrm{I}^{2}=0 \%$
M-H, Random, 95\% CI

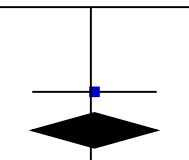

Not estimable

$0.65[0.33,1.29]$

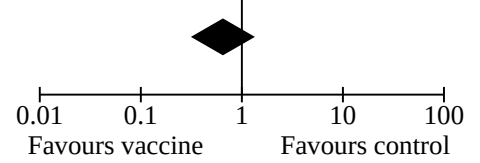


Analysis 11.7. Comparison 11: Influenza vaccines versus no vaccination: cohort studies in community-dwellers - no risk groups, Outcome 7: Hospitalisation for heart disease

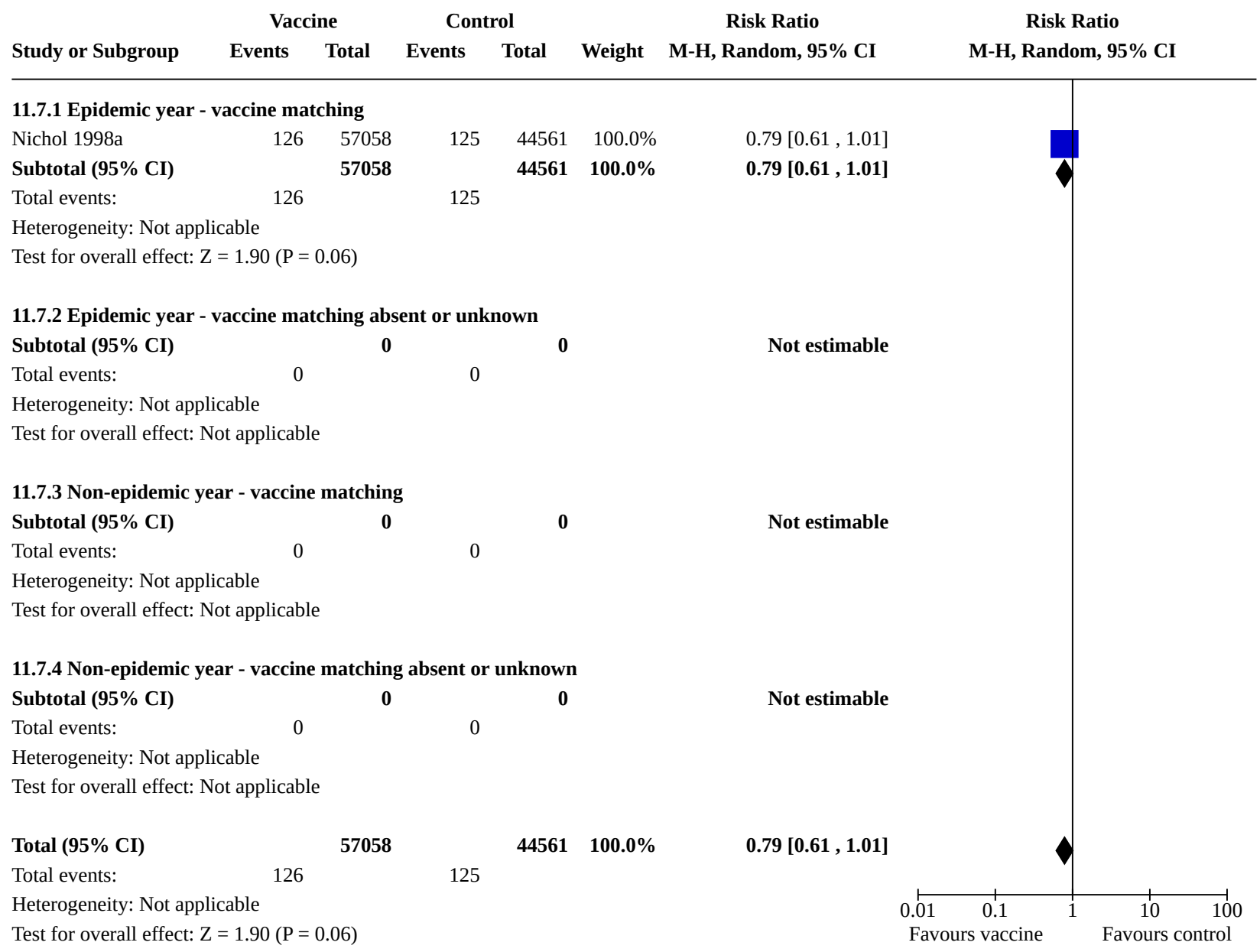


Analysis 11.8. Comparison 11: Influenza vaccines versus no vaccination: cohort studies in communitydwellers - no risk groups, Outcome 8: Combined outcome: all deaths or severe respiratory illness

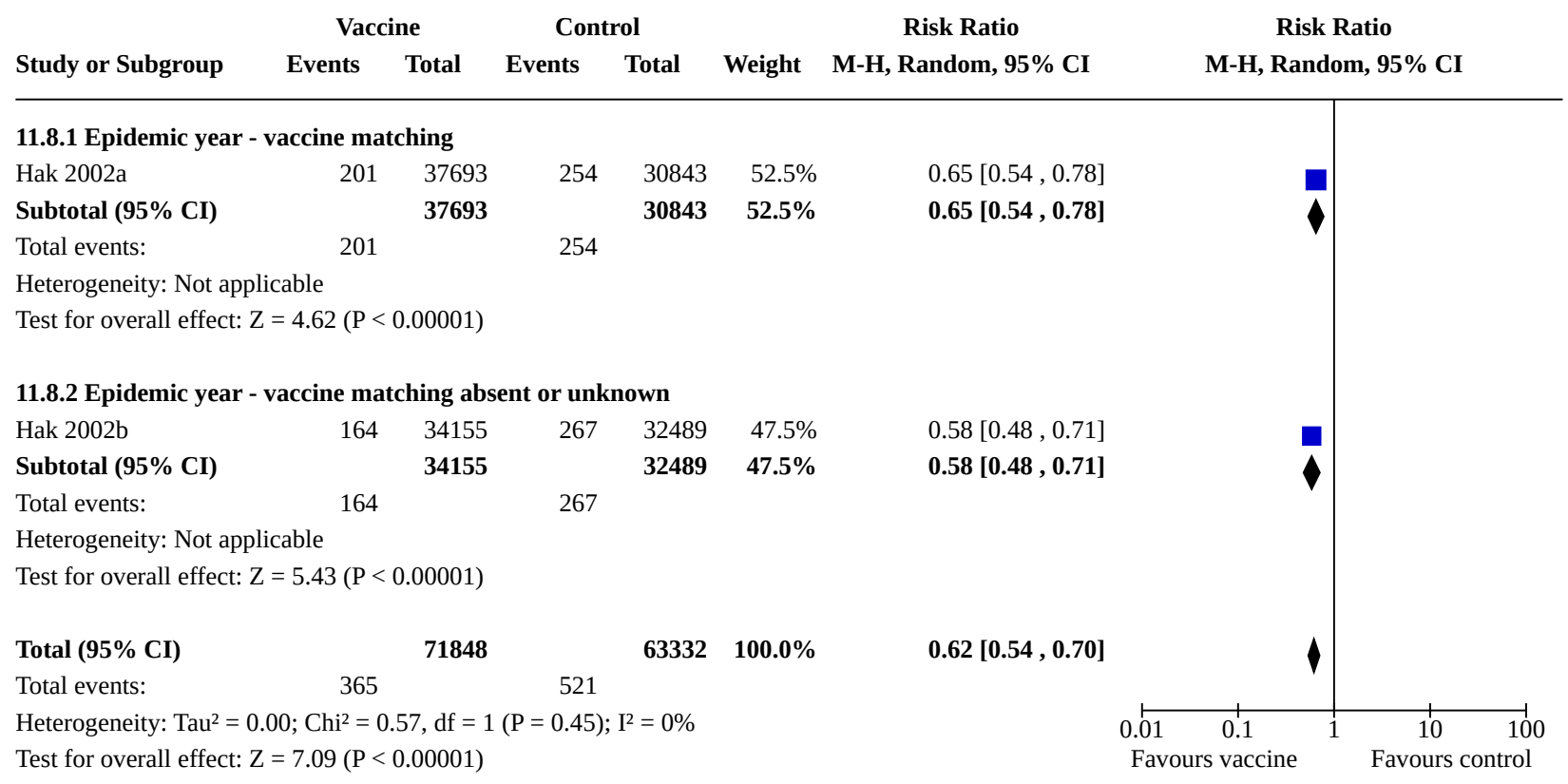

Comparison 12. Influenza and pneumococcal vaccines versus no vaccination: cohort studies in community-dwellers

\begin{tabular}{|c|c|c|c|c|}
\hline Outcome or subgroup title & No. of studies & $\begin{array}{l}\text { No. of partici- } \\
\text { pants }\end{array}$ & Statistical method & Effect size \\
\hline 12.1 Influenza-like illness & 1 & 374 & $\begin{array}{l}\text { Risk Ratio (M-H, Random, } \\
95 \% \mathrm{Cl})\end{array}$ & $0.32[0.16,0.64]$ \\
\hline $\begin{array}{l}\text { 12.1.1 Epidemic year - vaccine match- } \\
\text { ing }\end{array}$ & 0 & 0 & $\begin{array}{l}\text { Risk Ratio (M-H, Random, } \\
95 \% \mathrm{Cl})\end{array}$ & Not estimable \\
\hline $\begin{array}{l}\text { 12.1.2 Epidemic year - vaccine match- } \\
\text { ing absent or unknown }\end{array}$ & 0 & 0 & $\begin{array}{l}\text { Risk Ratio (M-H, Random, } \\
95 \% \mathrm{Cl})\end{array}$ & Not estimable \\
\hline $\begin{array}{l}\text { 12.1.3 Non-epidemic year - vaccine } \\
\text { matching }\end{array}$ & 1 & 374 & $\begin{array}{l}\text { Risk Ratio (M-H, Random, } \\
95 \% \mathrm{Cl})\end{array}$ & $0.32[0.16,0.64]$ \\
\hline $\begin{array}{l}\text { 12.2 Hospitalisation for influenza or } \\
\text { pneumonia or respiratory disease }\end{array}$ & 3 & 518748 & $\begin{array}{l}\text { Risk Ratio (M-H, Random, } \\
95 \% \mathrm{Cl})\end{array}$ & $0.67[0.64,0.70]$ \\
\hline $\begin{array}{l}\text { 12.2.1 Epidemic year - vaccine match- } \\
\text { ing }\end{array}$ & 2 & 518374 & $\begin{array}{l}\text { Risk Ratio (M-H, Random, } \\
95 \% \mathrm{Cl})\end{array}$ & $0.67[0.63,0.71]$ \\
\hline $\begin{array}{l}\text { 12.2.2 Epidemic year - vaccine match- } \\
\text { ing absent or unknown }\end{array}$ & 0 & 0 & $\begin{array}{l}\text { Risk Ratio (M-H, Random, } \\
95 \% \mathrm{Cl})\end{array}$ & Not estimable \\
\hline $\begin{array}{l}\text { 12.2.3 Non-epidemic year - vaccine } \\
\text { matching }\end{array}$ & 1 & 374 & $\begin{array}{l}\text { Risk Ratio (M-H, Random, } \\
95 \% \mathrm{Cl})\end{array}$ & $0.90[0.10,7.97]$ \\
\hline $\begin{array}{l}\text { 12.3 Deaths from influenza or pneumo- } \\
\text { nia }\end{array}$ & 1 & 259627 & $\begin{array}{l}\text { Risk Ratio (M-H, Random, } \\
95 \% \mathrm{Cl})\end{array}$ & $0.43[0.33,0.57]$ \\
\hline
\end{tabular}




\begin{tabular}{|c|c|c|c|c|}
\hline Outcome or subgroup title & No. of studies & $\begin{array}{l}\text { No. of partici- } \\
\text { pants }\end{array}$ & Statistical method & Effect size \\
\hline $\begin{array}{l}\text { 12.3.1 Epidemic year - vaccine match- } \\
\text { ing }\end{array}$ & 1 & 259627 & $\begin{array}{l}\text { Risk Ratio (M-H, Random, } \\
95 \% \mathrm{Cl})\end{array}$ & $0.43[0.33,0.57]$ \\
\hline $\begin{array}{l}\text { 12.3.2 Epidemic year - vaccine match- } \\
\text { ing absent or unknown }\end{array}$ & 0 & 0 & $\begin{array}{l}\text { Risk Ratio (M-H, Random, } \\
95 \% \mathrm{Cl})\end{array}$ & Not estimable \\
\hline $\begin{array}{l}\text { 12.3.3 Non-epidemic year - vaccine } \\
\text { matching }\end{array}$ & 0 & 0 & $\begin{array}{l}\text { Risk Ratio (M-H, Random, } \\
95 \% \mathrm{Cl})\end{array}$ & Not estimable \\
\hline 12.4 All deaths & 2 & 260001 & $\begin{array}{l}\text { Risk Ratio (M-H, Random, } \\
95 \% \mathrm{Cl})\end{array}$ & $0.44[0.41,0.46]$ \\
\hline $\begin{array}{l}\text { 12.4.1 Epidemic year - vaccine match- } \\
\text { ing }\end{array}$ & 1 & 259627 & $\begin{array}{l}\text { Risk Ratio (M-H, Random, } \\
95 \% \mathrm{Cl})\end{array}$ & $0.44[0.41,0.46]$ \\
\hline $\begin{array}{l}\text { 12.4.2 Epidemic year - vaccine match- } \\
\text { ing absent or unknown }\end{array}$ & 0 & 0 & $\begin{array}{l}\text { Risk Ratio (M-H, Random, } \\
95 \% \mathrm{Cl})\end{array}$ & Not estimable \\
\hline $\begin{array}{l}\text { 12.4.3 Non-epidemic year - vaccine } \\
\text { matching }\end{array}$ & 1 & 374 & $\begin{array}{l}\text { Risk Ratio (M-H, Random, } \\
95 \% \mathrm{Cl} \text { ) }\end{array}$ & $1.60[0.08,30.65]$ \\
\hline
\end{tabular}

Analysis 12.1. Comparison 12: Influenza and pneumococcal vaccines versus no vaccination: cohort studies in community-dwellers, Outcome 1: Influenza-like illness

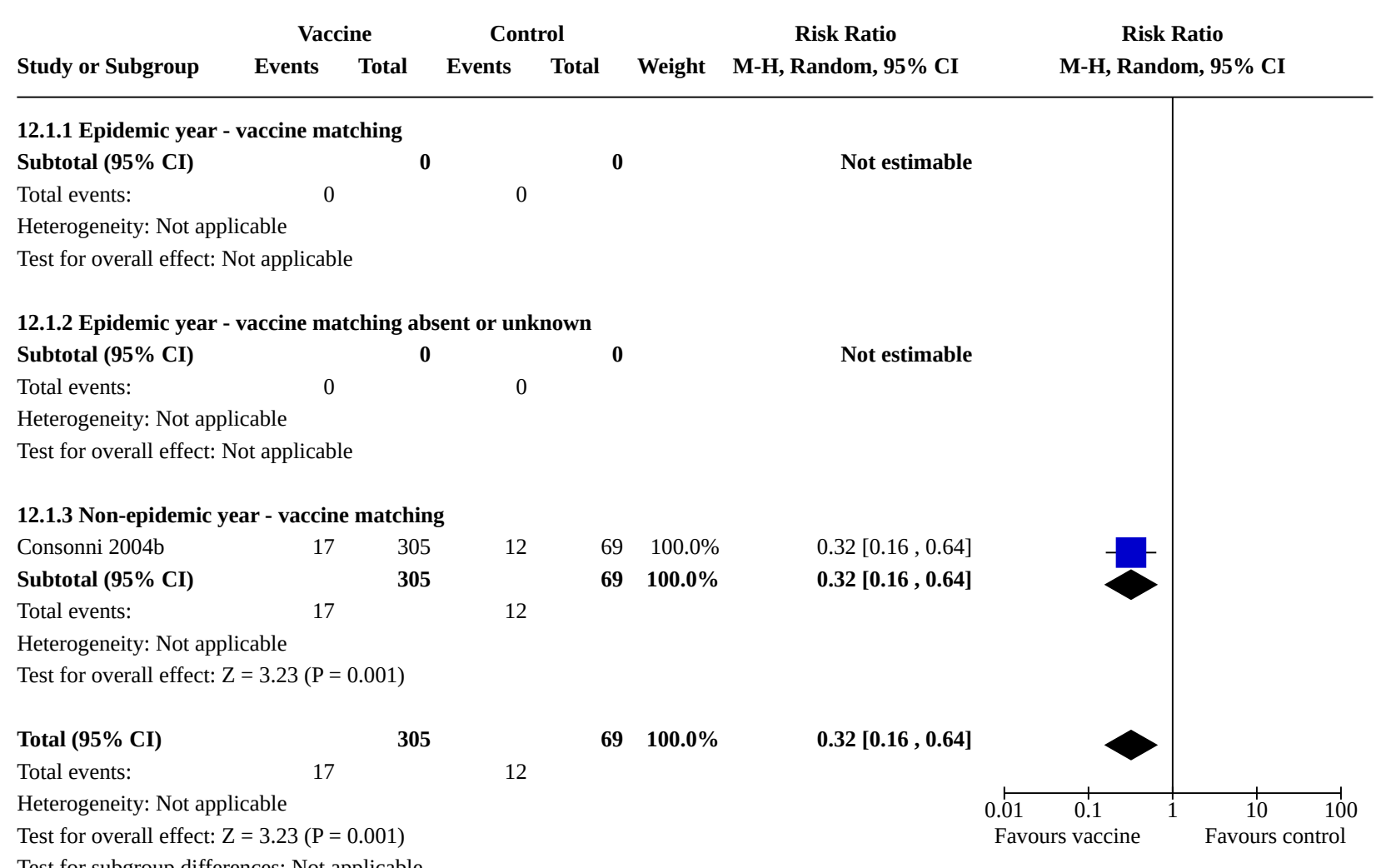



Analysis 12.2. Comparison 12: Influenza and pneumococcal vaccines versus no vaccination: cohort studies
in community-dwellers, Outcome 2: Hospitalisation for influenza or pneumonia or respiratory disease

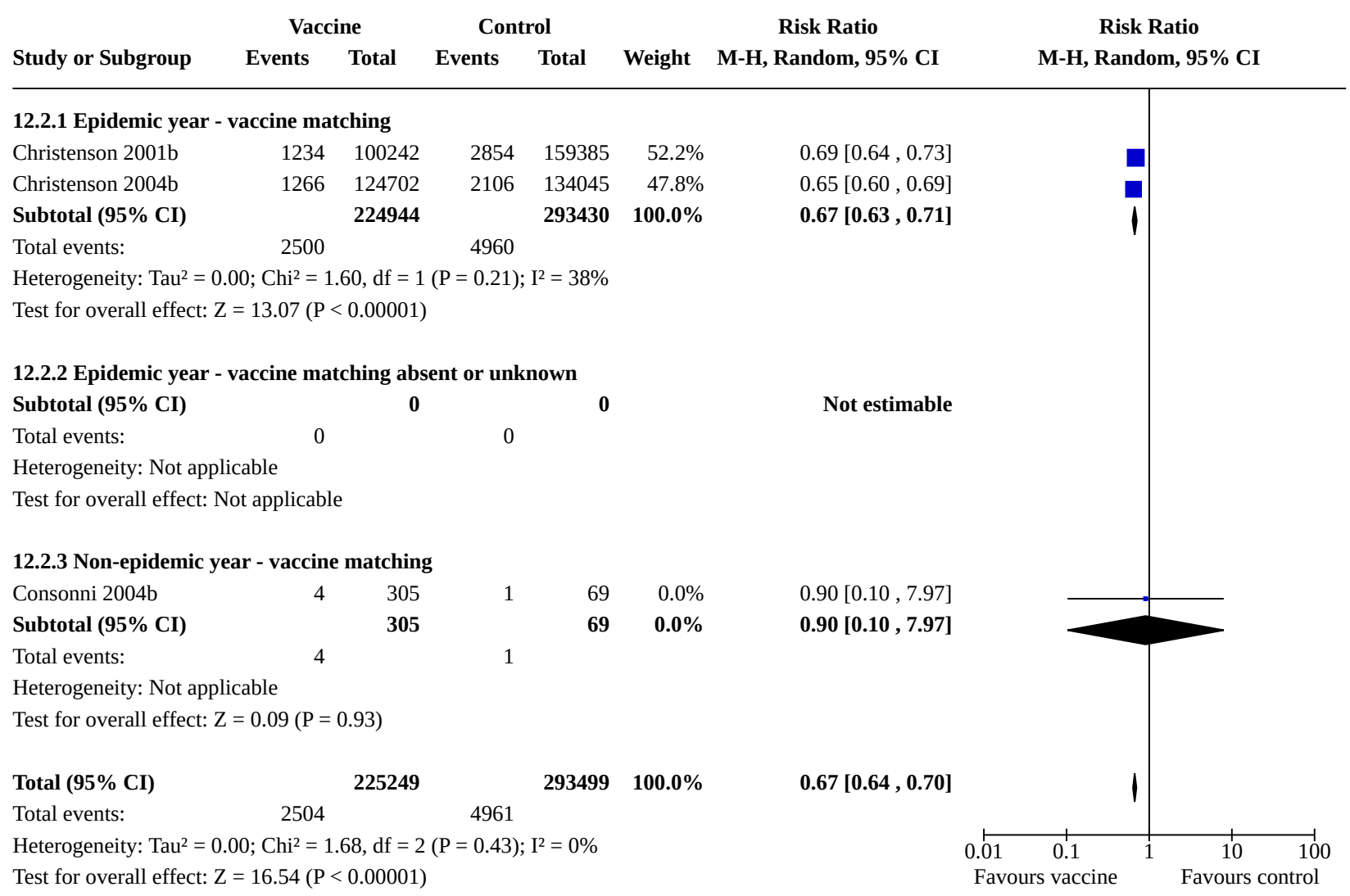


Analysis 12.3. Comparison 12: Influenza and pneumococcal vaccines versus no vaccination: cohort studies in community-dwellers, Outcome 3: Deaths from influenza or pneumonia

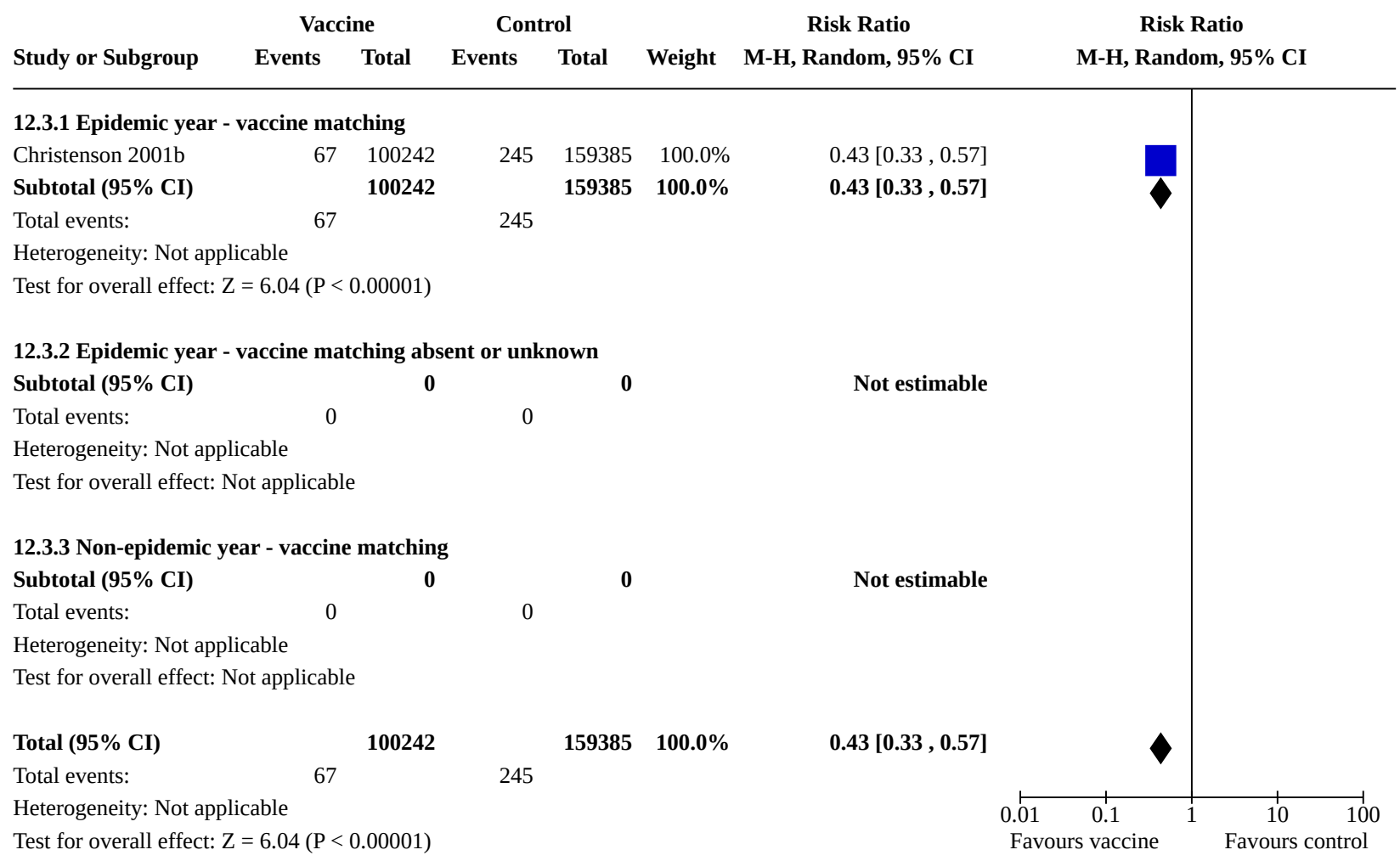


Analysis 12.4. Comparison 12: Influenza and pneumococcal vaccines versus no vaccination: cohort studies in community-dwellers, Outcome 4: All deaths

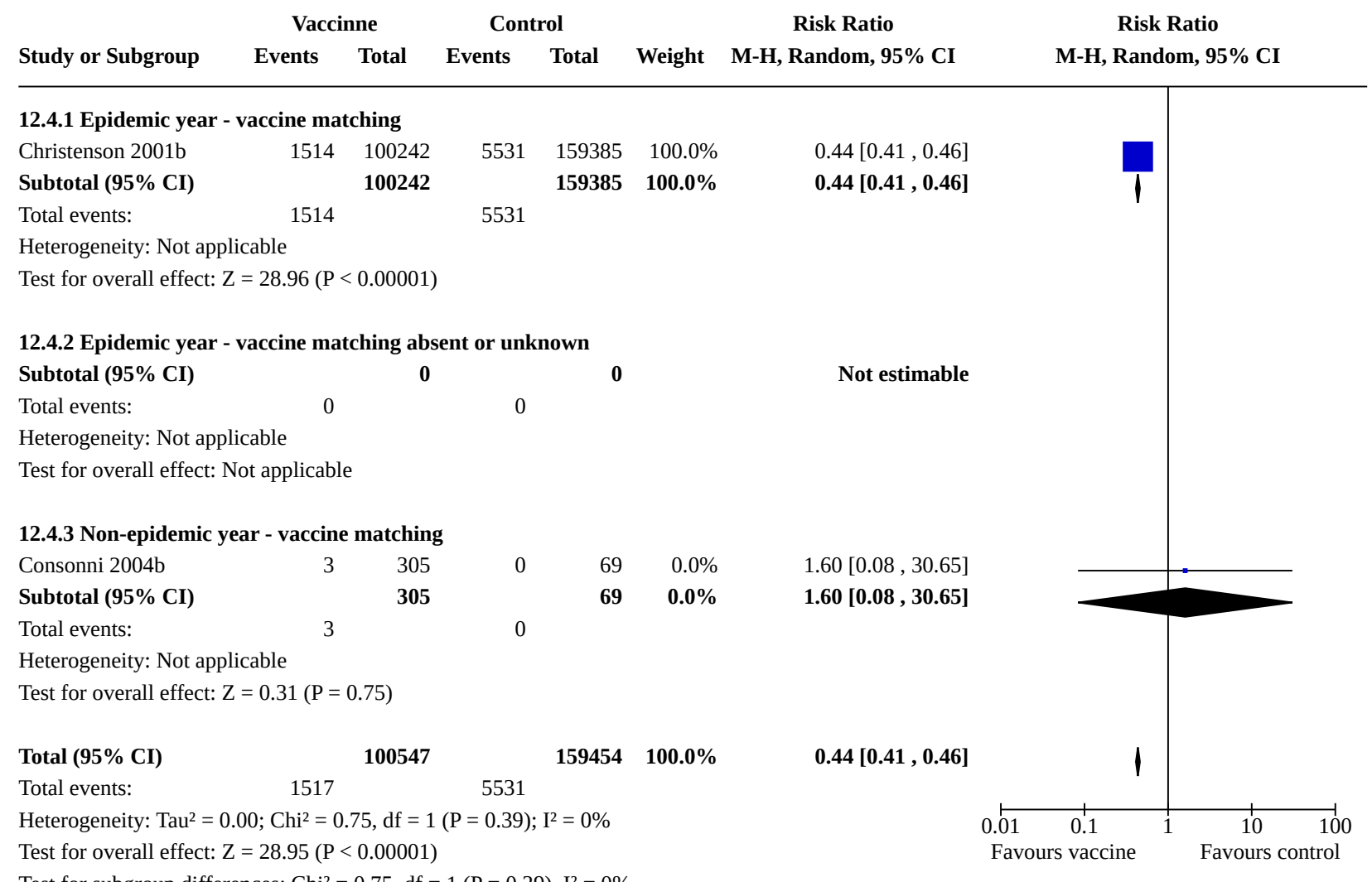

Comparison 13. Influenza vaccines with adjuvant versus no vaccination: cohort studies in community-dwellers

\begin{tabular}{|c|c|c|c|c|}
\hline Outcome or subgroup title & No. of studies & $\begin{array}{l}\text { No. of partici- } \\
\text { pants }\end{array}$ & Statistical method & Effect size \\
\hline 13.1 Influenza-like illness & 2 & 498 & $\begin{array}{l}\text { Risk Ratio (M-H, Random, } \\
95 \% \mathrm{Cl})\end{array}$ & $0.30[0.16,0.56]$ \\
\hline $\begin{array}{l}\text { 13.1.1 Epidemic year - vaccine match- } \\
\text { ing }\end{array}$ & 1 & 263 & $\begin{array}{l}\text { Risk Ratio (M-H, Random, } \\
95 \% \mathrm{Cl})\end{array}$ & $0.20[0.07,0.54]$ \\
\hline $\begin{array}{l}\text { 13.1.2 Epidemic year - vaccine match- } \\
\text { ing absent or unknown }\end{array}$ & 0 & 0 & $\begin{array}{l}\text { Risk Ratio (M-H, Random, } \\
95 \% \mathrm{Cl})\end{array}$ & Not estimable \\
\hline $\begin{array}{l}\text { 13.1.3 Non-epidemic year - vaccine } \\
\text { matching }\end{array}$ & 1 & 235 & $\begin{array}{l}\text { Risk Ratio (M-H, Random, } \\
95 \% \mathrm{Cl})\end{array}$ & $0.38[0.18,0.82]$ \\
\hline $\begin{array}{l}13.2 \text { Hospitalisation for influenza or } \\
\text { pneumonia or respiratory disease }\end{array}$ & 2 & 498 & $\begin{array}{l}\text { Risk Ratio (M-H, Random, } \\
95 \% \mathrm{Cl})\end{array}$ & $0.17[0.02,1.28]$ \\
\hline $\begin{array}{l}\text { 13.2.1 Epidemic year - vaccine match- } \\
\text { ing }\end{array}$ & 0 & 0 & $\begin{array}{l}\text { Risk Ratio (M-H, Random, } \\
95 \% \mathrm{Cl})\end{array}$ & Not estimable \\
\hline $\begin{array}{l}\text { 13.2.2 Epidemic year - vaccine match- } \\
\text { ing absent or unknown }\end{array}$ & 0 & 0 & $\begin{array}{l}\text { Risk Ratio (M-H, Random, } \\
95 \% \mathrm{Cl})\end{array}$ & Not estimable \\
\hline
\end{tabular}




\begin{tabular}{|c|c|c|c|c|}
\hline Outcome or subgroup title & No. of studies & $\begin{array}{l}\text { No. of partici- } \\
\text { pants }\end{array}$ & Statistical method & Effect size \\
\hline $\begin{array}{l}\text { 13.2.3 Non-epidemic year - vaccine } \\
\text { matching }\end{array}$ & 2 & 498 & $\begin{array}{l}\text { Risk Ratio (M-H, Random, } \\
95 \% \mathrm{Cl})\end{array}$ & $0.17[0.02,1.28]$ \\
\hline 13.3 All deaths & 1 & 235 & $\begin{array}{l}\text { Risk Ratio (M-H, Random, } \\
95 \% \mathrm{Cl})\end{array}$ & $2.10[0.10,43.10]$ \\
\hline $\begin{array}{l}\text { 13.3.1 Epidemic year - vaccine match- } \\
\text { ing }\end{array}$ & 0 & 0 & $\begin{array}{l}\text { Risk Ratio (M-H, Random, } \\
95 \% \mathrm{Cl})\end{array}$ & Not estimable \\
\hline $\begin{array}{l}\text { 13.3.2 Epidemic year - vaccine match- } \\
\text { ing absent or unknown }\end{array}$ & 0 & 0 & $\begin{array}{l}\text { Risk Ratio (M-H, Random, } \\
95 \% \mathrm{Cl} \text { ) }\end{array}$ & Not estimable \\
\hline $\begin{array}{l}\text { 13.3.3 Non-epidemic year - vaccine } \\
\text { matching }\end{array}$ & 1 & 235 & $\begin{array}{l}\text { Risk Ratio (M-H, Random, } \\
95 \% \mathrm{Cl} \text { ) }\end{array}$ & $2.10[0.10,43.10]$ \\
\hline
\end{tabular}

Analysis 13.1. Comparison 13: Influenza vaccines with adjuvant versus no vaccination: cohort studies in community-dwellers, Outcome 1: Influenza-like illness

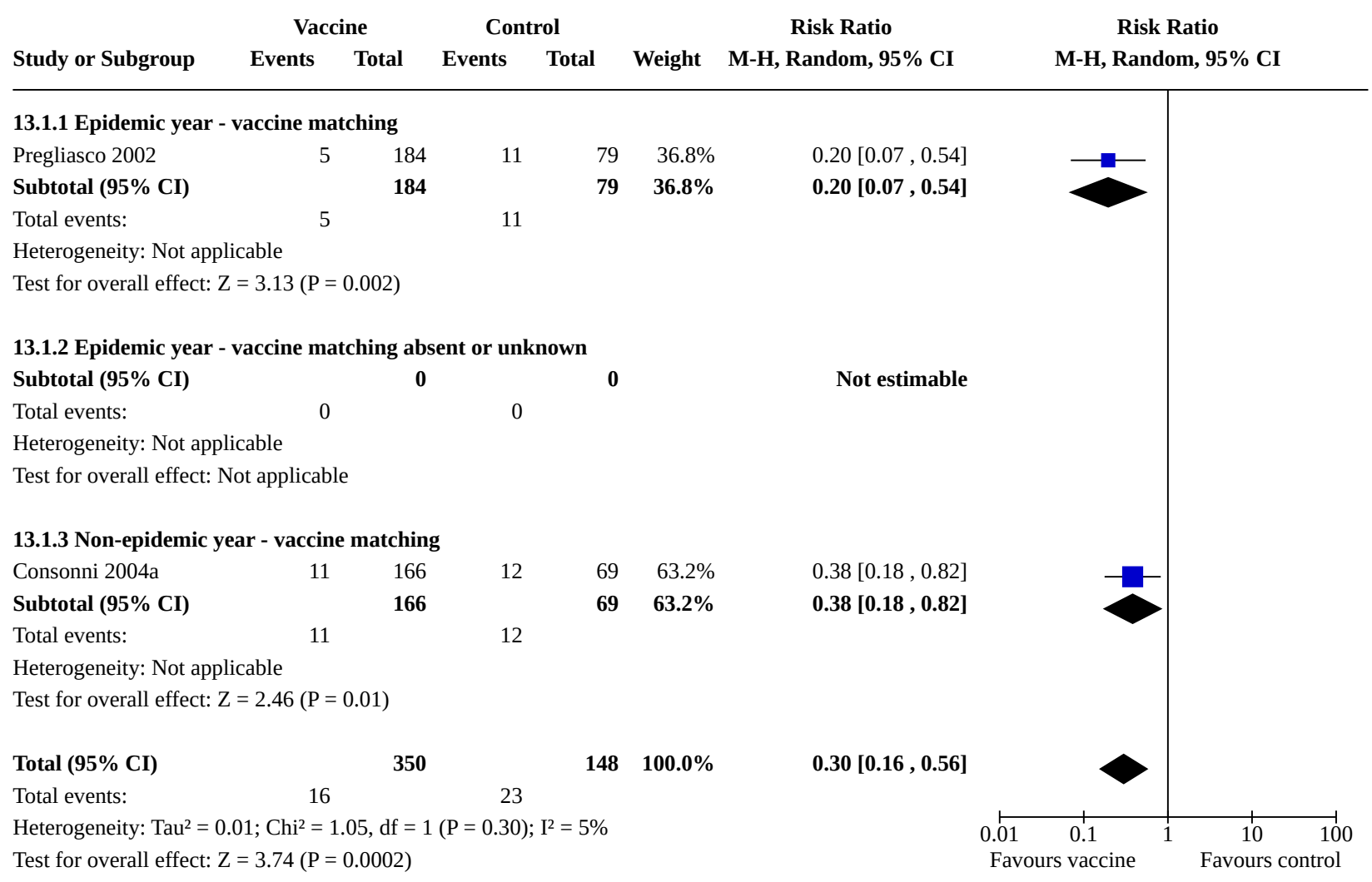


Analysis 13.2. Comparison 13: Influenza vaccines with adjuvant versus no vaccination: cohort studies in community-dwellers, Outcome 2: Hospitalisation for influenza or pneumonia or respiratory disease

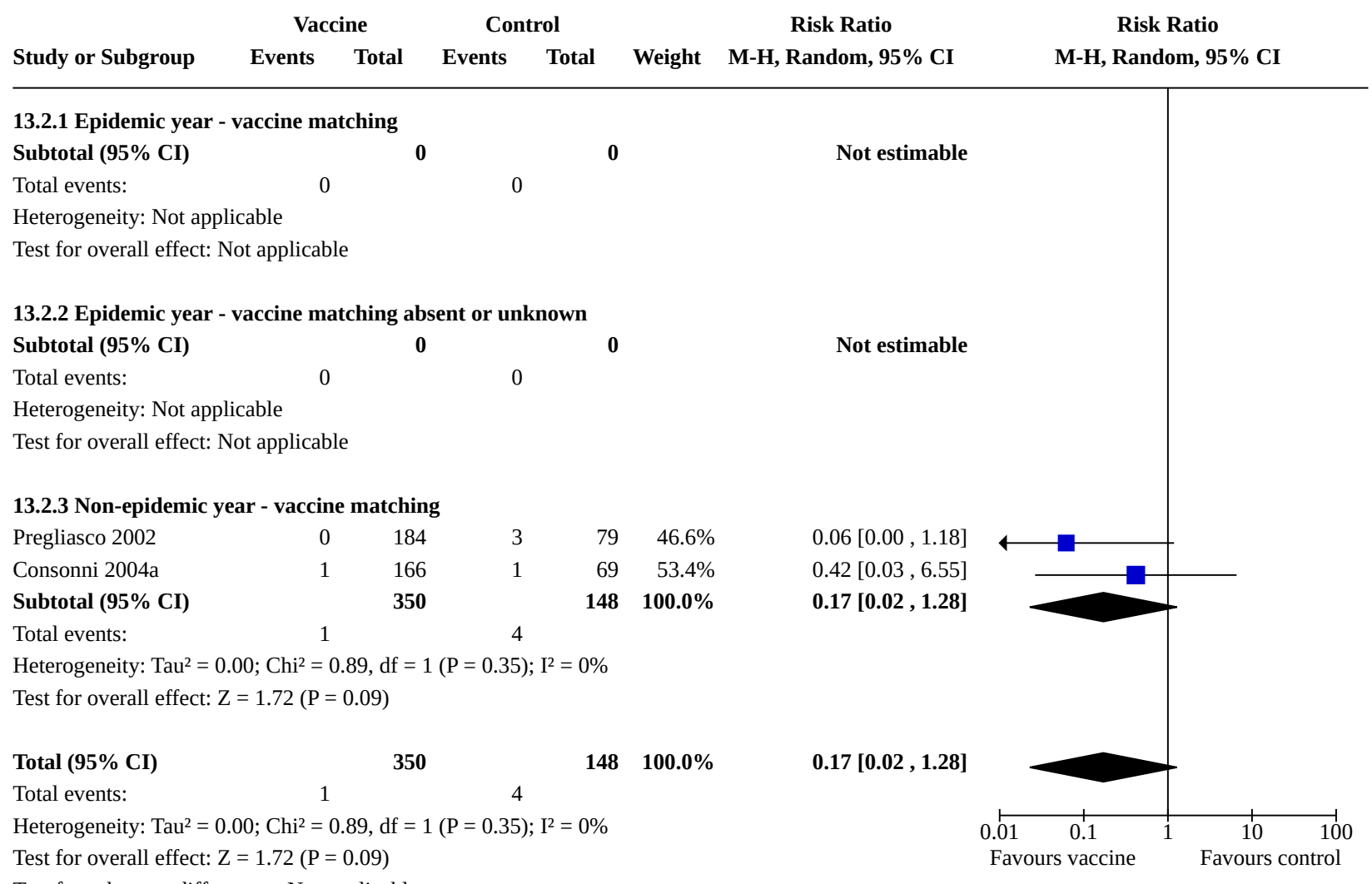


Analysis 13.3. Comparison 13: Influenza vaccines with adjuvant versus no vaccination: cohort studies in community-dwellers, Outcome 3: All deaths

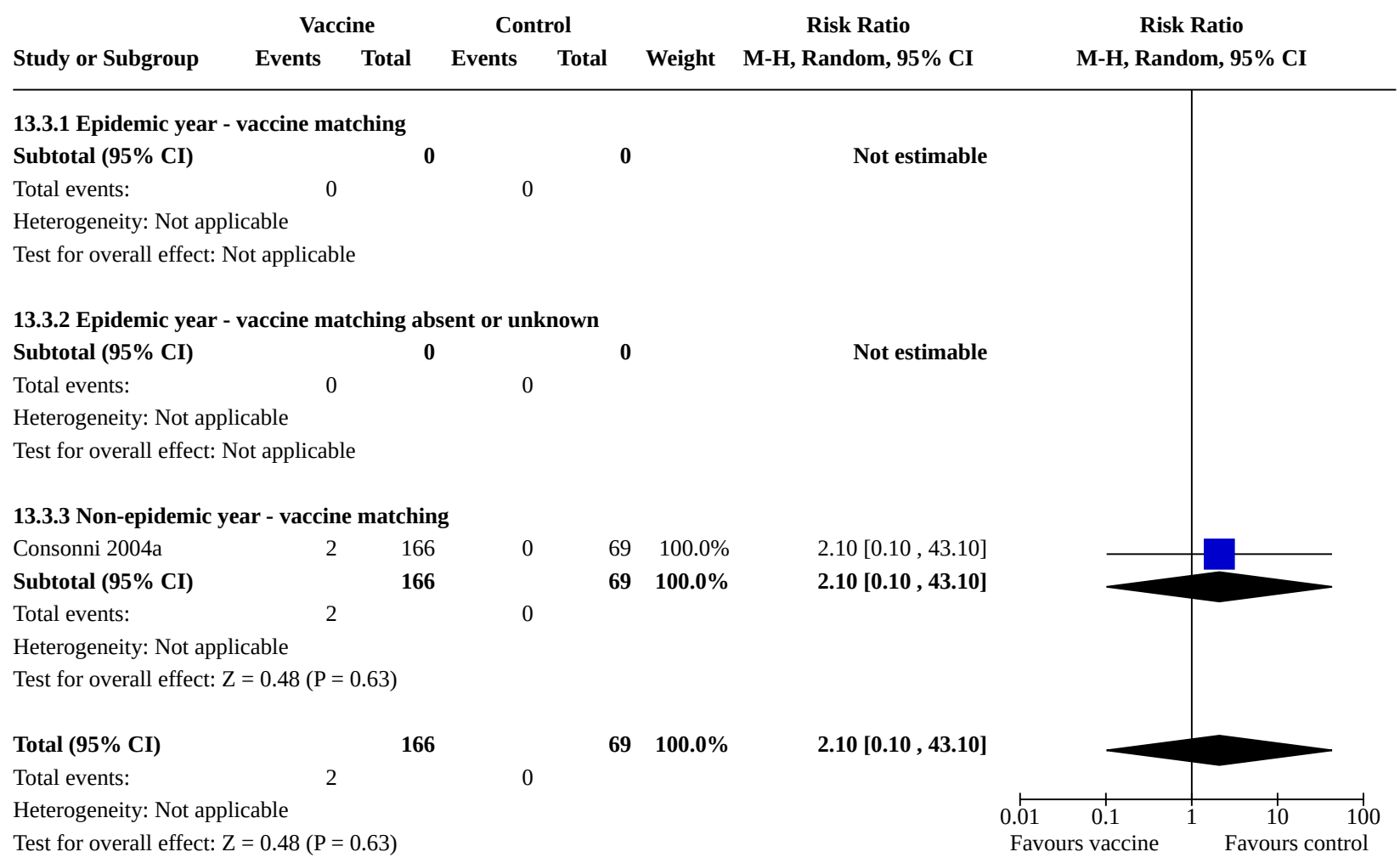

Comparison 14. Influenza vaccines versus no vaccination: case-control studies in community

\begin{tabular}{|c|c|c|c|c|}
\hline Outcome or subgroup title & No. of studies & $\begin{array}{l}\text { No. of partici- } \\
\text { pants }\end{array}$ & Statistical method & Effect size \\
\hline $\begin{array}{l}14.1 \text { Hospitalisations for influenza or } \\
\text { pneumonia }\end{array}$ & 2 & 1074 & $\begin{array}{l}\text { Odds Ratio (M-H, Random, } \\
95 \% \mathrm{Cl})\end{array}$ & $0.89[0.69,1.15]$ \\
\hline $\begin{array}{l}\text { 14.1.1 Outbreak - vaccine matching } \\
\text { (circulating strains) }\end{array}$ & 0 & 0 & $\begin{array}{l}\text { Odds Ratio (M-H, Random, } \\
95 \% \mathrm{Cl})\end{array}$ & Not estimable \\
\hline $\begin{array}{l}\text { 14.1.2 Outbreak - vaccine matching } \\
\text { absent or unknown }\end{array}$ & 1 & 825 & $\begin{array}{l}\text { Odds Ratio (M-H, Random, } \\
95 \% \mathrm{Cl})\end{array}$ & $0.92[0.69,1.22]$ \\
\hline $\begin{array}{l}\text { 14.1.3 No outbreak - vaccine match- } \\
\text { ing }\end{array}$ & 1 & 249 & $\begin{array}{l}\text { Odds Ratio (M-H, Random, } \\
95 \% \mathrm{Cl})\end{array}$ & $0.82[0.48,1.40]$ \\
\hline $\begin{array}{l}14.2 \text { Hospitalisations for any respira- } \\
\text { tory disease }\end{array}$ & 4 & 21378 & $\begin{array}{l}\text { Odds Ratio (M-H, Random, } \\
95 \% \mathrm{Cl})\end{array}$ & $1.08[0.95,1.23]$ \\
\hline 14.2.1 Outbreak - vaccine matching & 3 & 20582 & $\begin{array}{l}\text { Odds Ratio (M-H, Random, } \\
95 \% \mathrm{Cl})\end{array}$ & $1.08[0.92,1.26]$ \\
\hline 14.2.2 No outbreak - not matching & 1 & 796 & $\begin{array}{l}\text { Odds Ratio (M-H, Random, } \\
95 \% \mathrm{Cl})\end{array}$ & $1.02[0.68,1.52]$ \\
\hline
\end{tabular}




\begin{tabular}{|c|c|c|c|c|}
\hline Outcome or subgroup title & No. of studies & $\begin{array}{l}\text { No. of partici- } \\
\text { pants }\end{array}$ & Statistical method & Effect size \\
\hline $\begin{array}{l}\text { 14.3 Deaths from influenza or pneu- } \\
\text { monia }\end{array}$ & 1 & 1092 & $\begin{array}{l}\text { Odds Ratio (M-H, Random, } \\
95 \% \mathrm{Cl})\end{array}$ & $0.74[0.53,1.04]$ \\
\hline 14.3.1 Outbreak - vaccine matching & 1 & 1092 & $\begin{array}{l}\text { Odds Ratio (M-H, Random, } \\
95 \% \mathrm{Cl})\end{array}$ & $0.74[0.53,1.04]$ \\
\hline 14.4 Pneumonia (no better defined) & 1 & 519 & $\begin{array}{l}\text { Odds Ratio (M-H, Fixed, 95\% } \\
\text { Cl) }\end{array}$ & $0.87[0.57,1.33]$ \\
\hline 14.4.1 Outbreak - partially matching & 1 & 519 & $\begin{array}{l}\text { Odds Ratio (M-H, Fixed, 95\% } \\
\text { Cl) }\end{array}$ & $0.87[0.57,1.33]$ \\
\hline
\end{tabular}

\section{Analysis 14.1. Comparison 14: Influenza vaccines versus no vaccination: case- control studies in community, Outcome 1: Hospitalisations for influenza or pneumonia}

\begin{tabular}{|c|c|c|c|c|c|c|c|}
\hline \multirow[b]{2}{*}{ Study or Subgroup } & \multicolumn{2}{|c|}{ Vaccine } & \multicolumn{2}{|c|}{ Control } & \multirow[b]{2}{*}{ Weight } & Odds Ratio & \multirow{2}{*}{$\begin{array}{c}\text { Odds Ratio } \\
\text { M-H, Random, } 95 \% \text { CI }\end{array}$} \\
\hline & Events & Total & Events & Total & & M-H, Random, 95\% CI & \\
\hline \multicolumn{7}{|c|}{ 14.1.1 Outbreak - vaccine matching (circulating strains) } & \\
\hline Subtotal (95\% CI) & & $\mathbf{0}$ & & $\mathbf{0}$ & & Not estimable & \\
\hline Total events: & 0 & & 0 & & & & \\
\hline \multicolumn{8}{|c|}{ Heterogeneity: Not applicable } \\
\hline \multicolumn{8}{|c|}{ Test for overall effect: Not applicable } \\
\hline \multicolumn{8}{|c|}{ 14.1.2 Outbreak - vaccine matching absent or unknown } \\
\hline Crocetti 2001 & 133 & 275 & 278 & 550 & $77.3 \%$ & $0.92[0.69,1.22]$ & \\
\hline Subtotal $(95 \% \mathrm{CI})$ & & 275 & & 550 & $77.3 \%$ & $0.92[0.69,1.22]$ & \\
\hline Total events: & 133 & & 278 & & & & \\
\hline \multicolumn{8}{|c|}{ Heterogeneity: Not applicable } \\
\hline \multicolumn{8}{|c|}{ Test for overall effect: $\mathrm{Z}=0.59(\mathrm{P}=0.55)$} \\
\hline \multicolumn{8}{|c|}{ 14.1.3 No outbreak - vaccine matching } \\
\hline Puig-Barberà 1997 & 47 & 83 & 102 & 166 & $22.7 \%$ & $0.82[0.48,1.40]$ & \\
\hline Subtotal (95\% CI) & & 83 & & 166 & $22.7 \%$ & $0.82[0.48,1.40]$ & \\
\hline Total events: & 47 & & 102 & & & & \\
\hline \multicolumn{8}{|c|}{ Heterogeneity: Not applicable } \\
\hline \multicolumn{8}{|c|}{ Test for overall effect: $\mathrm{Z}=0.73(\mathrm{P}=0.46)$} \\
\hline Total (95\% CI) & & 358 & & 716 & $100.0 \%$ & $0.89[0.69,1.15]$ & \\
\hline Total events: & 180 & & 380 & & & & \\
\hline \multicolumn{7}{|c|}{ Heterogeneity: $\mathrm{Tau}^{2}=0.00 ; \mathrm{Chi}^{2}=0.13, \mathrm{df}=1(\mathrm{P}=0.72) ; \mathrm{I}^{2}=0 \%$} & $\begin{array}{ccc}1 & 1 & 1 \\
0.1 & 1 & 10\end{array}$ \\
\hline Test for overall effect & $=0.87(\mathrm{P}=$ & $0.39)$ & & & & $\mathrm{Fa}$ & urs vaccine Favours \\
\hline
\end{tabular}


Analysis 14.2. Comparison 14: Influenza vaccines versus no vaccination: casecontrol studies in community, Outcome 2: Hospitalisations for any respiratory disease

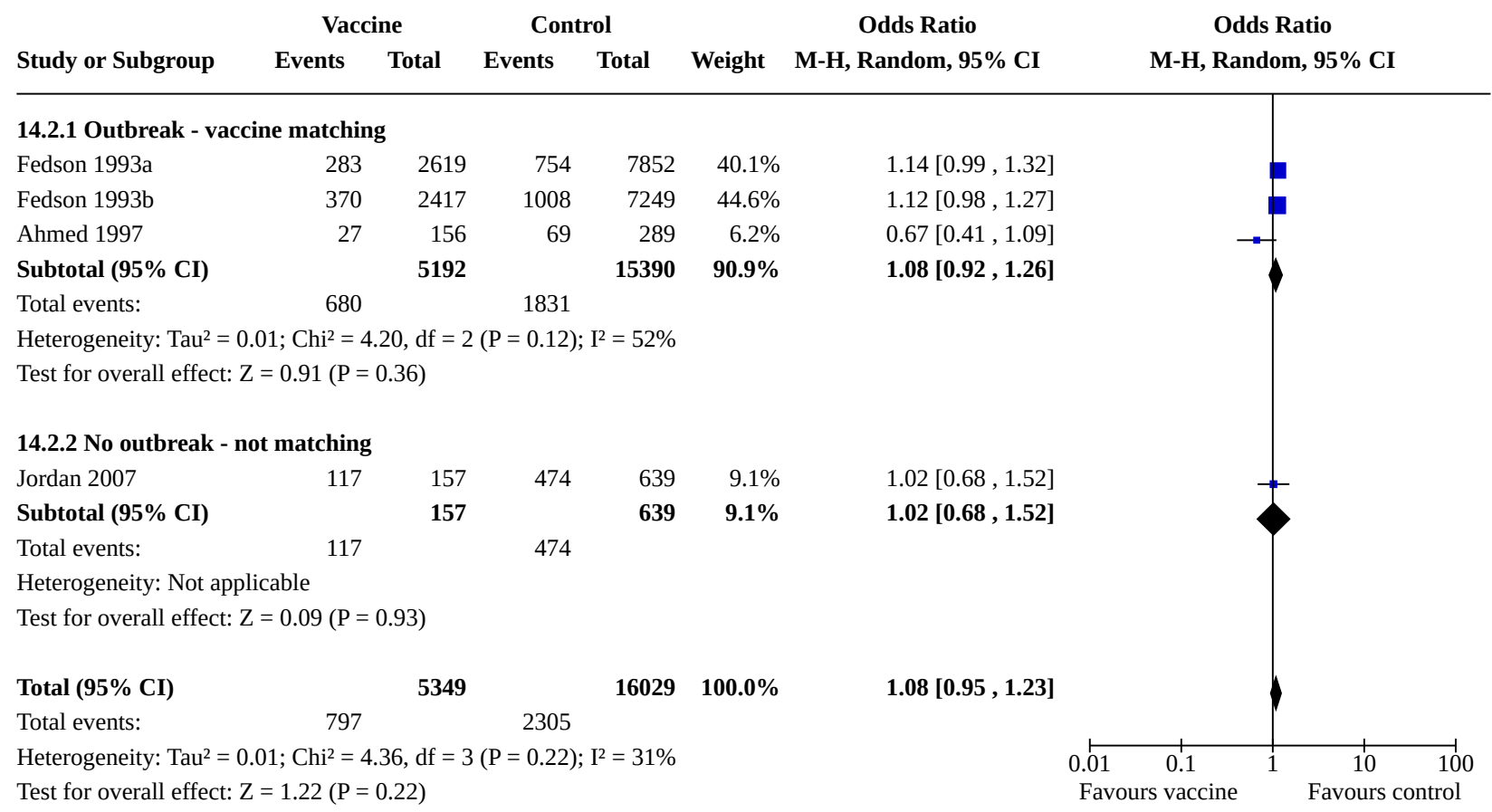

Analysis 14.3. Comparison 14: Influenza vaccines versus no vaccination: casecontrol studies in community, Outcome 3: Deaths from influenza or pneumonia
Vaccine
Control
Odds Ratio
Odds Ratio

Study or Subgroup Events Total Events Total Weight M-H, Random, 95\% CI $\quad$ M-H, Random, 95\% CI

$\begin{array}{lcccccc}\text { 14.3.1 Outbreak - vaccine matching } & & & & & \\ \text { Ahmed } 1995 & 57 & 315 & 178 & 777 & 100.0 \% & 0.74[0.53,1.04] \\ \text { Subtotal (95\% CI) } & & \mathbf{3 1 5} & & \mathbf{7 7 7} & \mathbf{1 0 0 . 0 \%} & \mathbf{0 . 7 4}[\mathbf{0 . 5 3 , \mathbf { 1 . 0 4 } ]} \\ \text { Total events: } & 57 & & 178 & & & \end{array}$

Heterogeneity: Not applicable

Test for overall effect: $\mathrm{Z}=1.75(\mathrm{P}=0.08)$

Total (95\% CI)

315

Total events:

57

$777 \quad \mathbf{1 0 0 . 0} \%$

Heterogeneity: Not applicable

Test for overall effect: $\mathrm{Z}=1.75(\mathrm{P}=0.08)$

Test for subgroup differences: Not applicable

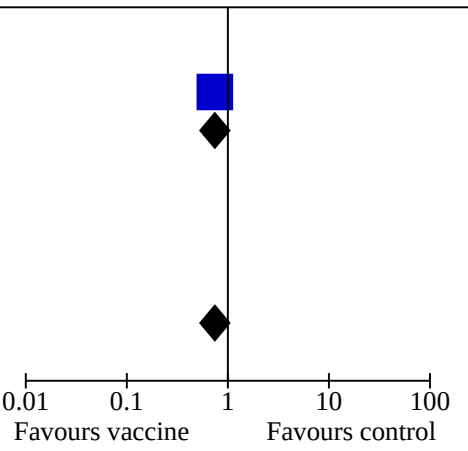


Analysis 14.4. Comparison 14: Influenza vaccines versus no vaccination: casecontrol studies in community, Outcome 4: Pneumonia (no better defined)

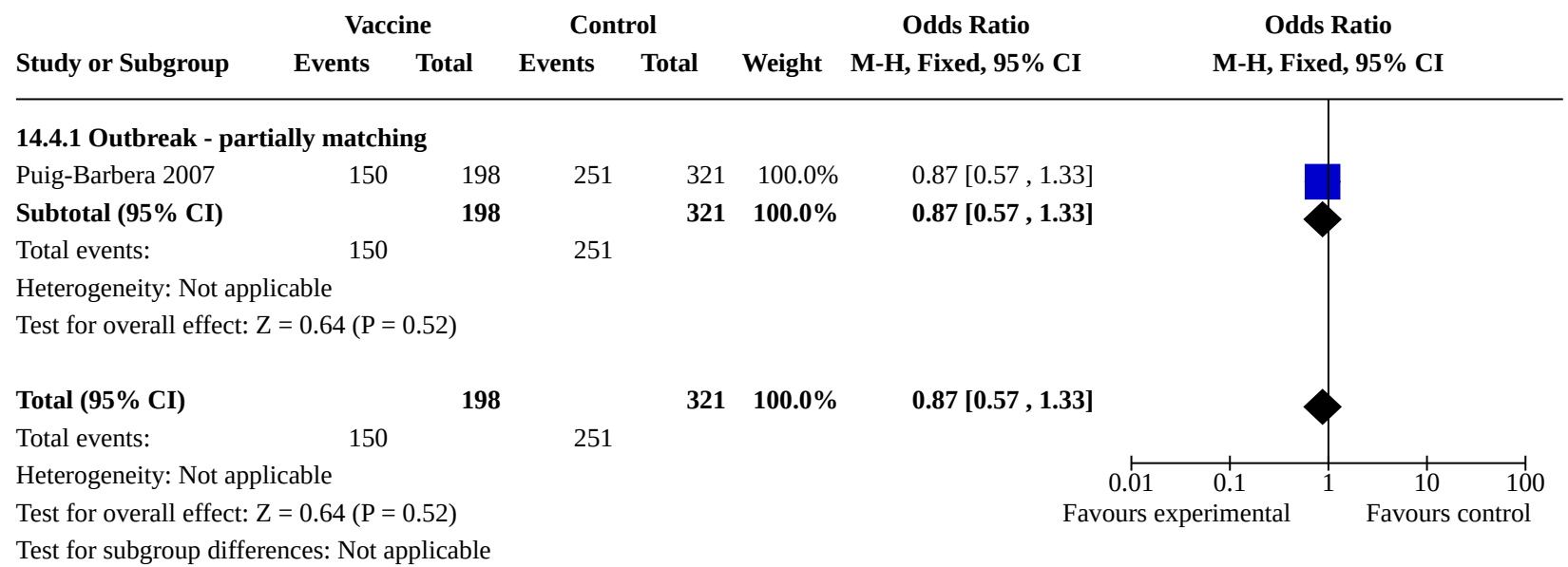

Comparison 15. Influenza vaccines versus no vaccination: case-control studies in community - adjusted rates

\begin{tabular}{|c|c|c|c|c|}
\hline Outcome or subgroup title & No. of studies & $\begin{array}{l}\text { No. of partici- } \\
\text { pants }\end{array}$ & Statistical method & Effect size \\
\hline $\begin{array}{l}15.1 \text { Hospitalisations for influenza or } \\
\text { pneumonia }\end{array}$ & 5 & & $\begin{array}{l}\text { Odds Ratio (IV, Random, } \\
95 \% \mathrm{Cl} \text { ) }\end{array}$ & $0.59[0.47,0.74]$ \\
\hline 15.1.1 Epidemic - vaccine matching & 1 & & $\begin{array}{l}\text { Odds Ratio (IV, Random, } \\
95 \% \mathrm{Cl})\end{array}$ & $0.55[0.36,0.85]$ \\
\hline $\begin{array}{l}\text { 15.1.2 Non-epidemic - vaccine not } \\
\text { matching }\end{array}$ & 0 & & $\begin{array}{l}\text { Odds Ratio (IV, Random, } \\
95 \% \mathrm{Cl})\end{array}$ & Not estimable \\
\hline $\begin{array}{l}\text { 15.1.3 Epidemic year - vaccine matching } \\
\text { absent or unknown }\end{array}$ & 2 & & $\begin{array}{l}\text { Odds Ratio (IV, Random, } \\
95 \% \mathrm{Cl})\end{array}$ & $0.68[0.58,0.79]$ \\
\hline 15.1.4 Non-epidemic - vaccine matching & 2 & & $\begin{array}{l}\text { Odds Ratio (IV, Random, } \\
95 \% \mathrm{CI})\end{array}$ & $0.37[0.16,0.87]$ \\
\hline $\begin{array}{l}15.2 \text { Hospitalisations for any respiratory } \\
\text { disease }\end{array}$ & 3 & & $\begin{array}{l}\text { Odds Ratio (IV, Random, } \\
95 \% \mathrm{Cl})\end{array}$ & $0.71[0.56,0.90]$ \\
\hline 15.2.1 Epidemic - vaccine matching & 3 & & $\begin{array}{l}\text { Odds Ratio (IV, Random, } \\
95 \% \mathrm{CI})\end{array}$ & $0.71[0.56,0.90]$ \\
\hline 15.2.2 Non-epidemic - vaccine matching & 0 & & $\begin{array}{l}\text { Odds Ratio (IV, Random, } \\
95 \% \mathrm{Cl})\end{array}$ & Not estimable \\
\hline $\begin{array}{l}\text { 15.2.3 Non-epidemic year - vaccine } \\
\text { matching }\end{array}$ & 0 & & $\begin{array}{l}\text { Odds Ratio (IV, Random, } \\
95 \% \mathrm{CI})\end{array}$ & Not estimable \\
\hline $\begin{array}{l}\text { 15.3 Deaths from pneumonia or influen- } \\
\text { za }\end{array}$ & 2 & & $\begin{array}{l}\text { Odds Ratio (IV, Random, } \\
95 \% \mathrm{CI})\end{array}$ & $0.74[0.60,0.92]$ \\
\hline 15.3.1 Epidemic year - vaccine matching & 1 & & $\begin{array}{l}\text { Odds Ratio (IV, Random, } \\
95 \% \mathrm{Cl})\end{array}$ & $0.76[0.60,0.97]$ \\
\hline
\end{tabular}




\begin{tabular}{lllll}
\hline Outcome or subgroup title & No. of studies & $\begin{array}{l}\text { No. of partici- } \\
\text { pants }\end{array}$ & Statistical method & Effect size \\
\hline $\begin{array}{l}\text { 15.3.2 Epidemic year - vaccine matching } \\
\text { absent or unknown }\end{array}$ & 1 & & $\begin{array}{l}\text { Odds Ratio (IV, Random, } \\
95 \% \text { CI) }\end{array}$ & $0.67[0.42,1.07]$ \\
\hline
\end{tabular}

\section{Analysis 15.1. Comparison 15: Influenza vaccines versus no vaccination: case-control studies in community - adjusted rates, Outcome 1: Hospitalisations for influenza or pneumonia}

Odds Ratio

Study or Subgroup $\quad \log [\mathrm{OR}] \quad$ SE $\quad$ Weight $\quad$ IV, Random, 95\% CI
Odds Ratio

IV, Random, 95\% CI

15.1.1 Epidemic - vaccine matching

$\begin{array}{lllll}\text { Foster } 1992 & -0.5978 & 0.2222 & 17.0 \% & 0.55[0.36,0.85] \\ \text { Subtotal (95\% CI) } & & & \mathbf{1 7 . 0 \%} & \mathbf{0 . 5 5}[\mathbf{0 . 3 6 , \mathbf { 0 . 8 5 }}]\end{array}$

Heterogeneity: Not applicable

Test for overall effect: $\mathrm{Z}=2.69(\mathrm{P}=0.007)$

15.1.2 Non-epidemic - vaccine not matching Subtotal (95\% CI)

Not estimable

Heterogeneity: Not applicable

Test for overall effect: Not applicable

15.1.3 Epidemic year - vaccine matching absent or unknown

$\begin{array}{lllll}\text { Mullooly } 1994 & -0.3823 & 0.0878 & 38.0 \% & 0.68[0.57,0.81] \\ \text { Crocetti 2001 } & -0.4005 & 0.1742 & 22.8 \% & 0.67[0.48,0.94] \\ \text { Subtotal (95\% CI) } & & & \mathbf{6 0 . 7 \%} & \mathbf{0 . 6 8}[\mathbf{0 . 5 8 , ~ 0 . 7 9 ]}\end{array}$

Heterogeneity: Tau$^{2}=0.00 ; \mathrm{Chi}^{2}=0.01, \mathrm{df}=1(\mathrm{P}=0.93) ; \mathrm{I}^{2}=0 \%$

Test for overall effect: $\mathrm{Z}=4.92(\mathrm{P}<0.00001)$

15.1.4 Non-epidemic - vaccine matching

$\begin{array}{lrrrr}\text { Puig-Barberà 1997 } & -1.5606 & 0.4918 & 4.8 \% & 0.21[0.08,0.55] \\ \text { Puig-Barberà 2004 } & -0.6539 & 0.2183 & 17.4 \% & 0.52[0.34,0.80] \\ \text { Subtotal (95\% CI) } & & & \mathbf{2 2 . 2 \%} & \mathbf{0 . 3 7}[\mathbf{0 . 1 6}, \mathbf{0 . 8 7}]\end{array}$

Heterogeneity: $\mathrm{Tau}^{2}=0.27 ; \mathrm{Chi}^{2}=2.84, \mathrm{df}=1(\mathrm{P}=0.09) ; \mathrm{I}^{2}=65 \%$

Test for overall effect: $\mathrm{Z}=2.27(\mathrm{P}=0.02)$

Total (95\% CI)

$100.0 \%$

$0.59[0.47,0.74]$

Heterogeneity: $\mathrm{Tau}^{2}=0.03 ; \mathrm{Chi}^{2}=7.08, \mathrm{df}=4(\mathrm{P}=0.13) ; \mathrm{I}^{2}=44 \%$

Test for overall effect: $\mathrm{Z}=4.65(\mathrm{P}<0.00001)$

Test for subgroup differences: $\mathrm{Chi}^{2}=2.56, \mathrm{df}=2(\mathrm{P}=0.28), \mathrm{I}^{2}=21.8 \%$

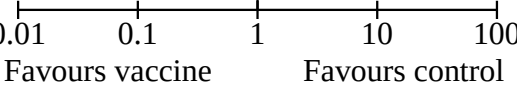


Analysis 15.2. Comparison 15: Influenza vaccines versus no vaccination: case-control studies in community - adjusted rates, Outcome 2: Hospitalisations for any respiratory disease

Odds Ratio

Study or Subgroup $\quad \log [\mathrm{OR}] \quad$ SE $\quad$ Weight $\quad$ IV, Random, 95\% CI
Odds Ratio

IV, Random, 95\% CI

15.2.1 Epidemic - vaccine matching

$\begin{array}{lrrrr}\text { Fedson 1993a } & -0.1863 & 0.0958 & 45.1 \% & 0.83[0.69,1.00] \\ \text { Fedson 1993b } & -0.3857 & 0.0865 & 47.5 \% & 0.68[0.57,0.81] \\ \text { Ahmed 1997 } & -0.9943 & 0.42 & 7.5 \% & 0.37[0.16,0.84] \\ \text { Subtotal (95\% CI) } & & & \mathbf{1 0 0 . 0 \%} & \mathbf{0 . 7 1}[\mathbf{0 . 5 6}, \mathbf{0 . 9 0}]\end{array}$

$100.0 \%$

$0.71[0.56,0.90]$

Heterogeneity: $\mathrm{Tau}^{2}=0.02 ; \mathrm{Chi}^{2}=5.09, \mathrm{df}=2(\mathrm{P}=0.08) ; \mathrm{I}^{2}=61 \%$

Test for overall effect: $\mathrm{Z}=2.79(\mathrm{P}=0.005)$

15.2.2 Non-epidemic - vaccine matching

Subtotal (95\% CI)

Not estimable

Heterogeneity: Not applicable

Test for overall effect: Not applicable

15.2.3 Non-epidemic year - vaccine matching

Subtotal (95\% CI)

Not estimable

Heterogeneity: Not applicable

Test for overall effect: Not applicable

Total (95\% CI)

$100.0 \%$

$0.71[0.56,0.90]$

Heterogeneity: $\mathrm{Tau}^{2}=0.02 ; \mathrm{Chi}^{2}=5.09, \mathrm{df}=2(\mathrm{P}=0.08) ; \mathrm{I}^{2}=61 \%$

Test for overall effect: $\mathrm{Z}=2.79(\mathrm{P}=0.005)$

Test for subgroup differences: Not applicable

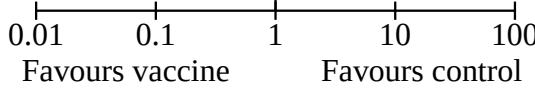


Analysis 15.3. Comparison 15: Influenza vaccines versus no vaccination: case-control studies in community - adjusted rates, Outcome 3: Deaths from pneumonia or influenza

Odds Ratio

Study or Subgroup $\quad \log [\mathrm{OR}] \quad$ SE $\quad$ Weight $\quad$ IV, Random, 95\% CI
Odds Ratio

IV, Random, 95\% CI

15.3.1 Epidemic year - vaccine matching

$\begin{array}{lrrrr}\text { Ahmed } 1995 & -0.2744 & 0.1225 & 78.9 \% & 0.76[0.60,0.97] \\ \text { Subtotal (95\% CI) } & & & \mathbf{7 8 . 9 \%} & \mathbf{0 . 7 6}[\mathbf{0 . 6 0 , 0 . 9 7 ]}\end{array}$

Heterogeneity: Not applicable

Test for overall effect: $\mathrm{Z}=2.24(\mathrm{P}=0.03)$

15.3.2 Epidemic year - vaccine matching absent or unknown

$\begin{array}{lllll}\text { Mullooly } 1994 & -0.3988 & 0.237 & 21.1 \% & 0.67[0.42,1.07] \\ \text { Subtotal (95\% CI) } & & & \mathbf{2 1 . 1 \%} & \mathbf{0 . 6 7}[\mathbf{0 . 4 2}, \mathbf{1 . 0 7}]\end{array}$

Heterogeneity: Not applicable

Test for overall effect: $\mathrm{Z}=1.68(\mathrm{P}=0.09)$

Total (95\% CI)

$100.0 \%$

$0.74[0.60,0.92]$

Heterogeneity: $\mathrm{Tau}^{2}=0.00 ; \mathrm{Chi}^{2}=0.22, \mathrm{df}=1(\mathrm{P}=0.64) ; \mathrm{I}^{2}=0 \%$

Test for overall effect: $\mathrm{Z}=2.76(\mathrm{P}=0.006)$

Test for subgroup differences: $\mathrm{Chi}^{2}=0.22, \mathrm{df}=1(\mathrm{P}=0.64), \mathrm{I}^{2}=0 \%$

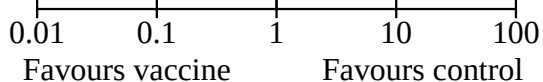

Comparison 16. Influenza and pneumococcal vaccines versus no vaccination: case-control studies in community

\begin{tabular}{lllll}
\hline Outcome or subgroup title & No. of studies & $\begin{array}{l}\text { No. of partici- } \\
\text { pants }\end{array}$ & Statistical method & Effect size \\
\hline $\begin{array}{l}\text { 16.1 Hospitalisations for influenza or } \\
\text { pneumonia }\end{array}$ & 4 & 6629 & $\begin{array}{l}\text { Odds Ratio (M-H, Random, } \\
95 \% \mathrm{Cl})\end{array}$ & $0.97[0.85,1.09]$ \\
\hline $\begin{array}{l}16.1 .1 \text { Outbreak - vaccine matching } \\
\text { 16.1.2 No outbreak - vaccine match- }\end{array}$ & 2 & 3617 & $\begin{array}{l}\text { Odds Ratio (M-H, Random, } \\
95 \% \mathrm{Cl})\end{array}$ & $0.95[0.69,1.31]$ \\
\hline \begin{tabular}{l} 
ing \\
\hline
\end{tabular} & 3012 & $\begin{array}{l}\text { Odds Ratio (M-H, Random, } \\
95 \% \mathrm{Cl})\end{array}$ & $0.93[0.80,1.08]$ \\
\hline
\end{tabular}


Analysis 16.1. Comparison 16: Influenza and pneumococcal vaccines versus no vaccination: case-control studies in community, Outcome 1: Hospitalisations for influenza or pneumonia

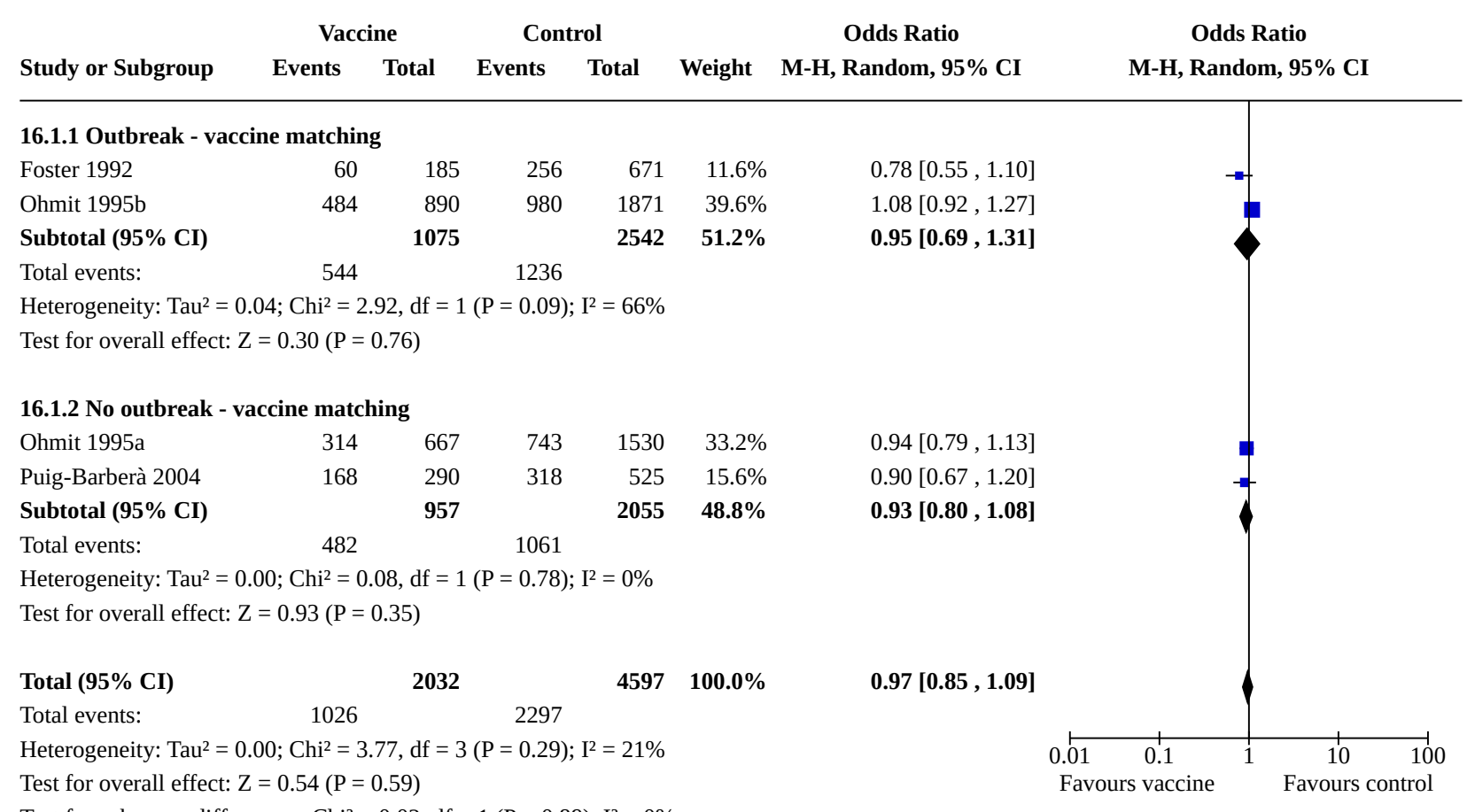

Comparison 17. Influenza and pneumococcal vaccines versus no vaccination: case-control studies in community adjusted rates

\begin{tabular}{|c|c|c|c|c|}
\hline Outcome or subgroup title & No. of studies & $\begin{array}{l}\text { No. of partici- } \\
\text { pants }\end{array}$ & Statistical method & Effect size \\
\hline $\begin{array}{l}\text { 17.1 Hospitalisations for influenza or } \\
\text { pneumonia }\end{array}$ & 2 & & $\begin{array}{l}\text { Odds Ratio (IV, Random, 95\% } \\
\mathrm{CI} \text { ) }\end{array}$ & $0.68[0.54,0.86]$ \\
\hline 17.1.1 Epidemic - vaccine matching & 1 & & $\begin{array}{l}\text { Odds Ratio (IV, Random, 95\% } \\
\mathrm{CI} \text { ) }\end{array}$ & $0.68[0.50,0.93]$ \\
\hline $\begin{array}{l}\text { 17.1.2 Non-epidemic - vaccine not } \\
\text { matching }\end{array}$ & 0 & & $\begin{array}{l}\text { Odds Ratio (IV, Random, 95\% } \\
\mathrm{CI} \text { ) }\end{array}$ & Not estimable \\
\hline $\begin{array}{l}\text { 17.1.3 Epidemic year - vaccine match- } \\
\text { ing absent or unknown }\end{array}$ & 0 & & $\begin{array}{l}\text { Odds Ratio (IV, Random, 95\% } \\
\mathrm{CI} \text { ) }\end{array}$ & Not estimable \\
\hline $\begin{array}{l}\text { 17.1.4 Non-epidemic - vaccine match- } \\
\text { ing }\end{array}$ & 1 & & $\begin{array}{l}\text { Odds Ratio (IV, Random, 95\% } \\
\mathrm{Cl} \text { ) }\end{array}$ & $0.69[0.49,0.97]$ \\
\hline
\end{tabular}


Analysis 17.1. Comparison 17: Influenza and pneumococcal vaccines versus no vaccination: casecontrol studies in community - adjusted rates, Outcome 1: Hospitalisations for influenza or pneumonia

Odds Ratio

Study or Subgroup $\quad \log [\mathrm{OR}] \quad$ SE $\quad$ Weight $\quad$ IV, Random, 95\% CI
Odds Ratio

IV, Random, 95\% CI

\begin{tabular}{lcccc}
\hline 17.1.1 Epidemic - vaccine matching & & & \\
Ohmit 1995b & -0.3857 & 0.1583 & $54.0 \%$ & $0.68[0.50,0.93]$ \\
Subtotal (95\% CI) & & & $\mathbf{5 4 . 0 \%}$ & $\mathbf{0 . 6 8}[\mathbf{0 . 5 0}, \mathbf{0 . 9 3}]$
\end{tabular}

Heterogeneity: Not applicable

Test for overall effect: $\mathrm{Z}=2.44(\mathrm{P}=0.01)$

17.1.2 Non-epidemic - vaccine not matching

Subtotal (95\% CI)

Not estimable

Heterogeneity: Not applicable

Test for overall effect: Not applicable

17.1.3 Epidemic year - vaccine matching absent or unknown Subtotal (95\% CI)

Not estimable

Heterogeneity: Not applicable

Test for overall effect: Not applicable

17.1.4 Non-epidemic - vaccine matching

$\begin{array}{lllll}\text { Ohmit 1995a } & -0.3711 & 0.1716 & 46.0 \% & 0.69[0.49,0.97] \\ \text { Subtotal (95\% CI) } & & & \mathbf{4 6 . 0 \%} & \mathbf{0 . 6 9}[\mathbf{0 . 4 9 , 0 . 9 7 ]}\end{array}$

Heterogeneity: Not applicable

$46.0 \%$

$0.69[0.49,0.97]$

Test for overall effect: $\mathrm{Z}=2.16(\mathrm{P}=0.03)$

Total (95\% CI)

$100.0 \%$

$0.68[0.54,0.86]$

Heterogeneity: $\mathrm{Tau}^{2}=0.00 ; \mathrm{Chi}^{2}=0.00, \mathrm{df}=1(\mathrm{P}=0.95) ; \mathrm{I}^{2}=0 \%$

Test for overall effect: $\mathrm{Z}=3.26(\mathrm{P}=0.001)$

Test for subgroup differences: $\mathrm{Chi}^{2}=0.00, \mathrm{df}=1(\mathrm{P}=0.95), \mathrm{I}^{2}=0 \%$

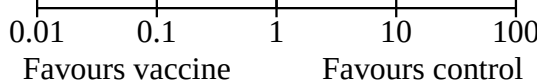

Comparison 18. Sensitivity analysis: comparison 01: subgroup analysis by study quality

\begin{tabular}{lllll}
\hline $\begin{array}{l}\text { Outcome or subgroup } \\
\text { title }\end{array}$ & No. of studies & $\begin{array}{l}\text { No. of partici- } \\
\text { pants }\end{array}$ & Statistical method & Effect size \\
\hline 18.1 Influenza-like illness & 25 & 9211 & Risk Ratio $(\mathrm{M}-\mathrm{H}$, Random, 95\% Cl) & $0.75[0.65,0.87]$ \\
\hline 18.1 .1 Quality A & 8 & 4502 & Risk Ratio (M-H, Random, 95\% Cl) & $0.78[0.65,0.94]$ \\
\hline 18.1 .2 Quality B & 13 & 3854 & Risk Ratio (M-H, Random, 95\% Cl) & $0.82[0.65,1.03]$ \\
\hline 18.1 .3 Quality C & 3 & 389 & Risk Ratio (M-H, Random, 95\% Cl) & $0.66[0.43,1.00]$ \\
\hline 18.1 .4 Quality D & 1 & 466 & Risk Ratio (M-H, Random, 95\% Cl) & $0.44[0.35,0.57]$ \\
\hline
\end{tabular}


Analysis 18.1. Comparison 18: Sensitivity analysis: comparison 01: subgroup analysis by study quality, Outcome 1: Influenza-like illness

\begin{tabular}{|c|c|c|c|c|c|}
\hline \multirow[b]{2}{*}{ Study or Subgroup } & \multicolumn{2}{|c|}{ Vaccine } & \multicolumn{2}{|c|}{ Control } & \multirow[b]{2}{*}{ Weight } \\
\hline & Events & Total & Events & Total & \\
\hline \multicolumn{6}{|l|}{ 18.1.1 Quality A } \\
\hline Patriarca 1985a & 113 & 548 & 155 & 470 & $6.8 \%$ \\
\hline Patriarca 1985b & 37 & 339 & 20 & 119 & $4.1 \%$ \\
\hline Strassburg 1986 & 34 & 65 & 11 & 19 & $4.5 \%$ \\
\hline Coles 1992 & 34 & 112 & 3 & 12 & $1.6 \%$ \\
\hline Taylor 1992 & 25 & 45 & 27 & 52 & $5.2 \%$ \\
\hline Caminiti 1994 & 12 & 169 & 12 & 73 & $2.5 \%$ \\
\hline Monto 2001 & 247 & 1728 & 98 & 623 & $6.7 \%$ \\
\hline Murayama 1999 & 25 & 60 & 38 & 68 & $5.3 \%$ \\
\hline Subtotal (95\% CI) & & 3066 & & 1436 & $36.8 \%$ \\
\hline Total events: & 527 & & 364 & & \\
\hline
\end{tabular}

Risk Ratio

Risk Ratio

M-H, Random, 95\% CI

M-H, Random, 95\% CI

Heterogeneity: $\mathrm{Tau}^{2}=0.03 ; \mathrm{Chi}^{2}=13.17, \mathrm{df}=7(\mathrm{P}=0.07) ; \mathrm{I}^{2}=47 \%$

Test for overall effect: $\mathrm{Z}=2.58(\mathrm{P}=0.010)$

\subsubsection{Quality B}

Ruben 1974

Horman 1986

Goodman 1982

Fyson 1983a

Arroyo 1984

Arden 1988

Cartter 1990a

Cartter 1990b

Cartter 1990c

Currier 1988

Morens 1995

Saito 2002a

Saito 2002b

Subtotal (95\% CI)

Total events:

Heterogeneity: $\mathrm{Tau}^{2}=0.09 ; \mathrm{Chi}^{2}=27.13, \mathrm{df}=12(\mathrm{P}=0.007) ; \mathrm{I}^{2}=56 \%$

Test for overall effect: $\mathrm{Z}=1.68(\mathrm{P}=0.09)$

\subsubsection{Quality C}

D'Alessio 1969

Meiklejohn 1987

Isaacs 1997

Subtotal (95\% CI)

Total events:

\section{8}

204

100

36

321

26

31

96

30

332

87

36

331

743

2373

$$
70
$$

12

24

$$
29
$$

44

$$
8
$$

$$
\begin{aligned}
& 8 \\
& 3
\end{aligned}
$$

$$
14
$$$$
25
$$

$$
\begin{aligned}
& 25 \\
& 15
\end{aligned}
$$

$$
\begin{array}{r}
15 \\
1
\end{array}
$$$$
112
$$$$
14
$$$$
371
$$

$\begin{array}{rr}192 & 5.5 \% \\ 59 & 3.2 \% \\ 84 & 2.3 \% \\ 224 & 3.9 \% \\ 90 & 3.9 \% \\ 24 & 1.9 \% \\ 35 & 1.3 \% \\ 55 & 3.2 \% \\ 126 & 4.9 \% \\ 34 & 4.5 \% \\ 3 & 0.7 \% \\ 368 & 6.1 \% \\ 187 & 3.7 \% \\ \mathbf{1 4 8 1} & \mathbf{4 5 . 1 \%}\end{array}$

$0.51[0.36,0.72]$

1.08 [0.58, 2.02]

$0.58[0.26,1.30]$

$0.55[0.33,0.93]$

$0.79[0.46,1.34]$

$0.58[0.23,1.45]$

1.82 [0.56, 5.92]

1.57 [0.84, 2.95]

$1.14[0.76,1.70]$

$0.94[0.60,1.48]$

$0.83[0.15,4.49]$

$0.58[0.44,0.76]$

$1.22[0.70,2.12]$

$0.82[0.65,1.03]$

Heterogeneity: $\mathrm{Tau}^{2}=0.07 ; \mathrm{Chi}^{2}=3.87, \mathrm{df}=2(\mathrm{P}=0.14) ; \mathrm{I}^{2}=48 \%$

Test for overall effect: $\mathrm{Z}=1.97(\mathrm{P}=0.05)$

\subsubsection{Quality D}

Mukerjee 1994

Subtotal (95\% CI)

62

131
36

7

$31 \quad 2.7 \%$

$0.98[0.47,2.03]$

$0.46[0.29,0.73]$

$0.73[0.47,1.14]$

$0.66[0.43,1.00]$

Total events:

250

121

$216 \quad 6.4 \%$

$0.44[0.35,0.57]$

Heterogeneity: Not applicable

$62 \quad 121$

$0.44[0.35,0.57]$

Test for overall effect: $\mathrm{Z}=6.49(\mathrm{P}<0.00001)$

Total (95\% CI)

Total events:

6005

Heterogeneity: Tau $^{2}=0.07 ; \mathrm{Chi}^{2}=61.54, \mathrm{df}=24(\mathrm{P}<0.0001) ; \mathrm{I}^{2}=61 \%$

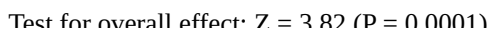

$3206 \quad \mathbf{1 0 0 . 0} \%$
891
$0.65[0.39,1.07]$

$1.21[0.44,3.37]$

$0.43[0.20,0.92]$

$0.75[0.52,1.08]$ 


\section{Analysis 18.1. (Continued)}

Heterogeneity: $\mathrm{Tau}^{2}=0.07 ; \mathrm{Chi}^{2}=61.54, \mathrm{df}=24(\mathrm{P}<0.0001) ; \mathrm{I}^{2}=61 \%$

Test for overall effect: $\mathrm{Z}=3.82(\mathrm{P}=0.0001)$

Test for subgroup differences: $\mathrm{Chi}^{2}=16.47, \mathrm{df}=3(\mathrm{P}=0.0009), \mathrm{I}^{2}=81.8 \%$

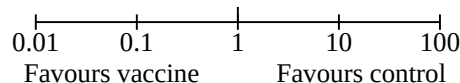

ADDITIONAL TABLES

Table 1. Studies included in the various versions of this review and their impact on our conclusions

\begin{tabular}{|c|c|c|c|c|}
\hline $\begin{array}{l}\text { Review version } \\
\text { (searches date) }\end{array}$ & $\begin{array}{l}\text { Number of in- } \\
\text { cluded trials } \\
\text { (RCTs/CCTs) }\end{array}$ & $\begin{array}{l}\text { Number of in- } \\
\text { cluded observa- } \\
\text { tional studies }\end{array}$ & $\begin{array}{l}\text { Estimates of effect } \\
\text { (RCTs/CCTs only) }\end{array}$ & Conclusions ( 1 to 2 lines from abstract) \\
\hline $\begin{array}{l}\text { Version } 1 \\
\text { (24 May 2006) }\end{array}$ & 9 & $62^{1}$ & $\begin{array}{l}\text { Influenza-like illness } \\
\text { LAIV = no data } \\
\text { TIV }=41 \%(95 \% \mathrm{Cl} 27 \% \\
\text { to } 53 \%) \\
\text { IAV = n.s. } \\
\text { Influenza } \\
\text { LAIV = n.s. } \\
\text { TIV = 58\% }(95 \% \mathrm{Cl} 34 \% \\
\text { to } 73 \%) \\
\text { IAV = n.s. }\end{array}$ & $\begin{array}{l}\text { In long-term care facilities, where vaccina- } \\
\text { tion is most effective against complications, } \\
\text { the aims of the vaccination campaign are ful- } \\
\text { filled, at least in part. However, according to } \\
\text { reliable evidence the usefulness of vaccines in } \\
\text { the community is modest. } \\
\text { The apparent high effectiveness of the vac- } \\
\text { cines in preventing death from all causes may } \\
\text { reflect a baseline imbalance in health sta- } \\
\text { tus and other systematic differences in the } 2 \\
\text { groups of participants. }\end{array}$ \\
\hline
\end{tabular}

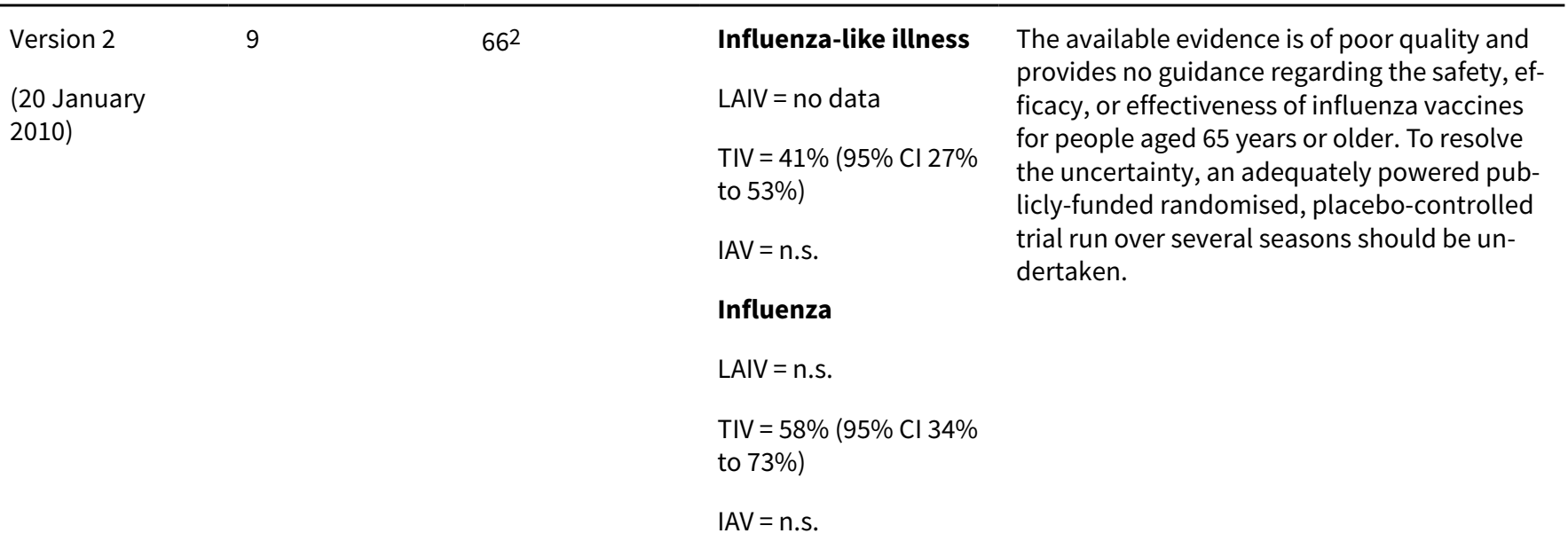

1These include 49 cohort studies for efficacy/effectiveness (79 data sets); 10 case-control studies for efficacy/effectiveness (12 data sets); 3 studies (cohorts) for Guillain-Barré syndrome.

${ }^{2}$ For this update, two cohort studies and two case-control studies were added to the review (all assessing efficacy/effectiveness).

Key: $\mathrm{CCT}=$ controlled clinical trial; $\mathrm{Cl}=$ confidence interval; IAV = inactivated aerosol vaccines; $\mathrm{LAIV}=$ live attenuated vaccines; $\mathrm{n} . \mathrm{S}$. = not significant; RCT = randomised controlled trial; TIV = trivalent inactivated vaccines 
Table 2. Guillain-Barré syndrome

\begin{tabular}{llllll}
\hline Study & $\begin{array}{l}\text { Influenza } \\
\text { season }\end{array}$ & Vaccine & Population & Age & RR (95\% CI) \\
\hline $\begin{array}{llll}\text { Schonberger } \\
1979\end{array}$ & 1976 to 1977 & $\begin{array}{l}\text { A/New Jersey/76 or A/New Jer- } \\
\text { sey/76 and A/Victoria/75 swine } \\
\text { vaccine }\end{array}$ & $\begin{array}{l}\text { All the USA popula- } \\
\text { tion }\end{array}$ & $>64$ years & $5.2(3.9$ to 7.0$)$ \\
\hline Kaplan 1982 & 1979 to 1980 & Inactivated trivalent & $\begin{array}{l}\text { All the USA popula- } \\
\text { tion }\end{array}$ & $>18$ years & $0.6(0.45$ to 1.32$)$ \\
\hline Kaplan 1982 & 1980 to 1981 & Inactivated trivalent & $\begin{array}{l}\text { All the USA popula- } \\
\text { tion }\end{array}$ & $>18$ years & $1.4(0.80$ to 1.76$)$ \\
\hline Lasky 1998 & 1992 to 1994 & Inactivated trivalent & 21 million & $>64$ years & 1.5 (0.7 to 3.3) \\
\hline
\end{tabular}

Key: $\mathrm{Cl}=$ confidence interval; $\mathrm{RR}=$ risk ratio

\section{A P P E N D I C E S}

\section{Appendix 1. Included studies design}

Case-control study: a retrospective epidemiological study usually used to investigate the association between two variables (e.g. hospitalisation for pneumonia and influenza vaccination). Study participants who have experienced an event (adverse or disease-related) are compared with participants who have not. Any differences in the presence or absence of hypothesised risk or protective variables are observed.

Cohort study: an epidemiological study where groups of individuals are identified who vary in their exposure to an intervention or hazard, and who are then followed to assess outcomes. Association between exposure and outcome are then estimated. Cohort studies are best performed prospectively, but can also be undertaken retrospectively if suitable data records are available.

Randomised controlled trial: any study on humans in which the individuals (or other experimental units) followed in the study were definitely or possibly assigned prospectively to one of two (or more) alternative forms of health care using random allocation.

Quasi-randomised clinical trial: any study on humans in which the individuals (or other experimental units) followed in the study were definitely or possibly assigned prospectively to one of two (or more) alternative forms of health care using some quasi-random method of allocation (such as alternation, date of birth, or case record number).

\section{Appendix 2. MEDLINE (Ovid) and CENTRAL search strategy}

1 Influenza Vaccines/

2 Influenza, Human/tm, pc, im, mo, ep [Transmission, Prevention \& Control, Immunology, Mortality, Epidemiology]

3 Influenza, Human/

4 exp Influenzavirus A/

5 exp Influenzavirus B/

6 (flu or influenza*).tw.

7 or/3-6

8 Vaccines/

9 vaccines, attenuated/ or vaccines, inactivated/ or exp vaccines, subunit/ or exp vaccines, synthetic/ or viral vaccines/

10 exp Immunization/

11 (vaccin $^{\star}$ or immuni* or inocul $\left.{ }^{\star}\right)$.tw.

12 exp Adjuvants, Immunologic/

13 (vaccin $^{\star}$ adj5 adjuvant $\left.^{\star}\right)$.tw.

14 Squalene/

15 (aluminium or squalene or MF59 or virosom ${ }^{\star}$ ).tw,nm.

16 or/8-15

177 and 16

181 or 2 or 17

$19 \exp$ Adult/ 
20 Men/

21 Women/

22 Retirement/

$23\left(\left(\right.\right.$ old $^{\star}$ or age $\left.e^{\star}\right)$ adj3 (people* or person ${ }^{\star}$ or adult* or women ${ }^{\star}$ or men ${ }^{\star}$ or citizen* or residen $\left.\left.{ }^{\star}\right)\right) . t w$.

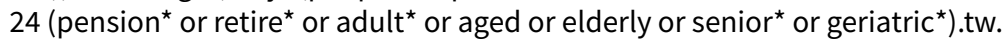

25 long-term care/ or nursing care/ or palliative care/

26 homes for the aged/ or nursing homes/

27 nursing home ${ }^{\star}$.tw.

28 or $/ 19-27$

2928 and 18

\section{Appendix 3. Embase (Elsevier) search strategy}

26. \#23 AND \#26

25. \#24 OR \#25

24. random*:ab,ti OR placebo*:ab,ti OR factorial*:ab,ti OR crossover*:ab,ti OR 'cross-over':ab,ti OR 'cross over':ab,ti OR assign*:ab,ti OR allocat*:ab,ti OR volunteer*:ab,ti OR ((singl* OR doubl*) NEAR/2 (blind ${ }^{\star}$ OR mask $\left.{ }^{\star}\right)$ ):ab,ti

23. 'randomized controlled trial'/exp OR 'single blind procedure'/exp OR 'double blind procedure'/exp OR

'crossover procedure'/exp

22. \#15 AND \#22

21. \#16 OR \#17 OR \#18 OR \#19 OR \#20

20. 'aged care':ab,ti OR 'nursing home':ab,ti OR 'nursing homes':ab,ti

19. 'nursing home'/exp OR 'hospice'/de OR 'residential home'/de

18. pension*:ab,ti OR retire*:ab,ti OR adult*:ab,ti OR aged:ab,ti OR elderly:ab,ti OR senior*:ab,ti OR geriatric*ab,ti

17. ((old ${ }^{\star}$ OR age $\left.{ }^{\star}\right)$ NEAR/3 (people* OR person* OR adult* OR women OR men OR citizen* ${ }^{\star}$ OR residen $\left.\left.{ }^{\star}\right)\right):$ ab,ti

16. 'adult'/de OR 'aged'/exp OR 'pensioner'/exp

15. \#1 OR \#14

14. \#5 AND \#13

13. \#6 OR \#7 OR \#8 OR \#9 OR \#10 OR \#11 OR \#12

12. aluminium:ab,ti OR squalene:ab,ti OR mf59:ab,ti OR virosom*:ab,ti

11. 'squalene'/de

10. $\left(\right.$ vaccin $^{\star}$ NEAR/5 adjuvant $\left.{ }^{\star}\right):$ ab,ti

9. 'immunological adjuvant'/de

8. vaccin*:ab,ti OR immuni*:ab,ti OR inocul*:ab,ti

7. 'immunization'/de OR 'vaccination'/de OR 'active immunization'/de OR 'immunoprophylaxis'/de OR 'mass immunization'/de

6. 'vaccine'/de OR 'acellular vaccine'/de OR 'dna vaccine'/de OR 'inactivated vaccine'/de OR 'live vaccine'/de OR 'subunit vaccine'/de OR 'virus vaccine'/de OR 'virosome vaccine'/de OR 'recombinant vaccine'/de

5. \#2 OR \#3 OR \#4

4. flu:ab,ti OR influenza*:ab,ti

3. 'influenza virus a'/exp OR 'influenza virus b'/exp

2. 'influenza'/exp

1. 'influenza vaccine'/de

\section{Appendix 4. Web of Science search strategy}

Topic=(influenza or flu or influenzavirus) AND Topic=(vaccine* or immuni* or inocul* or adjuvant ${ }^{\star}$ or squalene or aluminium or MF59 or virosom ${ }^{\star}$ ) AND Topic=(aged or elderly or senior ${ }^{\star}$ or geriatric ${ }^{\star}$ or retire or pension $^{\star}$ or old ${ }^{\star}$ people or old person $^{\star}$ or old $^{\star}$ adult* or old ${ }^{\star}$ men or old ${ }^{\star}$ women or old ${ }^{\star}$ citizen $^{\star}$ or old ${ }^{\star}$ residen* or nursing home*)

Refined by: Topic $=\left(\right.$ random $^{\star}$ or placebo* or rct or single blind ${ }^{\star}$ or double blind $\left.{ }^{\star}\right)$

Timespan $=2006$ to 2009 .

Appendix 5. CINAHL (EBSCO) search strategy

S1

(MH "Influenza Vaccine")

S2

(MH "Influenza, Human+/TM/PC/IM/MO/EP") 
(Continued)

(MH "Influenza, Human") OR (MH "Influenza A H5N1") OR (MH "Influenza, Pandemic (H1N1) 2009")
OR (MH "Influenza, Seasonal")

\begin{tabular}{|c|c|}
\hline S4 & (MH "Influenza A Virus+") \\
\hline S5 & (MH "Influenzavirus B+") \\
\hline S6 & $\mathrm{TI}$ ( influenza* or flu ) OR AB ( influenza* or flu ) \\
\hline S7 & $\mathrm{S} 3$ or $\mathrm{S} 4$ or $\mathrm{S} 5$ or $\mathrm{S} 6$ \\
\hline S8 & (MH "Vaccines+") \\
\hline S9 & (MH "Immunization+") \\
\hline S10 & (MH "Immunization Programs") \\
\hline S11 & TI (vaccin* or immuni* or inocul ${ }^{\star}$ ) OR AB ( vaccin* or immuni* or inocul* $)$ \\
\hline S12 & $\begin{array}{l}\text { TI ( aluminium or squalene or mf59 or virosom }{ }^{\star} \text { ) OR AB ( aluminium or squalene or mf59 or viro- } \\
\text { som }^{\star} \text { ) }\end{array}$ \\
\hline $\mathrm{S} 13$ & $\mathrm{~S} 8$ or $\mathrm{S} 9$ or $\mathrm{S} 10$ or $\mathrm{S} 11$ or $\mathrm{S} 12$ \\
\hline S14 & $\mathrm{S} 7$ and S13 \\
\hline S15 & $\mathrm{S} 1$ or $\mathrm{S} 2$ or $\mathrm{S} 14$ \\
\hline S16 & (MH "Aged+") \\
\hline S17 & (MH "Gerontologic Care") \\
\hline S18 & (MH "Nursing Homes") OR (MH "Residential Facilities") \\
\hline S19 & (MH "Nursing Home Patients") \\
\hline S20 & (MH "Long Term Care") \\
\hline S21 & (MH "Adult") \\
\hline S22 & (MH "Men") OR (MH "Aged, Hospitalized") OR (MH "Women") \\
\hline S23 & $\begin{array}{l}\text { TI ( pension* or retire }{ }^{\star} \text { or adult* or aged or elderly or senior* or geriatric }{ }^{\star} \text { ) OR AB ( pension* or re- } \\
\text { tire }^{\star} \text { or adult }{ }^{\star} \text { or aged or elderly or senior* or geriatric }{ }^{\star} \text { ) }\end{array}$ \\
\hline S24 & 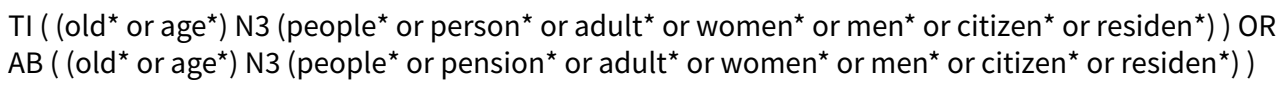 \\
\hline S25 & $\begin{array}{l}\text { TI ( "aged care" or "nursing home" or "nursing homes" ) OR AB ( "aged care" or "nursing home" or } \\
\text { "nursing homes") }\end{array}$ \\
\hline S26 & $\mathrm{S} 16$ or $\mathrm{S} 17$ or $\mathrm{S} 18$ or $\mathrm{S} 19$ or $\mathrm{S} 20$ or $\mathrm{S} 21$ or $\mathrm{S} 22$ or $\mathrm{S} 23$ or $\mathrm{S} 24$ or $\mathrm{S} 25$ \\
\hline S27 & S15 and S26 \\
\hline S28 & (MH "Clinical Trials+") \\
\hline
\end{tabular}


(Continued)

\begin{tabular}{|c|c|}
\hline S29 & PT clinical trial \\
\hline S30 & TI clinic trial $^{\star}$ OR AB clinic trial $^{\star}$ \\
\hline S31 & 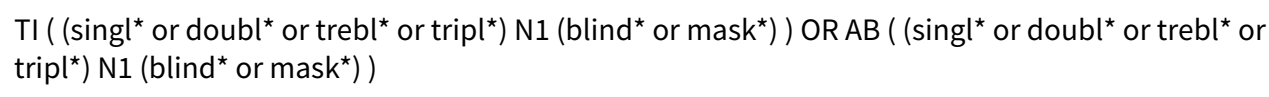 \\
\hline S32 & (MH "Random Assignment") \\
\hline S33 & (MH "Placebos") \\
\hline S34 & (MH "Quantitative Studies") \\
\hline S35 & $\mathrm{TI}$ ( random* or placebo* ${ }^{\star}$ OR AB ( random* or placebo* $)$ \\
\hline S36 & $\mathrm{S} 28$ or $\mathrm{S} 29$ or $\mathrm{S} 30$ or $\mathrm{S} 31$ or $\mathrm{S} 32$ or $\mathrm{S} 33$ or $\mathrm{S} 34$ or $\mathrm{S} 35$ \\
\hline S37 & S27 and S36 \\
\hline
\end{tabular}

\section{Appendix 6. LILACS (Bireme) search strategy}

(mh:"Influenza Vaccines" OR "Vacunas contra la Influenza" OR "Vacinas contra Influenza" OR "Vacunas contra Gripe" OR "Vacunas Antigripales" OR "Vacinas contra Gripe" OR "Vacinas Antigripais" OR ((mh:"Influenza,Human" OR "Gripe Humana" OR "Influenza Humana" OR grippe OR influenza* OR flu OR gripe OR "Influenza en Humanos" OR "Influenza em Humanos") AND (mh:"vaccines" OR vacunas OR vacinas OR mh:d20.215.894* OR mh:"Immunization" OR inmunización OR imunização OR vaccin^ OR immuni* OR inocul*))) AND (mh:"Aged" OR anciano* OR idoso* OR elderly OR mh:m01.060.116.100* OR mh:"adult" OR adulto OR idosa OR mh:"Retirement" OR retire* OR jubilación OR aposentadoria OR jubilado OR aposentado OR geriatric* OR geriátrica OR geriátricos OR pension* OR "old age" OR mh:"Homes for the Aged" OR "Hogares para Ancianos" OR "Instituição de Longa Permanência para Idosos" OR "Asilos de Ancianos" OR "Casas para Ancianos" OR "Instituição Asilar" OR "Asilos para Idosos" OR ancianatos OR mh:"nursing homes" OR "Casas de Salud" OR "Casas de Saúde") AND (instance:"regional") AND ( db:("LILACS") AND type_of_study:("clinical_trials"))

\section{Appendix 7. Trials registers search strategies \\ WHO ICTRP (http://www.who.int/ictrp/en/)}

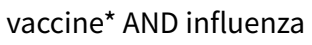

immuni* AND influenza

inocul* AND influenza

vaccine* AND flu

immuni* AND flu

inocul ${ }^{*}$ AND flu

\section{ClinicalTrials.gov (www.clinicaltrials.gov)}

(vaccine $O R$ vaccines $O R$ vaccinate $O R$ vaccination $O R$ vaccinated $O R$ vaccinating $O R$ immunise $O R$ immunised $O R$ immunising $O R$ immunisation OR immunize OR immunized OR immunizing OR immunization) AND (influenza OR influenza OR flu)

(inoculate OR inoculated OR inoculating OR inoculation) AND (influenza OR influenza OR flu)

\section{Appendix 8. Previous search details}

For the 2009 update we searched the Cochrane Central Register of Controlled Trials (CENTRAL), which contains the Cochrane Acute Respiratory Infections (ARI) Group's Specialised Register, the Cochrane Database of Systematic Reviews, and the Database of Abstracts of Reviews of Effects (The Cochrane Library 2009, Issue 4); MEDLINE (January 1966 to October Week 12009 ); EMBASE (1974 to October 2009) and Web of Science (1974 to October 2009). 
We used the search in Appendix 2 to search MEDLINE and CENTRAL. The search terms were combined with the Cochrane Highly Sensitive Search Strategy for identifying RCTs in MEDLINE: sensitivity- and precision-maximising version (2008) revision; Ovid format (Lefebvre 2011). This search was adapted for Embase (Appendix 3) and Web of Science (Appendix 4). The search terms were also combined with the SIGN (SIGN 2009) search strategy for identifying observational studies (see Appendix 11) and MEDLINE, Embase and Web of Science were searched for observational studies.

There were no language or publication restrictions. The search of CENTRAL included trial reports identified by the systematic search by hand of the journal Vaccine.

In order to identify additional published and unpublished studies:

1. We used the Science Citation Index to identify articles that cite the relevant studies;

2. We keyed the relevant studies into PubMed and used the Related Articles feature;

3. We searched the bibliographies of all relevant articles obtained, any published reviews and proceedings from relevant conferences for additional studies;

4. We explored Internet sources: NHS National Research Register (www.update-software.com/national/), the metaRegister of Clinical Trials (www.controlled-trials.com/) and the digital dissertations web site (wwwlib.umi.com/dissertations);

5. We searched the Vaccine Adverse Event Reporting System web site (www.vaers.org); and

6. We contacted vaccine manufacturers listed at the WHO web site.

For the 2006 update we searched the Cochrane Central Register of Controlled Trials (CENTRAL), which contains the Cochrane Acute Respiratory Infections (ARI) Group's Specialised Register, the Cochrane Database of Systematic Reviews, and the Database of Abstracts of Reviews of Effectiveness (The Cochrane Library 2006, issue 1); MEDLINE (January 1966 to March Week 3 2006); EMBASE (Dialog 1974 to 1979; SilverPlatter 1980 to December 2005); Biological Abstracts (SilverPlatter 1969 to December 2004); and Science Citation Index (Web of Science 1974 to December 2004). The following MEDLINE search terms were combined with a methodological search filter for high sensitivity in identifying randomised controlled trials in MEDLINE (Dickersin 1994) and adapted to search the other above mentioned electronic databases.

\section{MEDLINE (Ovid) (2006 update)}

1 exp Influenza Vaccines/

2 Influenza, Human/ep [Epidemiology]

3 Influenza, Human/im [Immunology]

4 Influenza, Human/mo [Mortality]

5 Influenza, Human/pc [Prevention \& Control]

6 Influenza, Human/tm [Transmission]

7 influenza vaccin $\$$.ti,ab.

8 (influenza or flu).ti,ab.

9 (vaccin\$ or immuni\$ or inocul\$ or efficacy or effectiveness).ti,ab.

10 and $/ 8-9$

11 or $/ 1-7,10$

12 RANDOMIZED CONTROLLED TRIAL.pt.

13 CONTROLLED CLINICAL TRIAL.pt.

14 RANDOMIZED CONTROLLED TRIALS.sh.

15 RANDOM ALLOCATION.sh.

16 DOUBLE BLIND METHOD.sh.

17 SINGLE-BLIND METHOD.sh.

18 or/12-17

19 Animals/

20 Humans/

2119 not 20

2218 not 21

23 CLINICAL TRIAL.pt.

24 exp Clinical Trials/

25 (clin\$ adj25 trial\$).ti,ab.

26 ((singl\$ or doubl\$ or trebl\$ or tripl\$) adj25 (blind\$ or mask\$)).ti,ab.

27 PLACEBOS.sh.

28 placebo\$.ti,ab.

29 random $\$ . t i, a b$.

30 or $/ 23-29$

3130 not 21

32 exp Research Design/ 
33 exp Comparative Study/

34 exp Evaluation Studies/

35 exp Follow-Up Studies/

36 exp Prospective Studies/

37 prospectiv $\$ . t i, a b$.

38 volunteer $\$$.ti,ab.

39 exp Case-Control Studies/

40 (cases and controls).ti,ab.

41 case control stud\$.ti,ab.

42 exp Cohort Studies/

43 cohort stud\$.ti,ab.

44 observational.ti,ab.

45 or/32-44

4645 not 21

47 or/ $22,31,46$

4811 and 47

\section{Appendix 9. Data extraction form}

\section{PART 1}

Background Information and Description of study

Reviewer:

Study unique identifier:

Published: $\mathrm{Y} / \mathrm{N}$

Journal: (if applicable)

Year of publication:

Period study conducted:

Abstract/full paper:

Country or countries of study:

Number of studies included in this paper:

Funding source (delete non applicable items):

Government, Pharmaceutical, Private, Unfunded, Unclear:

Paper/abstract numbers of other studies with which these data are linked:

Reviewer's assessment of study design (delete non applicable items):

Study Category - Study Design

Experimental - RCT/CCT; HCT ; $X$ cross-over RCT

Non-randomised analytical (specifically designed to assess association) - Prospective/

Retrospective Cohort ; Case Control ; X sectional

Non-randomised comparative (not specifically designed to assess association) - Case X Over/Time series ;

Ecological study; Indirect comparison (before and after)

Non-comparative EXCLUDE

Does the study present data distributed by age group/occupation/health status? (Yes/No)

Sub group distribution:

Age group $\mathrm{Y} / \mathrm{N}$

Occupation $\mathrm{Y} / \mathrm{N}$

Health status $\mathrm{Y} / \mathrm{N}$

Gender $\mathrm{Y} / \mathrm{N}$

Risk group $\mathrm{Y} / \mathrm{N}$

Description of study

Methods

Participants

Interventions/exposure

Outcomes

Notes

\section{PART 2a}

Methodological Quality Assessment RCT and CCT only

Randomisation:

$\mathrm{A}=$ individual participants allocated to vaccine or control group. 
$\mathrm{B}=$ groups of participants allocated to vaccine or control group.

Generation of the allocation sequence:

$A=$ adequate, e.g. table of random numbers or computer-generated random numbers.

$B=$ inadequate, e.g. alternation, date of birth, day of the week, or case record number.

$\mathrm{C}=$ not described.

Allocation concealment:

$A=$ adequate, e.g. numbered or coded identical containers administered sequentially, on-site computer system that can only be accessed after entering the characteristics of an enrolled participant, or serially numbered, opaque, sealed envelopes.

$\mathrm{B}=$ possibly adequate, e.g. sealed envelopes that are not sequentially numbered or opaque.

$\mathrm{C}=$ inadequate, e.g. open table of random numbers.

$\mathrm{D}=$ not described.

Blinding:

$A=$ adequate double-blinding, e.g. placebo vaccine.

$B=$ single-blind, i.e. blinded outcome assessment.

$\mathrm{C}=$ no blinding.

Follow up:

Average duration of follow up and number of losses to follow up.

\section{PART 2b}

Description of interventions and outcomes RCT and CCT only

Vaccines used

Vaccines and composition | Product and manufacturer | Schedule \& dosage and status | Route of administration

Arm 1

Arm 2

Arm 3

Arm 4

Placebo

Rule: index vaccine goes in the Arm 1 line, placebo in the last line

Status: primary, secondary or tertiary immunisation.

Vaccine Batch Numbers

Details of Participants

Enrolled | Missing | Reasons | Inclusion in analysis | Notes

Active arm 1

Active arm 2

Active arm 3

Active arm 4

Controls

Outcomes List - Efficacy and Effectiveness

Outcome | How defined | Description/Follow up/Notes

Outcomes List - Safety

Outcome | How defined | Description/Follow up/Notes

Investigators to be contacted for more information? Yes/No

Contact details (principal investigator, fill in only if further contact is necessary):

\section{PART 2C}

Data extraction and manipulation (to be used for dichotomous or continuous outcomes) RCT and CCT only

Comparison

Outcomes |n/N Index Arm | n/N Comparator

Outcomes $\mathrm{n} / \mathrm{N}$ Index Arm $\mathrm{n} / \mathrm{N}$ Comparator

Outcomes | n/N Index Arm | n/N Comparator

Notes (for statistical use only) 


\section{PART 3a}

Methodological Quality Assessment. Non-randomised studies only

Newcastle - Ottawa quality assessment scale (case-control and cohort studies ; see Appendix 10)

\section{PART 3b}

Description of interventions and outcomes. Non-randomised longitudinal studies only

Vaccines used

Vaccines and composition | Product and manufacturer | Schedule \& dosage and status | Route of administration

Group 1

Group 2

Group 3

Group 4

Comparator

Rule: index vaccine goes in the Group 1 line, placebo in the last line

Vaccine Batch Numbers

Details of Participants

Enrolled | Missing | Reasons | Inclusion in analysis | Notes

Group 1

Group 2

Group 3

Group 4

Comparator

Outcomes List - Effectiveness

Outcome | How defined (including length of follow up) | Description/Follow up/Notes

Outcomes List - Safety

Outcome | How defined (including length of follow up) | Description/Follow up/Notes

Investigators to be contacted for more information? Yes/No

Contact details (principal investigator, fill in only if further contact is necessary):

\section{PART 3C}

Data extraction and manipulation (to be used for dichotomous outcomes). Non-randomised longitudinal studies only

Comparison

Outcomes | n/N Index Group | n/N Comparator

Notes (for statistical use only)

\section{PART 3d}

Description of studies. Case-control studies only

Event 1

How defined | Enrolled | Missing | Reasons | Inclusion in analysis

Cases $\mathrm{n}=$

Controls $n=$

Exposure

How defined | How ascertained | Notes

Vaccine Exposure 1

Vaccine Exposure 2

Event 2

How defined | Enrolled | Missing | Reasons | Inclusion in analysis

Cases $\mathrm{n}=$

Controls $n=$ 
Exposure

How defined | How ascertained | Notes

Vaccine Exposure 1

Vaccine Exposure 2

Notes (for statistical use only)

\section{Part 3e}

Data extraction and manipulation. Case-control studies only

Status | Numerator | Denominator

Cases

Control

Notes (for statistical use only)

\section{Appendix 10. Methodological quality of non-randomised studies}

\section{Newcastle-Ottawa Quality Assessment Scale}

\section{Case-control studies}

\section{Selection}

1. Is the case definition adequate?
a. yes, with independent validation
b. yes, e.g. record linkage or based on self reports
c. no description

2. Representation of the cases
a. consecutive or obviously representative series of cases
b. potential for selection biases or not stated

3. Selection of controls
a. community controls
b. hospital controls
c. no description

4. Definition of controls
a. no history of disease (endpoint)
b. no description of source

\section{Comparability}

1. Comparability of cases and controls on the basis of the design or analysis
a. study controls for (select the most important factor)
b. study controls for any additional factor (this criteria could be modified to indicate specific control for a second important factor)

\section{Exposure}

1. Ascertainment of exposure
a. secure record (e.g. surgical records)
b. structured interview where blind to case/control status
c. interview not blinded to case/control status
d. written self report or medical record only
e. no description

2. Same method of ascertainment for cases and controls
a. yes
b. no

3. Non-response rate
a. same rate for both groups
b. non-respondents described
c. rate different and no designation 


\section{Newcastle-Ottawa Quality Assessment Scale}

\section{Cohort studies}

Note: A study can be awarded a maximum of one star for each numbered item within the 'Selection' and 'Outcome' categories. A maximum of two stars can be given for 'Comparability'.

\section{Selection}

1. Representation of the exposed cohort
a. truly representative of the average (describe) in the community
b. somewhat representative of the average in the community
c. selected group of users (e.g. nurses, volunteers)
d. no description of the derivation of the cohort

2. Selection of the non-exposed cohort
a. drawn from the same community as the exposed cohort
b. drawn from a different source
c. no description of the derivation of the non-exposed cohort

3. Ascertainment of exposure
a. secure record (e.g. surgical records)
b. structured interview
c. written self report
d. no description

4. Demonstration that outcome of interest was not present at start of study
a. yes
b. no

\section{Comparability}

1. Comparability of cohorts on the basis of the design or analysis
a. study controls for (select the most important factor)
b. study controls for any additional factor ${ }^{\star}$ (this criteria could be modified to indicate specific control for a second important factor)

\section{Outcome}

1. Assessment of outcome
a. independent blind assessment
b. record linkage
c. self report
d. no description

2. Was follow-up long enough for outcomes to occur?
a. yes (select an adequate follow-up period for outcome of interest)

b. no

3. Adequacy of follow-up of cohorts
a. complete follow up - all participants accounted for
b. participants lost to follow-up unlikely to introduce bias - small number lost -> provided of those lost*
c. follow-up rate < $\%$ (select an adequate \%) and no description of those lost
d. no statement $\%$ (select an adequate \%) follow-up, or description

\section{Appendix 11. SIGN filter for observational studies}

SIGN Scottish Intercollegiate Guidelines Network [Internet]. Edinburgh: c2001-2009; [Last modified 03 August 2009; accessed 02 October 2009]. Available from www.sign.ac.uk/methodology/filters.html on 02 October 2009 (SIGN 2009)

The Observational Studies search filter used by SIGN has been developed in-house to retrieve studies most likely to meet SIGN's methodological criteria.

MEDLINE 


\begin{tabular}{|c|c|}
\hline 1 & Epidemiologic studies/ \\
\hline 2 & Exp case control studies/ \\
\hline 3 & Exp cohort studies/ \\
\hline 4 & Case control.tw. \\
\hline 5 & (cohort adj (study or studies)).tw. \\
\hline 6 & Cohort analy\$.tw. \\
\hline 7 & (Follow up adj (study or studies)).tw. \\
\hline 8 & (observational adj (study or studies)).tw. \\
\hline 9 & Longitudinal.tw. \\
\hline 10 & Retrospective.tw. \\
\hline 11 & Cross sectional.tw. \\
\hline 12 & Cross-sectional studies/ \\
\hline 13 & Or/1-12 \\
\hline
\end{tabular}

\section{EMBASE}

\begin{tabular}{ll}
\hline 1 & Clinical study/ \\
\hline 2 & Case control study \\
\hline 4 & Family study/ \\
\hline 5 & Longitudinal study/ \\
\hline 6 & Retrospective study/ \\
\hline 7 & Prospective study/ \\
\hline 8 & Randomised controlled trials/ \\
\hline 9 & 6 not 7 \\
\hline 10 & Cohort analysis/ \\
\hline 11 & (Cohort adj (study or studies)).mp. \\
\hline 12 & (Case control adj (study or studies)).tw. \\
\hline
\end{tabular}




\section{FEE D B A C K}

\section{Vaccines for preventing influenza in the elderly,}

\section{Summary}

Dear Dr Rivetti,

We have several questions about the review 'Vaccines for preventing influenza in the elderly'.

Although the authors recognized that "The findings of the cohort studies that we included are likely to have been affected to a varying degree by selection bias.", the reviewers drew conclusions that "in long-term care facilities, where vaccination is most effective against complications," based on the results of cohort studies that is not compatible with the strict prospective study method of RCT.

However they argued that RCT can minimize the bias, they concluded that extracted RCTs can offer no definitive evidence due to their scant and bad reports. If so, they should suggest a well-designed placebo controlled RCT of influenza vaccination for preventing influenza in the elderly.

Moreover they insist that placebo-controlled RCT is no longer possible on ethical ground, because the influenza vaccinations are globally recommended.

The statement is very surprising. If it is true, RCTs are no longer possible after the recommendations or medical interventions have been globally implemented, even though they are clearly erroneous. We think the idea is against Cochrane Collaboration's principle.

On the contrary, we cannot ethically accept the scant and bad situation itself of RCTs on the vaccine, because flu vaccinations have been awkwardly recommended all over the world without high level evidence.

The reviewers discussed that "Consistent with other published studies, during influenza season, vaccination was associated with a $44 \%$ reduction in risk of all-cause mortality during influenza season. However, in the period before influenza vaccination was associated with a $61 \%$ reduction in risk of this outcome."

In fact, Japanese cohort studies which evaluated the influenza vaccine have also large selection bias favourable to the vaccinated group in various outcomes including mortality, fever and absence from school.

For examples, in the cohort study of over 65 years old at Geriatric Health Service Facility

1) vaccination associated with a $51.9 \%$ relative risk reduction in all-cause mortality during influenza season; but the mortality in the vaccinated group was $61.5 \%$ lower during extra-influenza season. This study also showed a $37.8 \%$ relative risk reduction in fever during influenza season, but fever rate in the vaccinated group was $37.3 \%$ lower during extra-influenza season.

In Japanese cohort studies which evaluated the effectiveness of the influenza vaccine for children

2 ) the vaccination was associated with a $12.2 \%$ relative risk reduction in fever during influenza season, but it also showed a $17.3 \%$ reduction prior to influenza season.

Moreover Takahashi $\mathrm{K}$ et al. reported the absence rate of vaccinated and unvaccinated students in Mie prefecture during influenza season and during prior to influenza season.

3) In the study of elementary school vaccination was associated with a $26.1 \%$ relative risk reduction in absence during influenza season, but it associated with a $23.7 \%$ reduction prior to influenza season. In the study of junior high school it associated with a $29.1 \%$ relative risk reduction during influenza season but it also associated a $31 \%$ reduction during prior to influenza season.

According to these cohort studies, the vaccinated groups revealed more increase of mortality, fever rate, or absence rate during influenza season relative to the extra-influenza season. 
In conclusion, "no firm conclusions can be drawn from" the cohort studies, because of its large bias as the review authors suggest. However the cohort studies may become more reliable after the outcomes during influenza season corrected at least with the outcomes during noninfluenza season, their results cannot replace evidences from well-designed placebo controlled RCT.

\section{References}

1) Hitoshi Kamiya. Summary and Group Report 1998-1999 'Study of the effectiveness of the influenza vaccine' (Koseik Kagaku Kenkyuhi Hozyokin Zigyou Zisseki Houkokusyo) [The study was supported by federal funds from the Japanese Ministry of Health, Labor and Welfare]

2) Hitoshi Kamiya 'Study of the effectiveness of influenza vaccine in infants and young children.' 2001 (Heisei 12, (Koseik Kagaku Kenkyuhi Hozyokin Zigyou Zisseki Houkokusyo) [The study was supported by federal funds from the Japanese Ministry of Health, Labor and Welfare]

3) Kosei Takahashi et al. Evaluation of the effectiveness of influenza vaccine by the absence rates of the elementary and junior high school students. Kusurino Hiroba 1988:96;2

I certify that I have no affiliations with or involvement in any organization or entity with a financial interest in the subject matter of my feedback.

\section{Reply}

Thank you for the comments. For the review we identified few RCTs and with small Ns. We stated that we needed to base our conclusions mostly on the large number of observational studies, and recommended that large well-designed and well-executed RCTs should be undertaken.

Daniela Rivetti

Alessandro Rivetti

Vittorio Demichelli

Tom Jefferson

Roger Thomas

Carlo Di Pietrantonj

Melanie Rudin

\section{Contributors}

Keiji Hayashi

Feedback comment and reply added 25 July 2007.

\section{WHAT'S NEW}

\begin{tabular}{lll}
\hline Date & Event & Description \\
\hline 6 October 2021 & Amended & $\begin{array}{l}\text { Correction made to the risk of bias assessment for Govaert } \\
\text { 1994a. In the 'Characteristics of included studies' for Govaert }\end{array}$ \\
& $\begin{array}{l}\text { 1994a, the authors' judgement for each bias in the Risk of Bias } \\
\text { table was marked as "low" for each bias, but the description in } \\
\text { the justification for the judgment did not correlate. This has now } \\
\text { been corrected. }\end{array}$
\end{tabular}

\section{H ISTORY}

Protocol first published: Issue 3, 2004

Review first published: Issue 3, 2006

\begin{tabular}{lll}
\hline Date & Event & Description \\
\hline 6 November 2019 & Amended & $\begin{array}{l}\text { Correction made to the risk of bias assessment for Govaert } \\
\text { 1994a. In the 'Characteristics of included studies' for Gov- } \\
\text { aert 1994a, the authors' judgement for each bias in the risk } \\
\text { of bias table was marked as "unclear" in error. This error }\end{array}$ \\
\hline
\end{tabular}




\begin{tabular}{|c|c|c|}
\hline Date & Event & Description \\
\hline & & $\begin{array}{l}\text { was introduced in the } 2018 \text { version of the review (https:// } \\
\text { doi.org/10.1002/14651858.CD004876.pub4) and has now been } \\
\text { corrected to "low" for each bias, as in earlier versions of this re- } \\
\text { view. }\end{array}$ \\
\hline 31 December 2016 & New search has been performed & $\begin{array}{l}\text { We updated our searches for randomised trials conducted. We } \\
\text { did not identify any new trials for inclusion or exclusion. }\end{array}$ \\
\hline 20 January 2010 & New search has been performed & $\begin{array}{l}\text { Searches conducted. We identified } 18 \text { potential trials. We includ- } \\
\text { ed four new trials, two case-control studies (Jordan 2007; Puig- } \\
\text { Barbera 2007), and two cohort studies (Hara 2006; Leung 2007). } \\
\text { We excluded } 13 \text { new trials (Castilla 2006; Garcia-Garcia 2009; } \\
\text { Hara 2008; Isahak 2007; Landi 2006; Manzoli 2007; Moreno 2009; } \\
\text { Nichol 2007; Ortqvist 2007; Skull 2009; Tsai 2007; van Vuuren } \\
\text { 2009; Voordouw 2006). One excluded trial was formerly awaiting } \\
\text { classification (Vila-Corcoles 2005). }\end{array}$ \\
\hline
\end{tabular}

20 January $2010 \quad$ New citation required and conclusions have changed
Three new authors (EF, LAA, ST) joined the review team, while previous authors no longer contributed to this update. Our conclusion changed in part. This was due both to a re-evaluation of the whole topic and to ambiguity in the previous text which readers found confusing.

\begin{tabular}{lll}
\hline 8 May 2008 & Amended & Converted to new review format \\
\hline 25 July 2007 & Feedback has been incorporated & Feedback comment and reply added to review. \\
\hline 24 May 2006 & New search has been performed & Searches conducted. \\
\hline
\end{tabular}

\section{CONTRIBUTIONS OFAUTHORS}

Alessandro Rivetti conducted the original searches.

Tom Jefferson, Daniela Rivetti, and Vittorio Demicheli applied inclusion criteria.

Tom Jefferson, Daniela Rivetti, and Melanie Rudin extracted the original data.

Vittorio Demicheli arbitrated and checked the data extraction.

Carlo Di Pietrantonj undertook the meta-analysis and performed statistical testing.

Tom Jefferson wrote the first review and the updates.

Eliana Ferroni extracted the data.

For the 2016 update, Sarah Thorning conducted the updated searches, Tom Jefferson and Alessandro Rivetti wrote the review, Vittorio Demicheli checked the data, and all authors contributed to the final updated review.

\section{DECLARATIONS OF INTEREST}

Vittorio Demicheli: none known.

Tom Jefferson (TJ) was a recipient of a UK National Institute for Health Research grant for a Cochrane Review of neuraminidase inhibitors for influenza. In addition, TJ receives royalties from his books published by II Pensiero Scientifico Editore, Rome and Blackwells. TJ is occasionally interviewed by market research companies about phase I or II pharmaceutical products (remunerated). In 2011-13, TJ acted as an expert witness in litigation related to the antiviral oseltamivir, in two litigation cases on potential vaccine-related damage, and in a labour case on influenza vaccines in healthcare workers in Canada (remunerated). He has acted as a consultant for Roche (1997-99), GSK (2001-2), Sanofi-Synthelabo (2003), and IMS Health (2013) (remunerated). In 2014 he was retained as a scientific adviser to a legal team acting on oseltamivir (remunerated). TJ has a potential financial conflict of interest in the drug oseltamivir. In 2014-16, TJ was a member of three advisory boards for Boerhinger Ingelheim (remunerated). TJ is holder of a Cochrane Methods Innovations Fund grant to develop guidance on the use of regulatory data in Cochrane Reviews. TJ was a member of an independent data monitoring committee for a Sanofi 
Pasteur clinical trial on an influenza vaccine (remunerated). Between 1994 and 2013, TJ was the co-ordinator of the Cochrane Vaccines Field. TJ is a cosignatory of the Nordic Cochrane Centre Complaint to the European Medicines Agency (EMA) over maladministration at the EMA in relation to the investigation of alleged harms of human papillomavirus vaccines and consequent complaints to the European Ombudsman. TJ is coholder of a John and Laura Arnold Foundation grant for development of a RIAT support centre (2017-20) and Jean Monnet Network Grant, 2017-20 for The Jean Monnet Health Law and Policy Network.

Carlo Di Pietrantonj: none known.

Eliana Ferroni: none known.

Sarah Thorning: none known.

Roger E Thomas: none known.

Alessandro Rivetti: none known.

\section{SOURCES OF SUPPORT}

\section{Internal sources}

- ASL 20 (Alessandria), ASL 19 (Asti), Regione Piemonte, Italy

\section{External sources}

- National Health and Medical Research Council (NHMRC), Australia

\section{DIFFERENCES BETWEEN PROTOCOLANDREVIEW}

Prior to starting the 2016 update of this review, we decided that evidence from observational studies should no longer be updated, given its inherent biases and our intention to focus the main synthesis, 'Summary of findings' tables, conclusions, and summary versions on randomised evidence. For historical purposes we have retained data from non-randomised evidence in the review.

In previous versions of this review, we computed the reciprocal of the pooled risk difference as the basis for calculating numbers needed to vaccinate (NNV). Given expected variation in control group risks, we decided to revise this approach and have calculated NNVs based on the difference between the assumed and corresponding risks based on the Summary of findings 1 .

\section{N DEX TERMS}

\section{Medical Subject Headings (MeSH)}

Influenza Vaccines [*administration \& dosage] [adverse effects]; Influenza, Human [ ${ }^{\star}$ prevention \& control]; Randomized Controlled Trials as Topic; Vaccines, Inactivated [administration \& dosage]

\section{MeSH check words}

Aged; Humans 